\title{
Microfinance : greater good or lesser evil?
}

Citation for published version (APA):

Augsburg, B. (2009). Microfinance : greater good or lesser evil? [Doctoral Thesis, Maastricht University]. Boekenplan. https://doi.org/10.26481/dis.20090429ba

Document status and date:

Published: 01/01/2009

DOI:

10.26481/dis.20090429ba

Document Version:

Publisher's PDF, also known as Version of record

\section{Please check the document version of this publication:}

- A submitted manuscript is the version of the article upon submission and before peer-review. There can be important differences between the submitted version and the official published version of record.

People interested in the research are advised to contact the author for the final version of the publication, or visit the DOI to the publisher's website.

- The final author version and the galley proof are versions of the publication after peer review.

- The final published version features the final layout of the paper including the volume, issue and page numbers.

Link to publication

\footnotetext{
General rights rights.

- You may freely distribute the URL identifying the publication in the public portal. please follow below link for the End User Agreement:

www.umlib.nl/taverne-license

Take down policy

If you believe that this document breaches copyright please contact us at:

repository@maastrichtuniversity.nl

providing details and we will investigate your claim.
}

Copyright and moral rights for the publications made accessible in the public portal are retained by the authors and/or other copyright owners and it is a condition of accessing publications that users recognise and abide by the legal requirements associated with these

- Users may download and print one copy of any publication from the public portal for the purpose of private study or research.

- You may not further distribute the material or use it for any profit-making activity or commercial gain

If the publication is distributed under the terms of Article $25 \mathrm{fa}$ of the Dutch Copyright Act, indicated by the "Taverne" license above, 
MICROFINANCE - GREATER GOOD OR LESSER EVIL? 

C2009 Britta Augsburg

All rights reserved. No part of this publication may be reproduced, stored in a retrieval system, or transmitted in any form, or by any means, electronic, mechanical, photocopying, recording or otherwise, without the prior permission in writing, from the author.

ISBN 9789086660834

Cover picture by Graham A.N. Wright

Published by Boekenplan, Maastricht 



\title{
MICROFINANCE - GREATER GOOD OR LESSER EVIL?
}

\author{
DISSERTATION
}

To obtain the degree of Doctorate at the Maastricht University, on the authority of the Rector Magnificus Prof. dr. G.P.M.F. Mols

in accordance with the decision of the Board of Deans

to be defended in public on Wednesday 29 April 2009, at 12.00 hours.

by

Britta Augsburg 
Supervisors:

Prof. Dr. Chris. De Neubourg

Prof. Dr. Orazio Attanasio, University College London, UK

Assessment Committee: Prof. Dr. Pierre Mohnen (chairman)

Prof. Dr. Thomas Dohmen

Prof. Emeritus Malcolm Harper (Cranfield University \& Visiting Prof. Nottingham Trent University)

Prof. Dr. Luc L.G. Soete

Prof. Dr. Jean-Pierre Urbain 


\section{Acknowledgments}

This dissertation is the result of three years' work (not counting all that led up to starting it). Three years of work, where work is the all-embracing word for work, leisure, social life and sleep (yes, sleep - a $\mathrm{PhD}$ involves many dreams and nightmares...). This synthesis makes it very difficult to acknowledge every person that had influence on the process and the result. But, I want to do so and will therefore give up on the idea of being brief. I want to tell the story of my $\mathrm{PhD}$ and acknowledge along the way those that made it possible.

I don't think I would have ever considered writing a dissertation if it hadn't been for the support of my master thesis supervisor JP Urbain - for me, a role-model academic! If he didn't think that doing a PhD was a good idea for me, I don't think I would have done it!

Chris de Neubourg, gave me the possibility to join the School of Governance - and assuring me that I would not have to be in Maastricht all the time (probably not realizing at that point how little time I would actually spend there - travelling so much that I am seriously considering to reduce the amount! me of all...). But, I ALWAYS loved coming back to Maastricht! And that above all because the School of Governance is such a special place with special people! Be it because they ran everything smoothly, helped with administrative stuff, kept cake sessions going (Celine, Susan, Charlotte, Rally, Janneke), because they were there to answer questions, read and comment on some of my things, support project ideas (Mindel and Franziska) or because they had it all under control (Mieke and Annemarie). Sounds like women run the school... and they do... but they of course have a great boss! Not to forget the student assistants and interns! And of course the students... of which, 13 made my PhD. In brief:

Bianca - the one of the two who got lucky at Eze's BBQ, who fought her way through windows and proposals.

Denisa - the one with whom it all started - until I moved out of our shared office... but who later moved into my heart.

Florian - the one that is the only Albanian I know but I cannot imagine that there is one with a better humor than him!

Frieda - the one that is "our Frieda", red-wine, cigarette and fun! (I know it always failed because of me but I still want to go on that vacation with you!!)

Hao - the one of whom we understand that she likes fish but of whom we don't understand what she works on...

Jessica - the one that proved Gosta wrong - there is no baby-shortage!

Lina - the one who shares my hat-enthusiasm (be it in Russia or creative in Maastricht)

Melissa - the one who knows it all - my office-mate, house-mate, dancing-mate, running-mate, triathlon-mate, gossip-mate, working-mate, organization-mate, 
"yes, I can do it"-mate - my dearest friend! (and the second one who got lucky at Eze's BBQ)

The Mexicans - the most amazing couple, whose wedding I missed which I still did not forgive myself.

Michal - the one who fled when possible - but was there long enough to be always a good interlocutor when it came to gossip (just like that, over a beer, or maybe even over a extremely yellow shot in the office)

Pascal - the one whom I initially thought to be so German but who isn't even punctual! (and who is the second triathlon-mate!)

Zina - the one who seems to have lived through all the stupid/funny/... things I have been through and was (and obviously is) therefore always the most amazing listener with the best advice at hand - which helped me a lot!! (this basically translates into being an amazing friend!); and the one from whom I know all about being a mum and all about Jordan! I cite from numerous classes: "In Jordan..." ;)

These are the people that "suffered" with me through the first nine months of the $\mathrm{PhD}$, covering 22 courses with exams, presentations, papers - and only the group made it possible. And I am serious - all other cohorts after us only managed because it was made so much easier after us guinea-pigs suffering hard...;)

Not exactly part of our cohort, but still very much part of especially this first year of the $\mathrm{PhD}$, going through the same process at UNU/Merit were Eze and Philipp. I think (actually, I am very sure) without our Monday Night Dinners the year would have been only half as much fun!!!! (on the other hand, I would probably remember things from classes on Tuesdays...). Also the second and third year, Eze was a constant part of my PhD-life.

There are a few more people in Maastricht that deserve acknowledgment. Luc Soete, who not only supported generously activities such the Batavierenrace, but also supported me greatly in my 'academic career' - thanks PA! Then there is Denis de Crombrugghe, who always showed great interest in my work and whose support I am very thankful of; and Robin Cowan whose time I took for advice on my theoretical model, the absence of which in my dissertation I will for sure have to defend in case he is in my defense.

During the first year I went to India - initiated by my second thesis supervisor, Pierre Mohnen, who sent me this conference announcement and suggested I should make a paper out of my thesis and present it there. It got accepted and that was basically where my "real PhD" started; that was where I met Vijay Mahajan who invited me to come and visit BASIX India, I went, and he made this innocent suggestion of me conducting a survey. And there it was - a survey; mix it with information on the institution, two names (Radhika and Prashant) and then formulate your research question, design a survey and do it - as simple as that. Thank you Vijay for this amazing opportunity!!!! 
Back in Maastricht I did not have too much time to think since the Development Economics Seminar needed to be organized. I invited the guest speaker Stephan Dercon, I presented and that was where the second foundation stone for my $\mathrm{PhD}$ was laid. The presentation brought me to a $\mathrm{PhD}$ conference in Germany, where Pamela Krishnan suggested me to contact Orazio Attanasio. who accepted my request and became my supervisor. It was a chain of lucky events and I am very glad he accepted - his input as well as coming time and again to London shaped my $\mathrm{PhD}$ (and actually my life after the $\mathrm{PhD}$ ) in a very special way.

All settled: Maastricht - backbone, India - survey, London - supervisor. The rest of my life was anything else than settled after that. I travelled a lot, especially because of the survey. But, many people along the way made it the most amazing time ever, made it possible for me to go on, not to get totally annoyed by having to pack again, sleeping again in a new bed (or on a new floor), a night on the train, a night on the bus, a night on the beach...

Some of the "human cornerstones" on this never-ending travel:

Andy - the one who was the "working-anchor" in Hyderabad - invited for lunch, made possible I would join the half-marathon, offered all help needed.

Cyril - the one who came to India and suffered through two co-authored papers with me, who introduced me to my favorite street-food stand near Charminar and who could be convinced that econometrics is not that bad after all...

Chiara and Marta - the ones who later made the decisions to join EDePo the easiest one ever.

Dagmar \& Volker - the ones who took me to the Hash, who made me have a German Christmas dinner in the middle of November in the middle of India, who were the second anchor in Hyderabad.

Dina, Chanti \& Ini - the ones whose couch I love... no, the ones whom I love. Who made London the city to live in for me!, who named the pineapple after me, who are simply great!!!!!!!

Emla - the one who always helped me track down Orazio when needed, who read some of my work and always had an open ear and ideas!

JD - the one who is simply special.

Karuna - the one who wrote the amazing paper...

Kris's housemates - the ones for whom I was the most frequent visitor in Dubai (seven times in 2007!!) - always one of the greatest breaks for me!

Lina - the one whose flat we lived in, who got me data, who gave all the Hyderbadtips.

Manju - the one who took me in, who showed me how to make chapatti, who invited me to Jaipur where I had an amazing time, whose husband Ajab should also be named!

Nora - the one whom I share Hyderabad with - we weren't there much at the same time but when we were, had a great time! 
Tom - the one who knows how to make use of a business class ticket and whose travel-path I then crossed time and again.

Most of my time in India (especially end of 2007/beginning of 2008) was devoted to my household survey. And, while it feels very much like my own project, I received a lot of help on the way. I still hear Anthony Arundel saying that: "Unless there is no way to avoid it - don't collect your own data". Jumping into the adventure, I quickly understood why he had said this. Nevertheless, not a second did I regret the initial decision not to listen to him. And in the end - to be exact on the $14^{\text {th }}$ of February 2008 the $1041^{\text {st }}$ (and last) interview was collected and on the $20^{\text {th }}$ of March 2008 I was sitting on the plane back to Maastricht (well, of course Dubai and Oman first, and then London, and then Spain for the writing camp), in my luggage a CD with all the data my data! Admittedly, I had been looking forward to this day the moment I made the decision to collect the data - and it was as nice as I had imagined it to be (blocking out the fear that the data would prove of poor quality which it luckily did not). But, while being happy to fly back, I of course left a lot of amazing people behind without whom it would not have been possible for me to make the data collection happen (and here I am most afraid of leaving someone out...)

First and foremost there are people from BASIX: Radhika Desai who was involved from the beginning to end, always there for me, ready to discuss, make things possible, and direct me to the right people... also Prashant gave me, especially in the beginning phase, much valuable feedback. And then there is everybody else at headquarter - I think I must have approached every single one of them at some point: of course Rama K. (not at last for our German-Hindi-Telugu word of the day), N.V. Ramana, D. Sattaiah, S. Datta; Vani (who showed so much patience with all my data requests!!!), S. Amarnath, Navin, Gowri, Sashi (partly responsible for all my travel - making some of the booking for me) Vasumathi, Gunar, Sharada, Suresh, Venu, Mendu, Srinivas, Vara Prasad, Venkatesh......

Then there were all those who gave me their time and knowledge when I went on my field visits to different units - Parbhani, Ramayanpet, Anantapur, Nalgonda, Khammam as well as my visit to Sarvodaya Nano Finance Limited (SNFL) and Krishna Bhima Samruddhi Local Area Bank Limited (KBSLAB). On these trips, I got the chance to talk to - and more importantly listen to - clients and potential clients of BASIX, which helped me a lot in my research. Unfortunately, I do not have the names of these people, but a great thank you goes to them for taking their time and sharing their stories!

Then there is everybody in Anantapur, where the survey actually took place. These are the people that were the most important ones in helping to make my survey come true. As before, the order in which I mention people is not related to the importance of their influence. The same will hold here, but I do want to stress especially the input of Rajeshwari and Sunitha. It was them who took me into their flat and home. I cannot thank them enough for being my roommates and more than that: becoming my friends! I learned so much living with them - and I also ate so much! They are the best cooks ever! 
I want to thank R. Reddy, unit head of Anantapur (successor of Suresh M., whom I got to know at my first field visit to Anantapur and whom I could also afterwards always consult and thank for that), D. Adinarayana, who together with Ramu and RiskThomas (who will not like that I call him like that...) helped me a great deal especially in the beginning phase with crucial practicalities of the survey (such as finding competent interviewers, organizing and participating in the training...) but also along the way - always there with support when something came up. Then of course, the atmosphere in the office would not have been the same without Sudhakar, Prakashant and 'the girls' - Rajeshwari, Bhavani and Sunitha. Also, the regular 'visitors' like Mohan, whom I cannot thank enough for his support in things like getting access to the non-client data base and general information and of course also all the Livelihood Service Advisors (LSAs).

Then there is my own staff - having had probably the greatest influence on the success of the survey. I am greatly indebted to Jagan, my assistant, who put all his energy into this project and to our fourteen interviewers: Maheshwari, P. Ravi, Chinna Balakka, B. Adinarayana, Shaik Basha, S.M. Jaleel, Shivamma, Thulasi, P. Ampamma, J. Arunamma, Lakshmi Devi, Nagaraju, Ravi Bushan and Sumathi. They made a great team, which showed not at last in our final trip which turned out to be an amazing day!

To complete the survey, the data needed to be entered, which was done by Samruddhi Marketing Assistance for Rural Territory (S-MART) in their Business Process Outsourcing units (BPOs) in Kuppam. Here I want to thank Gunar, Gopi, Rinesh and Suresh as well as the team that actually did the data entry work: Betappa, Chitra, Karthik, Punyavathy, Sree Raghavendra and Thimmarajulu.

A few other people deserve mentioning, such as the Hyderabad Centre for Microfinance Research (CMR) Team (especially Aparna and Kalyan), who were so nice to meet with me and share their experiences in conducting surveys which was extremely valuable for me. Also, my translator deserves mentioning.

I would say this more or less sums the process of my $\mathrm{PhD}$ until getting back to Maastricht and having my data ready. After that followed the time of writing up (or actually writing two more chapters and then writing up...). Four months to do so - that was the plan. Initially, the main motivation derived from funding ending after those four months - three years being completed (the second major motivation came as an email from Rob Markless at IFS).

The main thing that kept me sane during this time was probably cycling. Going out on rides was the perfect balance to sitting in front of the computer. And here I want to thank especially Geranda (but also Ad and Eric) for getting me into cycling in the beginning of the $\mathrm{PhD}$. In the end-phase it was Ruud whom I could not have dispensed of (still the case of course). And one of the best decision during those months was to join him and Bert, Koen, Maurice and Stefan to a cycling trip in the Alps. It was the period when I was waiting for feedback on my first draft from Orazio - somewhat of a nerve-wrecking phase. Climbing and climbing and climbing hills on a bike until there was ice around us was the perfect distraction - thanks guys! 
$30^{\text {th }}$ of August 2008 the day I handed-in my dissertation! No one could have thought at that point that it would still take ages for me to defend. But probably, I would not have cared knowing it anyway. I was sitting at the kitchen table in my new home in London ready to head to Dinah and Chanti's wedding - pressing 'send'!

'The end' would even rhyme at this point.

But, I am still far from being done with my little story. This is because I so far left out the most important people that made this PhD happen! These are the people that came into the picture much before the start of my $\mathrm{PhD}$.

For one, there are those friends with whom I share my time in Maastricht (before the $\mathrm{PhD}$ began), who became special people in my life and who were also there when I had to decide what to do. Three of them I would like to mention specifically, namely Ewa, Britta and Volker. I will cite a passage that Ewa will remember: "you know for what!" Without them Maastricht would not have been the same for me, I don't know whether I would have considered staying there (although all three of them left...). Britta was also more directly involved in my $\mathrm{PhD}$, proofreading it, which I cannot thank her enough for! The other person who had a special influence is Sandra. Our time goes back further - all the way to Idstein. It was one of the best things that she decided to come to Maastricht! Becoming sentimental of good old times when listening to Ani di Franco, she once wrote to me: "Friends forever... (probably)... and that would for sure not be the worst that could happen to us...!!!" - I totally agree!

I am coming to an end, which brings me to the most important people - my parents and my sister.

Let me first talk about my sister - she who hated me when being small, who threw me off my high-chair, who never failed to point out my geography-"knowledge", even hit me with an atlas (and whose face I would love to see when reading this for the first time since these are the stories that I always bring up...). When the hate faded off, we became best friends. And that is really what sums it best - she was there as my best friend, probably more often the critical than the supportive one. And this she might not even realize, but in my view she has the most amazing personality, humor, smarter than most I know (how else should she have come up with the title of this dissertation?), a general knowledge that I could only dream off (I am sure she inherited this from our dad!), simply a person to look up to - my 'big' sister!

And, last but not least - my parents. It was them who always believed in me, never questioned anything I wanted to do and on the contrary supported any decision I made. I cannot even remember one incident in which they would have raised their eyebrows and asked "Are you sure?!?" (except of course when I claim to have my key...). It was therefore no surprise that they didn't even consider suggesting some other plan when I mentioned the possibility of doing a PhD. On the contrary, if need had been, they would have done anything to make this possible for me. And this backbone was there - during my $\mathrm{PhD}$, during my life! It is not always easy to properly show appreciation for this. But I want to take this opportunity to especially thank them - you raised me in a way that I always trusted myself enough to do things I wanted to do, and then did them. Thanks - you are the most amazing parents that one can have!!! 


\section{Contents:}

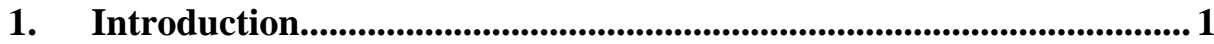

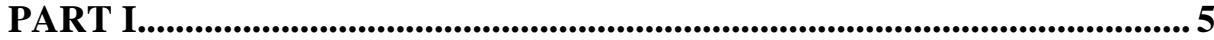

2. Why There? The Reach of Microfinance in India .................................6 6

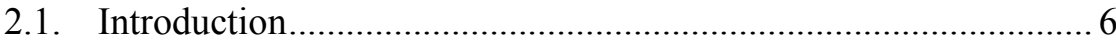

2.2. Spatial Distribution \& Variation of Microfinance Development... 8

2.2.1. The Self-Help Groups Bank Linkage Programme in India ........... 8

2.2.2. The case of Tamil Nadu ............................................................. 12

2.3. Econometric Analysis of the Determinants of the Evolution....... 14

2.3.1. Methodology .......................................................................... 15

2.3.2. Explanatory Variables .............................................................. 19

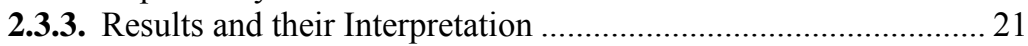

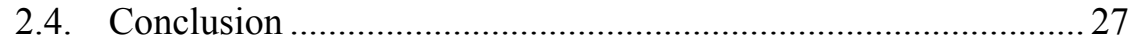

3. Profit Empowerment: The Microfinance Institutions' Mission Drift

36

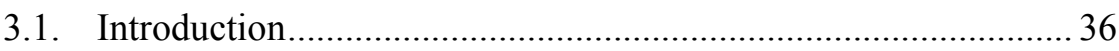

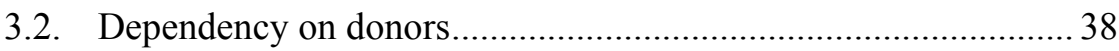

3.3. Mission drift: practitioners between injunctions and the neo-liberal

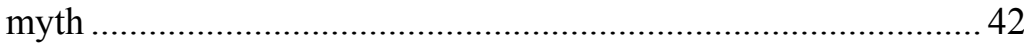

3.3.1. How to have cost-covering and still low interest rates ................ 43

3.3.2. How to secure the portfolio .......................................................... 44

3.3.3. How to secure Repayment and high Repayment Rates ............... 46

3.4. The Crisis in Andhra Pradesh (AP) ........................................... 48

3.4.1. The Events............................................................................ 49

3.4.2. Between Sustainability, mercantile interest rates and populism.. 49

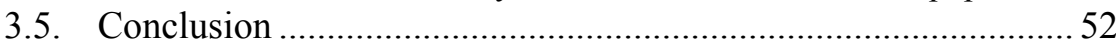

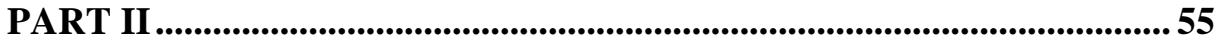

4. Using expectation data to model expected income and expenditures

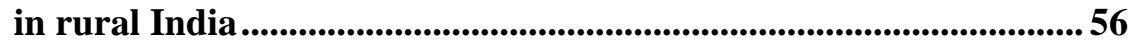

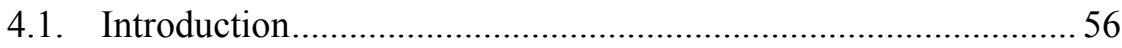

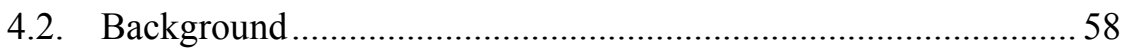

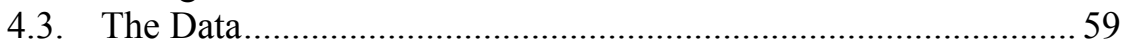

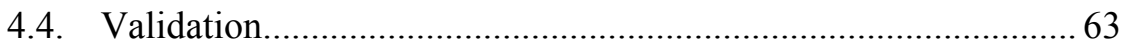

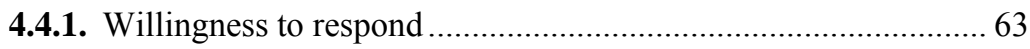

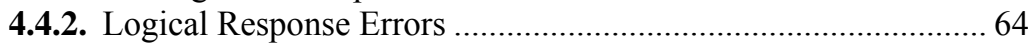

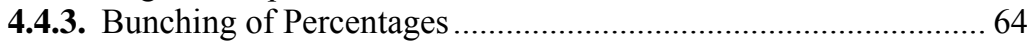

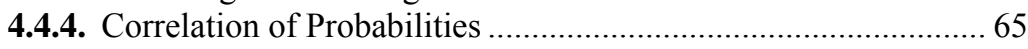

4.5. Fitting a Subjective Income Distribution ....................................... 68

4.6. Simple comparison of expectations and realizations .................. 71

4.7. Empirical Predictions of income expectations - a time-series

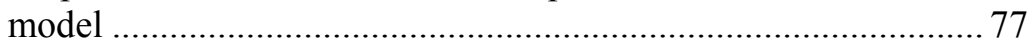

4.7.1. Estimates from Expectations Data............................................. 78 
4.8. Is engaging in Dairy Welfare Improving? .................................. 81

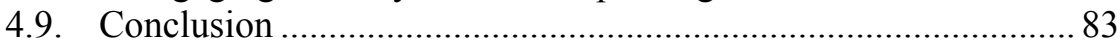

5. The impact of BASIX's Dairy intervention: Evidence from realized

outcomes and expected returns to investment .................................86

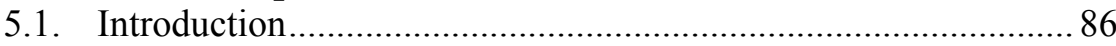

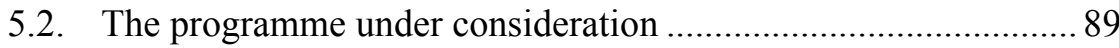

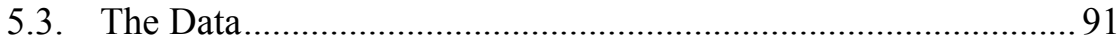

5.3.1. Survey Design ........................................................................... 91

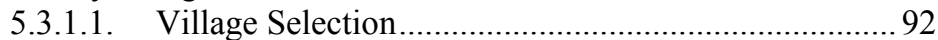

5.3.1.2. Household Selection .................................................. 92

5.3.2. Characteristics across treatment and control groups.....................94

5.3.3. Outcome variables ....................................................................... 95

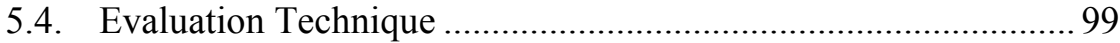

5.5. Impact evaluation of BASIX's dairy intervention ..................... 102

5.5.1. Impact of being a dairy customer of BASIX (in Anantapur)..... 102

5.5.2. Average versus Intention to Treatment Effect).......................... 106

5.5.3. Impact of receiving additional (non-financial) Services............. 107

5.5.4. Impact of having Livestock Insurance and receiving Ag/BDS.. 110

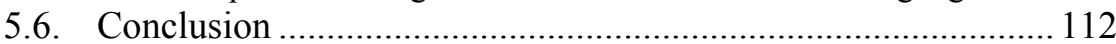

6. Microfinance Plus: Impact of the 'plus' on customers' income in

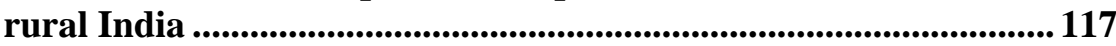

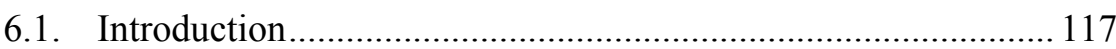

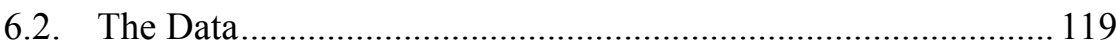

6.3. Strategy to address endogeneity................................................. 121

6.4. Estimation Results ............................................................... 124

6.4.1. Estimates of Ag/BDS Impact on income - Simple OLS Results and Testing for Endogeneity.................................................... 124

6.4.2. Estimates of $\mathrm{Ag} / \mathrm{BDS}$ Impact on income - Instrumental Variable

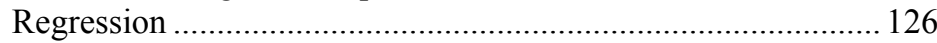

6.4.3. Estimates of Ag/BDS Impact on income - Including information

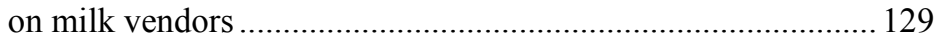

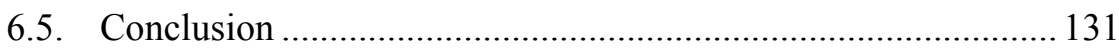

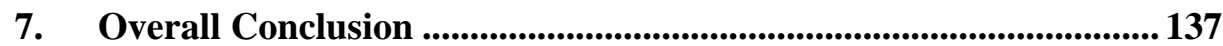

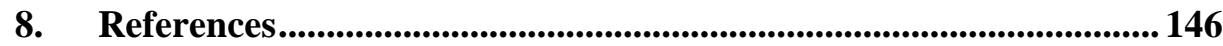

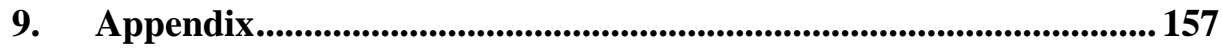

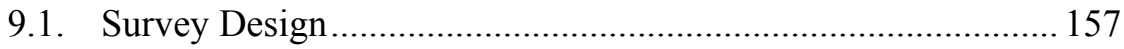

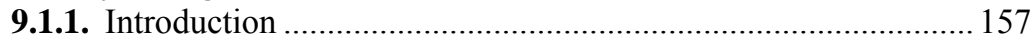

9.1.1.1. The program to be evaluated...................................... 157

9.1.1.2. Design and evaluation methodology .......................... 157

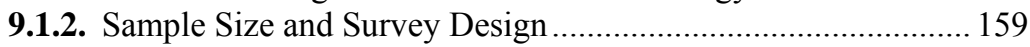

9.1.3. Sample Selection .................................................................... 160

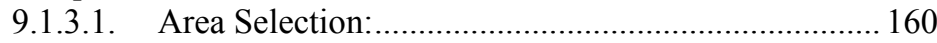

9.1.3.2. Selection of program and control villages ................ 160

9.1.3.3. Selection of households within villages ..................... 162 
9.1.4. Questionnaire Design and Piloting .............................................. 163

9.1.4.1. Questionnaire Design: .............................................. 163

9.1.4.2. Translation of Questionnaire: .................................... 165

9.1.4.3. Piloting of the Questionnaire:..................................... 165

9.1.5. Data Collection:.......................................................................... 166

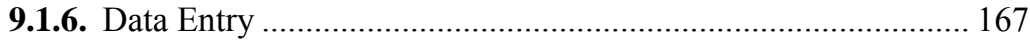

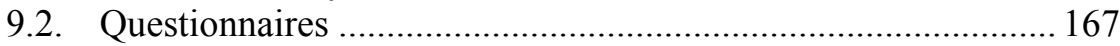

9.2.1. Household Questionnaire ....................................................... 167

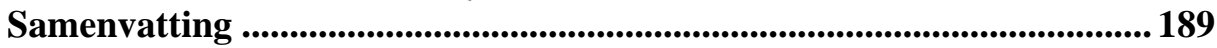

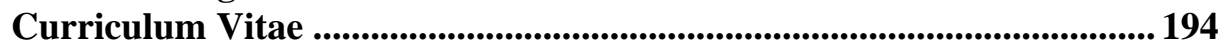




\section{List of Figures:}

2.1. SHG - Bank Linkage 1992 - 2006

2.2. State variations in relative share of SHGs (measured by standard deviation)

2.3. Evolution of the SHG bank linkage system in the State of Tamil Nadu according to the number of SHG (1999-2006)

2.4. Evolution of the SHG bank linkage system in the State of Tamil Nadu according to the amount of disbursed Rupees (1999-2006)

2.5. Local autocorrelation within districts of Tamil Nadu

2.A1. State's names of India

2.A2. District names of Tamil Nadu, India

2.B1. Districts variations in the pace of change of Tamil Nadu's Self-Help Groups - 2000/01-2005/066 (measured by natural breaks) (average annual growth rate) $(\%)$

2.B2. District variations in relative share of Tamil Nadu's Self-Help Groups (measured by standard deviation)

4.1a. The Piece-wise Uniform Distribution - Household Income

4.1b. The Piece-wise Uniform Distribution - Medical Expenses

4.2. Typical, Last year's \& expected household income (total sample, DI \& No DI)

4.3. DI \& No DI (Typical, Last year's and expected household income)

4.4. Realized and Expected Cattle Health Costs

4.5. Expected Incomes and Costs

4.6a. Lorenz Curve (Realized and Expected Household Income, by having income from dairy or not)

4.6b. Generalized Lorenz Curve (Realized and Expected Household Income, by having income from dairy or not)

5.1: Effect on Realized and Expected Incomes

5.B1: Histogram of Propensity Score of being a participant 


\section{List of Tables:}

2.2. Diagnostic Test for spatial autocorrelation in the dependent variable

2.1. Areas of Social Protection and corresponding variables

2.4. Estimation Results of the Final Model Specification

2.A2. District's names of Tamil Nadu

2.B1. Descriptive Statistics of Regional Characteristics

2.B1. Results from testing for local spatial autocorrelation

2.C1. Results from testing for local spatial autocorrelation

2.D1. OLS results - Final Model Specification

2.D2. Diagnostic Test for spatial dependence in OLS regression

4.1. Response Rates

4.2. Tabulation of Reported Probabilities

4.3a. Correlations of Probabilities - Total Household Income

4.3b. Correlations of Probabilities - Income from Dairy

4.3c. Correlations of Probabilities - Animal Health Costs

4.4a. Probabilities Assigned to Sections of Income Distribution

4.4b. Probabilities Assigned to Sections of Dairy Income and Medical Cost

4.5. Income from different sources as percentage of overall income

4.6. Summary Statistics for Household Income Variables

4.7. Summary Statistics for Dairy Income Variables

4.8. Summary Statistics for Animal Health Costs

4.9. Summary statistics of selected explanatory variables

4.10. Least Square Estimates of expected income conditional on realizations

4.11. Estimates of expected income conditional on realizations and consumption

4.12. Least Square Estimates of expected income - extended model

4.13. Inequality Measures

4.A1. Bunching of Percentages (Dairy Income and Health Costs)

5.1: Income Sources ( $\%$ of overall)

5.2: Income Sources ( $\%$ of overall)

5.3: Saving Sources ( $\%$ of total)

5.4: Descriptive Statistics of Outcome Indicators - General

5.5a: Effect of participating in BASIX's Dairy Intervention

5.5b: Effect of participating in BASIX's Dairy Intervention - General

5.6: ATT versus ITT

5.7a: Effect of additional Non-financial services - Investment Returns

5.7b: Effect of Add. Non-financial Services - General

5.8a: Effect of having a loan \& Livestock Insurance \& Ag/BDS - Investment

Return

5.8b: Effect of having a loan \& Livestock Insurance \& Ag/BDS - General 
5.A.1 - Household Characteristics - by Group

5.B1: Propensity Score of being a participant vs. Control

5.B2: Balancing Property

6.1. Socio-Economic Characteristics of sample

6.2. Loan information of sample

6.4. Simple OLS regression Results

6.5. Test statistics for the endogeneity of Ag/BDS

6.6. Instrumental Variables

6.7. First Stage \& 2SLS (IV) Regression Results

6.8. Information on Milk Vendors in Sample Villages

6.9. Estimation Results - Model including Information on milk vendors

6.A1. Distribution of Customers by Purpose of Loan

6.A2. Comparison of Dropped and Kept observations

6.B1. Comparison of observations in Model with and without information on milk-vendors

6.C1. Test statistics for the endogeneity of $\mathrm{Ag} / \mathrm{BDS}$

6.C2. $1^{\text {st }}$ Stage Regression Results 


\section{Prologue}

I started my $\mathrm{PhD}$ from a very simple viewpoint: There is this incredible idea of microfinance, seen to be the tool to combat poverty, and I wanted to know what it actually does to the living conditions of the poor. No more, no less.

Now, three years later, I have put this dissertation together and it has ended up to be quite different from what I expected it to be (as much as one can have expectations about a $\mathrm{PhD}$ when starting) - and maybe surprising to myself, I am rather more happy than disappointed about this.

The main reason for this is that my $\mathrm{PhD}$ gave me the opportunity to learn a lot about an issue that I had basically only read about. Reading books and articles and reports and studies about microfinance, things became extremely clear and I had the feeling to have a very good idea what microfinance is all about.

And then I went to the field and realized that I actually know basically nothing.

I want to start with a little story, which I wrote during my second longer-term field visit in India. I hope this story gives an idea about why I am not disappointed about my dissertation not being the way I anticipated it to be. Because in the end, it is stories like these that shaped my research, which I, today, find at least as important as the "rigorous academic research".

Microfinance can be broadly defined as the provision of loans to the poor for the purpose of supporting an income generating activity. In most cases, it can be seen that loans are not actually used for the purpose they were initially (or officially) intended for. Case studies show that about $60 \%$ of loans are used for domestic purposes, such as payment of wedding expenses, religious festivals, consumption, or even the repayment of other debts. Quite logically (and especially the latter issue will be taken up in one of the chapters), this is seen as a big problem, since it usually entails a deterioration rather than improvement of the poor clients' living conditions. During one of my last field visits, I saw something similar - while one of the clients used the loan for its intended purpose, the reason behind it cannot really be related to the general idea of microfinance. Nevertheless, this story shows that in some cases, it might be more important to satisfy a higher goal than to stick too close to the established rules.

Let me tell you the story: The client I am talking about is a farmer in the State of Andhra Pradesh in the South East of India. This client took a "housing loan" - a loan 
that is, as the name suggests, provided to improve the condition of the home or business. His intention was to build a toilet. Since he did not plan to rent it out, this is obviously not a loan in the traditional sense of microfinance - an 'income-generating' one, but given all the positive results that come from proper hygiene and sanitation and, considering that an incredible amount of households in India do not have one, one can easily argue that this is a perfectly viable reason for taking a loan.

So, why am I telling this story? Things became puzzling when observing that the client in fact already had a toilet. Looking at his living situation more closely, the roof could actually use some repairing and the new toilet was built about 3 meters closer but was in a perfectly usable condition nonetheless. So, why then did this man decided to get into debt - for something he didn't really need - while being poor? The answer is simple: building a new toilet would resolve all the problems which he had with the neighbours and the fights within the family that were going on over the last decade both of which, to be mentioned, did not evolve around the toilet. Still unclear? The secret is the principle of 'Vashtu Shastra' which is comparable to the Chinese idea of 'Feng Shui' - an ancient philosophy of how the design of one's environment, let's say a house, can influence the flow of energies, i.e., luck. About ten years ago, an expert in Vashtu had already told the farmer that the water tank of the toilet was built in the wrong corner of the garden. Being "young and stubborn" at that point in time, the farmer did not listen and did nothing to change the position of the water tank. The result was that over the years, more and more difficulties began to arise. Ten years later and much wiser, the farmer finally decided to do something about it and build a new toilet. And, surprise, surprise, for this he needed a loan. At the time of my field visit, the old toilet was still in use and the problems were not solved yet. Whether they will be solved in the future needs to be seen. But then - who are we to judge? Maybe, one should not always look for rational explanations - 'rational' as defined in the west that is. It is important for this man and his family, for them it is a legitimate reason; he is paying back his debt, building his toilet and feeling happier. And, is feeling happier and hence having improved living conditions not the ultimate goal?

Definitely, the ultimate goal of a field visit is the realization that we need to overcome our preset 'western assumptions' in order to understand and study other cultures. The story might put a smile on your face - it did for me. 


\section{Introduction}

Its stupendous population consists of farm labourers. India is one vast farm - one almost interminable stretch of fields with mud and fences between. Think of the above facts: and consider what an incredible aggregate of poverty they place before you.

Mark Twain, Following the Equator, 1897.

This was India more than 100 years ago. Since then, a high rate of economic growth has contributed to a steady reduction in poverty. In the 1980 s, more than 40 per cent of Indians lived below the official poverty line, a number that fell to 36 per cent in $1993 / 94$ and further to 27.5 per cent in $2004 / 05^{1}$. But even thought this is a great decrease, this percentage translates into an enormous amount of people: of India's population of nearly one billion almost 300 million are primarily worried about how to afford their next meal, while their children die from easily preventable diseases. Seventy-five per cent of these people live in rural areas. Mark Twain's observation from 1897 still holds true today in large parts of the country.

To the poor, the state is both an enemy and a friend. It tantalises them with a ladder that promises to lift them out of poverty, but it habitually kicks them in the teeth when they turn to it for help. It inspires both fear and promise. To India's poor the state is like an abusive father whom you can never abandon. It is through you that his sins are likely to live on.

Edward Luce, In Spite of the Gods, 2006.

One means embraced by the Indian government to reduce poverty is microfinance.

Microfinance started to develop about forty years ago, in the 1970s when experimental programmes in Bangladesh, India, Brazil, and several other countries extended tiny

\footnotetext{
${ }^{1}$ The all-India poverty index is provided by the Indian government. It is a weighted average of the state-wise poverty indexes. These are based on state-wise poverty lines, calculated using data from the Consumer Price Index of Agricultural Laborers (CPIAL) for rural poverty lines and Consumer Price Index for Industrial Workers (CPIIW) for urban poverty lines. For details see Planning Commission, Government of India (2007).
} 
loans to the poor to invest in micro-businesses. ${ }^{2}$ The best known of these programmes is undoubtedly the Grameen (Village) Bank in Bangladesh, initiated by Professor Muhammed Yunus, who in 2006 received the Nobel Peace Price for their work. Yunus' initiative is often credited for being one of the first microfinance operations, making small loans to poor local villagers who lacked access to traditional formal financial institutions. Since then, microfinance has come a long way. While initially concentrating purely on the provision of formal credit, the term nowadays encompasses a broad range of financial services such as savings, insurance and money transfers. The providers follow the social mission of poverty alleviation and a broader impact on livelihood opportunities to the poor through capital creation and hence risk mitigation and consumption smoothing.

The concept proved to have enormous implications: Microfinance generated vast enthusiasm among aid donors, nongovernmental organizations (NGO's), practitioners, politicians and academics alike. It was, and continues to be seen, as an instrument for reducing poverty, even as an instrument believed to have the potential to realize the Millennium Development Goal of cutting absolute poverty in half by 2015 .

The reality though is not as bright as is often portrayed. To its clients, microfinance has turned out to be both "an enemy and a friend". While it is certainly not an 'enemy" in the traditional sense, and most would agree that its legitimacy is beyond doubt, it does display certain adverse traits. These traits are not clearly apparent to many people. Others prefer to ignore or dismiss them. But there remain those that are left to deal with the antagonistic flaws. And without doubt, they would be better off if helped in doing so.

This dissertation has two objectives:

The first objective is to draw attention to those aspects of microfinance that under certain circumstances can be characterized as the lesser evil rather than the greater good. The second is to get a deeper understanding of a special intervention designed to bring out the greater good in microfinance.

Specifically, the first part of the dissertation consists of two chapters.

The first chapter analyses the spread of microfinance in India and its determinants. Despite the explosive growth of the sector, this is one of the first studies addressing this issue. Among others, the results of this study indicate that microfinance serves as a

\footnotetext{
${ }^{2}$ When talking about "the poor" this dissertation follows the conventional approach and adopts the absolute poverty line set by the World Bank in their World Development Report from 1990. According to this document, the poor in developing countries are those that live on US\$ 1 (or to be precise "\$1.08 purchasing power parity for the USA in 1993") a day or less.
} 
replacement for other social programmes. This is a greater evil in the sense that microfinance "is nowhere close to being as important as primary health care, primary education, decent nutrition and a decent infrastructure, decent government and security." (Harper, 2007)

The second chapter explains how Microfinance Institutions (MFIs) experience a mission drift away from social goals towards business values. It is argued that this drift results in microfinance institutions neglecting their social objectives, which translates into unethical practices that are detrimental to the clients. The chapter further points to the role that donor agencies play in this process.

The second part of this dissertation consists of three chapters. It focuses on one specific microfinance programme that helps the rural poor to diversify their income sources by engaging in milk-production as an extra income generating activity. This type of intervention is strongly promoted by the Indian government in an effort to increase the livelihood of the deprived rural population. In view of this, the fourth chapter examines whether this overall strategy does indeed improve welfare and whether households really derive economic benefits from selling dairy products - as perceived by an outsider as well as by the beneficiaries themselves.

The last two chapters analyse an intervention by an Indian microfinance institution within this dairy sub-sector. The providing organization, BASIX India, sees itself not as a microfinance institution but a livelihood promotion institution, offering services that go beyond financial support. The institution is one of the drivers of the integrated sector approach to microfinance in India. It is seen as one of the most innovative institutions - almost an experimental microfinance laboratory, following their strategy of the livelihood triad as explained in chapter five.

Two types of evaluations of institutional intervention in the dairy sub-sector are being conducted in this dissertation. One uses readily available data from the Management Information System (MIS) of the organization, while the other applies household survey data. Comparing results of these two approaches gives new insight into the usefulness of administrative microfinance data (data that was not designed for evaluation purposes) to estimate the impact of components of the programme.

These studies are among the first that evaluate not only the credit-impact of microfinance but also the impact of additional financial and non-financial services on several outcome indicators. A positive (and for certain indicators significant) overall programme effect is found, but interestingly, customers with additional non-financial services do not seem to benefit to a greater extent. This latter conclusion is drawn irrespective of which data set is used in the analysis but relates only to economic indicators. On the other hand, additional services do seem to reduce uncertainty in income streams. This latter observation is possible despite the fact that only crosssectional data is available for analysis - data on subjective expectations of the 
customers allows distinguishing between heterogeneity and uncertainty. Work with this type of data is a relatively new but growing field. This dissertation adds to the literature by collecting new data in a developing country on a population that faces above average uncertainty as well as by eliciting expectations not only on income but also on investment-specific returns.

I independently designed and conducted a household survey of just over 1,000 households. The survey was a thorough process, starting with deciding on the precise purpose of the survey, designing the questionnaire, hiring and training interviewers, managing their work, supervising the data entry and finally cleaning and analysing the data. This allowed me to design the survey and overcome constraints that were experienced when evaluating the programme with data available through the MIS of the MFI. The non-availability of proper control groups as well as a very constrained set of outcome indicators were among these constraints.

As mentioned above, the survey includes a unique set of information that allows working with the subjective expectations of clients. On average a third ( $\sim 25$ minutes) of each interview was used to elicit probabilities on the beliefs of the respondents beliefs about their future household income as well as two outcome variables directly related to the intervention under consideration - income from the dairy activity as well as expected health expenditures and foregone earnings in the case of the animals falling ill.

These subjective expectations data are used in the overall analysis of the extra-income generating activity and its contribution to the improvement of social welfare as well as in the evaluation studies. The use of this data in the evaluation study serves to estimate the subjectively expected return to investment, an estimation of the impacts that customers themselves expect in the future. This type of analysis is new in microfinance literature and for that matter, in evaluation literature as a whole. Work with subjective expectations was pioneered by Charles F. Manski a few decades ago. Nevertheless, given considerable initial scepticism as well as criticism of this approach validation of answers by respondents to expectation questions was and still remains the initial focus of research. This holds true especially for this type of data collected in developing countries, of which very limited numbers of surveys exist up to date. In this dissertation I go one step further, using the data in the analyses.

First though, I will give an overview of the Indian microfinance sector and an insight into the field of operations provided. 


\section{PART I}

\section{Greater Good or Lesser Evil?}

This first of two parts of the dissertation serves to provide a macro as well as a micro perspective of the microfinance sector in India.

The macro perspective refers to an overview of where microfinance is operational in India and what factors contribute to the observed geographical spread. The micro perspective is an analysis of observations from several months of field work in India including my experience made by working at and with a microfinance institution, numerous discussions with practitioners, academics and of course clients.

The main lessons that are being highlighted in this first part are negative ones, pointing to the fact that microfinance is not always as satisfactory as it is often portrayed to be. Many problems exist that need to be addressed in order for microfinance to develop its full potential - that being the greater good rather than the greater (or even lesser) evil. 


\section{Why There? The Reach of Microfinance in India}

\subsection{Introduction ${ }^{3}$}

According to Ghate (2007a), India is home to the worldwide largest microfinance sector having grown rapidly in recent years both in terms of size and institutional diversity. Two delivery models dominate the sector: The Microfinance Institution (MFI) model and the Self-Help Group (SHG) Bank Linkage Programme (SBLP). Both these models have contributed to the observed growth of the sector, but the SBLP is the more dominant model by far, in terms of the number of borrowers and loans outstanding.

While the second part of this dissertation turns to a microfinance intervention that falls under the MFI model, this chapter is concerned with analysing the enormous growth of this SBLP.

The SBLP was a proposed solution by the National Bank of Agriculture and Rural Development (NABARD) for the failed attempts of the Indian government to reach financial deepening. Their suggestion made in the early 1990s was to link informal credit groups - the SHGs - to formal banks. ${ }^{4}$ A SHG is a homogeneous group of on average fifteen poor people that voluntarily form to save small amounts. These pooled resources are forwarded to members for meeting their credit needs in the form of loans, either for consumption or income generating activities. Once the groups show mature financial behaviour, banks become encouraged to provide loans to the SHGs. Typical for microfinance loans, these bank loans are given without any collateral and at interest rates not higher than market interest rates And peer pressures ensure timely repayments (Seibel and Dave 2002).

This was the basic idea behind the Self-Help Group Linkage Programme, which turned out to be the main policy instrument of the Indian government to tackle the inefficacy of existing rural credit institutions, especially the "twin problems of non-viability and poor recovery performance" (Rangarajan 1996).

\footnotetext{
${ }^{3}$ This chapter is based on work with Cyril Fouillet, University Lumière Lyon 2, France.

${ }^{4}$ The idea had actually been initiated in the late 1980 s by the NGO MYRADA operating in Southern India (Karnataka). NABARD picked up the idea in 1991 and it was approved by the Reserve bank of India (RBI) in 1992.
} 
The Indian SHG Bank Linkage Programme developed into one of the most important microfinance programmes across the world with 964,611 linked SHGs during financial year 2005-2006 5 alone. In the period from March 1993 to March 2006 the programme managed to incorporate more than fourteen million households into the financial sector, experiencing an average annual growth rate of 82 per cent, at the same time credit amounts grew at a rate of 110 per cent.

Nevertheless, territorial inequalities are an ongoing reality in this process of microfinanciarization ${ }^{6}$. The dissemination of banking services is limited, with strong inequalities in the distribution of branches between urban areas and the rest of the country (Ramnachandran and Swaminathan 2005). In the words of Y.S.P. Thorat, Managing Director for the National Bank for Agriculture and Rural Development (NABARD): "The uneven spread of the SHG-Bank Linkage Programme has been a matter for concern". Understanding the spatial dynamics at work in India is a crucial component in the future development of SHGs. This especially holds in view of the fact that the SBLP seems to do slightly better than the MFI model when targeting those living below the poverty line (Ghate, 2007a).

Very little information exists that gives insight into the patterns and determinants of spatial distribution and evolution of this economic phenomenon across India. There is hence a clear need for a greater understanding of questions such as: where does the SBLP primarily operate and where does it not? How can one explain the spatial variations of the process, if there are any? What are the factors that influence the geographical spread?

This chapter analyses the above mentioned questions by briefly discussing the development in India as a whole before focusing on Tamil Nadu. ${ }^{7}$ This latter analysis is based on a panel data set covering all districts ${ }^{8}$ in Tamil Nadu over the period 1999/2000-2005/2006.

Results show that the spread of SHGs did not evolve evenly over time within the state of Tamil Nadu. A natural question to arise is therefore what the influencing factors of the distributional variations are? To answer this question, an econometric analysis of

\footnotetext{
${ }^{5}$ This number includes the number of new SHGs provided with bank loan during the financial year 2005-06 $(620,109)$ plus the number of existing SHGs provided with repeat bank loan during the financial year $(344,502)$. Also, important to note is that NABARD data is not always specific as to whether a loan distributed to a group is indeed its first loan or actually its second, third...Reported numbers are therefore likely to overstate the numbers of SHGs.

${ }^{6}$ In the broadest sense, microfinanciarization is the process of structural change that involves financial inclusion, bancarization, or regulations of the informal financial practices, and utilization of voluntary sector and third sector capabilities in financial service provision to the people who do not have access to financial and banking institutions - i.e. 60 to $90 \%$ of the whole population. It is one of the most fascinating features of today's financial economics.

${ }^{7}$ A map indicating the names of all Indian States is given in Appendix 2.A, Figure 2.A1.

${ }^{8}$ India is divided into sub-national administrative units. Districts form the second form of such subdivision below states.(versteh ich nicht...below??)
} 
the determinants of this evolution is conducted. Three issues that are of great importance and debate when it comes to the spatial dimension of the microfinance sector are addressed: whether microfinance operates in areas that are less developed than others or not; whether there is an existing trade-off for governments between the support of creation of SHGs and other social protection programmes; and whether SHG programmes really go where people have no access to formal financial services. The analysis takes into account the potential impact of SHGs in one area considering the likelihood of SHGs in a nearby or far away location, i.e. itconsiders the question of whether the spatial patterning of SHGs is consistent with some kind of diffusion process.

The chapter is structured as follows: The next section gives an overview of the SelfHelp Group Bank Linkage Programme and its spatial distribution and variation in India as a whole, followed by a detailed discussion of the state of Tamil Nadu. The second part of the chapter looks at the determinants behind the observed distribution by doing an econometric analysis. The final section draws conclusions.

\subsection{Spatial Distribution \& Variation of Microfinance Development}

\subsubsection{The Self-Help Groups Bank Linkage Programme in India}

India is experiencing a huge expansion in the number of households linked to microfinance, and more specifically to SHGs. According to Sa-Dhan, an association lobbying for the microfinance sector, this approach accounts for two thirds of the total number of microfinance clients. ${ }^{9}$ While it is banks, microfinance organisations and cooperatives that are involved, the most important driver of the program's development is indisputably NABARD with the SHG Bank Linkage Program. ${ }^{10}$

The growth of the program according to the cumulative data of NABARD (various years) is displayed in Figure 2.1. Reddy (2005) divides the development into three phases: "The evolution of the SHG Bank-Linkage Programme could be viewed in terms of three distinct phases, viz., (i) pilot testing during 1992 to 1995, (ii) mainstreaming during 1996 to 1998 and (iii) expansion from 1998 onwards."

The first peak in Figure 2.1 marks the end of the piloting phase: NABARD initiated the SBLP process by forming 225 SHGs in 1992 and between March 1994 and March 1995 the real start up of the pilot phase took place during which the cumulative number of SHG passed from 620 to 2,122. In the two years thereafter "mainstreaming" took place, including among other several projects initiated by the International Fund for Agricultural Development (IFAD) in collaboration with several Non-Government

\footnotetext{
${ }^{9}$ Note that the growth of MFI clients is increasing which implies a relatively rapid change in this percentage. ${ }^{10}$ It is worth pointing out though that while NABARD initiates, trains and subsidises (and sometimes refinances) SHG loans, it is the banks, microfinance institutions and cooperatives that take all the risk.
} 
Organizations (NGOs) in India (like Myrada in Tamil Nadu). The third phase started in March 1998 and implied a drastic change of scale. NABARD launched a major initiative for accelerating credit linkage to SHGs during that year. Various national schemes ${ }^{11}$ supported the formation and strengthening of SHGs across the country and within two years, more than one hundred thousand SHGs were linked.

Figure 2.1 SHG - Bank Linkage 1992 - 2006

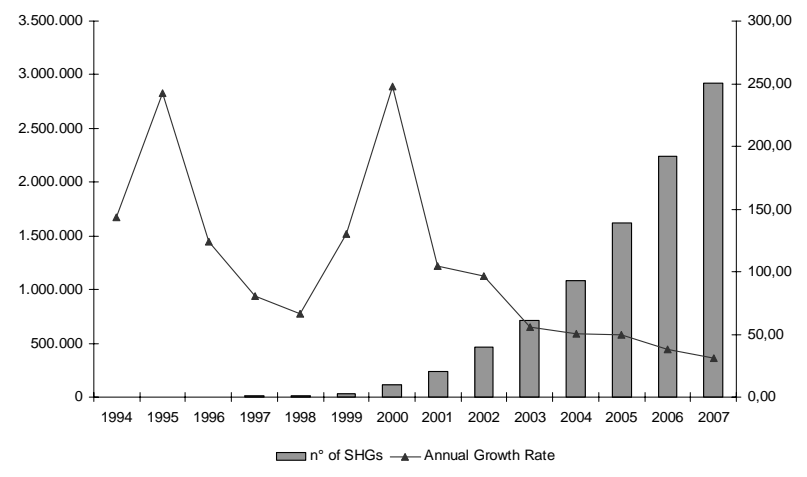

Source: NABARD (various years)

While numbers for India as a whole tell a continuously promising story, great regional variations are to be found within this, as will be exemplified in what follows by looking at the proportion of households engaged in a SHG as well as the corresponding standard deviation within Indian states. Following common practice (NABARD various years, Daley-Harris 2005) the number of households linked to one SHG is assumed to be fifteen. ${ }^{12}$ This average group-size is multiplied with the total number of SHGs linked by formal agencies (commercial banks, Regional Rural Banks and cooperatives) during each financial year. This number is divided by the number of households, whereas the corresponding standard deviation is used to compare the evolution within the Indian states across time.

The importance of not looking at absolute numbers to detect patterns of microfinance coverage is exemplified by the state of Uttar Pradesh in the North of India, bordering

\footnotetext{
${ }^{11}$ These include Rashtriya Mahila Kosh (RMK, an autonomous organisation promoted by Department of Women and Child Development (DWCD), Swarnjayanti Gram Swa-rozgar Yojana (SGSY) and Watershed Development Projects of Ministry of Rural Development, etc.

${ }^{12}$ Note that observations from the field show that this assumption is not adequate for all areas in India. As Malcolm Harper pointed out in a personal conversation, in West Bengal, for instance, SHG are often made up of less than ten members. The reason for this lies in cooperative banks in this area being strongly influenced by the Grameen Bank from across the border. Since we were not able to collect such information on all areas, we decided to stick to the commonly made assumption of SHGs sizes of on average fifteen members. We believe though that the variation in our case study, Tamil Nadu, is less than in India as a whole.
} 
with Nepal. In terms of absolute numbers of SHGs, this Indian state is ranked fifth among all of twenty-eight states in March $2001^{13}$. Nevertheless, taking its big population base into account leaves the State to be one of the weakest ones in India with respect to its relative strength in SHGs.

In 2000, it was the state of Andhra Pradesh (AP) in the South that at nine per cent had the highest percentage of households participating in SHGs. This needs to be compared to Northern states such as Sikkim, Assam and Punjab, where not even every ten thousandth household was home to a member of a SHG. This spatial pattern is mapped in Figure 2.2, where the states are grouped using the standard deviation of the relative share of SHGs. The dark spot on the map is for example Andhra Pradesh, the state with the highest number of SHGs per households; more than three standard deviations above the mean ${ }^{14}$.

Figure 2.2 State variations in relative share of SHGs (measured by standard deviation)

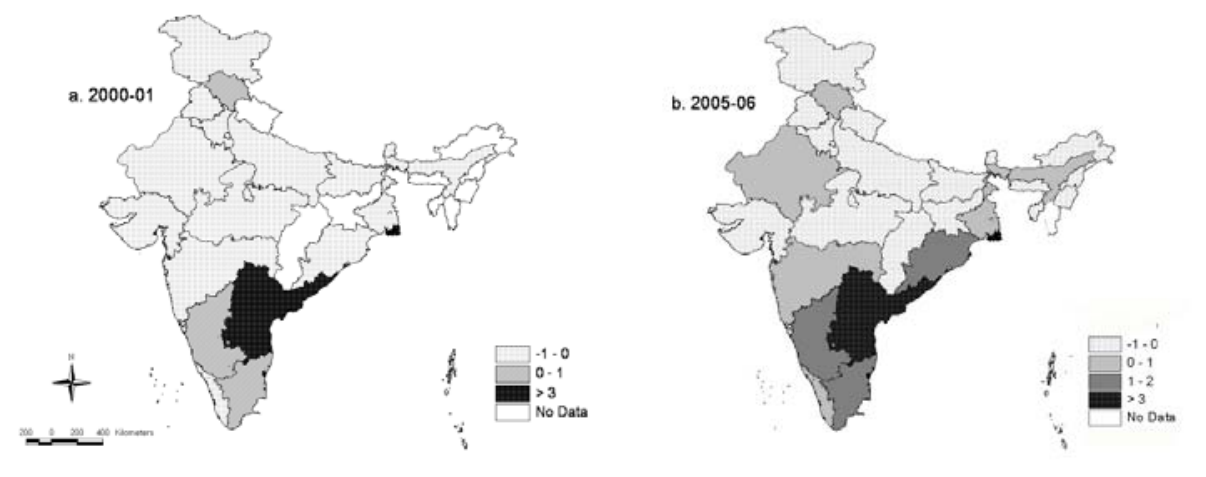

During that same year, it was mainly southern states (except for Kerala in the southwest) as well as Himachal Pradesh in the north that formed the second leading group after Andhra Pradesh. The states had approximately 15 out of 1,000 households participating in SHGs, which translates into one standard deviation above the mean. The weakest states - those with below average percentage of households linked to the formal financial sector through SHGs - were all to be found in the North of India.

\footnotetext{
${ }^{13}$ District wise date on the SHG-bank linkage programme is only available after 2000-2001. Unfortunately, this data are not available at the district level before this date.

${ }^{14}$ As pointed out by Harper and Nath (no year), the contrast becomes even starker when looking at the number of households below the poverty line linked to SHGs.
} 
While these disparities continued to exist in the years thereafter, one observes a slight convergence in the relative strength of the SHGs among states, as evidenced in the decline of the average coefficient of variation from 1.99 in 2001 to 1.15 in $2006 .{ }^{15}$

Five years later, in March 2006 (Fig. 2.2b) a "catching-up" can be observed.

Andhra Pradesh had further consolidated its role as the leading state in the SHG movement, with now about 28 per cent of households participating in SHGs. Also other states had increased their rate of linking households. Only the northern states could not keep up with the trend: In Uttaranchal and Jharkhand there were less than thirty-two households participating in SHGs for every 1,000. In Jammu and Kashmir, Haryana, Punjab and Arunachal Pradesh there were less than ten households participating in SHGs for every 1,000 of the total households.

The remainder of this chapter is concerned with getting a better understanding of dynamics that are at work behind this uneven spread of the SHG movement. To do so, the analysis will concentrate on one Indian state. The rationale of this decision for one lies in data limitations regarding comparable statistics on a national level. The decision is mainly supported by the fact that the SBLP is developed and managed by District Rural Development Agencies and hence within states and not on a national level.

In fact, on a national level/nationwide, most of this unequal spatial pattern can be readily explained. The SHG Bank Linkage Programme has, since its beginning, been predominant in certain states, showing spatial preferences especially in the south Andhra Pradesh, Tamil Nadu, Kerala and Karnataka but also for the northern State of Himachal Pradesh. These preferences are predominantly driven by engaged individuals such as Chandrababu Naidu, at the time the Chief Minister of Andhra Pradesh, pushed mightily for the extension of the SHG-Bank Linkage Program in his State. Also, the presence of Vijay Mahajan, founder of BASIX India, one of the mostknown microfinance institutions in India as well as SHARE showed great support for the initiative. This again attracted donors into these regions. ${ }^{16}$ From these states, a spill over to many states in the eastern region of India, especially along the coast of the Bay of Bengal, was observed and made these states part of the leading provinces with high ratios of microfinance. It was most states in the north, in the centre and in the eastern region (except for West Bengal and Assam) that exhibited less support and hence a much less developed microfinance sector.

The analysis to follow concentrates on the south-eastern state of Tamil Nadu. Tamil Nadu was chosen for several reasons. Firstly, together with Andhra Pradesh, it was one

\footnotetext{
${ }^{15}$ The coefficient of variation is a measure of dispersion of a probability distribution. It is defined as the ratio of the standard deviation to the mean.

${ }^{16}$ In Andhra Pradesh, for example, the government initiated a microfinance programme called 'Velugu' with the assistance of the World Bank and made up by two projects: the District Poverty Initiatives Project and the Rural Poverty Reduction Program. Another society called Society for the Elimination of Rural Poverty channel funds and provides effective implementation.
} 
of the first states to experiment with the idea of SHG's and thus has one of the longest histories and best developed microfinance sectors. It also has extensive field experience on which to draw and enjoys a strong political role in the development of the movement. Tamil Nadu is thus both an interesting case study and one with many years of data to base the analysis on. Most other states only recently started to become engaged with the linkage of Self-Help Groups. Furthermore, personal knowledge gained through extensive field-work in this state facilitated the gathering of information and data, as well as the interpretation of results.

\subsubsection{The case of Tamil Nadu}

In Tamil Nadu, the SHG-bank linkage programme emerged from the Tamil Nadu Women's Development Programme (TNWDP) (called also Mahalir Thittam 'women scheme'). TNWDP was an initiative of the International Fund for Agriculture and Development (IFAD) together with the government of Tamil Nadu and several NGOs. The initiative was taken to compensate for the disappointing effect of the Integrated Rural Development Programme (IRDP) resulting from mistargeting, as well as low repayment rates (on average 24 to 40 per cent) ${ }^{17}$. The main innovation in the TNWDP as compared to previous programmes was the use of women's groups to channel individual and group loans and to offer trainings within different fields, including economics, social studies and marketing. (Holvoet, 2005; Tesorio, 2005)

Overall, the SHG-bank linkage programme in Tamil Nadu, represented by the Mahillar Programme (Seibel, various years), is experiencing an expansion comparable in its size to the national level. An average annual growth rate of linked SHGs of 174.5 per cent was observed for the State of Tamil Nadu in the period from March 1999 to March 2006, with a 210.7 per cent growth rate in terms of disbursed bank loans. At the national level, the corresponding figures are 175.2 per cent and 279.6 per cent respectively. Figure 2.3 displays the number of SHGs linked in TN for the period 1998 to 2006 .

\footnotetext{
${ }^{17}$ IRDP is a major self employment programme for poverty alleviation. Its objective was to provide suitable income generating assets through a mix of subsidy and credit to below poverty line families with the objective of bringing them above the poverty line (Gaiha et al., 2001; Ghosh, 1998; IFAD, 1989; Mahajan and Ramola, 1996; World Bank, 1991). Nevertheless, recognizing the effectiveness of microfinance through group lending methodology, the government of India has given up on IRDP along with several other programmes (such as JRY, Rural Landless Employment Guarantee Programme (RLEGP), National Rural Employment Programme (NREP), Drought Prone Areas Programme (DPAP), Training of Rural Youth for Self-employment (TRYSEM) that had all been implanted in the 1980's.
} 
Figure 2.3 Evolution of the SHG bank linkage system in the State of Tamil Nadu according to the number of SHG (1999-2006)

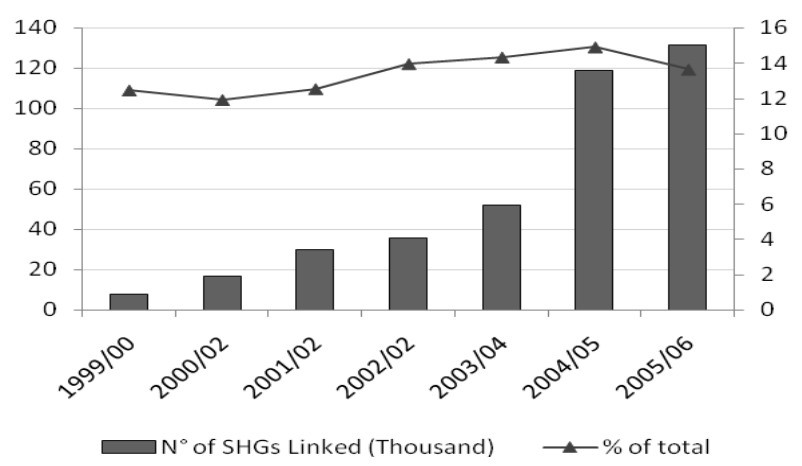

Sources: NABARD (various years)

It is interesting to note that even if Tamil Nadu's contribution to the development of the all-India Indian microfinance sector is relatively stable at about 14 per cent during the period, the average loan size given to a SHG for Tamil Nadu was 30,662 rupees during the financial year 1998-99 and increased to 78,661 in 2005-06, which is to be compared to the national average of almost half that size with 17,883 and 46,641 rupees respectively. ${ }^{18}$ The evolution amount of Rupees disbursed can be seen in Figure 2.4 .

Figure 2.4 Evolution of the SHG bank linkage system in the State of Tamil Nadu according to the amount of disbursed Rupees (1999-2006)

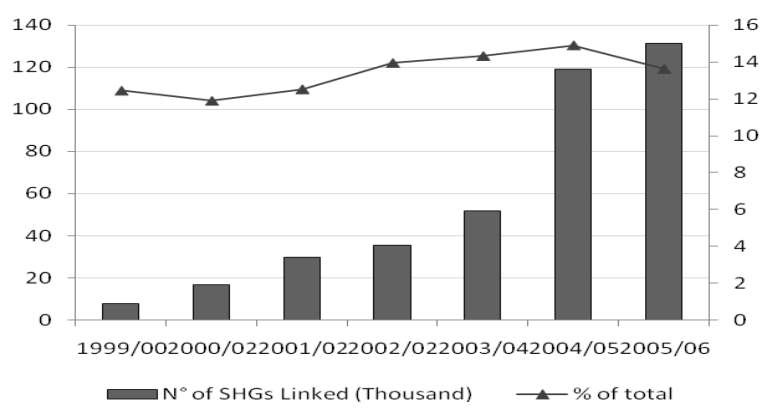

Sources: NABARD (various years)

The rapidly expanding development of the SHG model reflects the major role the microfinance sector plays in the life of Tamil Nadu's population. After a first cycle of

\footnotetext{
${ }^{18}$ The exchange rate Euro to Rupees in the financial year 2006/06 was approximately 1:55.
} 
growth, during which the number of clients went from a few thousand to several million, microfinance is now at the core of many agendas - irrespective of being public or private.

Indian microfinance, both in terms of the number of clients and the volume of disbursed credit, is no longer anecdotal. Because of the socio-economic, political, even cultural questions it raises, microfinance has become a challenge for society.

This makes it important to judge the growth of the sector not only in terms of generating income and employment for the poor ${ }^{19}$ but to also pay attention to its regional distribution.

Appendix 2.B gives details on the absolute as well as the relative strength of the SHGs in the state's districts and the district variation over several years, repeating the analysis that was previously presented on an all-India level. Results show that while Tamil Nadu is ranked among those states with a high level of microfinance development, the intra-state analysis shows significant district inequalities. These intra-state inequalities are very significant and partially call into question the successes that seem so apparent when considering the numbers for the state as a whole.

Given this uneven spread it is of interest to understand the factors, which influence the distributional variations. These will be analysed in the next section by empirically testing several variables that are theorized to influence the spatial distribution.

\subsection{Econometric Analysis of the Determinants of the Evolution}

In the analysis of the spread of the SBLP the cumulative number of linked SHGs per household contributes the dependent variable. 'Linked' means that a group received at least one loan from a formal bank. An alternative would have been to look at the number of groups formed - which implies the inclusion of groups that might never have been linked to a bank. These groups would probably have started to save and maybe also to forward these savings as loans, but due to targets in terms of promoting a certain number of SHGs, group formation unfortunately does not always receive the needed attention. This implies that the focus is not always on the formation of functioning groups and that the subsequent nurturing and development is neglected (Pramod, 2006). Especially in view of the long-term benefits of the SHG programme this is a matter of concern. A study supported by NABARD showed that $70-80 \%$ of poor households use up the first two credits for consumption purposes, but that an increasing proportion of them use further credit for non-conventional microenterprises within two years. The need to take a long-term perspective becomes

\footnotetext{
${ }^{19}$ For a comprehensive review see for example Ghate (2007).
} 
apparent and it is important to understand where successful groups (in terms of having been linked to formal financial services) are in operation ${ }^{20}$.

One way of getting an insight into which factors influence the spread of the number of linked SHGs per households is to apply simple ordinary least square (OLS) regressions, maybe including area dummies to capture spatial influences. Nevertheless, since dealing with a geographical component, problems are likely to arise with this conventional econometric technique. The matter of concern is that spatial dependence is expected to exist between regions. Put differently, it is likely that the increase in the number of SHGs in one district is not independent of what is happening in a neighbouring district. If this is the case, OLS results are no longer valid and inference on t-statistics misleading. Techniques that account for the fact that geographic context might condition or moderate the effect of certain explanatory variables on the number of SHGs in a certain location are called for.

Therefore, before going into the analysis of structural determinants, the potential impact of SHGs in one district on the likelihood of SHGs in a nearby or far away location is addressed, i.e., is the spatial patterning of SHGs consistent with some kind of diffusion process? This latter issue is one of the main distinguishing methodological features of spatial data analysis.

\subsubsection{Methodology}

Spatial data analysis takes into account the spatial arrangement of the observational units, which are typically called locations (Anselin, 1992a) - corresponding to the state's districts in this analysis. This spatial arrangement is represented by a spatial weights matrix $W$ whose elements $w_{i j}$ express the presence/absence (binary weight matrix) or the degree (non-binary weight matrix) of potential spatial interaction between each possible pair of locations.

This interaction is consistent with spatial dependence, also referred to as spatial autocorrelation, and can be defined as the phenomenon that occurs when the spatial distribution of the variable of interest - in this case the number of SHGs per household - exhibits a systematic pattern (Cliff and Ord 1981).

Three different weight matrices are used in this analysis to test, and if necessary account, for spatial dependence in the data: The simplest one (and also the one mostoften used in studies) is the binary neighbour matrix, indicating border sharing between districts (this is henceforth referred to as 'neighbour matrix'). The second matrix is a slight refinement on the first, indicating the length of common border as a

\footnotetext{
${ }^{20}$ NABARD started to report also the number of SHGs that opened a savings account with a bank. As will be discussed in the subsequent chapter, the microfinance sector has the tendency to promote indebtedness. In the SHG model, this shows by some groups being put under pressure to borrow, rather than merely to save in most cases in order to meet targets. This can be pernicious and needs to be kept in mind when defining 'linked groups' as more successful than 'formed groups'.
} 
ratio to total border of both districts together ('border matrix'). Finally, the third matrix uses the driving distance (in $\mathrm{km}$ ) between capitals of the districts, implying that the matrix has only zeros on the diagonal ('distance matrix') $)^{21}$.

Three measures of global spatial autocorrelation are looked at and presented in Table 2.2: Moran's $I$ (Moran 1948), Geary's c (Geary 1954), and Getis and Ord's $G$ (Getis and Ord, 1992) to test for dependences in the spread of the SHG Bank Linkage Programme in Tamil Nadu.

Table 2.2. Diagnostic Test for spatial autocorrelation in the dependent variable

\begin{tabular}{lccccc}
\hline Moran's I & $\mathrm{I}$ & $\mathrm{E}(\mathrm{I})$ & $\mathrm{sd}(\mathrm{I})$ & $\mathrm{z}$-stat & $\mathrm{p}$ \\
\hline \hline (1) neighbour matrix & 0.160 & -0.037 & 0.115 & 1.723 & 0.042 \\
(2) border matrix & 0.257 & -0.037 & 0.138 & 2.128 & 0.017 \\
\begin{tabular}{l} 
(3) distance matrix \\
\hline Geary's $c$
\end{tabular} & -0.083 & -0.037 & 0.020 & -2.322 & 0.010 \\
\hline \hline (1) neighbour matrix & 0.735 & 1.000 & 0.167 & -1.589 & 0.056 \\
\hline \begin{tabular}{l} 
Getis \& Ord's $G$ \\
\hline (1) neighbour matrix
\end{tabular} & $\mathrm{G}$ & $\mathrm{E}(\mathrm{G})$ & $\mathrm{sd}(\mathrm{G})$ & $\mathrm{z}$ & $\mathrm{p}$ \\
\hline $\begin{array}{l}\text { Please note that Geary's c, and Getis and Ord's G can only be calculated when } \\
\text { the weight matrix is binary. Therefore, these statistics are only provided for the }\end{array}$ \\
first of our three matrices. \\
\hline
\end{tabular}

The statistics strongly confirm suspicion that the distribution of the number of SHGs in the State of Tamil Nadu is not totally random. Except for Getis \& Ord's $G$, all statistics indicate significant global spatial autocorrelation in the variable of interest on a six per cent significance level. Furthermore, all statistics agree that this spatial autocorrelation is a positive one. In other words, the value taken on by $Y$ (number of SHGs per households) at each location (district) $i$ tends to be similar to the values taken on by $Y$ at spatially contiguous locations. Note that for the distance matrix numbers show negative autocorrelation ( $I$ is smaller than its expected value), which is due to the fact that a bigger number in the matrix stands for districts being further away from each other while a bigger number in the other two matrices implies the opposite. Therefore, the change in sign - the interpretation remains the same.

The analysis continues using the distance matrix as the weight matrix. ${ }^{22}$ This choice is founded on statistical results (Table 2.2 shows that results suggest strongest global autocorrelation when using this matrix) but also on theoretical considerations: the SHG Bank Linkage programme is developed and managed by District Rural Development Agency (DRDA) of which the offices are located in the respective

\footnotetext{
${ }^{21}$ These driving distances are calculated using the interactive mapping portal www.mapmyindia.com.

${ }^{22}$ Where appropriate and interesting, results obtained when using one of the other matrices is pointed out.
} 
district capitals. Significant influences between neighbouring districts can be related back to DRDA's collaboration. To understand this, one should keep in mind that social relationships and personal exchange still play a crucial role in day-to-day as well as business life in India (as elsewhere) that cannot be fully replaced by the internet or other media.

The measures of spatial autocorrelation as discussed above are global measures meaning they offer an "average" picture of the spatial distribution of the variable of interest. It is possible to test whether clustering is especially present in certain districts and less in others. These measures of local spatial autocorrelation reveal areas exhibiting significant deviation from spatial randomness and help to identify those locations that contribute most to the overall pattern of spatial clustering (Sokal et al. 1998).

Figure 2.5: Local autocorrelation within districts of Tamil Nadu

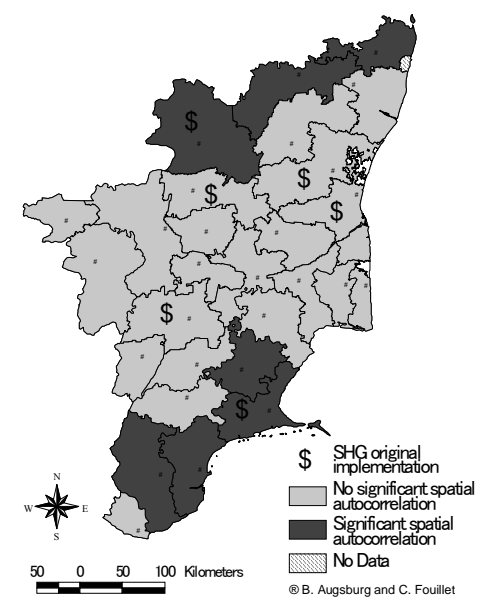

When employing so called 'local statistics' to detect significant spatial clustering around individual locations six 'hotspots' are identified. These districts are the ones shaded darker in Figure 2.5 and correspond to Tirunelveli, Ramananthapuram, Sivagangai, Thoothukudi, Tiruvallur, and Dharmapuri. ${ }^{23}$ From the previous section it is known that these are districts that were either continuously strong in terms of microfinanciarization over the years or showed a fast growth in the number of households linked to banks (see discussion of Figure 2.6). It is worth pointing out that only two out of these seven districts are among those where the programme was initially started.

\footnotetext{
${ }^{23}$ A map indicating the names of all districts is given in Appendix 2.A Figure 2.A2.
} 
The above analysis gives strong indication of a significant pattern of spatial clustering. The spatial autocorrelation statistics show that the values taken on by the variable of interest at the different locations are more spatially clustered than they would be under a random assignment. This is the first step in the analysis of spatial data. The second step is to find out why such clustering occurs (Anselin 1992) so that the appropriate econometric model can be applied in the analysis.

In the literature, typically two types of spatial dependences are considered: The first one takes the form of a spatial autoregressive process in the error term and is referred to as the spatial error model. The second takes the form of a mixed regressive spatial autoregressive process, called the spatial lag model.

Spatial error model: $Y=\beta X+\varepsilon$ where $\varepsilon=\lambda W \varepsilon+\mu$. Where $Y$ is the number of linked SHGs per households in a certain district, $X$ are covariates, $\varepsilon$ is an error term, $\lambda$ is the spatial autoregressive parameter, $W$ the weight matrix and $\mu$ denotes a vector of homoskedastic and uncorrelated errors (Anselin and Hudak 1992).

Spatial lag model: $Y=\rho W Y+X \beta+\mu$, where $\rho$ denotes the spatial autoregressive parameter, $W Y$ denotes the spatially lagged dependent variable, and all the other terms are defined as above (Anselin and Hudak 1992). ${ }^{24}$

Statistical tests for both kinds of spatial dependence are performed. To do so, a simple OLS model will be estimated first. The Moran's $I$ statistic can then be used to gauge the level of spatial dependence in the residuals of this OLS regression and thus provide some additional justification for using more rigorous spatial econometric methods (see, e.g. Tiefelsdorf 2000 for details). The Lagrange Multiplier tests can then be used to test which spatial error model is most appropriate ${ }^{25}$.

Results of this testing procedure (Tables are provided in Appendix 2.E) lead to the decision of estimating a spatial lag model. In addition to the estimated test statistics, the motivation for a spatial lag model is supported by formal theoretical concerns since this model is generally seen to be appropriate when the focus of interest is the assessment of the existence and strength of spatial interactions.

A spatial lag model is hence used to analyse determining factors of the observed spread, using a distance matrix as weight matrix.

\footnotetext{
${ }^{24}$ In this model the covariates in the other countries only indirectly impact the current yi, through their impact on the yj for other countries, which then in turn impacts the current yi. It is also possible to allow the covariates in other countries to directly impact the current yi, by adding a wix term to the model, where $\mathrm{x}$ refers to the values of the covariates for all countries. This is easy to do using standard methods, and causes no econometric problems. See Pace and Barry (1998) to obtain more details of this type of model.

${ }^{25}$ Details of these tests can be found in Anselin and Hudak (1992) and Anselin et al. (1996).
} 


\subsubsection{Explanatory Variables}

In determining the explanatory variables of the analysed microfinance spread, three areas that are of great importance and debate when it comes to the spatial dimension of the microfinance sector are used as a theoretical guideline. A short outline of these issues is given below. More details on specific variables and how estimated coefficients have to be interpreted will be given when discussing the results of the analysis.

\section{Level of Development}

The first concern is the relationship between microfinance and the level of development in the different regions of Tamil Nadu. Since microfinance, here represented by SHGs, is a tool to eradicate poverty one would hope that it interacts in areas where it is most needed, hence where dimensions such as income or human development are lowest. Initially, the implementation of the programme followed a spatial approach. Selected indicators of women's status (including educational attainment, literacy, maternal mortality, dependency upon agriculture for employment, percentage of scheduled caste and scheduled tribe ${ }^{26}$ in female population) were analysed and taken as a basis by IFAD in consultation with the Tamil Nadu government and civil society to decide on where to implement the pilot phases. Decision was taken to operate in those districts of Tamil Nadu with the lowest scores, i.e. the districts of Dharmapuri and South Arcot (now divided into Cuddalore and Villupuram) (Holvoet, 2005). It is of interest whether the priority towards these lesser developed districts prevailed in the years after the set-up of the programme or whether primacies shifted.

\section{Level of Banking}

Microfinance is targeted at that part of the population that does not have access to formal financial services. This aim of financial inclusion is given major importance. Clear signals that stress the priority of microfinance as a tool to eradicate poverty were given by the international community over recent years: The G8 meeting in 2004, the declaration of the year 2005 as the year of microfinance by the United Nations, the accolade of Mohammed Yunus and the Grameen Bank with the Nobel Peace Price in 2006, to name but a few. Besides poverty reduction, these meetings set the additional target of focusing on financial inclusion - coinciding with one of the main objectives of the SHG model (Parekh, 2006). Attention is therefore paid in our analysis to whether or not the SHG movement operates predominantly in areas where such formal financial services are available or not.

\footnotetext{
${ }^{26}$ Scheduled tribes and scheduled castes are Indian communities that are granted special status by the constitution of India in order to extend positive discrimination against these groups. There is no unified theory on how the caste system developed in India but it is generally associated with Hinduism.
} 


\section{Level of Social Protection}

The third issue is whether districts that are more actively involved in the provision of social protection than others also foster more than average the development of SHGs. Social protection consists of policies and programmes designed to reduce poverty and vulnerability. The Asian Development Bank (ADB) identifies five areas of social protection. The data available allows testing variables on four of these areas. The dependent variable of the analysis falls into the fifth and final of this classification. The areas and available variables are displayed in Table 2.1.

\section{Table 2.1. Areas of Social Protection and corresponding variables}

\begin{tabular}{|c|c|}
\hline SOCIAL PROTECTION AREA & VARIABLE USED IN THE ANALYSIS \\
\hline $\begin{array}{l}\text { 1. Labour market: } \\
\text { Policies and programmes designed to } \\
\text { promote employment, the efficient } \\
\text { operation of labour markets and the } \\
\text { protection of workers }\end{array}$ & $\begin{array}{l}\text { Prime Minister Rozgar Yojana's programme aiming to } \\
\text { provide self-Employment to Educated Unemployed Youth } \\
\text { was announced by the Prime Minister on 15th August, } \\
\text { 1993. The goal was to provide self-employed opportunities } \\
\text { to one million educated unemployed youth in the country. } \\
\text { The Scheme was formally launched on 2nd October, } 1993 \text {. } \\
\text { The amount of Rupees disbursed per household is used as } \\
\text { an indicating variable. }\end{array}$ \\
\hline $\begin{array}{l}\text { 2. Social insurance: } \\
\text { Programmes to cushion the risks } \\
\text { associated with unemployment, ill } \\
\text { health, disability, work-related injury } \\
\text { and old age }\end{array}$ & $\begin{array}{l}\text { The number of elderly benefiting from old-age benefit } \\
\text { scheme as a percentage to total population is used as the } \\
\text { indicating variable (please note that no information was } \\
\text { available on the size of the elderly population itself }\end{array}$ \\
\hline $\begin{array}{l}\text { 3. Social assistance: } \\
\text { Social assistance and welfare service } \\
\text { programmes for the most vulnerable } \\
\text { groups with no other means of adequate } \\
\text { support, including single mothers, the } \\
\text { homeless, or physically or mentally } \\
\text { challenged people. }\end{array}$ & $\begin{array}{l}\text { The emphasis in the successive Five Year Plans developed } \\
\text { by the Planning Commission of India has been to bring } \\
\text { about economic and social development of disadvantaged } \\
\text { groups in the society, scheduled castes and scheduled tribes } \\
\text { receiving special attention. Effort has been made to } \\
\text { increase equality through socio-economic development } \\
\text { schemes. The number of free housed distributed to } \\
\text { members of the scheduled castes is one example that } \\
\text { reflects such a social scheme. }\end{array}$ \\
\hline $\begin{array}{l}\text { 4. Child protection: } \\
\text { to ensure the healthy and productive } \\
\text { development of children. }\end{array}$ & $\begin{array}{l}\text { With the aim to reduce the economic cost of sending a child } \\
\text { to school and by this increase enrolment, the State } \\
\text { Government of Tamil Nadu has introduced various } \\
\text { schemes, including the Noon Meal Scheme as well as the } \\
\text { provision of free textbooks and uniforms. Data on the latter } \\
\text { two were available on a district level. Such textbooks and } \\
\text { uniforms are provided to all children studying up to Class } \\
\text { VIII in the government and government-aided schools } \\
\text { (uniforms cover even all kids up to class X). } \\
\text { Furthermore, information provided by family welfare } \\
\text { centres in rural as well as urban areas is used. }\end{array}$ \\
\hline $\begin{array}{l}\text { 5. Micro-and area-based schemes: } \\
\text { to address vulnerability at the } \\
\text { community level, including } \\
\text { microinsurance, social funds and } \\
\text { programmes to manage natural disasters. }\end{array}$ & $\begin{array}{l}\text { This is the area to be tested. The dependent variable is the } \\
\text { cumulative number of SHGs per number of households in a } \\
\text { district (to be elaborated on below). }\end{array}$ \\
\hline
\end{tabular}




\subsubsection{Results and their Interpretation}

The final model includes variables that can be placed under one or more of these described areas of debate. Table 2.4 presents the final results. ${ }^{27}$

Table 2.4. Estimation Results of the Final Model Specification

\begin{tabular}{|c|c|c|c|c|}
\hline & Coeff. & Std. Err. & Z-stat & $\mathrm{P}>|\mathrm{z}|$ \\
\hline Income index & -9.827 & 3.593 & -2.73 & 0.006 \\
\hline Literacy & -0.072 & 0.032 & -2.23 & 0.026 \\
\hline Human Development Index & 21.001 & 8.363 & 2.51 & 0.012 \\
\hline No of rural bank branches (per hh) & 9.732 & 2.321 & 4.19 & 0.000 \\
\hline$\%$ of amount disbursed to agricultural sector & -1.677 & 1.474 & -1.14 & 0.255 \\
\hline$\%$ of amount borrowed to other small industries & -7.541 & 2.626 & -2.87 & 0.004 \\
\hline Youth Unemployment programme (per hh) & -6.459 & 1.918 & -3.37 & 0.001 \\
\hline Area & 0.0002 & 0.00003 & 5.74 & 0.000 \\
\hline Constant & 1.927 & 3.772 & 0.51 & 0.609 \\
\hline rho & -2.672 & 0.357 & -7.49 & 0.000 \\
\hline Wald test of rho $=0:$ & \multicolumn{4}{|c|}{$\operatorname{chi} 2(1)=56.124(0.000)$} \\
\hline Likelihood test of rho $=0$ : & \multicolumn{4}{|c|}{$\operatorname{chi} 2(1)=14.598(0.000)$} \\
\hline Lagrange multiplier test of rho $=0$ : & \multicolumn{4}{|c|}{$\operatorname{chi} 2(1)=6.033(0.014)$} \\
\hline Variance Ratio $=$ & \multicolumn{4}{|c|}{0.666} \\
\hline Squared Corr. $=$ & \multicolumn{4}{|l|}{0.800} \\
\hline Sigma $=$ & \multicolumn{4}{|l|}{0.49} \\
\hline $\begin{array}{l}\text { Notes: Spatial lag model where the weight } \\
\text { capitals. }\end{array}$ & trix refle & he dist & & \\
\hline
\end{tabular}

Given the nature of the programme under consideration, most estimated coefficients are best discussed in the context of Sharma and Zeller (1999). The authors propose a placement rule for a Bangladeshi NGO, incorporating the fact that profit is not the principal aim of this institution. The four proposed areas that are considered in the placement decision are: (1) targeting poverty, (2) expected demand for services, (3) cost of supplying services, and (4) perceived riskiness in operation. A more detailed discussion of each of these is provided in Box 2.1. In brief, when deciding where to supply services, microfinance organisations face the problem that most determining factors contributing to the social mission of microfinance work contrary to the objective of minimizing costs and risk.

This discrepancy is reflected in the interpretation of the estimated coefficients. The example below clarifies how one variable can influence several of the four areas in a way that makes the prediction of the expected sign ambiguous.

\footnotetext{
${ }^{27}$ Please note that the model only includes a limited number of variables. The choice to go for such a parsimonious model was made given the limited degrees of freedom with just 28 observations (districts in the state of Tamil Nadu).
} 
For example the availability of banking services (represented by the variable 'no of rural bank branches per 1,000 households) influences the 'cost of supply' and 'perceived riskiness' positively in the sense that the availability of banking services in an area is hypothesised to induce an institution to operate within the same area. This is due to microfinance providers (and especially the SHG Bank Linkage Program) typically depending on these formal financial institutions to make cash disbursement and deposits. Furthermore, it is likely that banks themselves are found in areas with favourable supply conditions such as good infrastructure - which again reduces costs in operation.

\title{
Box 2.1: Sharma and Zeller's (1999) Placement Rule
}

\begin{abstract}
Microfinance is praised today as the tool to eradicate poverty and most institutions and organisations specifically mention poverty-targeting in their mission statement. Their principal aim is the social mission; to "reduce poverty" (Vital Finance, Benin), to "promote a large number of sustainable livelihoods" (BASIX India), to "give people the tools to work their way out of poverty" (ACCION International), "to promote the economic development of Dominican women and integrate them and their families into the formal economic system" (ADOPEM, Dominican Republic) to name just a few. One would therefore assume that delivering institutions, including the government, operate in areas where it is most needed, hence where poverty indicators are highest.

Nevertheless the cost of supply has - not surprisingly - been shown to be especially high when serving the neediest. There is a great debate in the microfinance sector as to how these costs should be covered. The debate evolves about the sustainability of microfinance and the depth of its outreach (Robinson, 2001; Cull and all, 2007). It emerged from the demonstration that due to innovations in the microfinance sector, a substantial portion of this new market could in fact be lent to profitability. This realization has then drawn profit-motivated lending institutions into these markets and donors have and are questioning the need for continued subsidies, resulting in the recent focus on "institutional sustainability" in the MFI sector (McIntosh and Wydick, 2005). Microfinance became business. Critics of this development fear that MFIs tend to be so much preoccupied by their own financial sustainability that they move away from the poor as their preferred clientele and tend to start providing bigger loans closer to "low income section" of the population instead of deepening their outreach to include the most needy.

Of further importance to be able to cover costs - but also to have greatest impact, is a certain mass of customers. Where demand is highest, the marginal impact on participating households is also likely to be the highest, while at the same time reducing the marginal cost of supplying services. This explains the weight of expected demand in the placement decision.

Finally, institutions place considerable weight on perceived riskiness of operations when deciding where to operate. It is of course important for an organization to keep high repayment rates to cover costs and to keep access to mainstream on a continuous basis,
\end{abstract} which is best achieved when risk is minimized.

Nevertheless, microfinance is seen as a tool to "bank the unbanked" - people that have no access (including physical access) to formal financial services. Therefore, in view of the social mission of an MFI (and hence of 'poverty targeting'), one would hope that MFIs operate predominantly in areas where formal financial services are not as readily available, where the human development indicators are low, etc. Therefore, in 
terms of 'cost of supply', the estimated coefficient of availability of banking services is theorized to be positive, and negative when considering the goal of targeting excluded groups such as the 'unbanked' 28 .

As in this example, also in the remaining cases this ambiguity turns out to be favourable when deriving conclusions with respect to the three issues of concern previously discussed. This will become clear in the following discussion of estimated coefficients of the model.

Income Index \& Literacy:

Fewer SHGs per household are found in areas that are more developed, as defined by the indicators on income and literacy.

There are more SHGs in areas where income is lower: The estimated coefficient of the 'Income Index ${ }^{29}$ is significantly negative, meaning that the higher the income in the region, the less number of SHGs per households were linked, and, respectively, the higher the literacy rate in a region, the fewer number of SHGs were provided with a formal bank loan.

These findings can be related to the overall mission of the programme to serve the poor but can additionally be attributed to the fact that during the pilot phase, the targeting concentrated on the poorest women in rural areas. Geographically, the project was implemented initially in four contiguous districts (Dharmapuri, Salem, Cuddalore and Villupuram) and extended to two other districts during implementation (Madurai and Ramanathapuram). According to a report of IFAD:

"The project focused on districts that were backward in terms of human development, such as Dharmapuri and Ramanathapuram, and other areas with high levels of female infanticide such as Madurai and Salem." (IFAD, 1998)

Nevertheless, as will be discussed next, this focus does not seem to have taken place as significantly as one would have hoped for.

\footnotetext{
${ }^{28}$ This is not to say that a positive coefficient implies that no poverty targeting takes place. Many poor might live within a reasonable distance from a bank branch but are excluded from accessing their services due to a number of other possible reasons; such as being too poor to afford needed official papers or not even being allowed to enter a branch.

29 "Values of per capita GDP (PPP\$) for women and men are calculated from the female share (sf) and male share (sm) of earned income. These shares, in turn, are estimated from the ratio of the female wage (w f) to the male wage (wm) and the percentage shares of women (ea f) and men (ea m) in the economically active population. When the data on the wage ratio are not available, a value of 75 per cent is used." (Tamil Nadu Human Development Report (2003), p.4)
} 


\section{Human Development Index:}

The model includes the Human Development Index, which was calculated by The Government of Tamil Nadu in 2003. It is a composite index, covering the following three dimensions of living standards:

\begin{tabular}{|l|l|}
\hline Dimension & Dimensions Variables \\
\hline 1. Attainment in longevity & Life expectancy at birth \\
\hline 2. Educational attainment & $\begin{array}{l}\text { a) Adult literacy rate } \\
\text { b) Combined enrolment ratio (primary, secondary and tertiary) }\end{array}$ \\
\hline 3. Command over resources & Real per capita income \\
\hline
\end{tabular}

The model results suggest that a higher level of human development is associated with more linked SHGs. Specifically, the positive sign of the HDI seems to be driven by attainments in longevity, the enrolment ratio, or both. This is because variables falling under the remaining two dimensions of the HDI (literacy rate and the income index) are estimated to have a negative coefficient.

"Longevity as an indicator of human development captures several aspects of welfare, because of its close correlation with nutrition, health and other biological and social achievements." (Tamil Nadu Human Development Report (2003), p.4).

Given these results, it seems that Thorat (2003) was right in his observation that "[...] in states which have a larger share of the poor, the coverage is comparatively low." Also Vijay Mahajan, founder of BASIX, an influential livelihood promotion institution in India highlights the problem: "there is a real risk that in celebrating the SHG Bank linkage microcredit programme, attention is diverted from the larger problem of financial exclusion of the poor and banks are let off the hook from their real job." Mahajan (2005)

The next discussion underlines this latter statement.

Number of rural bank branches per 1000 households, Amount disbursed for agricultural credit (as percentage to total amount disbursed) \& Amount borrowed to 'other small industry' sector ${ }^{30}$

As laid out in the example above, the sign of the coefficient of number of bank branches is influenced by several considerations - some favouring the operation where

\footnotetext{
${ }^{30}$ Small Enterprises is defined by the RBI as small (manufacturing) enterprises engaged in manufacture/ production, processing or preservation of goods, and small (service) enterprises engaged in providing or rendering of services, and whose investment in plant and machinery and equipment (original cost excluding land and building and such items as mentioned therein) does not exceed a certain amount. It furthermore includes any person providing inputs to or marketing the output of artisans, village and cottage industries, handlooms and to cooperatives of producers in this sector.

Other Small Business / Service Enterprises then include small business, retail trade, professional \& selfemployed persons, small road \& water transport operators and all other service enterprises.
} 
a banking network is in place (cost and risk considerations), others factors supporting rather the decision to locate in areas less served by financial institutions (social mission).

The model as presented in Table 2.4 estimates a positive coefficient in the number of rural bank branches per households, which supports a statement made by the chairman of NABARD:

"Banks through their rural branches have played and continue to play an important role in providing financial services to the poor on a standalone basis." (Thorat, 2006)

The bank branches playing a strong role at the same time though imply that the SHG movement does not go into areas where formal financial institutions are not available. On the contrary, the SHG movement makes use of and reinforces the old rural bank network, which was established in the phase of 'social banking' in India. Indeed, linking SHGs with banks was made a national priority from 1999 onwards by the government of India through its periodic policy and Budget announcements. NABARD takes over the role of nurturing the expansion of the outreach of the programme by providing umbrella support to the stakeholders. It might then be claimed that, while the objective of NABARD with the SHG movement is the right one, the general goal of microfinance is not met in areas where people lack access to formal financial services.

One explanation for this particular spread, which is so strongly linked to the rural banking network is the integration of borrowing to SHGs and microfinance institutions (MFIs) into the priority sector. In 2000, the Reserve Bank of India allowed banks to lend to MFIs and treated such lending as part of their priority sector obligations.

From the results it seems, that banks that concentrate on other areas than microfinance in the priority sector also lend less to SHGs: Estimated coefficients on the number of agricultural credit accounts (as a percentage to total accounts) is significantly negative and so is the amount borrowed by the 'other small industry' sector ${ }^{31}$. The negative impact of agricultural accounts can further be explained by the fact that banks are obliged to have a certain ratio of agricultural to total accounts to ensure operation in this sector - keeping in mind that it is the main source of employment in India and 60 per cent of the labour force work in the agricultural sector. Forty per cent of a banks

\footnotetext{
${ }^{31}$ Small Enterprises is defined by the RBI as small (manufacturing) enterprises engaged in manufacture/ production, processing or preservation of goods, and small (service) enterprises engaged in providing or rendering of services, and whose investment in plant and machinery and equipment (original cost excluding land and building and such items as mentioned therein) does not exceed a certain amount. It furthermore includes any person providing inputs to or marketing the output of artisans, village and cottage industries, handlooms and to cooperatives of producers in this sector.

Other Small Business / Service Enterprises include then small business, retail trade, professional \& selfemployed persons, small road \& water transport operators and all other service enterprises.
} 
operation has to take place within the priority sector of which again 18 per cent has to go to the agricultural sector.

In an interview for The Hindu daily newspaper, Mr S.K. Mitra, Executive Director of NABARD, said, "the SHG linkage programme is better suited to the Indian scenario and we have already laid sound foundations for disbursement of funds through the establishment of 196 regional rural banks and 336 district central co-operative banks". (The Hindu, 2005, "NABARD prefers SHG linkage model for microfinance", New Delhi, 25 October)

Youth Unemployment programme (per household):

The negative sign of the estimated coefficient suggests that more involvement by the district in social protection schemes is associated with a lesser number of SHGs - here to be seen through the variable 'youth unemployment (per household)'. ${ }^{32}$ Aiming to provide self-Employment to Educated Unemployed Youth Prime Minister Rozgar Yojana's programme was announced by the Prime Minister on 15th August, 1993. The goal was to provide self-employed opportunities to one million educated unemployed youths in the country. The Scheme was formally launched on 2 nd October, 1993. The variable has a negative coefficient, which means that an increase in Rupees spent (per household) on this program, results in fewer numbers of SHGs linked.

One might have suspected that more "engaged" districts also support the formation of SHGs more, but there seems to be a sort of trade-off. The reason for this is summarized by Pramod (2006): "Keeping in view the efficacy of the SHG concept for organizing and assisting the rural poor, the structure of several government sponsored schemes, both centrally sponsored and state sponsored, has been modified to make the SHGs the sole or important vehicle for extending assistance to the poor."

The Tamil Nadu Human Development Report (2005: 38) states the same idea from the opposite perspective: "Unemployment rates are quite high in Tamil Nadu, especially in terms of daily unemployment. In the past, poverty alleviation schemes have focused more on asset creation - as a result not enough emphasis has been placed on employment generation." This observation underlines the idea that a shift at the policy level to put more emphasis on programmes such as the youth unemployment one, can stir away from other poverty schemes - such as the creation of SHGs.

Results suggest that there are districts that see SHGs as an apparently better option than other social programmes, though the two are not mutually exclusive.

\footnotetext{
${ }^{32}$ This statement is here only supported by the estimate for one variable. Nevertheless, the inclusion of other variables (described in Appendix 2.C) lead to the same conclusion.
} 
Interpretation of RHO (Influence of "Neighbours")

As already laid out above, strong evidence for spatial autocorrelation is found, which is now confirmed again by the significant spatial autocorrelation parameter, rho. Interestingly, it is the distance between district capitals that plays an influential role and not national borders, meaning that accounting for direct neighbourhood through a binary indicator or more refined by indicating the length (in $\mathrm{km}$ ) of shared border is not significant.

As one would have expected, the influence of geographical distance between capitals is estimated to be negative, indicating that proximity has a positive influence on the spread of the SHG movement. In other words, a change in the number of SHGs in one district has a greater influence on neighbouring or close districts than on ones further away.

\subsection{Conclusion}

A visible body of literature documenting the development of the microfinance sector development has grown in recent years. However, there remains a dearth of research addressing the spatial dynamics of the observed expansion (Dasgupta 2001). This chapter is a first step to fill this void by empirically exploring the spread of the major model of microfinance in India.

The study gives a picture of the geographical inequalities that lie behind an enormously growing and successful delivery system of microfinance services. While more and more Indian households are being reached, certain areas only very recently come into contact with this model, while others are still totally neglected.

Reasons behind this are of course many fold. Important ones were analyzed in the second part of this chapter. The estimation of significant determinants of the prevailing spread show several interesting results, some of which of great importance to policy making.

For one, it becomes clear that the programme is predominantly active in areas where a banking network exists. This is not an unexpected finding given that the aim of the program is to link groups to banks. It implies though that while the programme addresses the population that is 'unbanked' mainly due to their economic status, it excludes those that are (additionally) 'unbanked' in a physical sense. To overcome this problem the Indian government needs to either push for an extension of the existing banking network or for a solution that is less dependent on the formal banking network. Perhaps it will be the microfinance institution model that plays a role in solving this problem and particularly technological innovations can be the great hope. Or maybe this is where NGOs come in. While most still need to enhance their skills and 
understanding of finance, it is their focus on values such as inclusion, equity, justice and democracy that qualifies them to fulfil a function in the process.

Of greater concern is the second major finding of this study.

Vijay Mahajan, CEO and Managing Director of the BASIX group of companies, gave an account of this problem very much to the point in his speech for Dr. MS Swaminathan ${ }^{33} 80^{\text {th }}$ birthday:

"A second risk that the poor may suffer as a result of an overemphasis on a microcredit strategy, is the reduction in government budgetary allocations for other efforts at poverty alleviation, such as the well-tried but less dramatic strategies of investment in human capital such as through primary health and primary education programs. While there is no denying that such social sector programmes can be run more cost-efficiently and that they can be better targeted to the poor, the replacement of such programmes with microcredit programmes will be double disaster for the poor. If the implicit subsidies to microcredit institutions are made explicit, then subsidizing microcredit programmes versus subsidizing social sector programmes can become an informed policy choice, rather than be carried out under the mistaken notion that the former will require only temporary and diminishing subsidies. But the implicit subsidies to microcredit, legitimate as they may be, are not being described or analysed."

Results from the model indicate that it is not particularly education programmes that one needs to be concerned about. In fact, the SBLP seems to be more dominant in areas where literacy rates are above average.

But, evidence is brought forward that support his general claim, namely that the focus on SHGs seems to be a sort of a trade-off with other social schemes. While no clear statement can be made as to whether the programme operates in areas where schemes are not in place rather than replacing them, the bottom line remains the same: In these areas, only a certain part of the population is primarily targeted by social interventions. The targeted population is females that are willing and able to become a member of a group, to save regularly, and to eventually take a loan (for "productive" purpose!). This does not include those with too uncertain or variable income. Think of for example migrating households, most often for seasonal wage employment; for example in the district of Mahaboonbnagar (Andhra Pradesh), 78\% of households have

\footnotetext{
${ }^{33}$ Dr. MS Swaminathan is the chairman of M. S. Swami Nathan Research Foundation in Chennai. Given his extensive contributions, he is known as the "Father of the Green Revolution in India" or also described by the United Nations Environment Programme as "The Father of Economic Ecology".
} 
(seasonal) migrants (Deshingkar, 2004). These are not able to fulfil the minimal requirements of being a member of a SHG such as attending the regular meetings or contributing the regular savings. Also experiencing high barriers to joining a SHG are those that are not able to make these contributions because their economic status is too low - the very poor. This can then lead to exclusion - 'self-exclusion' but also exclusion by group members or SBLP staff.

But besides excluding some that would actually be part of the target group, of greater concern is that a big part of the population gets neglected that would not even be eligible to participate - these include for example the elderly, the youth or the handicapped: exactly those groups that are typically highly dependent on support from social protection schemes.

The finding that the movement comes with a replacement (or at least modification) of government programmes should be of great concern and calls for immediate policy reaction.

The conclusion of this chapter is very much directed at macro-level, policy recommendations. The next chapter concentrates on problems that are observed at the micro-level and analyses how policies are being implemented in the field. A greater focus is placed on the second major model of microfinance, microfinance institutions, but also policies of the SHG Bank Linkage Programme are being addressed. It will become clear, that also at the micro-level, major shortcomings need to be addressed if the ultimate goal of helping the poor is to be achieved. 


\section{Appendix 2.A}

Figure 2.A1: State's names of India

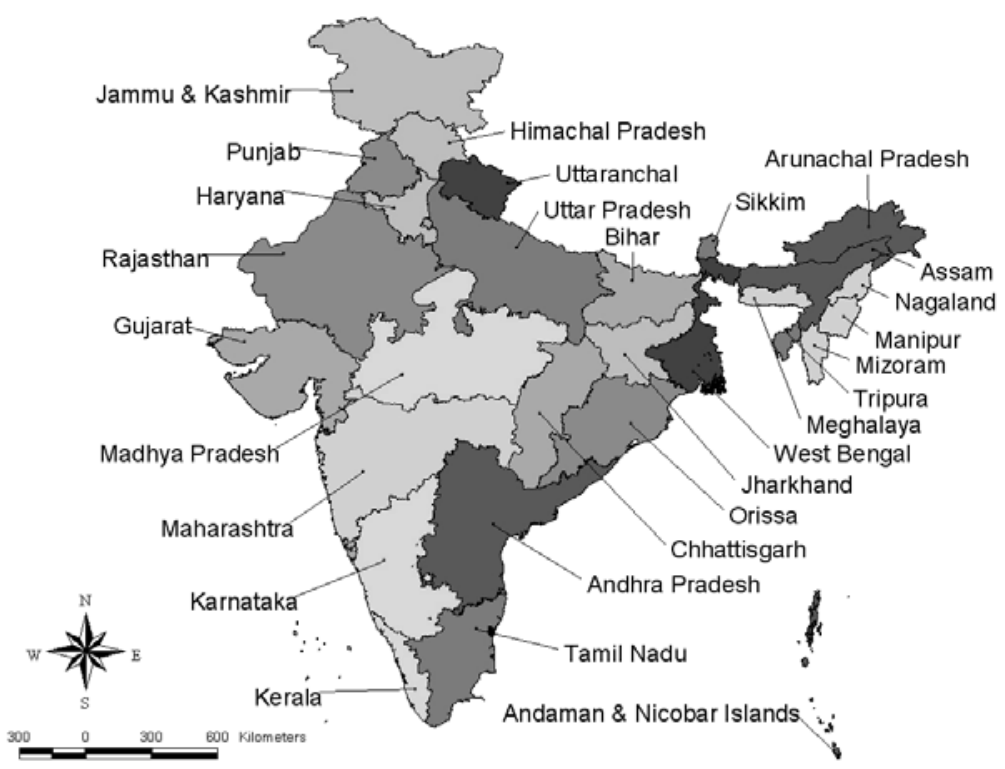

Table 2.A2: District's names of Tamil Nadu

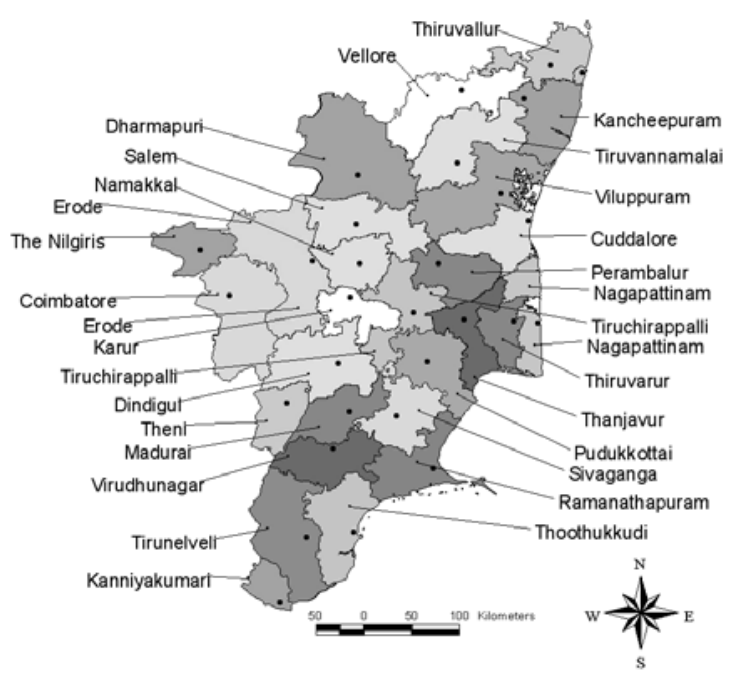


Appendix 2.B - Descriptive Statistics of the SBLP development in Tamil Nadu

Pace of microfinanciarization - the period 2000/01-2005/06

As is the case in India as a whole, where the high growth of the SHG Bank Linkage Programme is not undergone by all states, also not all districts experience the same pace in this growth as shown in Figure 2.B1.

For example between 2000/01 and 2005/06, the district Thiruvallur in the far North of Tamil Nadu multiplied its number of SHGs by more than 50: from 139 groups in the financial year 2000 to 7,033 in 2005 . It was the fastest growing microfinance district during this period from 2000 to 2006 in Tamil Nadu with an average annual growth rate of 119.2 per cent. This number highlights the efforts made by this district's authorities to develop the microfinance sector with the support of the SHG methodology. At the opposite end is the Nilgris district in the far west which experienced a weak average annual growth rate of 2.9 per cent (from 90 to 104 groups but with a peak in 2003/04 at 643); or the case of Nagapattinam on the east coast with a growth of 4.1 per cent (from 1182 to 1447 and no peak). Relatively high growth rates were experienced in the darkly shaded districts in Figure 2.B1 (Erode, Pudukkottai, Theni, Thanjavur and Coimbatore) with their average annual growth rate ranging from 46.6 to 72.1 per cent. The disparities in number of SHGs across districts in Tamil Nadu are apparent.

Figure 2.B1. Districts variations in the pace of change of Tamil Nadu's Self-Help Groups - 2000/01-2005/066 (measured by natural breaks) (average annual growth rate) (\%)

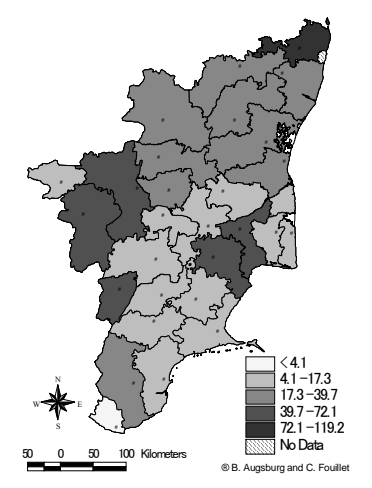

Relative Strength of the SHG among Tamil Nadu's district

Figure 2.B2 shows the evolution of relative share of Tamil Nadu's Self-Help Groups from $2000 / 01$ to $2005 / 06$ and highlights the vast variation between districts as to where SHG are linked (numbers given in brackets). 
Areas that show a very fast pace of microfinance coverage are regions in the far north and south. In 2000/01 districts such as Thiruvallur and Tirunelveli were among those with the smallest proportion of households involved in a linked SHG (about 16 SHGs per 1,000 households). Within five years, these districts had increased the number of linked SHGs tenfold.

Districts that did not follow this strong pace of growth are again predominantly districts in the west. It can be seen that in districts such as The Nilgris and Coimbatore the development over the years is very slow if at all existent. Theni and Coimbatore, for example, had only five and one households respectively participating in a SHG for every 10,000 households. These numbers hardly changed in the years thereafter. It is to be noted that these are all hill districts, which, due to a general lack of awareness of social schemes, might explain the comparatively low coverage in these districts. More details on determinants will be given in the following section.

\section{Figure 2.B2 District variations in relative share of Tamil Nadu's Self-Help Groups (measured by standard deviation)}
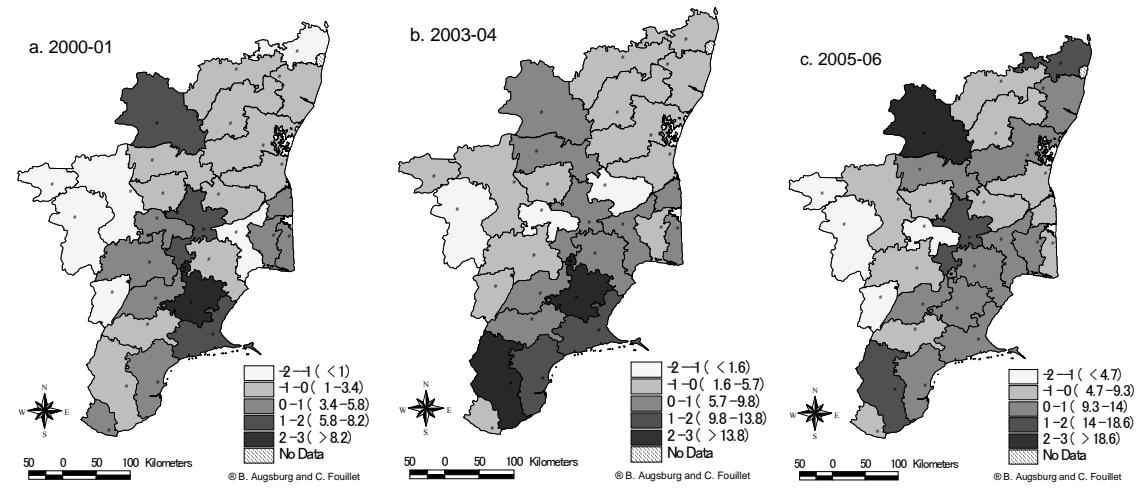

Districts that remained very active in linking households to SHGs over five years were among other Dharmapuri, Ramanathapuram and Sivaganga. In 2000 (Fig. 2.B2a), Sivaganga was ranked first, with more than two units of standard deviation above the mean. Dharmapuri and Ramanathapuram also had a relatively strong SHG sector, with more than one standard deviation above the mean. Five years later, in 2005 (Fig. 2.B2c), Sivaganga had lost its leading position being replaced by Dharmapuri, where 213 out of 1000 households participated in a SHG. Ramanathapuram and Sivaganga formed an intermediate group with ratios within one standard deviation above the mean with more than ninety-eight households participating in SHG for every 1,000 households. 
Appendix 2.C - Table 2.B1: Descriptive Statistics of Regional Characteristics

\begin{tabular}{|c|c|c|c|c|c|c|}
\hline & & obs & mean & sd & $\min$ & $\max$ \\
\hline \multirow{9}{*}{ 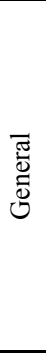 } & Area $(\mathrm{km} 2)$ & 28 & 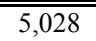 & 3,254 & 1,685 & $17 \overline{17,831}$ \\
\hline & density & 28 & 473 & 182 & 275 & 992 \\
\hline & Rainfall: Deviation from Normal (\%) & 28 & -0.14 & 0.21 & -0.60 & 0.20 \\
\hline & Area under cereal cultivation ( $\%$ of total) & 28 & 0.096 & 0.089 & 0.00 & 0.37 \\
\hline & Milkproduction (in 1,000 tons) & 28 & 170 & 75 & 60 & 320 \\
\hline & Population (in 1,000 ) & 28 & 2,063 & 1,120 & 493 & 5,437 \\
\hline & Population: Rural (\%) & 28 & 0.62 & 0.162 & 0.34 & 0.88 \\
\hline & Population: Scheduled Caste (\%) & 28 & 0.204 & 0.062 & 0.40 & 0.324 \\
\hline & Population: Scheduled Tribe (\%) & 28 & 0.01 & 0.012 & 0.005 & 0.037 \\
\hline \multirow{9}{*}{ 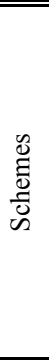 } & No. of textbooks per household (hh) & 28 & 0.413 & 0.141 & 0.262 & 1.037 \\
\hline & No. of uniforms per household & 28 & 0.355 & 0.136 & 0.185 & 0.934 \\
\hline & No. of unemployed youth per hh & 28 & 0.132 & 0.064 & 0.013 & 0.359 \\
\hline & No. of rural welfare centres per $10,000 \mathrm{hh}$ & 28 & 0.296 & 0.111 & 0.184 & 0.790 \\
\hline & No. of urban welfare centres per $10,000 \mathrm{hh}$ & 28 & 1.427 & 0.672 & 0.422 & 3.636 \\
\hline & Population: Receiving free houses (\%) & 28 & 0.776 & 0.538 & 0.168 & 2.89 \\
\hline & Population: Receiving old age benefit (\%) & 28 & 0.767 & 0.467 & 0.116 & 2.592 \\
\hline & Pop. (female): Receiving old age benefit (\%) & 28 & 0.968 & 0.657 & 0.140 & 3.373 \\
\hline & Pop. (male): Receiving old age benefit (\%) & 28 & 0.567 & 0.330 & 0.093 & 1.793 \\
\hline \multirow{7}{*}{ 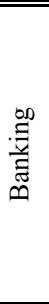 } & No of rural banks per $1,000 \mathrm{hh}$ & 28 & 0.135 & 0.065 & 0.051 & 0.419 \\
\hline & No of urban banks per $1,000 \mathrm{hh}$ & 28 & 0.055 & 0.060 & 0.000 & 0.197 \\
\hline & No of semi-urban banks per $1,000 \mathrm{hh}$ & 28 & 0.103 & 0.0516 & 0.028 & 0.215 \\
\hline & $\begin{array}{l}\text { Operation of Commercial Banks (Rs in } \\
\text { crores): Agricultural advance as } \% \text { total }\end{array}$ & 28 & 33.48 & 18.35 & 7.430 & 85.93 \\
\hline & Credit accounts of agric. activity (\% total) & 28 & 0.564 & 0.135 & 0.272 & 0.776 \\
\hline & Credit acc. artisans, village, tiny industry (\%) & 28 & 0.006 & 0.005 & 0.002 & 0.027 \\
\hline & Credit acc. other small industries (\% total) & 28 & 0.010 & 0.007 & 0.001 & 0.031 \\
\hline \multirow{19}{*}{ 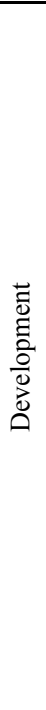 } & Income Index 2001 & 28 & 0.490 & 0.046 & 0.417 & 0.631 \\
\hline & Income per hh & 28 & 0.865 & 0.243 & 0.546 & 1.813 \\
\hline & Income per capita & 28 & 0.249 & 0.362 & 0.058 & 2.048 \\
\hline & Adjusted Average Income (male) & 28 & 0.552 & 0.045 & 0.477 & 0.691 \\
\hline & Adjusted Average Income (female) & 28 & 0.390 & 0.047 & 0.318 & 0.533 \\
\hline & Human Development Index (HDI) 2001 & 28 & 0.648 & 0.034 & 0.584 & 0.712 \\
\hline & Gender Development Index (GDI) 2001 & 28 & 0.645 & 0.035 & 0.582 & 0.710 \\
\hline & Education Index 2001 & 28 & 0.763 & 0.054 & 0.628 & 0.885 \\
\hline & Population: Literacy (\%) & 28 & 0.728 & 0.059 & 0.634 & 0.876 \\
\hline & Gross Enrolment Rate (1999) & 28 & 0.823 & 0.054 & 0.698 & 0.932 \\
\hline & Roads Unsurfaced (km/area) & 28 & 0,603 & 0,461 & 0,066 & 1,777 \\
\hline & Roads Surfaced (km/area) & 28 & 1.465 & 0.673 & 0.261 & 3.492 \\
\hline & Commercial Vehicle per 100 capita & 28 & 0.871 & 1.420 & 0.136 & 7.854 \\
\hline & $\begin{array}{l}\text { Sqkm of rural habitations fully covered w. } \\
\text { water supply (min } 401 / \text { consumption/day) }\end{array}$ & 28 & 16.518 & 6.959 & 5.32 & 32.06 \\
\hline & $\begin{array}{l}\text { Sqkm of rural habitations partially covered } \\
\text { with water supply (10-39 lpcd) }\end{array}$ & 28 & 11.541 & 8.154 & 0.59 & 30.54 \\
\hline & Same as above but: $0-9$ lpcd & 28 & 1,151 & 3,16 & 0,000 & 16,71 \\
\hline & $\begin{array}{l}\text { Policestations per } 1,000 \mathrm{hh} \text { (incl. outposts \& } \\
\text { all-female) }\end{array}$ & 28 & 0,106 & 0,040 & 0,051 & 0,213 \\
\hline & Hospital Beds per hh & 28 & 0,002 & 0,001 & 0,001 & 0,004 \\
\hline & Doctors per hh & 28 & 0,000 & 0,000 & 0,000 & 0,000 \\
\hline
\end{tabular}




\section{Appendix 2.D}

Table 2.c1Results from testing for local spatial autocorrelation

\begin{tabular}{|c|c|c|c|c|c|}
\hline Location & Ii & E(Ii) & sd(Ii) & z-stat & p-value \\
\hline 26*** (Tirunelveli) & -0.467 & -0.037 & 0.101 & -4.243 & 0.000 \\
\hline 23*** (Ramananthapuram) & -0.271 & -0.037 & 0.097 & -2.415 & 0.008 \\
\hline $25^{* * *}$ (Sivagangai) & -0.291 & -0.037 & 0.108 & -2.363 & 0.009 \\
\hline 27** (Thoothukundi) & -0.230 & -0.037 & 0.103 & -1.868 & 0.031 \\
\hline $2 * *$ (Tiruvallur) & -0.198 & -0.037 & 0.095 & -1.689 & 0.046 \\
\hline $5 *$ & -0.171 & -0.037 & 0.102 & -1.312 & 0.095 \\
\hline 10 & -0.161 & -0.037 & 0.107 & -1.153 & 0.124 \\
\hline 3 & -0.110 & -0.037 & 0.105 & -0.692 & 0.245 \\
\hline 11 & -0.098 & -0.037 & 0.092 & -0.665 & 0.253 \\
\hline 6 & -0.092 & -0.037 & 0.108 & -0.511 & 0.305 \\
\hline 28 & -0.080 & -0.037 & 0.092 & -0.467 & 0.320 \\
\hline 14 & -0.086 & -0.037 & 0.107 & -0.452 & 0.326 \\
\hline 8 & -0.080 & -0.037 & 0.113 & -0.381 & 0.351 \\
\hline 7 & -0.058 & -0.037 & 0.108 & -0.194 & 0.423 \\
\hline 4 & -0.038 & -0.037 & 0.109 & -0.005 & 0.498 \\
\hline 1 & -0.025 & -0.037 & 0.100 & 0.119 & 0.453 \\
\hline 18 & -0.013 & -0.037 & 0.093 & 0.262 & 0.397 \\
\hline 15 & -0.009 & -0.037 & 0.103 & 0.269 & 0.394 \\
\hline 17 & -0.008 & -0.037 & 0.103 & 0.285 & 0.388 \\
\hline 19 & -0.005 & -0.037 & 0.099 & 0.322 & 0.374 \\
\hline 16 & -0.002 & -0.037 & 0.108 & 0.323 & 0.373 \\
\hline 20 & 0.004 & -0.037 & 0.112 & 0.371 & 0.355 \\
\hline 22 & 0.010 & -0.037 & 0.107 & 0.439 & 0.330 \\
\hline 24 & 0.016 & -0.037 & 0.106 & 0.501 & 0.308 \\
\hline 13 & 0.033 & -0.037 & 0.105 & 0.664 & 0.253 \\
\hline 12 & 0.021 & -0.037 & 0.087 & 0.673 & 0.251 \\
\hline 21 & 0.064 & -0.037 & 0.100 & 1.018 & 0.154 \\
\hline 9*** (Dharmapuri) & 0.303 & -0.037 & 0.097 & 3.519 & 0.000 \\
\hline
\end{tabular}

Notes: Stars indicate significant spatial autocorrelation $(* * *=$ significant at $1 \%$, $* *=$ significant at $5 \%, *=$ significant at $10 \%$ ) 
Appendix 2.E - Procedure followed for model selection

Selecting the variables for the final model relied heavily on theoretical grounds since a lot of information was available but with 28 observations not many degrees of freedom were available to work with. Furthermore, after selecting variables hypothesized to influence the distribution of SHGs (summary statistics can be found in Appendix 2.B), these could be classified according to the areas of interest. The data used stem from official statistics of Tamil Nadu as well as the Tamil Nadu Human Development report from 2003, which provides district wise data on indexes such as human development, gender development and income.

OLS regression results of this model can be seen in Table 2.D1:

Table 2.D1: OLS results - Final Model Specification

\begin{tabular}{lcccc}
\hline & coeff. & se & t-stat & $\mathrm{p}>|\mathrm{t}|$ \\
\hline \hline Income index & -12.08 & 6.35 & -1.93 & 0.069 \\
Literacy & -0.035 & 0.06 & -0.63 & 0.538 \\
Human Development Index & 22.25 & 14.61 & 1.52 & 0.144 \\
No of rural bank branches (per hh) & 11.44 & 4.03 & 2.84 & 0.011 \\
\% of amount disbursed to agricultural sector & -1.81 & 2.57 & -0.70 & 0.491 \\
\% of amount borrowed to o. small industries & -7.38 & 4.59 & -1.61 & 0.124 \\
\hline Youth Unemployment programme (per hh) & -7.26 & 3.34 & -2.17 & 0.043 \\
\hline Area & 0.0002 & 0.0001 & 3.44 & 0.003 \\
\hline Constant & -5.104 & 6.38 & -0.80 & 0.434 \\
\hline F(8,19) & 3.20 & & & \\
Adjusted R2 & 0.395 & & & \\
\hline Notes: Ordinary Least Square Regression
\end{tabular}

Tests of robustness as well as a jackknife procedure applied to test for outliers. The model is subsequently tested for spatial dependence. The results of all three weight matrices described above are displayed in Table 2.D2.

Table 2.D2: Diagnostic Test for spatial dependence in OLS regression

\begin{tabular}{|c|c|c|c|c|c|c|}
\hline & \multicolumn{2}{|c|}{ Neighbour } & \multicolumn{2}{|c|}{ Border } & \multicolumn{2}{|c|}{ Distance } \\
\hline & Statistic & $\mathrm{p}$ & Statistic & $\mathrm{p}$ & Statistic & $\mathrm{p}$ \\
\hline \multicolumn{7}{|l|}{ Spatial error: } \\
\hline Moran's I & 2.907 & 0.004 & 3.125 & 0.002 & - & - \\
\hline Lagrange multiplier & 4.968 & 0.026 & 6.194 & 0.013 & 5.956 & 0.015 \\
\hline Robust Lagrange multiplier & 0.293 & 0.589 & 0.039 & 0.844 & 0.004 & 0.950 \\
\hline \multicolumn{7}{|l|}{ Spatial lag: } \\
\hline Lagrange multiplier & 5.224 & 0.022 & 8.919 & 0.003 & 6.033 & 0.014 \\
\hline Robust Lagrange multiplier & 0.549 & 0.459 & 2.763 & 0.096 & 0.081 & 0.776 \\
\hline \multicolumn{7}{|c|}{$\begin{array}{l}\text { Notes: "Neighbour" is the binary matrix, indicating border sharing between districts, "Border" } \\
\text { indicates the length of the shared border as a ratio of total border, and "Distance" indicates the } \\
\text { driving distance ( } \mathrm{km} \text { ) between district capitals. }\end{array}$} \\
\hline
\end{tabular}




\section{Profit Empowerment: The Microfinance Institutions' Mission Drift}

\subsection{Introduction ${ }^{34}$}

While the legitimacy of microfinance as a tool of financial inclusion is beyond doubt, the optimism that surrounds it seems to have blinded the international sphere. Concentrating on the often praised financial indicators, microfinance institutions are being pushed to make goals such as financial self-sustainability their primary objective - more often than not at the expense of their social mission. International organizations play a crucial role in this mission drift. The intention and arguments behind their acting may be justified but institutions seem to overlook crucial consequences on the micro-level. These are consequences that should be a major concern if the ultimate aim is to help the poor.

At the outset, the key players of microfinance were non-profit, socially motivated lenders seeking to reach as many disadvantaged clients with credit as they were able to, given their limited budgets. Often coming from the big social movement of the 1970s, the focus of these organizations ${ }^{35}$ was explicitly on reducing inequality and inducing social change. It was such grassroot NGOs into which donors initially channelled their aid. Nevertheless, in the process, organizations demonstrated that through the use of new lending technologies such as joint liability contracts and dynamic incentives, a portion of this new market could in fact be lent to profitability. Such realizations drew profit-motivated lending institutions into the market and a focus on efficiency and effectiveness, monitoring and accounting systems, resulted in a "culture of professionalization and depolitization of NGOs" (Kamat 2004:167) ${ }^{36}$. This progression led donors to question the need for continued subsidies, resulting in the recent focus on 'institutional sustainability' in the microfinance sector ${ }^{37}$. Microfinance has become business.

\footnotetext{
${ }^{34}$ This chapter is based on work with Cyril Fouillet, University Lumière Lyon 2, France.

${ }^{35} \mathrm{See}$, for example in India, Assefa in Tamil Nadu coming from the Bhoodan Movement advised by the Ghandian principle of sarvodaya (development for all) (see Zadek 1993), or the concept of 'people economy' of the Sewa cooperative in Gujarat, etc.

${ }^{36}$ On this topic see also Ferguson (1994), Harriss (2001) and Mosse (2005).

${ }^{37}$ In microfinance jargon, sustainability is usually equated with financial self-sufficiency. An intermediate step in becoming financially sustainable and consequently able to cover the cost of funds, including
} 
Incorporated in a historical perspective, microfinance has to be seen as a result of neoliberal ideologies. Development strategies in the late 1980s and early 1990s promoted principles that set finance and money as neutral policies and advertised their spread in the process of global financial deepening (Schümperli et al. 2007:13). By doing this, international organizations follow de facto the "process of justification" (Boltanski and Thévenot 2006) of a poverty eradication tool, whose limits are not much questioned.

The ongoing focus can be understood within the context of what Bourdieu (2000) coined "Making the Economic Habitus". As will be explained in this chapter, microfinance fully takes part in this process in which a "rationalized economic cosmos" (Bourdieu 2000:17) is imposed. One observes the introduction and application of a real doctrine of financial discipline. For example the Consultative Group to Assist the Poor answers the question "What is needed for successful microcredit?" (CGAP 2002:4) ${ }^{38}$ with: "Successful microcredit rests on two basic principles: client discipline and institutional discipline". In his study of the Grameen Bank Brigg Morgan (2006:79-80) shows how this client discipline is sometimes turned into a veritable ritual. When the loan officer arrives every week, the group members stand up, welcome him (often even salute him) and recite the MFI slogan: "Discipline, Unity, Courage, and Hard Work", before handing him their loan repayments.

In this chapter, concern about imposed institutional discipline is raised.

The debate concentrates on the Indian microfinance sector. India has been and continues to be one of the leading countries pushing the development of the microfinance sector forward. It has extensive experience in delivering financial and non-financial services to the poor - on the positive as well as on the negative side. The chapter has a further focus on the State of Andhra Pradesh. This choice is partly

inflation, is reaching operational sustainability. It is referred to when a microfinance institution covers the administrative costs and expenses involved in the non-payment of loans. Sustainability is also the only way to attract capital equity and debt, which is needed to achieve the massive outreach that is required, and to reduce dependence on donors.

${ }^{38}$ To support the building of an inclusive financial system that serve the poor via microfinance, the World Bank Group and a group of 33 public and private founding organizations - bilateral and multilateral development agencies, private foundations, and international financial institutions - created the CGAP. CGAP serves today, among others, as one of the main producer of studies, guidelines and technical notes on microfinance topics and can be seen as a key driver in the development of the sector. 
determined by the authors' field experience in this area ${ }^{39}$, but also by the fact that this area has an extremely high concentration of poor population ${ }^{40}$.

The next section will lay out the extent to which one can talk about the microfinance sector being dependent on donors, whether being local or foreign. This is followed by an illustration of practices that microfinance institutions apply in order to reach the objectives often pushed for by the international community. These objectives include low interest rates which are nevertheless cost-covering, as well as high repayment rates which ensure that the organization's portfolio remains secure. In the third section the microfinance crisis that broke out in India in March 2006 will be described. It will be shown how private microfinance players are guided by commercial principles while public microfinance is being dominated by a populist point of view. The final section concludes.

\subsection{Dependency on donors}

Sinha and Sinha (2002:279) found in their performance analysis of Indian microfinance that "Dependence on subsidies is high". They found that about 47 per cent of the sampled organizations' net worth is made up of donated equity. A more recent estimate by M-CRIL (2007) shows a sharp decline in this percentage over recent years. The latter estimate that in 200330 per cent of microfinance funds were grants, in 2005 eight per cent and in 2007 only 3.4 per cent. Nevertheless, there was still a huge increase in institutional debt (34.4 per cent in 2003, 62.2 per cent in 2005 and 75.4 per cent in 2007). In these numbers, no distinction was made between 'normal' and 'soft' loans ${ }^{41}$, the latter ones - while decreasing - still playing a major role in microfinance financing ${ }^{42}$. Also, the report shows that the general trend in the area remains, with South Asia receiving on average $22.5 \%$ of their funds as grants and

\footnotetext{
${ }^{39}$ The chapter uses both secondary as well as primary data sources. Regarding secondary data sources, a thorough press literature review was conducted (Newspapers, local television, etc. in English and in Telugu), and secondary data was used to give also quantitative support to qualitative case studies (in particularly a study conducted by APMAS in reaction to the crisis in Andhra Pradesh - APMAS 2006). Primary data were collected through (semi directed) interviews mainly done in Andhra Pradesh with leading MFIs and government officials. These interviews are conducted on all kinds of levels ranging from high management to field staff and clients. In both of our cases, detailed field notes are often complemented by other data collected through informal conversations done during several MFI monographs.

${ }^{40}$ According to a UNICEF study, India has a much higher percentage of stunted children and underweight babies than for example Pakistan or Bangladesh (UNICEF 2006).

${ }^{41} \mathrm{~A}$ soft loan is a loan that is given with below-market interest rates - typically by governments or bilateral organizations for the financing of development projects. In addition to offering low interest rates, soft loans often have extended grace periods during which no repayments are made or only service charges are due. Morduch (1999b) calculates for example that the Grameen Bank in Bangladesh received about $40 \%$ discount on interest on their soft loan from the Bangladesh Bank.

${ }^{42}$ Fisher and Sriram (2002) for example observed that $28 \%$ of microfinance funds in India are soft loans provided by development banks and microfinance wholesalers.
} 
South East Asia 29.7\% (note that again, soft loans are not included in these numbers). Sinha and Sinha's comment remains valid. Titus (2002) makes this point:

"Most of the promotional resources for developing microfinance services still come from donors, often based abroad. Many domestic sources are restricted to funding statepromoted organizations. [...] In terms of resources for promotion, NGOs and other agencies promoting Self-Help Groups $(\mathrm{SHGs})^{43}$ have at best received Rs. 25 crore (Rs. 250 million or US\$ 5 million) from domestic resources over the past decade. Compare this to the over US\$ 150 million of the grants and soft loans that the Grameen Bank alone has received $[\ldots]^{\prime \prime}(\mathrm{p} .309)$

Not only are domestic resources available for limited non-state promoted organizations but the regulatory environment makes it difficult for organizations to start operations without donated equity. In the current Indian context, microfinance institutions have to register as non-banking financial companies (NBFCs), being obliged to be in possession of start-up capital of about Rs. 20 million. Once they have NBFC status, the institution is only allowed to take deposits after having been rated by two different rating agencies. This takes considerable time and effort ${ }^{44}$.

Based on such observations and the fact that the provision of microfinance services is expensive it comes as no surprise that foreign donations play a major role in the financial situations of microfinance organizations and that "micro-finance has been largely a donor-driven phenomenon everywhere.” (Harper 2002:177).

While the interest of bilateral and multilateral donor agencies helps NGOs to attract more funding and increase their activities, it also poses a dilemma for the organizations. For by extending their dependence on official funds they risk losing their autonomy and "their identity as a 'nongovernmental' institution" (Vahlhans 1994:22; Petras 1997). Brown et al. (2002) examined the political consequences of internationally funded programmes targeting local NGOs and found that:

"Injections of international resources into underdeveloped, often clientelistic societies can fundamentally change the nature of the local political arena, affecting access to economic

\footnotetext{
${ }^{43}$ SHGs, the real cornerstones of the Indian microfinancial system, are savings and leading groups of less than 20 persons. Often mono-caste, these groups are working informatively in the form of rotating savings and credit associations (tontine) but with a banking link. SHGs cannot claim credits only after a savings period about six months during which these groups must show proof of, among others, their capacity to save regularly.

${ }^{44}$ Moreover, the reliability of ratings as a mean to attract funds is questionable: In a recent study Hartarska and Nadolnyak (Forthcoming) indicate that "not all ratings agencies had equal impact on MFI abilities to raise extra funds since rating by some raters helped raise debt or equity, while rating by others did not".
} 
resources, social benefits, and ultimately the quality of democratic representation. ${ }^{, 45}$ (P.814).

A consequence of this growing dependence on funding is that NGOs increasingly prioritize economic programmes (mainly microfinance) over activities such as social programmes (Devine 2003; Mosse 2005) ${ }^{46}$. But, while this shift away from traditional NGO activities towards a focus on microfinance activities might be a stepping stone towards financial sustainability, it has multiple consequences. For one, this change in institutional focus tends to absorb the vast proportion of NGO staff time, efforts and energies, including the need to recruit more qualified, technically competent and professional staff, as observed by Stiles (2002) and Guerin, Fouillet and Palier (2007). In addition, simply changing its status from an NGO to a microfinance institution does not automatically make funds secure since microfinance institutions clearly feel the push by donors towards sustainability and take appropriate actions.

MFIs are usually given two to three years to achieve financial self-sustainability (Goodwin-Groen 2007). Such pressure does not come exclusively from the microfinance institutions themselves but is often exerted from their donor organizations. Increasingly, funders emphasize financial viability (Mayoux 2000). This view is stressed in a review to United Nations Capital Development Fund ${ }^{47}$ (UNCDF 1999:19) which states that “a donor's principal role should be to identify and develop strong partnerships with potential MFI "winners", MFI's that have the potential to reach financial self-sufficiency, maintain outreach to the poor, and a credible plan for doing so".

Unfortunately, not everyone sees these three aspects as equally important: the CGAP has promoted institutional sustainability before poverty reduction. Cases, where programmes with excellent development potential and social impact were discontinued by donors in favour of sustainability, are no longer just anecdotal. Microfinance programmes are currently caught in a 'financial self-sustainability paradigm' (Mayoux 2001b). This is illustrated in the Nampula Artisanal Fisheries Project (NAFP), a project introduced by CARE in 1993 with funding from the International Fund for Agricultural Development (IFAD) to service the needs of poor fishing communities. The project had been described as "socially desirable and environmentally sound, technically feasible and economically viable. The proposed project is a high priority in the poverty reduction strategy of the GOM [Government of Mozambique] and is consistent with the Bank Group vision as well as the Bank Group strategy for Mozambique." (De Vletter 2001:8) Nevertheless, despite this excellent developmental

\footnotetext{
${ }^{45}$ On this subject, see also Kamat (2002).

${ }^{46} \mathrm{It}$ is not rare anymore to observe NGOs changing their statutes from 'NGO' to 'financial institution' (Glosser 1994; Hulme and Mosley 1996).

${ }^{47}$ The UNCDF offers a combination of investment capital, capacity building and technical advisory services to promote microfinance and local development.
} 
potential and sought-after social impact, the programme was discontinued by CARE for sustainability reasons.

Further evidence of institutions being pushed to provide financially sustainable microfinancial services too fast is given in a report to the FinMarkTrust (GoodwinGroen 2007). The report investigates the microfinance situation in South Africa, finding that:

"The problem lies with donors and the state, who are trapped in an orthodoxy that prioritizes adherence to 'market principles', even when the target beneficiaries of many microfinancial services initiatives are not 'in the market' of the mainstream economy." (P.22). "Donors expect quick results", they go on and state "DTI expects MFIs to be commercially oriented, and see no value in a long-term strategy of institutional development" ${ }^{48}$.

In numerous other cases promising projects are dropped from the portfolios of sustainability driven institutions for the simple reason that they are a financial drain on the implementing institutions.

It becomes apparent that microfinance providers are exhorted to aggressively pursue sustainability. It is worth repeating again the idea of UNCDF that one of the donors' functions is to identify MFI 'winners', that is, "MFIs that have the potential to achieve financial self-sufficiency, maintain outreach to the poor, and a credible plan for doing so".

The next section will follow the line of many donor agencies and concentrate on the issue of attaining financial self-sufficiency. The focus lies on practices of microfinance institutions that allow sustaining their future operations.

The section will address three questions that concern microfinance on a day-to-day basis. It will be argued that these issues result in practices and techniques that harm a sector whose legitimacy is without doubt, a sector with extreme potential to help the poor break the cycle in which they often are. The questions are:

(1) How- in a market of extremely high transaction costs - can interest rates be fixed that are cost-covering but are not so high that institutions can be compared with moneylenders who are often portrayed as "coldly preying upon their cultivator clients, luring them further and further into debt, and finally sucking them dry of surplus, savings, property, and liberty" (Rudner 1994:36)

\footnotetext{
${ }^{48}$ Héloïse Weber (2002:10) argues that microfinance services facilitate financial sector liberalization: "The 'dual function' of microcredit minimalism served well to sustain as well as facilitate the liberalization agenda from the "bottom-up"”.
} 
(2) How - in a market of assetless and "highly risky" clients - can the portfolio be secured without having to invest in and experiment with new technologies that drive up costs and hence interest rates?

(3) How - in a market with a very vulnerable clientele - can repayment be secured and is it possible to report repayment rates in line with the expectations of the international community?

\subsection{Mission drift: practitioners between injunctions and the neo- liberal myth}

Concepts such as group lending, joint liability, dynamic incentives and peer pressure applied in microfinance are typically quoted as the 'secret' recipe for achieving high repayment rates that make financial institutions in developed countries envious.

Group lending is a mechanism that allows borrowers without collateral, to act as guarantors for each other. It was this innovative joint liability condition that allowed the Grameen Bank to grow explosively. Practitioners, policy-makers and academics alike have been intrigued by Grameen's contracts, and Economic theorists, such as Joseph Stiglitz (1990), devoted a considerable body of literature to the mechanisms of joint liability 49 .

Dynamic incentives are another often-stated method of assuring repayment. For one, only those clients who successfully repaid their loan are eligible to re-apply. And, after showing reliability, loan sizes are gradually increased. Such incentives are observed to ensure on-time repayment by the customer.

Other 'microfinance tricks' such as small and high frequency installments and doorstep collection help to make microfinance a successful way of reaching and serving the poor.

Nevertheless, there are many other (dubious) methods and resulting (bad) practices that deserve attention - methods that are increasingly applied in the sector and especially in the field but that are hardly ever - if at all - discussed. These are methods that also aim at keeping interest rates low, at achieving high repayment rates, and at securing the portfolio of the organization. But contrary to methods such as jointliability and a carefully designed loan product, these cannot be claimed to be in the interest of the customer. 'Not being in the customer's interest' would be a very mild form of describing the methods - 'harming the customer' would be much more appropriate. More details are given in the following three sub-sections.

${ }^{49}$ The literature is surveyed in Ghatak and Guinnane (1999), Morduch (1999), Armendariz and Morduch (2005). 


\subsubsection{How to have cost-covering and still low interest rates}

Many people are highly concerned by the interest rates that MFIs charge. Due to high transaction costs, rates of 24-36 per cent and higher are no exception, but all too often and all too easily, such rates are dismissed as way too high to effectively serve the poor. These rates are indeed high, if compared to those for loans in developed countries. However, it is generally acknowledged that comparisons with rates charged by commercial banks are inappropriate, as larger loans mean lower transaction costs and result in lower interest rates.

"The monitoring and collection costs are higher than those for other types of credit, more information about customers is required and the large number of small customers requires more infrastructures and more staff to serve them. To this is added the high staff turnover in the microfinance industry, and scant methodology that exists to measure risk in the sector. [...] all adding up to the industry having high administrative costs" $" 50,51$.

Nevertheless, while holding the view that cost-covering rates are a necessity in order for microfinance institutions to eventually no longer be dependent on donor funds and subsidies and making the sector less dependent on outside funding and intervention, the purpose is not to discuss whether high interest rates serve or hamper the livelihood promotion of the poor.

The intention is to bring attention to the way interest rates are stated by microfinance institutions. Certain ways of reporting are being adopted that allow the institutions to state interest rate levels much below the real rate being paid by the customer. While this might be beneficial and of help when it comes to attracting donor funding, it for sure makes it difficult for the clients to understand the real costs and conditions of the loan contract they commit themselves to.

It is for example common practice in microfinance to quote a 'flat interest rate' rather than the Annual Percentage Rate (APR), or effective interest rate, as is the banking standard in the developed world. Flat interest refers to charging interest on the full original loan amount, rather than on the declining balance. For example, with group based loans, an interest rate is about $3 \%$ per month, flat, for four months. This means that a US\$ 100 principal amount lent is multiplied by $3 \%$, and then by four months to come up with US\$ 12 in interest. Thus, US\$ 112 would be repaid over four months instalments. Based on how frequently the principal is collected (weekly, monthly or at

\footnotetext{
${ }^{50}$ Statement by Efraín Camacho, general administrator of the Bolivian Superintendency of Banks and Financial Entities, cited in "Back From The Shadows", by Samuel Silva.

${ }^{51}$ According to Murdoch (1999b), Grameen Bank in Bangladesh would have to increase their interest rate by $65 \%$ in order to reach full economic sustainability - translating into an annual rate of 33\% per year in 1999 .
} 
the end of the term), and assuming no additional fees, the above loan has an APR of between $39 \%$ and $71 \%^{52}$.

The use of flat interest rates is usually legitimized by it being perceived to be easier to calculate than a declining balance interest and to facilitate "understanding by poorly educated and illiterate clients" ${ }^{\prime 3}$ (CGAP). While this sounds honourable, the reality often looks different. The bottom line is that customers are repeatedly deceived by the use of flat interest rates, which, depending on the terms of the loan, can result in an actual interest rate which is twice as high. A study undertaken by Andhra Pradesh Mahila Abhivruddhi Society ${ }^{54}$ (APMAS) interviewing 130 Self-Help Groups (SHGs) from 12 villages in 7 mandals ${ }^{55}$, finds that "most of the members [two thirds] don't know about the effective rate of interest, method of calculation, or any other loan operational charges, sometimes, due to their inability to understand the information provided by the MFI and, sometimes, due to a lack of transparency in MFI operations." (APMAS 2006:7)

\subsection{2. $\quad$ How to secure the portfolio}

A further point of discussion, when talking about practices related to the costs of a loan, are the amounts collected at the time of loan sanctioning: administrative charges are applied and most often a deposit is collected. This latter amount, the security deposit, is raised by the borrower in order to have access to a line of credit from an MFI and is generally given back to the borrower upon completion of the transaction unless it defaults. As is observed, the deposit is often the first resort of the MFI in case of default and hence serves as a mean to secure repayment and increase repayment rates.

Several issues are worth debating when it comes to security deposits. First "it is unclear if the interviewees have sufficient knowledge of the charges they are paying" as stated in a report by the Asian Development Bank (ADB) on microfinance in Jiangkou County, China (Hickson 2005:37) when discussing security deposits. Those that do - in particular repeat borrowers who proved their reliability - perceive the charged security as distrust. Furthermore, the security deposit is often as high as one loan instalment making it necessary for many clients to use part of the loan itself to cover the cost, reducing the loan size by a considerable amount.

\footnotetext{
${ }^{52}$ In India the average microfinance loan size can vary from Rs. 2,000 to Rs. 20,000 . If an interest rate of $15 \%$ flat, on a declining balance is taken, it will work out to an effective rate of $33 \%$ per annum. But in many cases, these rates are not to mention all the hidden costs such as insurance, bank and stationery charges, but also membership fee, card fee, etc. which, at the end, can give an interest rate of 50 to $80 \%$ per annum (1 US dollars is equivalent to 50 Indian rupees in 2007).

${ }^{53}$ See on the CGAP website, 07/05/2008: http://www.microfinancegateway.org/section/resourcecenters/ auditcenter/helpdesk/auditors

${ }^{54} \mathrm{~A}$ microfinance lobbying association at the state level in India.

${ }^{55}$ India is divided into subnational administrative units. Mandals form the third such subdivision below states and districts.
} 
The severity of such security deposits can be debated but consensus should be found that the practice of not paying and in certain cases even charging interest on this amount, is very questionable.

An extreme example of these issues comes from the Andhra Pradesh Rural Poverty Reduction Project, called 'Velugu' (literally meaning 'light' in Telugu), whose key institution building strategy is "to organize the poor, particularly the poorest of the poor, into Self-Help Groups at the grassroots" "56,57. The program, which will be come back to in the final section of the chapter, is heavily funded by the World Bank. Unfortunately, while being able to produce numerous success stories, certain bankers and DRDA Officials (District Rural Development Agency, the implementing agency) have made the process a mockery.

The acknowledged success of the SHG approach in reducing poverty led to a huge amount of money being channelled into the program. Yearly targets increased tremendously, even double in certain areas, which left DRDAs with the task of linking too many groups in too short a time. In order to still meet these targets, SHGs were being "advised" to repay their current loan by taking out a new and bigger loan. New and bigger loans were indeed sanctioned, but in many cases, only $80 \%$ of the amount was (and is) actually disbursed. The remaining amount was kept as a security deposit, with no documents given, but with the full loan showing up in the Savings Account Pass Book and members expected to repay the whole amount, which they had not really taken out.

These practices have a considerable impact on the actual interest rate of a loan, the actual amount of loans disbursed and also on the increase in debt-burden, which not only results from the new 'bigger' loan but also from the debts incurred in order to repay the previous loan, which in turn then allowed the new big loan to be taken.

As mentioned, the intention of this chapter is not to judge whether or not such security deposits are or are not a necessity but to make people understand what is going on in the sector and to voice the issues that are often not being said. Statement such as "During the period April 2005 to March 2006, 620,109 new SHGs were financed by banks to the tune of Rs 44.99 billion by way of loans." need to be understood in the right context, meaning that they cannot be read as "NABARD having provided Rs. 44.99 billion working capital to the rural poor" - a crucial difference when referring to the ultimate goal of microfinance as being a tool to empower the poor.

\footnotetext{
${ }^{56} \mathrm{http} / / /$ www.velugu.org/What_Velugu/velugu_genesis.html?id=0 1, accessed 25.04.2008.

${ }_{77}$ The Indian SHG Banking Linkage Programme is the microfinance model that reaches the most clients in India by far and can also be credited with being one of the most important microfinance programmes across the world.
} 


\subsubsection{How to secure Repayment and high Repayment Rates}

One of the key determinants of the observed success of microfinance lies in the existence of high repayment rates (Morduch 1999a:1571). While rural credit programmes from the early 1950s through to the 1980s experienced repayment rates below $50 \%{ }^{58}$, most microfinance programmes usually report loan repayment rates of above $95 \%$, often even as high as $100 \%$ - not least since this is what is nowadays expected from them and can serve as a door-opener to donor funding. To reach the objective of near to perfect loan recovery, organizations working in the microfinance sector have been using various techniques - most of which do not relate to the special features of microfinance services outlined above (i.e. group lending, joint liability, small and frequent instalments, doorstep policies and dynamic incentives).

In case a customer is not able to repay an instalment, one of the first measures (especially practiced with SHGs) is to charge a fine. The amount of this fine is often decided by the groups themselves and can range from Rs. 1 to 80. In case of continued delay, pressure is exerted. This can take several forms but usually starts with the group's leader or MFI staff visiting the defaulting borrower. Such a visit can already have the desired effect since other village members become aware of the borrower's inability to repay, which strongly influences his or her socio-economic status as well as other credit opportunities in society. Other methods of damaging the defaulter's reputation are to publicly announce their failure - sometimes the announcement is done by a board specifically created for this purpose ${ }^{59}$. One consequence that is frequently observed as a means to avoid such public humiliation is that the poor take up a second loan in order to repay the first one, which pulls them into a vicious circle, making them go deeper and deeper into debt - an issue whose consequences will be elaborated on in the following section.

In cases where making public or 'simple' visits are not enough, other methods are being used. These can range from sending a whole "recovery team" to harass the defaulter to even hiring others to take over the bullying. "If someone is unable to pay the instalment, we come in the village and can be rude to him. (...) We try to intimidate him and it is also as a warning to other clients" a loan officer confided. These comments are confirmed by several sources and notably by T. Vijay Kumar, Chief Executive Officer of the government-sponsored Society for the Elimination of Rural Poverty (SERP), when they were looking into the activities of some prominent MFIs in Andhra Pradesh. In fact, recruiting some hired hand to recover loansinstalments is not rare and, private money lenders, commercial banks,

\footnotetext{
${ }^{58}$ Such as the Integrated Rural Development Programme in India (Pulley 1989).

${ }^{59}$ When the importance of reciprocal system in which are engaged all households in rural India is known, it is possible to measure effects due to a reputation of bad debtor. On this subject of debts and debtors and more generally the phenomenon of indebtedness, see the book edited by C. Malamoud (1983).
} 
landowners and contractors all turn to this practice instead of instituting legal proceedings from time to time.

In some cases, even physical force and manhandling are used as indicated in the APMAS study initiated by the District Rural Development Agency (DRDA) and Indira Kranti Patam/Velugu (IKP) in 2006.

The last recovery method to be discussed is the one of a non-asset based collateral. Such collateral includes, for example, promissory notes. A promissory note is simply a written promise by the borrower to pay a stated amount of money in accordance with certain terms, which includes the principal amount of the loan, a specified rate of interest, and a maturity date. Such a note is common practice when issuing a loan and should not be of great concern. Nevertheless, some of these promissory notes are unwritten. A promissory note contains an affirmative undertaking to pay the amount stated. If the lender is free to fill in any amount, this can put immense pressure on the borrower since severe consequences would result, which are highlighted below. Of the 130 borrowers interviewed in the APMAS study, $33.8 \%$ reported having signed empty papers. According to the authors, it is evident from their responses "that most of the members think that non-asset based formalities are part and parcel in the loan documentation process. Because of their illiteracy and pressing financial needs, they do whatever is required to avail a loan. [...] Members did not understand what would happen with those documents and because of the lack of transparency in loan documentation, were not told so by the loaning institution." (APMAS 2006:8)

Even worse than unwritten promises is the fact that some institutions make the borrowers sign blank checks. Besides the fact that these make the institution have unlimited assets and hence liabilities on the balance sheet ${ }^{60}$, such checks can be extremely dangerous for the borrower, because whoever obtains the check could write in any amount and would legally be able to cash it, as could the MFI. One might wonder why MFI staff would involve themselves in such underhand practices, knowing that the checking account does not contain such funds and that consequently the money could not be obtained - and as a result the check would bounce back. But it would not simply bounce back: when a check bounces, the police immediately gets involved and pays the owner of the bank-account a visit. In the worst case, the client ends up in prison. This threat is highly efficient in making the customers repay whatever it takes and hence is seen as an effective tool to be (unofficially) used by MFIs.

\footnotetext{
${ }^{60}$ A leading microfinance institution in India actually had to deal with the head of their accounting department at some point refusing to sign the balance sheet when finding out about the practices of issuing blank checks. (Informal interview in fall 2007 with a former employee of this institution).
} 
One much easier method of achieving high repayment rates that does not involve any harassment of the client or similarly underhand practices, is to simply issue the client another loan, which can be used to repay the first.

Our own observations, when joining agents on their daily 'credit rounds', confirmed that the moment an outstanding loan appears, it is easier for the agent to grant a new loan to cover the outstanding one than to try to solve the problem ${ }^{61}$. This makes it possible to ensure repayments above $95 \%$. In Southern India, people make it a point of honor to repay their debts. MFIs know this and count on this fact to find a way to balance the accounts.

As explained before, the volume of credits granted and the height of repayment rates is one of the criteria used in evaluating the quality of a program; a 'good' MFI is obviously one which guarantees repayment. By the cascade effect, staff passes on such objectives to field agents by imposing strict repayment standards. These field agents in turn pass on this pressure to the clients, sometimes to the group leader, who in turn passes it on to the members. "It is also possible, as some experience in Bangladesh has shown that pressure for high recoveries can lead the bank workers to act even more oppressively than fellow members." (Harper 2002:191). This statement underlines the need for concern about this chain reaction.

The next section describes the microfinance crisis that broke out in India in March 2006. It is an example of how above described practices can have severe consequences if cumulated and unaddressed. It at the same time illustrates the clash between private microfinance players that are guided by commercial principles and public microfinance following a discourse of populism.

\subsection{The Crisis in Andhra Pradesh (AP)}

The international (as well as the national) press is one of the main drivers of the observed microfinance enthusiasms. Nevertheless, it was the problem of debt and debt burden that triggered a tremendous amount of talk in the Indian media about microfinance in February and March 2006. For once, the headlines were no longer flattering - microfinance institutions were accused of charging usurious interest rates and being the cause of 10 to 60 suicides in the Krishna district (Andhra Pradesh): "MFI harassment: 60 suicide cases reported"; "MFIs liable for prosecution", "Official enquires into row over functioning of MFIs in State", "Micro-finance victims petition rights panel", "MFIs recover Rs. 200 crores as "hidden costs", "Multiple loans land SHGs in debt trap", etc.

\footnotetext{
${ }^{61}$ While in some cases, it is the credit agent's own initiative, such practices are politically imposed by the organization itself in other cases.
} 


\subsubsection{The Events}

Just preceding this outbreak, in the short period of November 2005 to end of February of 2006 several cases of suicide were recorded in the district of Krishna (Andhra Pradesh) - all of these were MFI clients of the private sector. In November 2005, a couple committed suicide by consuming cyanide. Kumari had borrowed Rs. 25,000 (US\$ 500) from an MFI for her husband's business. To compensate for the financial difficulties encountered by her husband, Kumari took on two new loans for the same amount from two other MFIs. The situation quickly became difficult and the repayment of the loans turned out to be impossible. With the pressure from the other group members as well as the organizations increasing, the couple committed suicide. This is just one of many cases that tell a similar story, where MFI clients experience repayment difficulties and non-repayment result in verbal and sexual harassment, culminate in prostitution, imprisonment and confiscation of goods - and finally suicide.

Following many cases of this type in the district of Krishna, several village organizations decided to make their concerns heard by the district collector so that he could start proceedings against MFIs accused of being responsible for these suicides. Local councillors, the Members of the Legislative Assembly (MLA), found themselves under pressure from village organizations and the media. Fingers were pointed at MFIs and their responsibilities were started to be questioned.

\subsubsection{Between Sustainability, mercantile interest rates and populism}

These events clearly exemplify the possible consequences of using the recovery methods described in order to be able to report high repayment rates and secure the portfolio.

But the calamity experienced in Andhra Pradesh also underlines the dire consequences of not facing the real costs of providing microfinance services. It was the issue of interest rates that has been at the heart of this crisis. (See Ghate (2007b) for a detailed analysis).

There has, in fact, been a long discussion in the sector as a whole, about the costs of microfinance services and while many understand and support the need for charging higher interest rates than in other financial markets, others deny this need and denounce the practice as being unfair. These competing views are mirrored in the crisis, which turned out to be a fight between public and private microfinance.

To understand how such a fight could come about, one needs to know the basic conditions of the microfinance sector in the state of Andhra Pradesh. In fact, during the process of banking sector reforms in the early 1990s in India, microfinance became an important part of bank intermediation and Andhra Pradesh is today the Indian state with the most extensive microfinance network in the country. The variety of 
microfinance models which took hold there - SHGs, Grameen, co-operatives and micro-banks - and the growth of this movement, gave Andhra Pradesh a prime spot on the world microfinance map. Together, public microfinance - mainly in the form of the SHG model - and private microfinance - mainly in the form of the microfinance institution model - secured an unprecedented linkage of the poor to the formal financial sector. Civil society, private financial institutions (increasingly refinanced by the private banking system) and governmental institutions promoted more than 28,000 village organizations and more than 1,000 SHG federations registered under the Mutually Aided Co-operative Societies Act (MACs). This act was passed in favour of a new environment for the co-operatives in Andhra Pradesh and taken up by five other states after a long struggle. According to C.S. Reddy, General Manager of the APMAS, each village in Andhra Pradesh has at least one SHG. According to data of the National Bank for Agriculture and Rural Development (NABARD), the number of SHGs having received credit rose from less than 6,600 for the financial year 19981999 to more than 294,300 in 2005-2006. That is a ratio of 1 to 45 . At the national level, in 2005-2006, this state represented nearly $33 \%$ of all the financed SHGs (Augsburg and Fouillet 2007). Even if the preponderance of Andhra Pradesh in terms of number of SHGs is decreasing, its place in the field of Indian microfinance remains very significant in volume as well as in diversity, innovation and studies of the financial tools used. Harper \& Nath (no year) show that AP is home to one SHG per 22 rural below poverty line (BPL) families, which needs to be compared to an all Indi average of one group per 269 rural BPL families.

The two main microfinance delivery models in Andhra Pradesh (and India as a whole for that matter) are the SHG model and the microfinance institution model: the former being dominated by the public sphere: the latter by the private one. In the aforementioned crisis, these two clashed - the gist of the clash boiling down to the issue of interest rates.

Given the pressure exerted by the media and the public in reaction to the farmer suicides, officials did not take long to react: On March 11, the administration of Krishna district in Andhra Pradesh, under the influence of its district collector (prefect) Navin Mittal, made the decision to close 50 agencies of two MFIs, Share Microfin Limited (SML) and Spandana. Besides accusing MFIs of resorting to strong-arm methods to recover their loans, their recourse to excessive interest rates was the principal reason invoked.

Some of the executives of the private MFIs, who agreed to share their point of view, said that the microfinance private sector had made the mistake of protesting against a governmental programme called Pavala Vaddi. According to certain MFIs, the scandal, which shook the region, has now given the government an excuse to swing into action. It was not only Spandana and the SML that were under attack, but all MFIs in the region. The government was clear and did not hesitate to say that Andhra Pradesh did 
not require MFIs and that these should rather operate in states where the government is not able to manage credit distribution in rural areas.

To understand how this political power struggle links to the issue of interest rates, one needs to go back to the late nineties, when the then Chief Minister of Andhra Pradesh Chandrababy Naidu ${ }^{62}$, established partnerships with the World Bank in order to create a network of SHGs throughout the state ${ }^{63}$. This programme was already mentioned in the context of securing the portfolio by means of extremely high security deposits deposits that, if taken into account when calculating real interest rates, would drive the rates up by a considerable percentage. Leaving this point aside, loans granted through Velugu are highly subsidized, which allows low interest rates of around nine per cent per annum. The row between public and private actors first began at the time of the 2004 elections when the new government of Rajshekhara Reddy ${ }^{64}$ set-up the famous Pavala Vaddi ${ }^{65}$ program. This programme was introduced to supplement the Velugu subsidies, making it possible to offer credit to SHGs no longer at nine per cent, but at three per cent. SHGs applied the nine per cent rate and once the loan was repaid, six per cent was to be credited to their account. One year later, the state wanted to go even further and invited SHGs to pay only three per cent directly. The state would pay off the remainder.

At that time, the representatives of several private sector MFIs were horrified by these announcements and did not fail to let it be known. For them, these artificially low interest rates made the private sector unattractive to SHGs. Moreover, what would happen if people started to create SHGs in order to use these loans to lend them to non-SHG members? (In fact this had already happened in several places, for example, Rao 2005.) Even more significant in their eyes, this programme was going to attack the very core of the SHG ideal. With this level of subsidies, the financial discipline related to the practices of credit and savings could go completely off the rails.

\footnotetext{
${ }^{62}$ Chandrababu Naidu was Andhra Pradesh's Chief Minister between 1995 and 2004. After to making his debut in the ranks of Congress Party, he joined the Telugu Desam Party (party funded by his brother in law Nandamuri Taraka Rama Rao) of which he is the actual president. Sometimes considered as one of the most dynamic Indian leaders (Business World, 1999), Chandrababu Naidu embodies above the example of the « control freak» in opposition at some Chief Minister advocating more of politic pluralism as Digvijay Singh in Madhya Pradesh or S.M. Krishna in Karnataka (Manor 2000:821)

${ }^{63}$ Mainly through two schemes, the District Poverty Initiatives Project and the Rural Poverty Reduction Program. To manage funds allocated by the World Bank, the Government created the Society for the Elimination of Rural Poverty (SERP). These schemes are in line with a development architecture called "Vision 2020" and driven by the researchers of the neoliberal institute Adam Smith, the World Bank and the management consultants McKinsey and Co.

${ }^{64}$ Also Chief Minister of Andhra Pradesh, he represents the Congress party. His brother, Vivekananda Reddy, also a member of the Congress, represents actually Cuddapah district at the Lok Sabha, the lower house in the Parliament of India.

${ }^{65}$ In Telugu, Pavala Vaddi means 3\% interest.
} 
And indeed, comparing these nine per cent to the official average rate of 24 per cent charged by microfinance institutions (and a rate that is typically accepted as just costcovering), one can easily understand the worries of private institutions - but also how a point could be made of these private organizations charging excessively large, basically exploitative interest rates. The general manager of the Society for the Eradication of Rural Poverty (SERP), and thereby SERP itself, went as far as accusing private MFIs of not having followed a strategic vision but rather a random development strategy. Congress Party leader P. Venkat Rao told the press that "The government should have taken measures against these companies five years ago, when they organized the 'pillage' of the lending activity in the name of microfinance. The government must identify the microfinance companies which misled people and acted fraudulently to get their loans repaid" (Guntur 2006). For others, Pavala Vaddi was a very good media coup in view of the elections, but did not make sense financially. In the eyes of the private MFI, this programme could - and did - create dissension and instability between private and public sectors, causing unfair competition.

Whichever side one takes, the crisis makes clear that transparency of operations needs to be a priority concern in order for a stable microfinance environment to be established. Such transparency will then help the appropriate setting of priorities. Kamat's (2004:171) comment about NGOs holds equally strong for microfinance institutions:

"Thus, rather than deepening the gains made on the basis of popular democratic struggles, NGOs are being re-inscribed in the current policy discourse in ways that strengthen liberalism and undermine democracy. Given this trend, it is unlikely that NGOs can be the honest brokers of people's interests."

\subsection{Conclusion}

In this chapter, caution is raised regarding the overwhelming push for microfinance institutions to become financially self-sustainable, a push more often than not exerted by donor organizations. Such a push can have severe consequences, ranging from a substantial one like a mission drift to questionable practices employed by institutions. And, especially when being aware of some of these practices, one becomes clairvoyant when reading comments by development agencies such as "But once such loans have fallen delinquent, the fact that they are unsecured justifies requiring them to be provisioned more aggressively than a conventionally collateralized portfolio." (CGAP 2002:21).

In the microfinance sector, the key words became autonomy, financial viability and sustainability, overdue, outstanding loans, repayment rates, rate of investment returns. Actors in the field seem to believe that the satisfaction and emancipation of the clients 
follow naturally. This link is taken for granted and even misused. The financial performance of a microfinance institution, whether it is positive or negative, is only one effect among many of a particular program. That an institution can survive autonomously is regarded as the best proof of its impact. This presupposition seems naive, to say the least. The repayment rate or the rate of investment returns do not tell us anything about the quality of services delivered, particularly when there is no competition in the sector.

Furthermore, there is a proliferation of articles, conferences and books about the question of refinancing MFIs and their accession to private markets in order to widen their potential. The largest MFIs engage marketing specialists to develop promotional campaigns targeting the poor for loans and insurance. But who bothers to know whether clients are able to absorb these new loans, or rather all that comes with the debt?

The question is especially important in the context of India, where the visible microfinance crisis is just the tip of the iceberg. In 1997 India experienced its best publicised spell of farmer suicides - a reaction to a number of agricultural hardships that led to the irreversible indebtedness of small and marginal farmers. Rising costs of cultivation, degenerating input quality ${ }^{66}$, rapidly decreasing prices of farm products, and a lack of formal credits for small farmers, driving them to alternative and much more expensive lending sources, were some of the major determinants of the crisis. Between 1997 and 2006, more than 250,000 Indian farmers committed suicide among others, due to bad harvests and their inability to keep up with debt repayment schedules (Assadi 2006).

The microfinance crisis that on the one hand originated from the generally hard conditions for Indian farmers at the same time reflects a frenzy of private and public actors, driven by motives that are hard to relate to a fight against poverty: A new commercial niche for the private actors and a collection of vote banks for public actors. Microfinance is far from being the panacea it is made out to be by media and international organizations. Being subject to reinterpretation and reappropriation, microfinancial services are permanently distorted - resulting in their being pushed to move away from their social objectives ${ }^{67}$.

\footnotetext{
${ }^{66}$ In 1998, following structural adjustment policies, India opened its seed sector to global agribusiness and with that to genetically engineered seeds which are non renewable, i.e. they have to buy new seeds every year At the same time, under pressure from seed international companies, the Indian government reduced the minimum germination rate for seeds from 85 to $60 \%$. As a result, in numerous small household farms, these changes lead to severe indebtedness.

${ }^{67}$ See the anthropological case study of Célina Jauzelon (2007) which describes a microfinance project carried out by an Indian NGO in Tamil Nadu and attempts to demonstrate the complexity of the solidarity practices and their representations. Also, for a description of the limits of the Grameen model, see Aminur Rahman (1999), and for an ethnography of aid policy and practice in India, cf. David Moose (2005).
} 
One needs to ask the question of whether the crisis in Andhra Pradesh is a minor phenomenon or whether it reveals that the 'microfinance machine' has gone berserk. Whatever the answer, it as an occasion to trigger a collective and widespread reflection on the dysfunction of microfinance, not only in India but within the worldwide sector as a whole ${ }^{68}$.

This chapter's purpose is to highlight consequences of the observed widespread microfinance mission drift and by doing so to call for putting the welfare of the client back on top of the agenda. Today, microfinance is far from being the panacea of poverty which it is made out to be by the public sphere, media and international organizations. Microfinance is indeed a powerful tool to face the challenge of poverty eradication. The second part of this dissertation discusses an intervention that has been designed and implemented with care and - while still with limitations - helps their customers to improve their livelihoods. But, it is exactly these limits that need to be acknowledged. Only by doing so can the limits be pushed backwards or even be eliminated totally.

\footnotetext{
${ }^{68}$ On April 20th 2007, the Mexican MFI Compartamos put 30\% of its capital up for sale on New York and Mexican stock markets. The following day, the trading volume reached 321 million Euros, i.e. 12 times the nominal value, and ensured at the shareholder to store up huge profit to the detriment of clients whose credits are among the most expensive ones of the country (annual interest of $100 \%$ ). Nevertheless, despite an announcement, grants and subventions of several million Euros were not passed on to clients by the MFIs shareholders.
} 


\section{PART II}

\section{Lesser Evil or Greater Good?}

This second part of the dissertation looks at milk as an extra income generating activity for the poor with a focus on a microfinance programme that gives loans for their clients to engage in this livelihood strategy. The main aim is to evaluate this strategy and the intervention in particular.

The general analysis is part of chapter four where special focus is placed on the subjective expectations of those involved in the activity. Chapters five and six concentrate on evaluating the programme offered by the microfinance institution. A thorough description of the latter is given in chapter five placing emphasis on the nonfinancial component of the program.

The core data source for the analysis is the household survey I conducted in the course of my PhD. Chapters four and five make use of the data and give information that is of specific interest for the respective study. A complete description of the survey design and a copy of the questionnaire are provided in Appendix nine, including the questionnaire. 


\section{Using expectation data to model expected income and expenditures in rural India}

\subsection{Introduction}

Beliefs and expectations play a major role in (investment) decision-making processes especially when a high degree of uncertainty is involved. However, only limited research addresses the nature of beliefs of financial actors and tries to measure the expectations that investors hold - especially when potential investors are the rural poor in least and less developed countries (LDCs).

Latest since Paul Slovic's (1972) paper on individual's misperceptions about risk and Amos Tversky and Daniel Kahneman's (1979) papers on heuristic-driven decision biases and decision frames do we know that beliefs and expectations of agents play a major role in the process of deciding to invest or not. Daniel et al. (2002) reviews the literature on recent research in behaviour finance.

Despite advances in especially the field of behavioural economics, most (conventional) financial models and studies in the field concentrate on actual objective circumstances and on realized outcomes of human behaviour and assume that all investors have homogeneous expectations of the joint distributions of investment returns.

This chapter is concerned with investigating subjective expectations of the rural poor with respect to income as well as investment returns and costs. Contrary to the bulk of the literature on the issue, the focus will not be exclusively on actual outcomes and be constrained to homogeneous beliefs. The study will on the other hand address the subjectiveness of perception. The information the agents possess and the beliefs they have determine the possible outcomes foreseen and their subjective probabilities.

The major part of this chapter lies in describing the elicitation process of subjective expectations and in validating the answers provided by the respondents. Thereafter, respondents' fitted subjective mean is modelled to learn how expectations vary with individual attributes.

The extensive focus on the way expectations were collected and on showing that the answers provided are 'reasonable' and conform to basic probability laws is justified given two major concerns - academic vindication as well as the specific context of the study. Considerable scepticism as well as criticism of this approach exists and most often economists prefer to avoid its use. This is often based on studies working with measurements of expectations stemming from vaguely worded qualitative questions 
though - as Dominitz \& Manski (1997) put it "There is no empirical evidence supporting condemnation of all expectations data". Given the widespread scepticism of the approach, validation of answers by respondents to expectation questions was and still remains the initial focus of research (Manski, 2004). This is even more important given that respondents in this study are the rural poor in India. These are agricultural labourers or farmers, most of which have no or very little education. The ability to use probabilities in the form of a number between zero and 100 cannot be naturally understood.

Up to date, most of these studies that make use of subjective expectations data concentrate on high-income countries. Only a few researchers have started to apply the approach in the developing world, where its use is impeded by individuals being generally less (if at all) educated and hence less or not familiar with the concept of probabilities. Notable exceptions are studies by Attanasio et al (2005) on the use of probability distributions of future income in Colombia, Delavande (2004) on the efficacy of contraceptive methods in Ghana, and Luseno et al. (2003) and Lybbert et al. on pastoralists' rainfall expectations in East Africa.

This work distinguishes itself and improves on the studies that relate to LDCs in two important matters. First, subjective expectations not only on household income but also on specific investment returns and costs were collected, the importance of such information for investment decisions outlined as above. Secondly, elicited data goes beyond point-probabilities, which allows calculating an individual expected outcome distribution.

This latter distinctive attribute of these subjective expectations is of particular interest in the context of this study since it allows - contrary to cross-sectional realization data - to distinguish between uncertainty and heterogeneity. To exemplify this consider a population of two individuals with a standard deviation in realized income of $\sigma_{y}>0$. This tells us that the population is heterogeneous; the expected value of income differs for both individuals. It does not tell us anything about the uncertainty in their income streams though: While one individual might earn a much higher income than the other, both might be very certain about the amount they are going to receive. The subjective expectation data on the other hand allows calculating the standard deviation of the subjective individual expected income distribution. This standard deviation reflects the uncertainty in income as perceived by the individual. The data hence gives information on heterogeneity within the population as well as on uncertainty of individuals.

To start with, the next section provides information on the context of the study. Thereafter, details on what data are used and how information on the respondents' expectation was collected is given. This is followed by a comprehensive description of the elicited probabilities and a validation of the same; the response rate to the expectations questions is examined as well as the coherence of answers. Assuming a distributional form of the expectation data allows calculating moments of the expected outcome distributions, which are compared to realizations of the same variables. Thereafter, estimates of these potential subjective outcomes, which are conditional on observed attributes are presented. Estimates will be interpreted as best linear predictors for these outcomes. Before concluding, the income distributions are used to look at 
welfare ranking, addressing the question of whether engaging in dairy is indeed a mean to reduce inequality within society. The final section concludes.

\subsection{Background}

Expected prospective outcomes are a central component to models of intertemporal choice. Especially the distribution of future income has continuously been of major concern to economic theory and economic policy. Income and expectations thereof among others influence consumption and savings decisions, schooling decision, insurance purchase, enrolment into welfare programs and investment decisions. The importance of taking action in response to beliefs about what will happen in the future further increases when future outcomes are uncertain.

The beliefs that are being analysed in this study relate to perceived costs and benefits of engaging in milk-production as an extra-income generating activity.

Milk production plays a pivotal role in the livelihoods of the rural poor, particularly of women, in India. It is one of the few possible means of supporting themselves and their families. Especially in areas that are dominated by agricultural activities characterized by high seasonal dependency, milk production offers a way of ensuring an additional income stream. In fact, it is not only the milk production that offers return to the families; "all body parts are used including horns and hair. A buffalo forms a part of the property, possession and profession of rural farmers. Not only that, they are an easily 'convertible currency' and a reliable 'living bank' to serve the immediate needs of the rural masses in several communities." (Nanda \& Nakao, 2003)

It therefore comes as no surprise that this extra income generating activity highly promoted by the Indian government as a means to improve the living conditions of farmers in rural areas and it is estimated that the underprivileged families constitute about 70 to 80 per cent of total livestock production in India (Kurup 2004). In 1965 the National Dairy Development Board (NDDB) was created based on the initiative of Lal Bahadur Shastri, the then Prime Minister of India. Its mandate was to replicate the Amul (Anand Milk Unit Limited) dairy model, which is a genuine example of a successful long-standing cooperative organization, credit only being a small part of the intervention. Amul is said to have spurred the White Revolution in India, which has made India the largest producer of milk worldwide. Supportive of this development was a rural development programme, called Operation Flood, which NDDB under called Operation Flood started and led in the 1970s. In 2008, it involved 13.4 million farmer-members supplying an average of 23,000 metric tons of milk per day. Especially in Gujarat, the state where Anul was established, the programme is still very present and successfully running.

More recent action was taken in February 2008 when the chief minister of the state of Andhra Pradesh announced to set-up bulk milk chilling units in 31 mandals of Kadapa district by the end of the year and started parallel to distribute several thousands of milk cattle. It is interesting to note that the political support in the livestock sector is mainly constrained to the market of milk. Especially anti-cow slaughter politics 
prevent livestock owners from realizing the full potential of their animals. This is unlikely to change in the near future as great social pressure is exerted given the popular understandings of Hinduism - cow slaughter being seen as contrary to what the Hindu religion dictates. See Turner (2004) and Jha (2004) for a review of the livestock sector in Andhra Pradesh and an illuminating description of the issue of cow slaughter.

The chapter looks into the legitimacy of promoting this livelihood strategy by analyzing the distributions of three outcome indicators. The first indicator is overall household income and the other two are directly related to the intervention, namely income from dairy and animal health expenditures. Of special concern are the respondents' expectations of these outcome indicators.

Beliefs of investors play a major role in this decision-making process especially due to the high degree of uncertainty that is involved. On the one hand, the population under consideration in this study faces extreme volatility and uncertainty in their household income streams. This is mainly attributed to the fact that households depend on agricultural activities as their major source of earnings. Agricultural activities in themselves are uncertain but become even more so for the respondents of this study since they are living in the second most drought-prone area of India. Furthermore, engaging in milk-production incorporates an investment decision - namely to endow livestock. This investment decision is a risky one given that livestock is a particularly risky asset; not only can the animal fall ill or even die, but the owner needs knowledge in keeping and raising the animal and needs to be able to provide fodder on a regular basis. Given the uncertain setting in which the investors live, especially the issue of fodder-provision increases the riskiness of the investment.

The distribution of future outcomes is usually derived from the analysis of frequentist distribution of realizations (Dominitz, 2001). In order to infer such a distribution, assumptions on information individuals possess and on how they make use of this information necessarily have to be made. Typically, a single model of the income generating process is put forward which assumes individuals to form rational expectations.

Given the unique attribute of a primary data set collected, it will be possible to avoid making such stringent assumptions in this study. Instead of inferring the income distribution from realizations, this study uses data on households' subjective probability distributions, collected by asking respondents specifically about their beliefs.

\subsection{The Data}

The data used in the analysis stems from the household survey undertaken from January to March 2008 as described in more detail in chapter five as well as in Appendix 9.1. In brief, 1,041 households were interviewed on information related to 
their household composition, income, assets, consumption, risks and special sections on livestock and on credit, savings and insurance.

Data on expectations was elicited at three times during the interview - in the income section on total expected future household income and in the livestock section on expected future income from dairy activities as well as expected medical expenses for the animal.

The question format to elicit the subjective expectations is based on the ones used in the surveys undertaken for the evaluation of Familias en Accion in rural Colombia, which asks about the expected household income.

The expectations questions were worded as follows:

How likely do you think it is that your income in the coming year will be higher than (A/B/C) Rupees? ${ }^{69}$

The thresholds A, B and C, were determined by prior asking the respondents about the minimum and maximum amount they expect to earn within the coming months. This range was then equally divided into four sections, the thresholds being named A, B and $\mathrm{C}$.

The questions for the minimum and maximum had the following format:

Maximum: Imagine that you have a very good year, every member of working age in the household managed to have work, and there were no droughts or anything the like. What would be the maximum amount of income your household would receive in such a situation in one year?

Minimum: Now imagine the total opposite: the harvest is bad; animals get sick, finding work is not possible. What would be the monthly income of your household in such a situation?

As the majority of respondents had no or very little schooling it could not be expected for them to know the concept of probabilities and the probability laws that these follow - and hence to answer the question about their income with a number between zero and 100. Therefore, again following the format of the survey conducted in Columbia, a short introduction to percentages was given to the respondents in the form of a 'game'. This was done after asking about the minimum and maximum expected income and before eliciting the probabilities of the thresholds (A, B, C) occurring.

The game that was played had the subsequent format:

\footnotetext{
${ }^{69}$ For the expected animal-health costs the wording was as follows: How likely do you think it is that you will have to spend more than month?

$(\mathbf{A} / \mathbf{B} / \mathbf{C})$ Rupees on health services for your animals in the coming
} 
We have a ruler here with a scale from 0 to 100 . We will use this as an indicator of how sure you are that a situation will happen in the future.

Let's take rain as an example:

How sure are you that it will rain sometime tomorrow?

1. If you are absolutely sure that it will rain, point to the 100 on the ruler.

2. If you are absolutely sure that it will not rain tomorrow, point to 0 on the ruler.

3. If you are not sure whether it will rain or not but think that it is more likely to rain than not, point somewhere on the ruler between 0 and 100 but closer to 100 than to 0.

4. If you are not sure whether it will rain or not but think it is more likely that it will not rain, point somewhere on the ruler, but closer to 0 than to 100 .

A visual aid - namely a ruler - was employed to help the respondent. ${ }^{70}$

Subsequently, respondents were asked to give their belief on the probability of rain the coming day.

The understanding of the concept of probabilities is one important factor for the elicitation process; a second one is the understanding of certain basic probability laws. Important in this context is the concept of monotonicity. Since the income thresholds $\mathrm{A}, \mathrm{B}$, and $\mathrm{C}$ are increasing, the probability of earning these thresholds should not increase. In order for respondents to grasp this concept, an extension to the survey conducted in Columbia was employed. Respondents were not only asked about the probability that it would rain tomorrow but also how high the probability was that it would rain within the coming week and within the coming month. The probability of these occurrences should not decrease for monotonicity to hold.

Interviewers were trained to take a lot of time when explaining the concept of probabilities and were also allowed to give further explanations in case the respondents gave answers to the rain questions that did not obey the probability laws. Only when this concept was understood did interviewers go on asking about the probabilities of income reaching a certain threshold. Here, interviewers were not allowed to prompt and were supposed to note the answers as provided by the respondent. This was made clear in their training, which included a special section on these expectation questions. Nevertheless, while it was not done when interviews were supervised, some prompting cannot be ruled out.

As mentioned, not only subjective expectations on future household income were elicited but also on income from dairy and health expenditures for the animals. These

\footnotetext{
${ }^{70}$ Although the survey was conducted in one of the most drought-prone areas in India and outside the monsoon season, it was possible to get variation in the responses to questions on the probability of rain. During the time the survey was conducted, it rained several days - contrary to what is typical in the area.
} 
are hence subjective expectations on returns specific to the investment. Eliciting probabilities on such specific returns is new in the literature on subjective expectations, which mainly concentrates on income figures.

Some studies exist that work with subjective expectations on outcomes other than income. These include Hurd \& McGerry (1995) who evaluate the subjective probabilities of survival, working with the probability of living to 75 or 85 , Van der Klaauw (2000) who uses self-reported expected future occupation to estimate a structural dynamic model of teacher career decisions under uncertainty, Delavande (2005) who studies women's subjective expectations regarding existing birth control methods, and Delavande and Kohler (2007) who look at probabilistic subjective expectations about HIV infection. Most of the studies that deal with non-income related subjective expectations are constrained in that information is not rich enough to construct a probability distribution of future events.

The data collected on expected income from dairy and expected health costs is hence unique in the sense that specific investment returns are looked at and that several points on the cdf are available to construct a probability distribution as will be explained in section 4.4 .

The way this data was collected is in line with the previous description on expected income. The exact wordings of the questions were as follows:

Expected Income from Dairy:

Minimum: Imagine all your animals stay healthy and give quality milk. What would be the maximum amount of monthly income your household would receive in such a situation from selling by-products of your animals?

Maximum: Now imagine the total opposite: your animals fall ill and give no milk. What would be the monthly income of your household in such a situation from selling by-products of your animals?

Expectation Question: How likely do you think it is that your typical monthly income from selling products of the animals in the coming month will be higher than $(\mathbf{A} / \mathbf{B} / \mathbf{C})$ Rupees?

\section{Expected Animal Health Costs:}

Minimum: Imagine that your animals do not get any serious illness during the coming month. What would be the minimum amount of money you would have to pay for health-related costs of your animals? (this does not include normal day-to-day costs such as fodder)

Maximum: Now imagine the total opposite: your animals fall seriously ill and you need to have them treated. What would be the maximum amount you would have to pay on health related costs in such a situation? (include possible transportation costs) 
Expectation Question: How likely do you think it is that you will have to spend

more than $(\mathbf{A} / \mathbf{B} / \mathbf{C})$ Rupees on health services for your animals in the coming month?

\subsection{Validation}

\subsubsection{Willingness to respond}

As can be seen in Table 4.1, the questionnaire was administered to 1,041 households, 682 of which owned any type of cow or buffalo (including calves and bullocks) and 585 of these owned female animals that were old enough to reproduce and hence to produce milk. Out of these 1,041 households, 1,012 (97 per cent) gave answers to the questions on minimum and maximum expected overall household income as well as to the questions on probabilities. Of the 29 households whose probabilities were not elicited, 15 gave answers on the expected minimum and maximum income. In terms of characteristics, the respondents that did not give any answers do not seem to own less land and have a statistically significant lower income but are not significantly different in key characteristics such as education level, caste, primary activity of household, household composition and wealth (savings and assets) of the household. These response rates (which are even higher for realizations) therefore do not corroborate the common finding of substantial non-response for income questions.

Table 4.1: Response Rates

\begin{tabular}{|ll|c|c|c|}
\hline & & Income & Dairy Income & Health Costs \\
\hline Total \# of Obs. & $\mathbf{1 0 4 1}$ & $\mathbf{5 8 5}$ & $\mathbf{6 8 2} * *$ \\
\hline \multirow{2}{*}{ no \% given } & but answers to min/max given & 15 & 11 & 6 \\
\cline { 2 - 5 } & total & 29 & 18 & 29 \\
\hline \multirow{2}{*}{ Wrong answer } & violation of monotonicity & 5 & 2 & 6 \\
& wrong 'direction' & 2 & 4 & 7 \\
\cline { 2 - 5 } & total & 1005 & $\mathbf{6}$ & $\mathbf{1 3}$ \\
\hline TOTAL no. of Obs. Available & ** Number of respondents with any type of cattle \\
\hline
\end{tabular}

Unfortunately, the respondents' willingness to respond does not imply meaningful answers. Given the environment the respondents live in and the uncertainty they face, it would be crude to believe that these people do not think probabilistically about uncertain events. Nevertheless, a major concern in the elicitation of probabilities is that respondents may not make full use of modern probability theory when thinking about uncertain events (see for example Walley (1991)). This concern becomes especially relevant when talking about the rural poor in developing countries of whom many are not able to write their own name, having no or very little education.

The way the data was elicited tried to account for this knowledge gap and experience in the field confirmed their understanding. Nevertheless, it remains important to 
validate responses and to judge whether expectations are reported coherently. This will be done following Dominitz \& Manski (1997) and analysing the rate of logical response errors and the extent of bunching of responses.

\subsubsection{Logical Response Errors}

Numbers provided in Table 4.1 show that seven of the 1,012 respondents that provided probabilities related to the expected overall household income thresholds, gave answers not conforming to the basic probability laws; five respondents violated monotonicity and two reported increasing probabilities although, the way the questions were posed, the likelihood should have decreased or stayed the same. Nevertheless, these violations make up less than one per cent of the sample.

A similar pattern can be observed for subjectively expected income from dairy. More respondents reported violating probabilities in the later section on animal health costs. It is not clear why this is the case, given that respondents were faced with questions about subjective probabilities twice before getting to this question. It might be attributed to the fact that respondents learned to consider events where something is received and had problems applying it to the opposite situation of expenditures.

\subsubsection{Bunching of Percentages}

A clear pattern of bunching around multiples of tens and to a lesser extent around fives can be observed. Table 4.2 gives the frequencies of probabilities stated for the household income thresholds. This form of bunching can be explained by the ruler used to elicit probabilities. The ruler had marks only for steps of ten and these numbers were written on the ruler. Respondents might therefore have been induced to point to these marks instead of in-between them.

Of more interest is the extent of bunching of the percent chance responses at $0 \%, 50 \%$, and $100 \%$. When asked for the percentage chance that next year's overall household income will be higher than the first (and lowest) threshold, no respondent answered 0 per cent and two gave the mid-value of 50 per cent. For the second threshold (the midpoint) there were again no 100 s or 0 s stated but a clear bunching is apparent with more than half of the sample believing in a 50-50 chance of earning more than the midpoint in-between their expected minimum and maximum income. ${ }^{71}$ Finally, only one respondent sees a zero probability of earning an amount between this threshold and the expected maximum, 51 respondents (five per cent) state a 50 per cent probability and none 100. All in all the pattern of responses across thresholds is sensible, which also holds for the pattern of responses given to the questions on dairy income probabilities

\footnotetext{
${ }^{71}$ Note that there is no consistent difference in reporting 50 per cent between respondent that engage in dairy and those that do not.
} 
as well as expected medical expenses for the animal. The Tables are given in Appendix 4.A. ${ }^{72}$

Table 4.2: Tabulation of Reported Probabilities

\begin{tabular}{|c|c|c|c|c|c|c|}
\hline $\mathbf{0}$ & \multicolumn{2}{|c|}{ thr A } & \multicolumn{2}{c|}{ thr B } & \multicolumn{2}{c|}{ thr C } \\
& No & No & \multicolumn{2}{c|}{ No } & \% \\
\hline $\mathbf{0}$ & & & & & 1 & 0.1 \\
\hline $\mathbf{3}$ & & & & & 1 & 0.1 \\
\hline $\mathbf{5}$ & & & & & 1 & 0.1 \\
\hline $\mathbf{1 0}$ & & & & & 57 & 5.67 \\
\hline $\mathbf{1 5}$ & & & & & 5 & 0.5 \\
\hline $\mathbf{2 0}$ & & & & & 391 & 38.91 \\
\hline $\mathbf{2 5}$ & & & & & 32 & 3.18 \\
\hline $\mathbf{3 0}$ & & & 9 & 0.9 & 353 & 35.12 \\
\hline $\mathbf{4 0}$ & & & 99 & 9.85 & 106 & 10.55 \\
\hline $\mathbf{4 5}$ & & & 10 & 1 & & \\
\hline $\mathbf{5 0}$ & 2 & 0.2 & 544 & 54.13 & 51 & 5.07 \\
\hline $\mathbf{5 5}$ & & & 1 & 0.1 & & \\
\hline $\mathbf{6 0}$ & 33 & 3.28 & 259 & 25.77 & 6 & 0.6 \\
\hline $\mathbf{7 0}$ & 114 & 11.34 & 79 & 7.85 & 1 & 0.1 \\
\hline $\mathbf{7 5}$ & 6 & 2.59 & & & & \\
\hline $\mathbf{8 0}$ & 248 & 24.68 & 4 & 0.4 & & \\
\hline $\mathbf{8 5}$ & 2 & 0.2 & & & & \\
\hline $\mathbf{9 0}$ & 573 & 57.01 & & & & \\
\hline $\mathbf{1 0 0}$ & 7 & 0.7 & & & & \\
\hline
\end{tabular}

\subsubsection{Correlation of Probabilities}

Finally, answers to the probabilities of rain occurring are correlated with the probabilities of earning (or paying) a certain threshold (A, B, C). The purpose is to see whether these variables vary sensibly with each other.

With data from developing countries and the probability of rain tomorrow, one would naturally expect there to be no significant correlation. Only for very few people would the yearly household income depend on short-term rain prospects. The content of this study differs. For one, as will be elaborated on in section 4.5 (see Table 4.5), the primary income source of respondents is from agricultural activities - respondents have their own farm or work as agricultural labour. It can hence be expected that the probability of rain and the probability of earning a certain amount is not totally independent - especially if a longer perspective is taken. It is possible to do the latter since respondent were not only asked about their beliefs of how likely it is that it will rain tomorrow, but also how likely it is within the next week and the next month.

\footnotetext{
${ }^{72}$ Expected medical expenses experience a higher incidence of bunching at 0 per cent. This lies in the fact that an NGO operates in the area that provides health services free of charge. The issue will be elaborated on in more detail later in the study.
} 
Table 4.3a-c shows the pair-wise correlations and the corresponding significance level. Correlations are indicated with a star if the significance level does not exceed five per cent. Looking at correlations with probabilities of earning at least a certain amount of household income next year (Table 4.3a), it can be seen that no matter what time horizon and income threshold combination is considered, a significant and negative correlation exists. Intuitively, this is an unexpected result. Given that the survey was conducted in the second most drought-prone area in India, one would expect any prospect of rain to be positively correlated with income. Three possible explanations can be brought forward: for one, the survey was conducted when the harvesting period was coming to an end and during the harvesting period, rain can have a negative effect on the yield. The right panel of Table 4.3a supports this hypothesis - one can see that the correlation is insignificant for households whose main income source is other than from agricultural activity. Secondly, these are households that rely on labour work since they do not have their own land. Rains during crop harvesting reduce the scope to get harvesting and post harvesting related work to their family members.

Table 4.3a: Correlations of Probabilities - Total Household Income

\begin{tabular}{|c|c|c|c|c|c|c|}
\hline \multirow[b]{3}{*}{ probability of... } & \multicolumn{6}{|c|}{ Total Household Income } \\
\hline & \multicolumn{3}{|c|}{ Full Sample } & \multicolumn{3}{|c|}{$\begin{array}{l}\text { Households whose primary } \\
\text { income is not derived from } \\
\text { agricultural activity }\end{array}$} \\
\hline & prob $>A$ & prob $>B$ & prob $>\mathrm{C}$ & prob $>A$ & prob $>B$ & prob $>C$ \\
\hline ...rain tomorrow & $\begin{array}{c}-0.161^{*} \\
(0.00)\end{array}$ & $\begin{array}{c}-0.11^{*} \\
(0.00)\end{array}$ & $\begin{array}{c}-0.10^{*} \\
(0.00)\end{array}$ & $\begin{array}{c}-0.167 \\
(0.09)\end{array}$ & $\begin{array}{c}-0.013 \\
(0.89)\end{array}$ & $\begin{array}{c}-0.113 \\
(0.26)\end{array}$ \\
\hline ...rain within the next week & $\begin{array}{c}-0.091 * \\
(0.01)\end{array}$ & $\begin{array}{c}-0.11^{*} \\
(0.00)\end{array}$ & $\begin{array}{c}-0.11^{*} \\
(0.00)\end{array}$ & $\begin{array}{l}-0.105 \\
(0.29)\end{array}$ & $\begin{array}{c}-0.186 \\
(0.06)\end{array}$ & $\begin{array}{c}-0.36^{*} \\
(0.00)\end{array}$ \\
\hline ...rain within the next month & $\begin{array}{c}-0.096^{*} \\
(0.00)\end{array}$ & $\begin{array}{c}-0.16^{*} \\
(0.00)\end{array}$ & $\begin{array}{l}-0.17^{*} \\
(0.00)\end{array}$ & $\begin{array}{l}-0.114 \\
(0.25)\end{array}$ & $\begin{array}{l}-0.185 \\
(0.06)\end{array}$ & $\begin{array}{l}-0.30^{*} \\
(0.00)\end{array}$ \\
\hline
\end{tabular}

Nevertheless, the third - and pessimistic - reason that can be brought forward is best put in the words of Mohan Onteddu, employee of BASIX India, whom I would like to thank for going back to the farmers to discuss this finding first-hand: "Rural Indians' immediate response to any such surveys is that they try to tell you that they are the most unfortunate people in the country. They express frustration in answering that whether it rains or not, their lives would not change." It is important to note that this statement is based on discussion with farmers and not landless labourers. Nevertheless, one should not neglect such opportunistic behaviour of respondents - like taking the opportunity to voice their exasperation.

A similar finding holds for the correlation between rain probabilities and probabilities of earning a certain threshold from dairy activities. As can be seen in Table $4.3 \mathrm{~b}$ lower threshold probabilities correlate significantly with rain within the next week and higher threshold probabilities with the likelihood of rain in the coming month. 
Table 4.3b: Correlations of Probabilities - Income from Dairy

\begin{tabular}{|c|c|c|c|c|c|c|}
\hline \multirow[b]{3}{*}{ probability of... } & \multicolumn{6}{|c|}{ Income from Dairy } \\
\hline & \multicolumn{3}{|c|}{ Full Sample } & \multicolumn{3}{|c|}{$\begin{array}{c}\text { Households that primarily buy } \\
\text { the fodder for their animals and } \\
\text { have also their own land }\end{array}$} \\
\hline & prob $>A$ & prob $>B$ & prob $>C$ & prob $>A$ & prob $>B$ & prob $>\mathrm{C}$ \\
\hline ...rain tomorrow & $\begin{array}{l}-0.035 \\
(0.43) \\
\end{array}$ & $\begin{array}{c}-0.004 \\
(0.92) \\
\end{array}$ & $\begin{array}{r}-0.025 \\
(0.57) \\
\end{array}$ & $\begin{array}{l}0.47^{*} \\
(0.00)\end{array}$ & $\begin{array}{c}0.379^{*} \\
(0.00)\end{array}$ & $\begin{array}{l}0.146 \\
(0.29) \\
\end{array}$ \\
\hline ...rain within the next week & $\begin{array}{c}-0.09 * \\
(0.04) \\
\end{array}$ & $\begin{array}{c}-0.01 * \\
(0.02) \\
\end{array}$ & $\begin{array}{r}-0.073 \\
(0.10) \\
\end{array}$ & $\begin{array}{l}0.198 \\
(0.15) \\
\end{array}$ & $\begin{array}{c}0.185 \\
(0.18) \\
\end{array}$ & $\begin{array}{c}0.183 \\
(0.18) \\
\end{array}$ \\
\hline ...rain within the next month & $\begin{array}{c}-0.005 \\
(0.92)\end{array}$ & $\begin{array}{c}-0.10^{*} \\
(0.03)\end{array}$ & $\begin{array}{c}-0.07 * \\
(0.03)\end{array}$ & $\begin{array}{l}0.257 \\
(0.06)\end{array}$ & $\begin{array}{l}0.234 \\
(0.09)\end{array}$ & $\begin{array}{l}0.223 \\
(0.10)\end{array}$ \\
\hline
\end{tabular}

Again, the correlations are negative. This negative correlation does not mean that the rain reduces income from dairy - which would be a hypothesis difficult to defend. The explanation lies in a major factor of risk that cattle owners face - availability of fodder. It is not uncommon for landless households to turn to animal husbandry - most of these depend on fodder that they collect on other people's land or, if they can afford it, on fodder that they buy. The right panel in Table $4.3 \mathrm{~b}$ again shows the same correlation for a sub-set, namely for those households that buy at least some of their fodder and at the same time own agricultural land. For these, the correlation is positive and only significant with probability of rain tomorrow. These are households that own their own land. Rain increases the availability of quality fodder on their own land so that they can feed their animals with this. This puts landless households in the need to find another source of fodder for their animals.

And, finally the correlations of rain probabilities and the probabilities of having to pay a certain amount on animal health costs. As before, some negative and significant correlations are found. These are driven by cost expectations from households that derive income from selling milk - and not from households that only own non-milk cattle (as can be seen in the right panel of Table 4.3c). As will be shown later, the expected costs incorporate expected foregone earnings so that the significant positive correlations are in line with the results on correlations found when looking at expected income from dairy as just discussed.

Taking the negligible percentage of logical response error, the sensible pattern of probabilities for different thresholds, and the expected correlations between stated probabilities, one can be relatively certain that the answers provided conform to the basic laws of probability and that respondents did not give random answers for the sake of answering. 
Table 4.3c: Correlations of Probabilities - Animal Health Costs

\begin{tabular}{|c|c|c|c|c|c|c|}
\hline \multirow[b]{3}{*}{ probability of... } & \multicolumn{6}{|c|}{ Animal Health Costs } \\
\hline & \multicolumn{3}{|c|}{ Full Sample } & \multicolumn{3}{|c|}{$\begin{array}{c}\text { Households that do not derive } \\
\text { income from selling milk }\end{array}$} \\
\hline & prob $>A$ & prob $>A$ & prob $>A$ & prob $>A$ & prob $>B$ & prob $>C$ \\
\hline ...rain tomorrow & $\begin{array}{l}-0.032 \\
(0.44)\end{array}$ & $\begin{array}{l}-0.015 \\
(0.71)\end{array}$ & $\begin{array}{l}-0.020 \\
(0.62)\end{array}$ & $\begin{array}{l}-0.037 \\
(0.75)\end{array}$ & $\begin{array}{l}-0.005 \\
(0.97)\end{array}$ & $\begin{array}{l}-0.028 \\
(0.81)\end{array}$ \\
\hline ...rain within the next week & $\begin{array}{l}0.122^{*} \\
(0.00)\end{array}$ & $\begin{array}{l}0.129^{*} \\
(0.00)\end{array}$ & $\begin{array}{l}0.105^{*} \\
(0.01)\end{array}$ & $\begin{array}{l}-0.14 \\
(0.23)\end{array}$ & $\begin{array}{l}-0.104 \\
(0.37)\end{array}$ & $\begin{array}{r}-0.131 \\
(0.26)\end{array}$ \\
\hline ...rain within the next month & $\begin{array}{l}0.140^{*} \\
(0.00)\end{array}$ & $\begin{array}{l}0.122^{*} \\
(0.00)\end{array}$ & $\begin{array}{l}0.066 \\
(0.11)\end{array}$ & $\begin{array}{l}-0.153 \\
(0.19)\end{array}$ & $\begin{array}{l}-0.137 \\
(0.24)\end{array}$ & $\begin{array}{r}-0.172 \\
(0.14)\end{array}$ \\
\hline
\end{tabular}

\subsection{Fitting a Subjective Income Distribution}

The above conclusion allows interpreting answers to the percentage chance questions as points on the subjective cumulative distribution function of future household income (dairy income and medical expenses respectively).

One can hence fit a respondent-specific subjective income (cost) distribution, which can then be used to analyze how income (cost) expectations vary with respondents' realized income (cost).

This study assumes a piece-wise uniform probability distribution and focuses on the means and standard deviations of these distributions. Other, more complicated distribution functions can be thought of. Dominitz and Manski (1997) for example assume a log-normal income distribution fitted via non-linear least squares. The three probabilities elicited from each respondent are not sufficient to determine which distribution most closely describes the shape of the respondent's subjective outcome distribution. Therefore, the piece-wise uniform distribution was chosen and can, if need be, interpreted as an approximation to more complex distributions.

Table 4.4a shows the average probabilities assigned by respondents for the four sections of the expected household income distribution. The first block gives statistics for the whole sample. Below, the sample is divided into respondents for whom one source of overall income is dairy activities and into respondents who do not get income from selling milk products. The former are labelled 'DI' (=Respondents with Dairy Income) and the latter 'no DI'. 
Table 4.4a: Probabilities Assigned to Sections of Income Distribution

\begin{tabular}{|c|c|c|c|c|c|c|c|}
\cline { 3 - 8 } \multicolumn{2}{c|}{} & \multicolumn{7}{|c|}{ Income } \\
\cline { 2 - 8 } \multicolumn{1}{c|}{} & obs & min & max & median & mean & sd \\
\hline \hline \multirow{4}{*}{ Total } & Min - LQ & 1005 & 0 & 50 & 10 & 16.13 & 8.48 \\
\cline { 2 - 8 } & LQ - Midpoint & 1005 & 10 & 60 & 30 & 30.81 & 8.28 \\
\cline { 2 - 8 } & Midpoint - UQ & 1005 & 0 & 57 & 30 & 26.11 & 6.87 \\
\cline { 2 - 8 } & UQ - Max & 1005 & 0 & 70 & 30 & 26.95 & 9.71 \\
\hline \multirow{4}{*}{ DI } & Min - LQ & 550 & 0 & 40 & 10 & 15.45 & 8.06 \\
\cline { 2 - 8 } & LQ - Midpoint & 550 & 10 & 60 & 30 & 30.93 & 8.57 \\
\cline { 2 - 8 } & Midpoint - UQ & 550 & 0 & 57 & 30 & 26.14 & 7.16 \\
\cline { 2 - 8 } & UQ - Max & 550 & 0 & 70 & 30 & 27.49 & 10.17 \\
\hline \multirow{4}{*}{ No DI } & Min - LQ & 455 & 10 & 50 & 10 & 16.96 & 8.89 \\
\cline { 2 - 8 } & LQ - Midpoint & 455 & 10 & 50 & 30 & 30.67 & 7.93 \\
\cline { 2 - 8 } & Midpoint - UQ & 455 & 10 & 50 & 30 & 26.08 & 6.51 \\
\cline { 2 - 7 } & UQ - Max & 455 & 10 & 60 & 25 & 26.30 & 9.09 \\
\hline \multirow{2}{*}{$\begin{array}{l}\text { Notes: "DI" are all respondent households that receive income from dairy. "No DI" } \\
\text { are all households receiving income from other sources only. }\end{array}$} \\
\hline
\end{tabular}

Consistently for both of these groups, the first section (Minimum expected income, Min, to the lower quartile, LQ) has the lowest mean (and median) probability and the second section (Lower Quartile, LQ, to the midpoint) the highest. Income appears slightly right skewed, while the probabilities of the two intervals among the midpoint add up to the highest value (around 57 per cent). Figure 4.1a gives an idea of the average individual income distribution derived from the answers to the expectations questions.

Figure 4.1a: The Piece-wise Uniform Distribution - Household Income

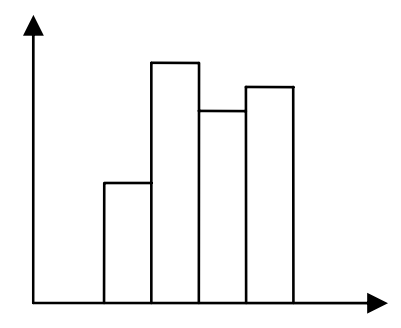

The average probabilities assigned to the sections of the Dairy Income distributions (as displayed in Table 4.3b) follow a similar pattern. As in the case of overall income, one finds all the section LQ-Midpoint to have the highest probabilities and the first interval (Min-LQ) to consistently have the lowest probability; although the latter probabilities are higher than the ones for the overall income distribution. Also, dairy income seems to be slightly right skewed, although somewhat less than overall household income. Numbers are reported in Table $4.4 \mathrm{~b}$. 
Table 4.4b: Probabilities Assigned to Sections of Dairy Income and Medical Cost Distributions

\begin{tabular}{|l|c|c|c|c|c|c|c|}
\cline { 3 - 8 } \multicolumn{2}{c|}{} & obs & min & max & median & mean & sd \\
\hline \hline \multirow{3}{*}{ Dairy Income } & Min - LQ & 562 & 0 & 60 & 10 & 17.48 & 9.40 \\
\cline { 2 - 8 } & LQ - Midpoint & 562 & 10 & 50 & 30 & 30.12 & 8.47 \\
\cline { 2 - 8 } & Midpoint - UQ & 561 & 10 & 50 & 30 & 25.91 & 6.84 \\
\cline { 2 - 8 } & UQ - Max & 561 & 2 & 60 & 25 & 26.44 & 8.79 \\
\hline \multirow{3}{*}{$\begin{array}{l}\text { Eedical } \\
\text { Expenses }\end{array}$} & Min - LQ & 604 & 0 & 100 & 20 & 33.31 & 30.39 \\
\cline { 2 - 8 } & LQ - Midpoint & 604 & 0 & 60 & 30 & 25.51 & 13.57 \\
\cline { 2 - 8 } & Midpoint - UQ & 604 & 0 & 50 & 20 & 20.99 & 10.91 \\
\cline { 2 - 8 } & UQ - Max & 604 & 0 & 50 & 20 & 20.19 & 11.79 \\
\hline
\end{tabular}

The distribution of expected Medical (Health) Costs exhibits a greater right-skewness than the expected income distributions. The average probability of the first interval (Min-LQ) has the highest probability among the four intervals, followed by the interval LQ-Midpoint, as depicted in Table $4.3 \mathrm{~b}$. The remaining probability is distributed equally over the upper half of the distribution. This right-skewness of the distribution stems from the fact that many observations ( $11 \%$ of the overall sample, $17 \%$ of respondents owning cattle) do not expect any expenditures for their animals' health. The Rural Development Trust (RDT) operates in many of the survey villages, an NGO that among others offers free health services (including emergency services) for livestock. Therefore, villagers can be sure that, even if their animal falls ill, they will not have to pay for the needed services. Note that when excluding these observations- as in the case of income - one observes the first interval (Min-LQ) to have the lowest and the second interval (LQ-Midpoint) to have the highest probabilities. A typical individual specific distribution of expected medical expenses for the animal (including observations that expect zero costs) is depicted in Figure 4.1b.

Figure 4.1b: The Piece-wise Uniform Distribution-Medical Expenses

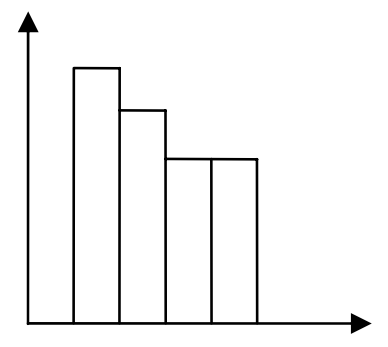

Based on the assumption of this piece-wise uniform distribution, means and standard deviations of the expected distributions of household income, income from selling milk and of medical expenses on cattle are derived. 
In what follows, these moments of expectations will be compared to realizations of the same variables.

\subsection{Simple comparison of expectations and realizations}

As already described above, expectations were elicited with respect to three outcome variables, namely total yearly household income, monthly income from dairy activities, and yearly medical costs for the owned animal(s).

More specifically, total household income is the sum of all income sources for the whole household of the respondent over the last year. The respondent was then asked whether this sum is his typical income and if not, what the typical income would be. In the analysis to follow, these variables will be referred to as 'last year's' and 'typical income'. A distinction is being made because one might expect typical income to be less noisy than last year's income. One might interpret typical income as representing the permanent component of income. Typical income was equal to last year's income for 48 per cent of the sample, higher for 35 per cent and lower for 18 per cent of respondents.

The same distinction between typical and last period was made for income from dairy. Typical health costs for the animal were not asked for. In additional to questions on medical expenses, respondents were asked about other losses they experienced due to the animal falling ill, such as foregone earnings or transport costs. A distinction is being made between purely 'medical' and 'full costs', the latter one including additional costs such as for transportation. Respondents were asked not to include dayto-day expenditures such as fodder.

All results presented are transformations of the variables. Given the skewedness of the data, overall household income was transformed using the Box-Cox power transformation $^{73}$, for income from dairy and medical expenses a log transformation with zero skewedness was applied. ${ }^{74}$ Note also that income is on a yearly and income from dairy on a monthly basis. Initially, both overall as well as dairy incomes were asked for on a monthly basis. Nevertheless, during piloting it was understood that respondents could most easily estimate their overall income on a yearly basis. This stems from the greatest part of respondents' income being from agriculture and hence strongly varying with harvesting seasons. In Table 4.5 it can be seen that for the whole sample on average $37 \%$ of overall income is from farm profit and 20 per cent from wages as agricultural labour.

\footnotetext{
${ }^{73}$ Transformed variable $T L=\left(\exp ^{\wedge} \mathrm{L}-1\right) / \mathrm{L}$, where $\mathrm{L}$ is chosen so that the TL exhibits a skewness of zero.

${ }^{74}$ Statistics of data in levels as well as in natural logarithms are available on request. So are statistics of income per household member as well as income from dairy and health costs per animal. As interpretations remain the same, only one set of results is presented.
} 
Table 4.5: Income from different sources as percentage of overall income

\begin{tabular}{|l|c|c|}
\hline INCOME SOURCE & mean & sd \\
\hline \hline Wages from non-agricultural sector - formal & 0.02 & 0.10 \\
\hline Wages from non-agricultural sector - informal & 0.01 & 0.06 \\
\hline Wages (possibly in-kind) from public relief work & 0.05 & 0.12 \\
\hline Non-farm self-employment (net-income) & 0.13 & 0.26 \\
\hline Farm profit & $\mathbf{0 . 3 7}$ & 0.31 \\
\hline Wages from agric. labor (not on own farm) & $\mathbf{0 . 2 0}$ & 0.25 \\
\hline Income from Dairy Activities & 0.16 & 0.21 \\
\hline \hline TOTAL & $\mathbf{0 . 9 4}^{75}$ & \\
\hline
\end{tabular}

Table 4.6 describes the household income variables concentrated on in this study. Looking at the empirical means and medians of the variables shows that the data consists of a sample of households that experienced a higher income in the previous year than they typically do and that they expect this increase to continue in the coming year. The mean of typical income is 71,184 Rupees (equivalent to approximately US\$ $1,820^{76}$ ), the mean of last year's income was slightly higher with 72,901 (US\$ 1,860 ) and the sample mean of expected income for the coming year is 73, 948 (US\$1,890). In levels, these differences are not statistically different. Realizations and expectations differ significantly when considering the box-cox transformation. ${ }^{77}$

The expected standard deviation of income indicates an overwhelming uncertainty in income, especially when considering the sample mean. As Dominitz (2001) points out, these means are sensitive to just a few outlying fitted expectations and can hence be misleading. The box-cox transformation is more robust to this type of measurement error and will hence be the focus of further analysis.

From the lower two panels of Table 4.6 as well as from Figure 4.2 one can see that respondent households who derive part of their income from selling milk had, typically have and also expect a significantly higher overall household income stream. In addition, their expected standard deviation in income is significantly lower for respondents who derive income from dairy than for those who do not. This lower expected standard deviation is also reflected in the smaller range between the average (and median) expected minimum and maximum incomes. As already explained in the introduction, this statistic provides a measure of idiosyncratic risk, something that cannot be extracted from the standard deviation of realized income. It gives a first indication that this income diversification strategy indeed helps in reducing volatility

\footnotetext{
${ }^{75}$ Remaining percentages are distributed among the following income sources: Sales of handicrafts or other non-agricultural, Traditional hereditary occupation, Migration income / remittances, Benefits from government schemes, Pensions, Dowry income, Other income sources (e.g. gambling)

${ }^{76}$ Doing simple calculations not adjusting for household composition but only for numbers of household members shows that the sample households typically live on just above one dollar a day (US\$ 1.05).

${ }^{77}$ With the log transformation, expectations do not differ from last year's income but do from typical income.
} 
in the overall household income stream - besides an increase in income, another major objective of the intervention.

Table 4.6: Summary Statistics for Household Income Variables

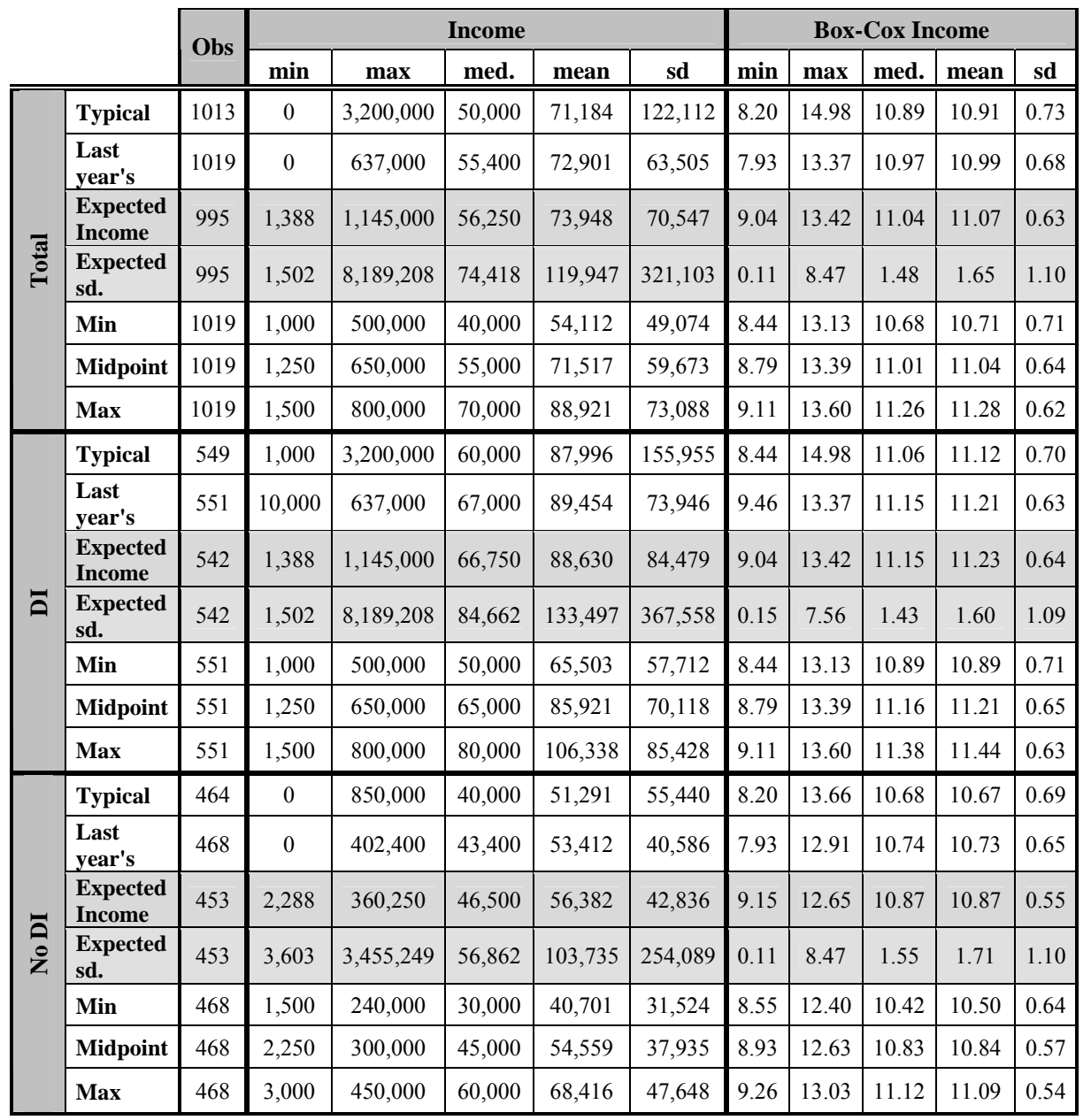


Figure 4.2: Typical, Last year's \& expected household income (total sample, DI \& No $D I)$
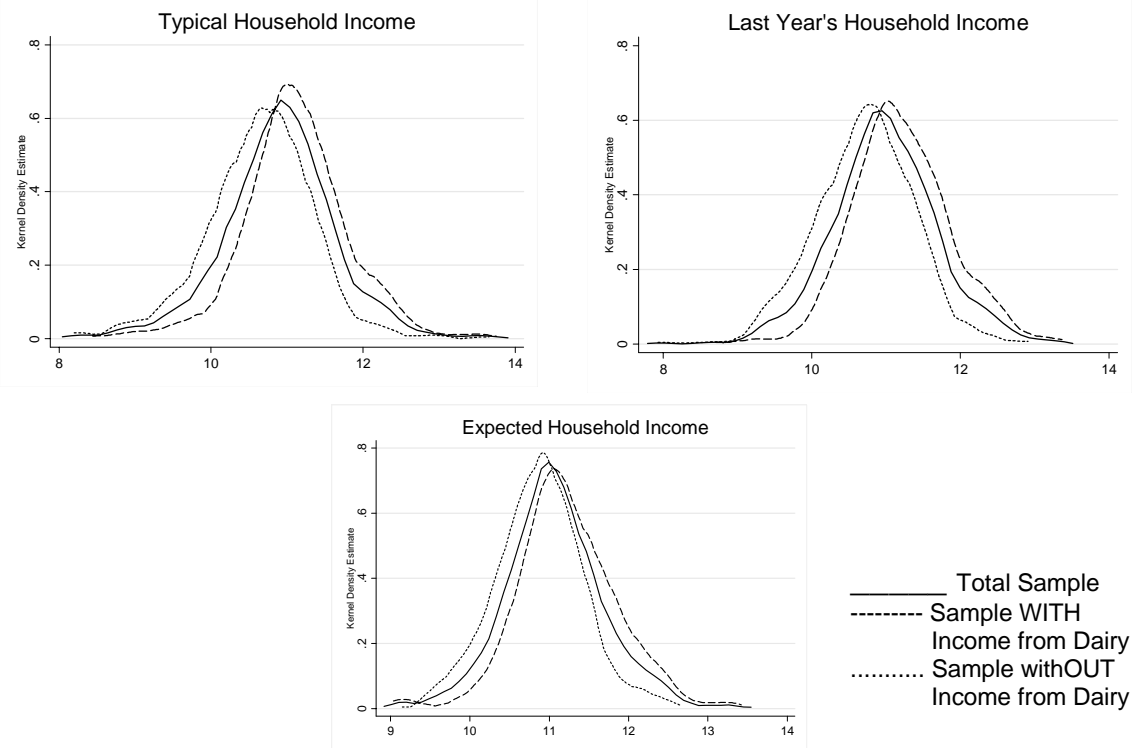

It is interesting to note that respondents who do not sell any products from milk cattle expect a much higher increase in their overall household income than the approximately other half of the sample as is depicted in Figure 4.3. The left graph shows typical, last year's and expected income for respondents with income from dairy and the right one for those without. This higher difference in expectations from realizations for the latter group is confirmed when testing for the difference in these variables to be zero. The t-statistics are above ten.

Figure 4.3: DI \& No DI (Typical, Last year's and expected household income)
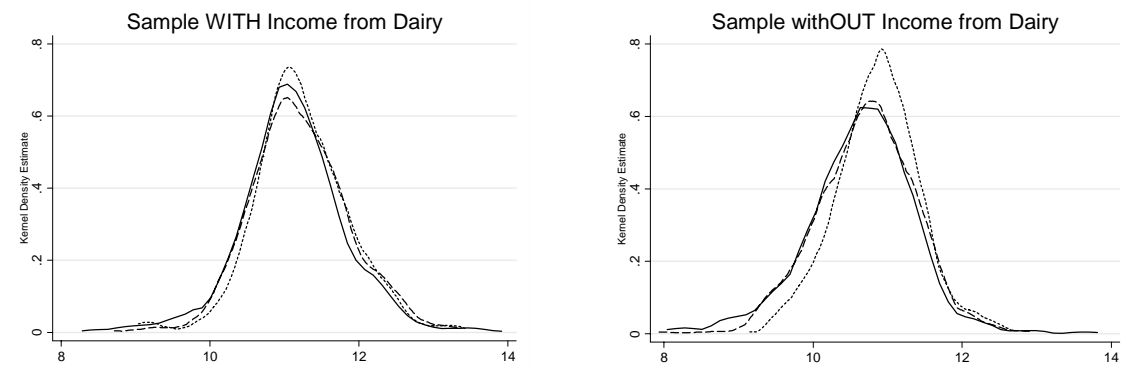

Typical Income

Last Year's Income

............ Expected Income 
It appears however that the expected increase in overall household income is not driven by an expected increase in income from dairy activities as depicted in Table 4.7. Considering the transformed variable of dairy income, less sensitive to outliers, mean expected income from dairy is slightly below last year's income but above the typical income. The difference between expectations and last year's income is insignificant though; the difference between typical and expected income on the other hand is significant.

Table 4.7: Summary Statistics for Dairy Income Variables

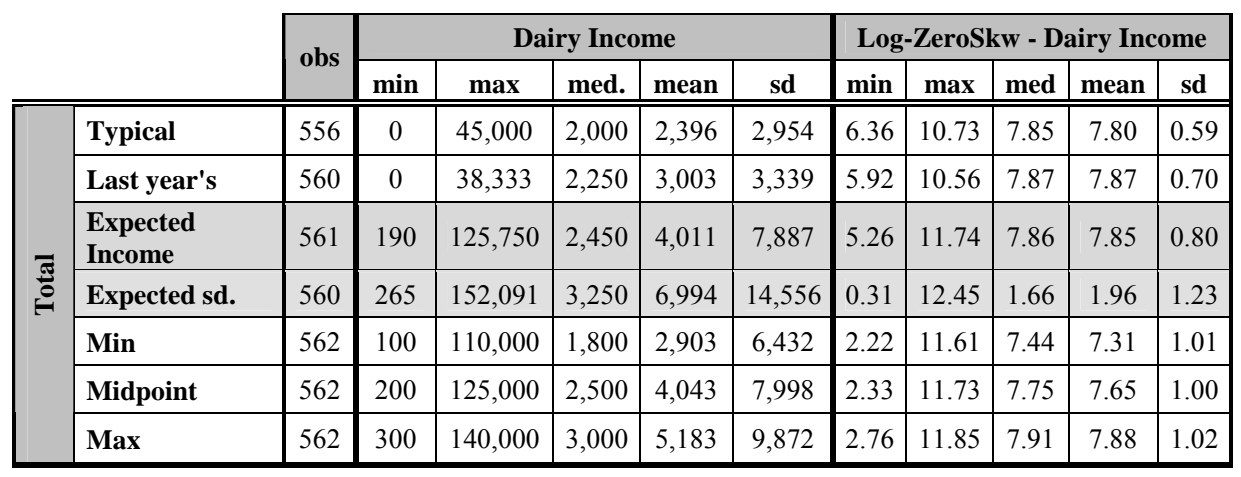

Table 4.8 shows summary statistics for experienced and expected veterinary expenses for the cattle owned. Respondents were asked to include in the expected health related expenditures possible transaction costs but to exclude day-to-day expenditures for the animal (such as fodder). This is reflected in a much closer mean as well as median of realized full costs to expected costs. These costs bear great uncertainty though, as reflected in high standard deviations as well as in considerably high expected standard deviations. Figure 4.4 graphs the variables. The first hump reflects customers that are able to make use of the free services offered by the non-governmental organisation RDT already mentioned before.

Table 4.8: Summary Statistics for Animal Health Costs

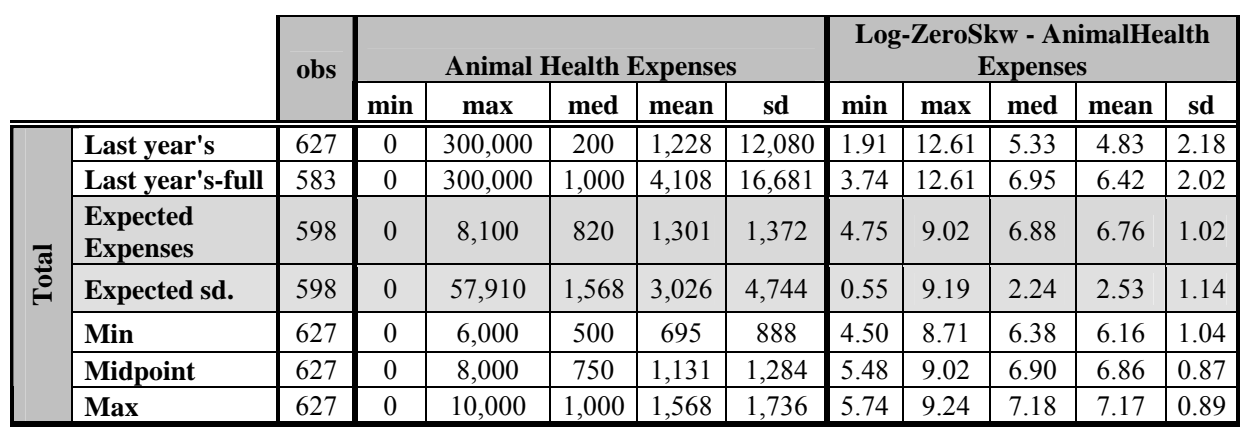




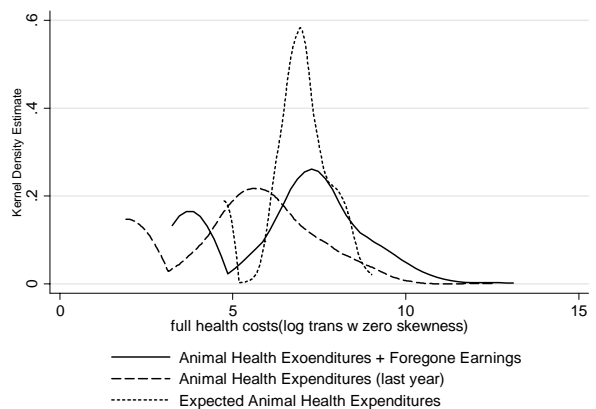

Finally, Figure 4.5 puts the three expectation distributions into relation. It can be seen that income from dairy bears a higher uncertainty than overall income, as reflected in a higher standard deviation of the distribution.

Figure 4.5: Expected Incomes and Costs

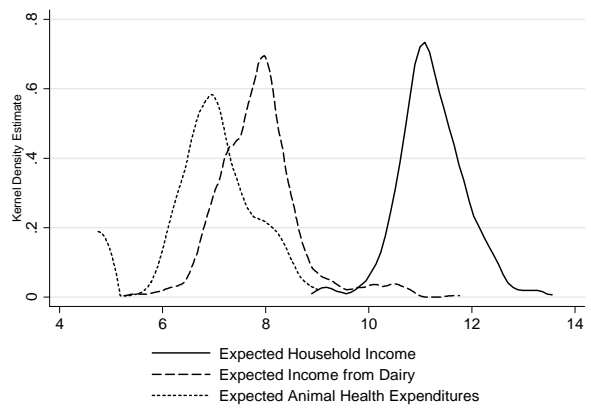

A finding of greatly differing realization and expectation distributions would have been no proof of expectation data being wrong, but finding them moving closely together can be seen as support for their validity. Comparing expectations and realizations implicitly assumes that observed behaviour of individuals is conditioned on expectations about future consequences of decisions. In other words, individuals act according to their beliefs and outcomes are contingent on the decisions taken. Their beliefs on the other hand depend on their experiences and hence on previous realizations. And, this latter dependence is expected to be especially dominant in an environment where income is very uncertain. These uncertainties emanate from various sources, but are especially noteworthy in the context of rural India, since climatic shocks can affect product prices and yields. In such contexts, where the livelihood of households depends heavily on sources they cannot control, last year's income might be the best predictor of future income.

The next section estimates a respondent's one year ahead expectations of income making use of expectations data available. The aim is to quantify the dependence of 
expectations on realizations and to relate the expected income distribution to a set of exogenous characteristics of the respondent households. It is of interest to see whether these relationships fit the predictions of theory.

\subsection{Empirical Predictions of income expectations - a time-series model}

The most common way of inferring an individual's expectation of future income is to estimate the relationship between income and characteristics from the previous year. Making assumptions on information available to the individual and how this information is used then allows making statements about expectations.

One would hence estimate a model such as the following:

$$
y_{t}^{i}=\alpha y_{t-1}^{i}+\beta x_{t-1}^{i}+u_{t}^{i},
$$

where $y$ is income, $x$ are individual or household characteristics, $\alpha$ and $\beta$ are unknown parameters and $u$ are idiosyncratic, mean zero, iid income innovations. Information on subjective uncertainty is typically inferred from the residual variance of realized income. If one is willing to assume that the stochastic component of first-differenced income follows a moving average process with heteroskedastic innovations, additional information on subjective uncertainty can be extracted from the squared residuals (note that this subjective uncertainty will be biased upwards if the individual possesses more information than the analyst in addition to the presence of a measurement error in income). It is common practice in the literature to either assume that the error of first-differenced (log) income follows such an MA(q) process or that the error of the equation estimated in levels, as given in (1), follows an AR(1) process.

This analysis will proceed without placing any structural assumptions on the error terms. Instead, elicited subjective expectations are used directly as the dependent variable in the model. Hence, instead of estimating (1), $y_{t}^{i}$ will be replaced by $\tilde{y}_{t}^{i}$, the tilde above the variable indicating subjective expectations. Equation (1) becomes:

$$
\tilde{y}_{t}^{i}=\alpha y_{t-1}^{i}+\beta x_{t-1}^{i}+\varepsilon_{t}^{i},
$$

Table 4.9 gives summary statistics for some of the explanatory variables used in the analysis. Statistics for the total sample is given and in addition a distinction between respondents who receive income from dairy and those that do not is made. The last column gives the t-statistic for the test of the difference in the mean of the two groups being zero.

A typical sample household consists of almost five members, belonging to the backward caste and engaging in agricultural labour as their primary activity. The 
household head is on average 44 years old, the spouse approximately seven years younger and in most cases, both have no formal education. In terms of household size, age and education, households seem not to differ, whether they engage in dairy as an income generating activity or not. Nevertheless, those that do engage in dairy activities seem to have a significantly higher consumption pattern, more engage in farming as their primary source of income and less belong to forward castes.

Table 4.9: Summary statistics of selected explanatory variables

\begin{tabular}{|l|c|c|c|c|c|c|c|c|c|c|}
\hline \multirow{2}{*}{ Variable } & \multicolumn{3}{|c|}{ Overall Sample } & \multicolumn{3}{c|}{ With Income from } & \multicolumn{3}{c|}{ No Income from } & \multirow{2}{*}{ ttest } \\
\cline { 2 - 12 } & med & mean & sd & med & mean & sd & med & mean & sd & \\
\hline \hline total consumption (log) & 11.01 & 11.02 & 0.54 & 11.08 & 11.12 & 0.51 & 10.92 & 10.90 & 0.55 & -6.48 \\
\hline food consumption (log) & 10.40 & 10.41 & 0.45 & 10.47 & 10.48 & 0.43 & 10.33 & 10.33 & 0.46 & -5.71 \\
\hline other nondurable cons (log) & 9.14 & 9.21 & 0.96 & 9.30 & 9.36 & 0.91 & 8.94 & 9.03 & 0.98 & -5.47 \\
\hline durable consumption (log) & 9.46 & 9.44 & 0.82 & 9.56 & 9.56 & 0.86 & 9.30 & 9.29 & 0.75 & -5.22 \\
\hline no. Of hh members & 4.00 & 4.73 & 1.72 & 5.00 & 4.80 & 1.70 & 4.00 & 4.65 & 1.74 & -1.45 \\
\hline caste: scheduled caste & 0.00 & 0.13 & 0.34 & 0.00 & 0.10 & 0.30 & 0.00 & 0.17 & 0.38 & 3.67 \\
\hline caste: scheduled tribe & 0.00 & 0.05 & 0.21 & 0.00 & 0.03 & 0.18 & 0.00 & 0.06 & 0.24 & 2.16 \\
\hline caste: backward & 0.00 & 0.49 & 0.50 & 0.00 & 0.44 & 0.50 & 1.00 & 0.54 & 0.50 & 2.99 \\
\hline caste: forward & 0.00 & 0.28 & 0.45 & 0.00 & 0.38 & 0.49 & 0.00 & 0.17 & 0.38 & -7.66 \\
\hline primary activity: farmer & 0.00 & 0.25 & 0.43 & 0.00 & 0.34 & 0.47 & 0.00 & 0.14 & 0.35 & -7.44 \\
\hline $\begin{array}{l}\text { primary activity: self- } \\
\text { employed }\end{array}$ & 0.00 & 0.06 & 0.24 & 0.00 & 0.03 & 0.18 & 0.00 & 0.09 & 0.29 & 4.08 \\
\hline $\begin{array}{l}\text { primary activity: } \\
\text { agricultural labour }\end{array}$ & 1.00 & 0.64 & 0.48 & 1.00 & 0.58 & 0.49 & 1.00 & 0.71 & 0.46 & 4.47 \\
\hline hhhead: age & 45.0 & 44.3 & 12.1 & 42.0 & 43.9 & 11.8 & 45.0 & 44.9 & 12.5 & 1.25 \\
\hline hhead: no education & 1.00 & 0.63 & 0.48 & 1.00 & 0.62 & 0.49 & 1.00 & 0.64 & 0.48 & 0.69 \\
\hline hhead: some primary educ. & 0.00 & 0.10 & 0.31 & 0.00 & 0.10 & 0.30 & 0.00 & 0.11 & 0.31 & 0.35 \\
\hline spouse: age & 35.0 & 36.9 & 11.1 & 35.0 & 36.7 & 10.9 & 35.0 & 37.2 & 11.4 & 0.73 \\
\hline spouse: no education & 1.00 & 0.69 & 0.46 & 1.00 & 0.70 & 0.46 & 1.00 & 0.68 & 0.47 & -0.48 \\
\hline spouse: some primary educ. & 0.00 & 0.07 & 0.26 & 0.00 & 0.07 & 0.26 & 0.00 & 0.08 & 0.26 & 0.01 \\
\hline
\end{tabular}

\subsubsection{Estimates from Expectations Data}

Least squares estimates of expected income (box-cox transformation) on realizations typical income, last year's income and both are presented in Table 4.10 respectively. Note that standard errors presented are clustered and bootstrapped to account for interclass correlation on the village level. ${ }^{78}$ Since explanatory variable data are drawn from respondents living in 67 different villages they exhibit a grouped structure. It is hence likely that errors of a regression model using the data are correlated within these groups $^{79}$ (see Moulton 1986 for a detailed analysis group effects on regression estimates).

\footnotetext{
${ }^{78}$ Nonparametric bootstrap with replacement is applied.

${ }^{79}$ For example a dummy indicator for a respondent that engages in dairy as an income-generating activity becomes insignificant when clustering the standard errors.
} 
It can be seen that both realization variables have a high explanatory power in determining expectations, last year's income more so than typical income. Both variables remain significant when included in the model together. The subjective mean increases strongly with typical and more so with last year's income.

Table 4.10: Least Square Estimates of expected income conditional on realizations

\begin{tabular}{|c|c|c|c|c|c|c|c|c|c|}
\hline \multirow{2}{*}{$\begin{array}{l}\text { Regress: Expected } \\
\text { box-cox (bc) income } \\
\text { on: }\end{array}$} & \multicolumn{3}{|c|}{$(9-1)$} & \multicolumn{3}{|c|}{$(9-2)$} & \multicolumn{3}{|c|}{$(9-3)$} \\
\hline & coeff & se & t-stat & coeff & se & t-stat & coeff & se & t-stat \\
\hline typical income (bc) & 0.67 & 0.04 & 15.57 & & & & 0.20 & 0.06 & 3.34 \\
\hline income last year (bc) & & & & 0.80 & 0.02 & 44.89 & 0.63 & 0.06 & 10.48 \\
\hline Constant & 3.75 & 0.49 & 7.72 & 2.32 & 0.20 & 11.88 & 1.99 & 0.17 & 11.55 \\
\hline Adj. R2 & 0.63 & & & 0.775 & & & 0.80 & & \\
\hline
\end{tabular}

Table 4.11 shows results of the above regressions, accounting additionally for yearly household consumption expenditures. Consumption expenditures are divided into three categories: food consumption (including the market value of home-produced food), other non-durable consumption (including for example alcohol and tobacco, transport costs and water/electricity bills) and durable consumption. The consumption variables on their own are all significant in determining income expectations. Durable consumption becomes insignificant when typical income is accounted for, which especially seems a sensible finding when interpreting typical income as the permanent component of income. All consumption variables lose their explanatory power once last year's income is accounted for in the model. What can be concluded from these results is that consumption variables seem to do badly as a proxy for typical income. As before, presented standard errors are clustered and bootstrapped.

Table 4.11: Estimates of expected income conditional on realizations and consumption

\begin{tabular}{|c|c|c|c|c|c|c|c|c|c|c|c|c|}
\hline \multirow{2}{*}{$\begin{array}{c}\text { Regress: } \\
\text { Expected box-cox } \\
\text { income on: } \\
\end{array}$} & \multicolumn{3}{|c|}{$(10-1)$} & \multicolumn{3}{|c|}{$(10-2)$} & \multicolumn{3}{|c|}{$(10-3)$} & \multicolumn{3}{|c|}{$(10-4)$} \\
\hline & Coef & se & t-stat & Coef & se & t-stat & Coef & se & t-stat & Coef & se & t-stat \\
\hline typical income & & & & 0.67 & 0.05 & 14.00 & & & & 0.20 & 0.06 & 3.57 \\
\hline income last year & & & & & & & 0.79 & 0.02 & 32.91 & 0.63 & 0.06 & 10.81 \\
\hline food consumption & -0.36 & 0.11 & -3.27 & -0.20 & 0.05 & -3.96 & -0.03 & 0.05 & -0.56 & -0.06 & 0.04 & -1.59 \\
\hline $\begin{array}{l}\text { other nondurable } \\
\text { cons }\end{array}$ & 4.85 & 0.85 & 5.74 & 0.95 & 0.39 & 2.44 & 0.47 & 0.54 & 0.87 & 0.41 & 0.37 & 1.10 \\
\hline durable cons. & 0.55 & 0.22 & 2.46 & 0.10 & 0.12 & 0.86 & 0.06 & 0.11 & 0.56 & 0.00 & 0.10 & -0.03 \\
\hline No. of Obs. & 992 & & & 986 & & & 992 & & & 986 & & \\
\hline Wald Chi (.) & 52.4 & & & 476 & & & 2253 & & & 2902 & & \\
\hline Adj. R2 & 0.09 & & & 0.63 & & & 0.77 & & & 0.80 & & \\
\hline
\end{tabular}

Estimates of an extended model, including a number of attributes of the respondent, as presented in Table 4.12, some of which were already presented in Table 4.8 and 
briefly discussed. ${ }^{80}$ In addition to those, information on housing, asset ownership, credit and debit sources and experienced risk is included. In line with the previously presented results, two models are shown. The first one (11-1) includes only last year's income and the second one (11-2) last year's income as well as typical income.

Table 4.12: Least Square Estimates of expected income-extended model

\begin{tabular}{|c|c|c|c|c|c|c|}
\hline \multirow{2}{*}{ Regress: Expected income on: } & \multicolumn{3}{|c|}{$(11-1)$} & \multicolumn{3}{|c|}{$(11-2)$} \\
\hline & coeff. & se & t-stat. & coeff. & se & t-stat. \\
\hline typical income (box-cox) & & & & 0.233 & 0.059 & 3.970 \\
\hline income last year (box-cox) & 0.763 & 0.018 & 41.920 & 0.561 & 0.059 & 9.580 \\
\hline caste: scheduled caste & -0.062 & 0.025 & -2.440 & -0.062 & 0.023 & -2.660 \\
\hline hh head: age2 & 0.000 & 0.000 & -0.970 & 0.000 & 0.000 & -1.780 \\
\hline hh head: some prim education & 0.015 & 0.025 & 0.610 & 0.024 & 0.022 & 1.100 \\
\hline spouse: age & -0.004 & 0.002 & -1.700 & -0.003 & 0.002 & -1.790 \\
\hline spouse:age2 & 0.000 & 0.000 & 1.840 & 0.000 & 0.000 & 2.550 \\
\hline spouse: no education & 0.038 & 0.027 & 1.400 & 0.030 & 0.026 & 1.170 \\
\hline spouse: some second. education & -0.055 & 0.045 & -1.210 & -0.061 & 0.041 & -1.490 \\
\hline primary activity 1 : farmer & 0.072 & 0.026 & 2.750 & 0.062 & 0.023 & 2.660 \\
\hline primary activity 2 : farmer & 0.043 & 0.023 & 1.830 & 0.034 & 0.020 & 1.660 \\
\hline primary activity 1 : self-employed & 0.118 & 0.040 & 2.920 & 0.081 & 0.029 & 2.760 \\
\hline Floor material: Tiles & 0.195 & 0.051 & 3.840 & 0.211 & 0.050 & 4.200 \\
\hline Floor material: Stone & 0.134 & 0.038 & 3.510 & 0.173 & 0.038 & 4.560 \\
\hline Floor material: mud/cow-dung & 0.079 & 0.034 & 2.340 & 0.111 & 0.032 & 3.520 \\
\hline bathing facility: closed in/outside house & -0.066 & 0.020 & -3.360 & -0.029 & 0.022 & -1.340 \\
\hline no. of bicycles owned & -0.018 & 0.017 & -1.030 & -0.015 & 0.016 & -0.980 \\
\hline no. of motorcycles owned & 0.077 & 0.025 & 3.080 & 0.061 & 0.025 & 2.470 \\
\hline no. of Radios owned & 0.088 & 0.047 & 1.860 & 0.075 & 0.040 & 1.870 \\
\hline no. of Sewing Machines owned & -0.071 & 0.034 & -2.090 & -0.047 & 0.028 & -1.670 \\
\hline no. of Clocks owned & 0.087 & 0.038 & 2.320 & 0.096 & 0.029 & 3.310 \\
\hline no. of Steel utensils owned & 0.013 & 0.009 & 1.490 & 0.051 & 0.016 & 3.200 \\
\hline no. of Irrigation equipment owned & -0.027 & 0.027 & -0.990 & -0.038 & 0.022 & -1.760 \\
\hline Meals of adults cut In last year $(\mathrm{y} / \mathrm{n})$ & -0.324 & 0.121 & -2.670 & -0.162 & 0.038 & -4.250 \\
\hline risk experienced: illness & 0.034 & 0.018 & 1.870 & 0.032 & 0.016 & 1.980 \\
\hline Credit from Public Sector Bank (y/n) & 0.055 & 0.017 & 3.170 & 0.049 & 0.017 & 2.890 \\
\hline Credit from SHG & -0.061 & 0.030 & -2.000 & -0.037 & 0.032 & -1.160 \\
\hline Credit from Relatives/Friends & 0.009 & 0.065 & 0.140 & 0.087 & 0.044 & 1.980 \\
\hline Deposit with Post Office (y/n) & -0.095 & 0.051 & -1.870 & -0.086 & 0.046 & -1.880 \\
\hline Deposit with SHG & 0.056 & 0.019 & 2.980 & 0.050 & 0.016 & 3.040 \\
\hline Constant & 2.460 & 0.201 & 12.250 & 2.027 & 0.185 & 10.970 \\
\hline No. of Obs. & 971 & & & 965 & & \\
\hline Wald Chi (29) & 7923 & & & 7621 & & \\
\hline Adj R2 & 0.819 & & & 0.850 & & \\
\hline
\end{tabular}

As before, the subjective mean increases significantly with realized income. The dependence is quantitatively smaller though once conditioning on other explanatory variables.

\footnotetext{
${ }^{80}$ Descriptive statistics of these variables are included in the Appendix 6.A-1 and 6.A-2 of the fifth chapter.
} 
And, conditional on realizations, the increase is higher when the household head has some primary education (remember that most of those respondents without primary education have no and not more education). A somewhat surprising finding is the fact that expected income increases when the spouse has no education, all else equal.

Furthermore, the availability and use of the credit and savings market is considered. These play a crucial role through their direct effect on asset accumulation. The use of investment assets helps to generate income and to smooth consumption. It can be seen that the income expected by respondents who borrow from a formal source and that are able to receive credit from friends or relatives, both seen as safe and relatively inexpensive credit sources, are positively influenced. Respondents that borrowed money from Self-Help-Groups (as well as from moneylenders, but this estimate was insignificant) on the other hand have lower expected income, all else equal.

In terms of savings, estimates on two sources are presented - deposits with a post office and deposit with SHGs, both saving sources that the better-off part of the population would typically not turn to. The coefficient on savings with a post office is (while insignificant) negative and the one for SHGs positive. This can be related to the fact that SHGs offer loans. Members might hence anticipate being able to borrow in the future and translate this into a positive outlook on their expected income.

\subsection{Is engaging in Dairy Welfare Improving?}

Before concluding, this section again turns to the distinction of having income from dairy or not. The question of concern is whether the livelihood strategy of adopting dairy as an extra-income generating activity can indeed be placed higher in a welfare ranking. A stochastic dominance ordering is applied to the strategy specific income distributions in order to answer this question. More specifically, the focal point of the analysis is the (Generalized) Lorenz Curve. ${ }^{81}$ In line with the previous analysis the realized as well as expected income distributions are looked at.

The concept is hence extremely appropriate in the setting at hand: Two groups are compared, one of which engages in dairy as an extra-income generating activity, while the other one does not. Given that this activity is highly promoted by the state as a welfare improving activity, the concept's property of giving a welfare ranking through information on inequality is suitable. Secondly, given that those households that

\footnotetext{
${ }^{81}$ The Lorenz curve shows the cumulative distribution of income against the cumulative frequency distribution of households earning this amount of income. Comparing this concentration of ownershipcurves of different groups in the society gives insight into which group exhibits greater inequality. A clear statement can be made when the curve of one group (A) lies above the curve of the other group everywhere (B). In such a situation A is said to Lorenz dominate B. This idea of Lorenz Dominance is equivalent with the concept of second order stochastic dominance; a stochastic dominance rule giving a partial ordering of a set of alternative investments.
} 
engage in the activity made an investment into a milk animal, calls for the concept's property of ordering alternative investments.

Figure 4.6a displays the Lorenz curve for households with income from dairy (dashed line) and those without (solid line). The curve for the population with income from dairy lies above the curve of the one without until a population share of about 55 per cent and below thereafter. Given that the two distributions cross and the way they cross it is very difficult to gauge which one of the two displays greater inequality.

\section{Figure 4.6a: Lorenz Curve (Realized and Expected Household Income, by having income from dairy or not)}

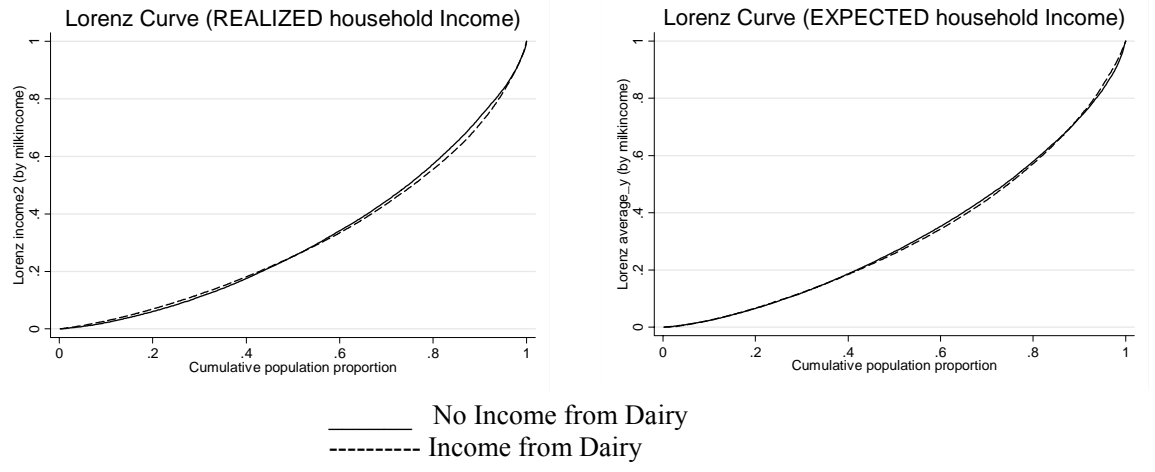

According to Shorrocks and Foster (1987), one can turn to the coefficient of variation in such a situation. If and only if the coefficient of variation for the with-milk-income distribution is smaller than the one for the without milk-income distribution can one conclude that the distribution of income for household that engage in milk-selling is more equal. As can be seen from Table 4.13, the coefficient of variation is slightly lower in the Dairy-Income distribution. Also the Gini Coefficient is slightly (but insignificantly) lower.

Table 4.13: Inequality Measures

\begin{tabular}{|l|c|c|c|c|}
\hline \multirow{2}{*}{ Inequality Measure } & \multicolumn{2}{|c|}{ Income } & \multicolumn{2}{c|}{ Expected Income } \\
\cline { 2 - 5 } & DI & No DI & DI & No DI \\
\hline \hline relative mean deviation & 0.26 & 0.26 & 0.26 & 0.25 \\
\hline coefficient of variation & 0.72 & 0.77 & 0.71 & 0.76 \\
\hline standard deviation of logs & 0.64 & 0.70 & 0.75 & 0.68 \\
\hline Gini coefficient & 0.36 & 0.37 & 0.36 & 0.35 \\
\hline \hline $\begin{array}{l}\text { Notes:'DI' stands for respondents who derive income from dairy, 'No DI' are } \\
\text { respondent who derive from other sources only. }\end{array}$
\end{tabular}

Since the differences are still quite small - especially when considering expectations an alternative representational tool is turned to. Instead of considering inequality one can look at social welfare. This can be done by scaling the Lorenz Curve by mean 
income at each point, which is called the Generalized Lorenz Curve. These are displayed in Figure 4.6b below.

Here, the picture is very clear, for realizations as well as expectations: the distribution of income from households that sell milk lies everywhere closer to the $45^{\circ}$ line than the one of households that do not get income from selling milk products. This result implies that the livelihood strategy of diversifying income into dairy $2^{\text {nd }}$ order stochastically dominates not engaging in dairy. From a welfare perspective this is the preferred strategy, social welfare being improved due to this activity.

Figure 4.6b: Generalized Lorenz Curve (Realized and Expected Household Income, by having income from dairy or not)
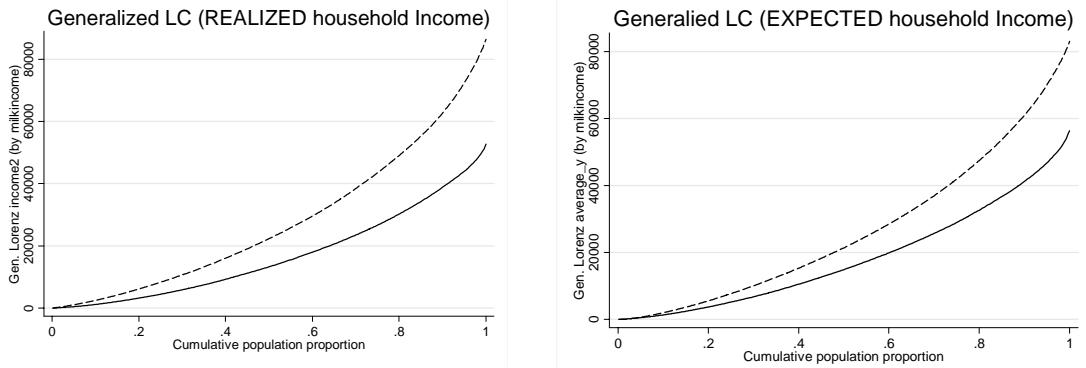

No Income from Dairy Income from Dairy

\subsection{Conclusion}

For approximately two thirds of the Indian population, land and livestock are the major assets of livelihood support. Low levels of these assets in combination with a low return and high uncertainty are the main sources of poverty within the country, which today stands at almost thirty per cent of the population. The challenges lie in reducing these people's vulnerability and in increasing their opportunities through strategies that fit within the prevailing system.

Several empirical studies provide evidence that it is the livestock sector that can offer such opportunities rather than the land holdings. Ali (2007), Adams \& He (1005) and Birthal \& Singh (1995) for example show that the distribution of livestock is more equitable than the one of land so that livestock rearing reduces income and employment inequalities.

This chapter gives further empirical support to this claim by using unique data to analyse household income of rural poor in India, comparing those that engage in dairy as an extra income generating activity to those that do not receive income from this livelihood strategy. The households studied live in the second most drought prone area 
of India ${ }^{82}$ where diversification of income, away from pure dependence on the traditional primary activity of direct or indirect agriculture is seen as detrimental to lift people out of poverty. In line with previous studies, the Lorenz-curve analysis undertaken in this chapter, shows that the strategy of engaging in milk-selling as an (extra) income-generating activity is indeed welfare-improving in terms of households' income.

This welfare improvement evolves since households which derive part of their income from selling milk had, typically have and also expect a significantly higher overall household income stream and they furthermore experience lower uncertainty in their income streams.

This latter statement can be made despite dealing with cross-sectional data due to the information on subjective expectations that was specifically collected.

A thorough analysis of this data on subjective expectations is conducted in the first part of this chapter in order to be able to make inference on respondent's beliefs of what will happen to their income stream in the future. All validity checks give confidence in the answers provided conforming to the basic laws of probability and that the respondents did not give random answers for the sake of answering.

The result of decreased uncertainty gives an indication that this income diversification strategy indeed helps in reducing volatility in the overall household income stream and hence decreases vulnerability - besides an increase in income, another major objective of the intervention.

To gain further insight into factors that influence expectations and with that uncertainty, the expected income distribution is related to a set of exogenous characteristics of the respondent households in a time-series regression analysis. Estimated coefficients show that the subjective mean of expected future household income increases significantly with realized income. Tested explanatory variables for example include information on education as well as access to credit and saving services. It is found that education positively affects the level of expected income; as does access to formal credit and saving sources.

Overall, results from this chapter greatly support the idea that dairy as a livelihood strategy deserves much attention as a tool for poverty eradication. The following two chapters address this issue in more detail. An intervention in the dairy sub-sector by a microfinance institution is analysed and the main focus lies on quantifying the impacts experienced by the program participants.

\footnotetext{
${ }^{82}$ www.indiastat.com: Meteorological Data; Rainfall.
} 


\section{Appendix 4.A}

Tale 4.A1: Bunching of Percentages (Dairy Income and Health Costs)

\begin{tabular}{|c|c|c|c|c|c|c|}
\multicolumn{9}{c|}{ Dairy Income } \\
\cline { 2 - 7 } \multicolumn{2}{c|}{ thr A } & \multicolumn{2}{c|}{ thr B } & \multicolumn{2}{c|}{ thr C } \\
\cline { 2 - 7 } & No & $\%$ & No & $\%$ & No & $\%$ \\
\hline \hline $\mathbf{2}$ & & & & & 1 & 0.18 \\
\hline $\mathbf{3}$ & & & & & 1 & 0.18 \\
\hline $\mathbf{8}$ & & & & & 1 & 0.18 \\
\hline $\mathbf{1 0}$ & & & & & 22 & 3.92 \\
\hline $\mathbf{1 5}$ & & & & & 4 & 0.71 \\
\hline $\mathbf{2 0}$ & & & 1 & 0.18 & 240 & 42.78 \\
\hline $\mathbf{2 5}$ & & & & & 17 & 3.03 \\
\hline $\mathbf{3 0}$ & & & 7 & 1.25 & 184 & 32.8 \\
\hline $\mathbf{3 5}$ & & & 1 & 0.18 & 1 & 0.18 \\
\hline $\mathbf{4 0}$ & 1 & 0.18 & 59 & 10.5 & 76 & 13.55 \\
\hline $\mathbf{4 5}$ & & & 5 & 0.89 & & \\
\hline $\mathbf{5 0}$ & 3 & 0.53 & 306 & 54.45 & 12 & 2.14 \\
\hline $\mathbf{5 5}$ & & & 3 & 0.53 & & \\
\hline $\mathbf{6 0}$ & 21 & 3.74 & 150 & 26.69 & 2 & 0.36 \\
\hline $\mathbf{6 5}$ & 1 & 0.18 & 1 & 0.18 & & \\
\hline $\mathbf{7 0}$ & 92 & 16.37 & 25 & 4.45 & & \\
\hline $\mathbf{7 5}$ & 9 & 1.6 & & & & \\
\hline $\mathbf{8 0}$ & 146 & 25.98 & 4 & 0.71 & & \\
\hline $\mathbf{8 5}$ & 3 & 0.53 & & & & \\
\hline $\mathbf{9 0}$ & 279 & 49.64 & & & & \\
\hline $\mathbf{1 0 0}$ & 7 & 1.25 & & & & \\
\hline
\end{tabular}

\begin{tabular}{|c|c|c|c|c|c|c|}
\multicolumn{9}{c|}{ Health Costs } \\
\cline { 2 - 7 } \multicolumn{2}{c|}{ thr A } & \multicolumn{2}{c|}{ thr B } & \multicolumn{2}{c|}{ thr C } \\
\cline { 2 - 7 } & No & $\%$ & No & $\%$ & No & $\%$ \\
\hline \hline $\mathbf{0}$ & 111 & 17.7 & 111 & 17.7 & 111 & 17.7 \\
\hline $\mathbf{1 0}$ & & & & & 77 & 12.28 \\
\hline $\mathbf{1 5}$ & & & & & 12 & 1.91 \\
\hline $\mathbf{2 0}$ & & & 12 & 1.91 & 217 & 34.61 \\
\hline $\mathbf{2 5}$ & & & 1 & 0.16 & 1 & 0.16 \\
\hline $\mathbf{3 0}$ & 4 & 0.64 & 48 & 7.66 & 155 & 24.72 \\
\hline $\mathbf{3 5}$ & & & 1 & 0.16 & & \\
\hline $\mathbf{4 0}$ & 7 & 1.12 & 89 & 14.19 & 47 & 7.5 \\
\hline $\mathbf{5 0}$ & 28 & 4.47 & 244 & 38.92 & 7 & 1.12 \\
\hline $\mathbf{6 0}$ & 62 & 9.89 & 110 & 17.54 & & \\
\hline $\mathbf{6 5}$ & 1 & 0.16 & & & & \\
\hline $\mathbf{7 0}$ & 63 & 10.05 & 11 & 1.75 & & \\
\hline $\mathbf{8 0}$ & 135 & 21.53 & & & & \\
\hline $\mathbf{8 5}$ & 1 & 0.16 & & & & \\
\hline $\mathbf{9 0}$ & 210 & 33.49 & & & & \\
\hline $\mathbf{1 0 0}$ & 5 & 0.8 & & & & \\
\hline
\end{tabular}




\section{The impact of BASIX's Dairy intervention: Evidence from realized outcomes and expected returns to investment}

\subsection{Introduction}

"Credit is important for development. It capitalizes farmers and entrepreneurs to undertake new investments or adopt new technologies." (Khandker \& Faruquee, 2003) Nevertheless, a huge part of the population has no access to formal financial services. These are the poor - often also referred to as the 'unbankable': 'unbankable' in the sense that they are deemed to be too risky and too expensive to serve, having no collateral to offer, demanding very small loans, and often living in difficult to access areas.

As elaborated on in the introduction of the dissertation, such unmet demand in combination with new delivering technologies led to what is sometimes referred to as the "microfinance revolution", 83 , Unfortunately, it is estimated that still only 16 percent of those that could benefit - only one sixth of the three billion poor people of working age - have access to such formal financial services (CGAP, 2005).

Studies show that it is typically the very poor who are being left out of microfinance (Coleman, 1999, 2000). Such observations lead practitioners and academics alike to the realization that not only microcredit but also microfinance alone is not enough; that microfinance is not a replacement for jobs that are not there, education and skills that do not exist, or markets that are inaccessible.

A new approach to microfinance developed. It carries names such as 'holistic', 'integrated' or 'credit plus'. Typically, microfinance is combined with complementary services with the aim of having an impact on the lives and livelihoods of poor men, women and their families. Such holistic approaches are complex but more and more examples can be named. Common to all approaches is that complimentary services, such as informal training and business and financial management, evolve around the client and aim to develop practical and relevant skills and knowledge.

In India, the debate between minimalist credit and integrated sectoral promotion approaches began to converge in the 1990s, when Vijay Mahajan, founder of BASIX

\footnotetext{
${ }^{83}$ According to Robinson (2001) the term was coined by María Otero and Elisabeth Rhyne in 1993.
} 
India $^{84}$, together with Thomas Dichter stressed the importance of a holistic and indepth understanding of the interplay between economic, social and cultural layers of the developmental process. They initiated the debate and put their ideas into practice, making this more complex strategy to combat poverty as part of BASIX's mission. ${ }^{85}$ The way the institution proceeds is to conduct studies on sub-sectors with the goal of identifying constraints on low-income actors within the sector. An intervention is then designed that creates opportunities for these poor through credit, technical assistance and if necessary, the establishment of market linkages.

This chapter is concerned with a programme that puts this complex mission into practise. The way the delivering livelihood promotion institution under consideration in this study, BASIX India, proceeds is to conduct studies on sub-sectors with the goal of identifying constraints on low-income actors within the sector. An intervention is then designed that creates opportunities for these poor through credit, technical assistance and if necessary, the establishment of market linkages.

The sector analyzed here is the dairy sub-sector. The next section of this paper gives more details on the circumstances that made the organisation intervene in this specific sector and how their intervention is precisely designed, explaining the financial as well as non-financial components. In brief, households get access to loans to invest in a dairy animal - a buffalo or a cow. They have the option to buy insurance for the animal, to be trained in livestock rearing and to be visited regularly by a veterinarian. Where needed, the organisation established market linkages so that households can actually sell the milk their animal produces.

The intention of this chapter is to analyze the effect of this intervention on customers hence on households that borrowed from BASIX to invest in a dairy animal. Besides looking at more standard outcome indicators such as household income and consumption, investment specific returns - benefits as well as costs - are estimated. One of the innovative contributions of this study is the distinction between realized and expected returns. Primary data was collected that allows to construct moments of

\footnotetext{
${ }^{84}$ BASIX India is a new generation livelihood promotion institution in Hyderabad, India. It was established in 1996 and is one of the first institutions to follow the holistic approach, adopting it after an impact study conducted by Indian Market Research Bureau (IMRB). Assessing BASIX services revealed that about $52 \%$ of clients expressed a positive impact, $23 \%$ no change and approximately $25 \%$ reported decline in their income. Clients ascribed this decline to the presence of unmanaged risk. To address this, BASIX chose the strategy of offering programmes that combine aspects of Livelihood Financial Services (Savings, short and long-term Credit, Insurance - for lives and livelihoods, Fund transfers, Commodity Derivatives, Financial Orchestration - ranging from grants to equity for livelihoods), Institutional Development Services (Formation of producers' groups, federations, cooperatives, mutual benefits, etc., Capacity building, including entrepreneurship development.), and Agricultural/Business Development Services (Credit Productivity enhancement, Risk mitigation (non-insurance), Alternate Market Linkages - Input supply, output sales), the latter ones being the main interest of this study.

85 "BASIX mission is to promote a large number of sustainable livelihoods, including ones for the rural poor and women, through the provision of financial services and technical assistance in an integrated manner." (www.basixindia.com, accessed July 2008)
} 
expected future outcome variables with which this study can go a step further than a traditional impact evaluation study, namely estimating the subjective expected returns to investment.

A further contribution to the literature is made by estimating not only the effect of the intervention as a whole, but also the specific effect of additional services that the organisation offers alongside the loan - distinguishing between the financial and nonfinancial services. Estimates of the impact of such additional services hardly exist in the literature. Those microfinance impact studies that do exist focus almost exclusively on the effect of loans. If other services are being offered, then the effect of these is engulfed in the overall programme impact.

Two known exceptions are McKernan (2002) and Karlan \& Valdivia (2006). The former looks at the overall programme impact and also the non-credit effects of the programmes by controlling for the level of productive capital. These non-credit aspects are mainly the general training of the customer, including issues such as vocational training, information in areas of health and civil responsibilities and rights. McKernan (2002) finds these to have a positive impact on productivity. Karlan \& Valdivia (2006) assess the impact of business training on female microfinance clients in Peru. Applying a randomized control trial, they find a positive impact of training on business knowledge, practices and revenues. Additionally, the institution seems to benefit as well through improved repayment and client retention rates.

While also this study finds positive effects of the intervention and its components, these are not experienced by the customers where one would initially expect them most. In fact - cost reductions related to the investment are insignificant and income from the activity is estimated to be significantly lower than for the control group. Still, looking at other outcome indicators, it is concluded that the intervention plays a crucial role in consumption smoothing of the household and that it has the potential to lift customers above the poverty line. This effect is stronger for those customers who additionally have non-financial services. Also results on customers who have additional financial services (here livestock insurance) indicate that this service effectively insures household against the loss of their important asset, the milk-animal.

Despite having only cross-sectional data available, several indications are provided that support the hypothesis of the importance of taking a longer-term perspective. Such a positive outlook is also reflected in the beliefs of the customers as captured by the above mentioned expectation data.

The next section gives more detail on the intervention and its design. After a description of the methodology used, the treatment effects - experienced as well as perceived by the customers - are presented and the final section concludes. 


\subsection{The programme under consideration}

The programme under consideration is an intervention in the Indian dairy sub-sector offered by the livelihood promotion institution BASIX India. An analysis of the sector helped BASIX to identify an opportunity for an intervention that would favour the low-income producers.

In the late 1960s, the National Dairy Development Board (NDDB) had made extensive country-wise investments in basic infrastructure such as chilling centres, feederbalancing dairy plants, cattle-feed plants, and veterinary medicine and vaccine plants. Nevertheless, many of these had to be closed down due to low procurement. BASIX decided to step in and to offer loans for cattle investments to the economically poor and to establish linkages between these new milk producers and the previously shutdown milk-chilling plants. In view of their complex livelihood promotion mission BASIX offers services alongside the loan, namely financial services (life, health and livestock insurance) as well as non-financial services, such as regular visits by a veterinarian, health camps, milk fat-testing, etc. In brief, these additional services address issues related to knowledge dissemination, risk mitigation and productivity enhancement.

The need for such services is stressed in a study undertaken in Pondicherry, India. It reveals for example that "the poor landless livestock keepers do not possess knowledge on many aspects of livestock rearing especially on animal health. [...] Lack of information on animal health practices (ignorance, one of the prime constraints of development) ultimately results in production losses through morbidity and sometimes mortality - all resulting in economic losses to the livestock owners."

BASIX started its microcredit operation in 1996 and adopted their current strategy of the so-called 'livelihood triad' in 2001. The three corners of this triad are made up of Institutional Development Services (IDS), Livelihood Financial Services (LFS), and Agricultural and Business Development Services (Ag/BDS). The dairy intervention under consideration in this study encompasses all three of these aspects. IDS in the context of this intervention include for example the formation of producers' groups, federations and cooperatives. The loan itself falls under LFS. The conditions are typically a loan period of on average 18 months, implying 18 loan instalments with an interest rate of 24 per cent per annum. An additional security deposit of 10 per cent of the loan (with an average loan size of 11,500 Rupees, approximately US\$ 290) is retained. Besides this security deposit no collateral is asked for but the loan is jointliability and it comes with health and life insurance for the client as well as the spouse. In addition, the customer has the option to buy insurance for the animal, covering its death. $\mathrm{Ag} / \mathrm{BDS}$ covers in brief credit productivity enhancement, non-insurance risk mitigation and the establishment of alternate market linkages, where needed. Currently, all customers that decide to buy these services are being charged a rate of 300 Rupees ( US\$7) for one year. For this amount, they can expect timely advisory services on 
preventive measurements to reduce and deal with the risks involved in their selective livelihood at his doorstep/village on fixed dates by a Livelihood Service Provider. ${ }^{86}$ Besides the overall programme effect, this study analyses the particular effect of these latter additional services on outcome indicators. A summary of the services that comprise BASIX's intervention are given below:

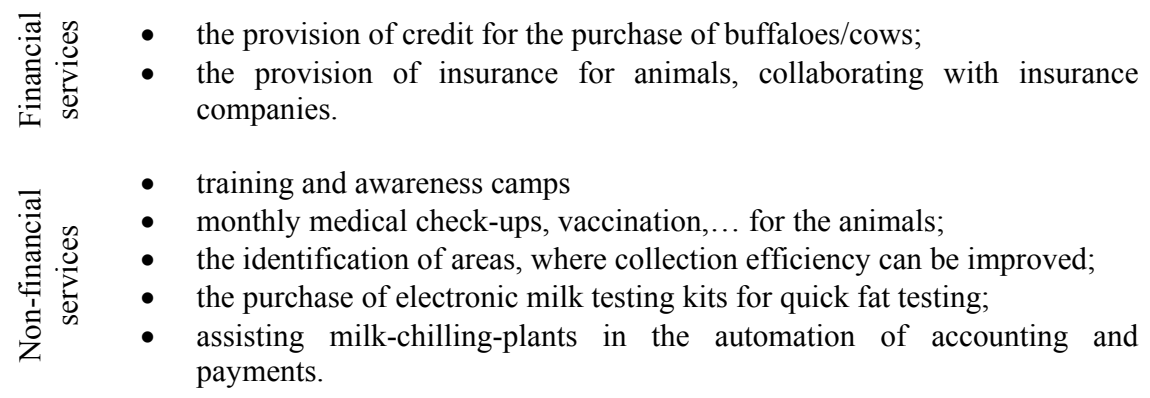

BASIX initially started this intervention in 1997 (at that time not part of the triad strategy) in Mahaboobnagar in the Indian state of Andhra Pradesh and a few months later also in the district of Anantapur, the most southern district in the same state. This latter district is the area of reference in this study.

This district was chosen for several reasons. For one, it is one of BASIX's oldest units, having been established in $2000 .{ }^{87}$ This results in BASIX having a certain presence in the state, which again implies more customers and hence a bigger sample which facilitates econometric analysis. More importantly, BASIX actually started its operation in that district due to the opportunity to become involved in the dairy subsector and the potential it saw for livelihood promotion. Furthermore, Anantapur is one of the most backward provinces in the state of Andhra Pradesh (Sreeramulu, 2006), which to a great extent results from it being the second most drought-affected district

\footnotetext{
${ }^{86}$ In more detail this implies that customers pay for regular and timely access to the physical presence of a Livelihood Service Provider (LSP) at his doorstep for a 12 months period (24 visits by LSP in a year), timely advisory services on their animals management aspects, which are appropriate at that time, exposure on latest technologies and market prices connected to his commodity, practical demonstrations on selected themes/activities by LSP (ex. disease identification method), possible facilitation for inputs supply of their choice and also for market linkages, and preventive vaccination for FMD or HS/BQ for 2 animals at free of cost/customer will be done apart from regular health check-ups, first aid treatment on need based, deworming etc..

${ }^{87}$ The unit office in Anantapur city was opened in 2000 but it was a split off from the office in Adoni (Anantapur district), which had been established about two years before, in April 1998. Once a unit office gets too big, implying that loan officers have to cover too many clients as well as too many kilometers to reach these, BASIX opens a new unit that takes over part of the clients.

As of December 2006, Anantapur unit's staff includes three field executives (FX), seventeen Livelihood Service Assistants (LSA) and four Livelihood Service providers (LSP) as well as ten other employees. Every LSA was responsible for 471 accounts, of which the unit had distributed 4,431 loans $(44,045,000 \mathrm{Rs})$ by the end of Dec 2006. The disbursed average loan size was 9,940 Rupees, as compared to an overall average for BASIX of 10,315 Rupees. The unit had an on-time repayment rate (OTRR) of $88.7 \%$, which lay below the general average of $98.2 \%$.
} 
of India. Depending on agricultural activities as their major source of earnings, the population faces extreme volatility and uncertainty in their income streams. This makes living conditions very hard; people are extremely vulnerable and poverty is highly prevalent. Aspects such as these make holistic microfinance interventions even more important but at the same time also much harder to implement. It is of interest to estimate the impact that an intervention like the one from BASIX has on these rural poor as well as what the customers expect themselves from undertaking the investment.

\subsection{The Data}

This section provides information on the data used for analysing the program's impact. A full description of the survey and the questionnaire are provided in Appendix 9.

\subsubsection{Survey Design}

For ethical considerations of denying benefits to eligible beneficiaries, the programme was not randomly assigned across localities or across eligible individuals. To evaluate its effect, outcomes of interest of non-customers are compared to those of customers. About half of these non-customers reside in areas in which BASIX offers its services and the other half where the programme was not implemented at the time of the survey. Evidence on the similarity between treatment and control groups within these areas are provided and it will be argued that suitable control households could be found for the majority of treated households in this experimental set-up.

In the beginning of 2008 a survey was conducted of BASIX clients with the unit office in the district capital of Anantapur district. As mentioned above, this is one of BASIX most established units. ${ }^{88}$ The advantage of choosing a unit where the programme under consideration has already been in place for several years lies in the fact that given the longer term experience, one can expect the program, and hence the effect on the customers to be close to the steady state. The idea is that the programme is already well established and programme effects are unlikely to be downward biased, or maybe even negative, due to initial start-up problems of the programme as well as an unsuitable design. The advantage at the same time poses challenges in the statistical analysis. Given that no baseline data is available, it is not possible to account for initial differences in outcome variables. This makes it even more important to place considerable emphasis on the choice of the control groups in the design stage of the survey, as well as in the later stage of the analysis.

\footnotetext{
${ }^{88}$ At the time of writing BASIX operates in 70 districts in the states of Andhra Pradesh, Karnataka, Orissa, Jharkhand, Maharashtra, Madhya Pradesh, Rajasthan, Bihar, Chattisgarh, West Bengal, Delhi and Tamil Nadu.
} 


\subsubsection{Village Selection}

Programme villages for the survey were selected based on information obtained from the organisation's Management Information System (MIS). A list of all active dairy clients was extracted on the $28^{\text {th }}$ of December 2007. Out of the 92 villages that these active clients lived in, only those villages were chosen where BASIX had at least nine customers. Dairy-loans are being given as joint liability with group sizes ranging from four to seven members. Choosing a minimum of nine customers per village hence ensured that at least two different joint-liability groups would be present in the village. ${ }^{89}$

Control villages were chosen to be located in areas that are closely comparable in selection criteria to the area where the intervention is being implemented. The strategy that was followed was to have staff of BASIX identify villages with 'dairy potential' those that are seen to be suitable for dairy intervention but where no such services were offered at the time of the survey. Reasons for this absence can be among others capacity or time constraints. This pre-selection assures that villages are more likely suitable counterfactuals for the programme villages. Thirty villages were identified through this process, so that altogether, respondents were drawn from 68 villages. This relatively higher number of villages is desirable since the variation in behaviour and outcomes across Indian villages is typically much larger than within them (Janssen, 2007). This implies that relatively few households are needed to represent a given township, while a larger number is appropriate in order to reflect the diversity among villages (Deaton, 1997).

\subsubsection{Household Selection}

The unit of analysis for the survey was chosen to be a household. The rationale behind choosing household is that microenterprises "exist as part of a larger portfolio of economic activities, and that decisions with respect to microenterprises - whether made jointly or individually vis à vis other members of the household - can be understood more clearly when considered in relation to tradeoffs within the overall household economy" (Sebstad et al. 1995, p. 1). In other words, economic activities are part of a larger, dynamic household economy - which holds particularly true in the survey area.

The program participants interviewed were selected from a list of all customers as obtained from the organisation's Management Information System (MIS).

The data set that was used for the sampling of 250 non-clients and 250 controls comes

\footnotetext{
${ }^{89}$ This decision was taken due to resource constraints. It should be noted that excluding villages with a very low number of dairy clients limits the representativeness of results for the program as a whole. This is the case if excluded villages differ systematically from survey villages. No data was available to test this.
} 
from the Rural Poverty Reduction Program, a programme funded by the World Bank and implemented by the Government of Andhra Pradesh. ${ }^{90}$ As part of the program, an independent society, the Society for Elimination of Rural Poverty (SERP), was established in 2001. The chairman is the serving Chief Minister of Andhra Pradesh and the CEO is the Senior IAS Officer. The programme is implemented in 22 out of 23 districts of Andhra Pradesh, only Hyderabad having been excluded as it is predominantly urban.

\section{Box 5.1: The 'Participatory Identification of the Poor'-Approach}

The poor were identified using the so-called Participatory Identification of the Poor (PIP) approach, which is based on extensive interaction with and participation of all interested villagers.

As a first step, a meeting with villagers was organised to explain the purpose and give information on the programme as well as to lay out the process of the 'Social Mapping' that was to follow. This 'Social Mapping' was the main tool to identify the poor and poorest of the poor in villages of Andhra Pradesh.

To start with, villagers were asked to draw their village on the ground including the main infrastructure such as roads and bus stops as well as other landmarks. Next, a card for each household was written and placed at the appropriate place on the village map.

As a next step, indicators for the World Bank categories were discussed. The categories are (1) Poorest of the poor, (2) Poor, (3) Not so poor and (4) Nonpoor, where the first two categories combined make up households living below the poverty line (BPL) and the latter two the ones living above (APL). Villagers were asked to identify which characteristic or indicator would contribute to which category - non-poor would own their own bathing facility, poorest of the poor would have no access to drinking water facilities and the like. After agreement of these characteristics for each category, card by card, each household was placed into one of the four categories. This was done by taking one card at a time and villagers deciding on a category for the respective household. Once the decision was taken, the characteristics of that category were read out: Housheold $\mathrm{XY}$ is.... After doing so, the categorization of the household was reconsidered and finalized. This way, about 45 per cent of all households in rural Andhra Pradesh were identified to live below the poverty line ( 20 per cent in category one and 25 per cent in category 2).

The main strategy of the Programme is to implement targeted poverty reduction programs. Special effort was hence put into the division of the population into the World Bank categories, namely (1) Poorest of the poor, (2) Poor, (3) Not so poor and (4) Non-poor. A description of the process is given in Box 5.1. Most of BASIX's dairy

\footnotetext{
${ }^{90}$ I would like to greatly thank Mohan ONteddu for helping me to obtain this data.
} 
customers fall into the second and third of these categories. Therefore, the random sample of non-customers was only drawn from households that had been classified by their fellow villagers into one of those two categories.

The survey questionnaire includes details on the household and its composition, income, assets, consumption, risks as well as one special section for customers and one for non-customers.

The final sample is composed of 513 customers, 277 non-customers in operating villages, and 251 respondents in non-operating villages, from now on referred to as 'controls'. The analysis to follow will concentrate on these 'controls' as these households constitute the appropriate control group in the evaluation (to be elaborated on below). The collection of information on non-customers in operating villages was done for two main purposes: for one, the group can be used to estimate possible spillover effects from the intervention. The second purpose was in anticipation of a second survey round. Non-customers in operating villages are potential customers and might self-select themselves into the program before the follow-up.

\subsubsection{Characteristics across treatment and control groups}

Section 5.4 describes the evaluation technique applied in this study. In brief, propensity score matching is applied, a methodology for which the choice of an appropriate comparison group ultimately determines the credibility of results.

With this in mind, Appendix 5.A displays median and average values as well as the standard deviation of an extensive range of household characteristics, including information on the household composition (number of household members, number of kids in different age groups) and proxies for household wealth (such as education levels for the household head and the spouse, conditions of the dwelling, household ownership and ownership of several asset variables, etc.).

The tables show sub-sample statistics (BASIX customers, non-customers and controls) as well as statistics for the test of difference in means of these variables between the groups. As can be seen from those last columns in the tables, the different groups are very close to each other on the basis of the available dimensions. As for those variables that do show statistically significant differences in means, given that the intervention was not randomly assigned, this is not an unexpected finding. It is mainly visible in education levels: BASIX customers seem to have spent more years in school than controls. This needs to be kept in mind, in order to control for these observed characteristics in the analysis - especially in the participation equation and when estimating over the common support. This issue will be taken up when discussing the evaluation technique applied and the choice of the control group will be revisited in section 5.2. 


\subsubsection{Outcome variables}

The effect of the programme on several outcome indicators is estimated. These are for one indicators that are directly linked to the intervention under consideration (investment returns) and second more general economic household level indicators. For the investment returns and for one general indicator, a distinction between previous year realizations and coming year expectations is made (to be elaborated on below).

Table 5.1 displays summary statistics for the outcome indicators directly related to the intervention. T-tests for the equality of means between customers and controls are provided. The first outcome indicator is the income the household receives from the dairy activity (conditional on getting income from this source) and the second relates to expenses incurred because the animal(s) got sick (conditional on having at least one cow or buffalo). These costs include foregone earnings. Interestingly, these summary statistics indicate that participants of the intervention earn significantly less from selling milk (products) than controls. ${ }^{91}$ Veterinarian expenses are on the other hand not statistically significantly different for the groups, c having a higher mean though.

Table 5.1: Income Sources (\% of overall)

\begin{tabular}{|l|c|c|c|c|c|c|c|}
\hline \multicolumn{1}{|c|}{ Variable } & \multicolumn{3}{c|}{ Customers (B) } & \multicolumn{3}{c|}{ Control (C) } & $\begin{array}{c}\text { ttest B } \\
\text { vs. C }\end{array}$ \\
\hline & med & mean & sd & med & mean & sd & t-stat \\
\hline \hline REALIZATIONS & 18,000 & 19,593 & 12,916 & 24,000 & 25,138 & 15,663 & 3.08 \\
\hline income from dairy & 1,000 & 2,731 & 5,509 & 825 & 2,123 & 4,538 & 0.47 \\
\hline $\begin{array}{l}\text { medical expensed } \\
\text { for animals }\end{array}$ & 19,140 & 22,688 & 18,703 & 23,750 & 29,488 & 26,401 & 0.95 \\
\hline \hline $\begin{array}{l}\text { ExPECTATIONS } \\
\text { expected income } \\
\text { from dairy }\end{array}$ & 800 & 1,177 & 1,150 & 775 & 1,199 & 1,145 & 0.14 \\
\hline $\begin{array}{l}\text { expected medical } \\
\text { expenses }\end{array}$
\end{tabular}

The lower panel of Table 5.1 gives summary statistics for the same variables, the difference being that they do not reflect what the respondents experienced previously but what their expectations are for the future.

A description of how this data was obtained, a detailed analysis validating responses and an explanation of how moments of distribution functions are constructed is given in Augsburg (2009). To briefly summarize, the question format to elicit the subjective expectations was based on previously implemented surveys that asked about the expected overall household income. The first step in the strategy followed is to ask the

\footnotetext{
${ }^{91}$ Please note that conclusions do not change when considering variables per owned animal.
} 
respondent to envision worst and best case scenarios for the coming year and to state corresponding minimum and maximum income streams. This range was then divided into equally spaced intervals and the respondent is requested to give the probability that household income will exceed the interval-thresholds. ${ }^{92}$

Validation of this data showed negligible percentage of logical response error, a sensible pattern of probabilities for different thresholds, and expected correlations between stated probabilities, which implies that one can be relatively certain that the answers provided conform to the basic laws of probability and that respondents did not give some random answers for the sake of answering. This conclusion allows interpreting answers as points on the subjective cumulative distribution function of future household income (dairy income and medical expenses respectively). A respondent-specific subjective income (cost) distribution is fitted, assuming a piecewise uniform probability distribution. This study focuses on the means of these distributions.

As can be seen from Table 1, the average survey respondent expects an increase in income from dairy as compared to the previous year. ${ }^{93}$ Both groups also expect lower veterinarian costs, the difference being bigger for customers. These results imply that the difference between means of outcome variables is expected to be smaller in the coming year than they were in the previous one.

Estimating the effect of programme participation on such subjective outcome indicators could be interpreted as the subjective programme effect. Nevertheless, one can expect this subjective effect to inherit an endogeneity bias that is not accounted for through the propensity score matching (to be described in the next section) - the socalled 'optimism bias'. The fact that clients made the decision to borrow money from the institution and to invest it into a risky asset shows that the hope of success is one of their characteristics. Independently of their degree of risk aversion, they are most likely optimistic about one or several things, including for example outside events (believing that market factors will develop in their interest), their own capabilities, or

\footnotetext{
${ }^{92}$ Two extensions were implemented. The first one was integrated when explaining the concept of probabilities - thorough understanding of which is a crucial precondition for the elicitation of sensible expectations. Questions were integrated that facilitated the understanding of the concept of basic probability laws, such as monotonicity. In order for respondents to grasp this concept, an extension to the survey conducted in Columbia was employed. The second extension was that not only expected income was asked about but also expected income from selling milk (products) and the expected expenditures on animal health. Both these latter variables are directly related to the investment and are therefore hypothesized to have a major influence on the investment decision.

${ }^{93}$ Please note that data collected on expected income from dairy was on a monthly basis, while the corresponding realization refers to a period of one year. This is due to the fact that overall household income was easier for respondents to give information on a yearly basis and income from dairy was one of the sources. The expectations and realizations were made comparable by multiplying the monthly expectation figures by the average number of month that animals give milk per year. For animals of customers this are 8.1 months a year, for non-customers 9.4 months and for controls 9.5 months.
} 
about what others tell them (in this case 'others' could for example refer to the field executive of BASIX or the veterinarian suggesting vaccinations).

While such bias is a problem if one were to estimate the subjective programme effect, it is important to realize that in the context of expected returns to investment this bias is actually of interest. This is because it (partly) reflects the underlying decisionmaking process of the respondents. ${ }^{94}$

The second set of indicators that are being looked at are more general ones, including overall household income, assets and savings and consumption data. The relevance of these outcome indicators in the context of microfinance are briefly explained next.

Microfinance is most often promoted as an opportunity for the poor to engage in an (extra) income-generating activity and an effectual means for increasing the poor's income as well as asset base. Income and assets are hence obvious indicators to analyse when evaluating a programme falling under the microfinance-umbrella.

The survey collected data on the households' income by asking the amount the household receives from a number of different activities and sources. The most important sources are displayed in Table 5.2. It can be seen that the greatest part of respondents' income is derived from agriculture and hence strongly varying with harvesting seasons - on average nine per cent of the household income is derived from farm profit and 39 per cent from wages as agricultural labour.

Information on asset was similarly determined, asking about all owned assets and their current market value.

Table 5.2: Income Sources (\% of overall)

\begin{tabular}{|l||c|c|c|c|}
\hline \multirow{2}{*}{ Income Source } & \multicolumn{2}{|c|}{ BASIX } & \multicolumn{2}{c|}{ Control } \\
\cline { 2 - 6 } & mean & sd & mean & sd \\
\hline \hline Wages from non-agricultural sector - formal & 0.147 & 0.203 & 0.273 & 0.273 \\
\hline Wages from non-agricultural sector - informal & 0.017 & 0.093 & 0.019 & 0.111 \\
\hline Wages (possibly in-kind) from public relief work & 0.004 & 0.031 & 0.009 & 0.085 \\
\hline Non-farm self-employment (net-income) & 0.036 & 0.087 & 0.067 & 0.138 \\
\hline Farm profit & $\mathbf{0 . 0 8 9}$ & $\mathbf{0 . 2 0 1}$ & $\mathbf{0 . 0 9 7}$ & $\mathbf{0 . 2 3 7}$ \\
\hline Wages from agric. labour (not on own farm) & $\mathbf{0 . 4 0 3}$ & $\mathbf{0 . 2 9 8}$ & $\mathbf{0 . 3 8 6}$ & $\mathbf{0 . 3 0 5}$ \\
\hline Income from Dairy Activities & 0.260 & 0.220 & 0.089 & 0.175 \\
\hline \hline Total** & 0.956 & & 0.94 & \\
\hline $\begin{array}{l}\text { Notes: } * * \text { Remaining \% are distributed among: sales of handicrafts or other non-agricultural, } \\
\text { Traditional hereditary occupation, Migration income/remittances, benefits from government } \\
\text { schemes, pensions, dowry income, other income sources (e.g. gambling) }\end{array}$ \\
\hline
\end{tabular}

\footnotetext{
${ }^{94}$ One caveat needs to be brought forward: evidence suggests that 'optimism bias' reduced with experience. Since the length of time that clients are with the LPI and that clients engage in the activity varies, the estimated effect will reflect an average of the expected return. Unfortunately, data does not allow distinguishing how long a client is with the LPI.
} 
Also increasingly stressed in the microfinance literature is the role of savings - another mean for capital mobilization. It might be a slower mean but at the same time it is less risky and especially important when talking about long-term growth objectives. The third outcome indicator considered is therefore savings of the household. Savings are the sum of several deposit options, including deposits with banks, private financial institutions, the post office, chit funds ${ }^{95}$, Self Help Groups (SHGs) ${ }^{96}$ and cash at home. The latter two are the dominant saving sources in the sample. Table 5.3 shows that almost 60 percent of savings are held with SHGs and 23 percent of the savings are kept as cash at home. Official saving sources are hardly used by the sample population.

Table 5.3: Saving Sources (\% of total)

\begin{tabular}{|l||c|c|c|c|}
\hline \multirow{2}{*}{ Deposit Sources } & \multicolumn{2}{c|}{ BASIX } & \multicolumn{2}{c|}{ Control } \\
\cline { 2 - 5 } & mean & sd & mean & sd \\
\hline \hline Bank & 0.06 & 0.23 & 0.08 & 0.26 \\
\hline Private Financial Institute & 0.02 & 0.12 & 0.02 & 0.15 \\
\hline Post Office & 0.07 & 0.24 & 0.04 & 0.19 \\
\hline Chit Fund & 0.07 & 0.24 & 0.01 & 0.09 \\
\hline Cash at Home & $\mathbf{0 . 2 1}$ & 0.38 & $\mathbf{0 . 2 5}$ & 0.41 \\
\hline SHG & $\mathbf{0 . 5 6}$ & 0.47 & $\mathbf{0 . 5 9}$ & 0.47 \\
\hline Other & 0.01 & 0.07 & 0.01 & 0.09 \\
\hline \hline Total & 1.00 & & 1.00 & \\
\hline
\end{tabular}

While microfinance is predominantly promoted for its role to improve economic indicators, it plays a major - probably even more important - role in consumption and risk smoothing. In a context where people are threatened in their livelihoods (if not in their survival) due to the absence of certain goods, increased income is important but secured consumption is vital. And especially when analysing a programme that stresses the importance of livelihood promotion, a programme where credit is only one of several components, it is of interest to see whether an effect on disposable income for consumption of food and other basic needs can be observed. To do so, the expenditures on certain consumption goods (food, other non-durable, durable, the latter one including for example educational expenses, repairs and dowries) are considered as outcome variables in the analysis. Note that food consumption includes the market value of home produced goods.

\footnotetext{
${ }^{95}$ A Chit Fund is comparable to a savings scheme, which has originated in India.

${ }^{96}$ A SHG is a homogeneous group of on average fifteen poor people that voluntarily forms to save small amounts. These pooled resources are on-lent to members for meeting their credit needs, either for consumption or income generating activities. Once the groups show mature financial behaviour, banks are encouraged to make loans to them (Seibel and Dave 2002).
} 
Table 5.4 shows summary statistics by groups for the just described general outcome indicators and, as before, t-tests for the equality of means between groups are provided. It is worth noting that for all of these variables - including subjective expectations about future household income, customers have a higher mean than households not engaging in the intervention - statistically insignificant only for savings. While this might be interpreted as an indication that households benefit from taking a dairy loan with BASIX, these differences could be simply due to underlying differences in characteristics between the groups. The following analysis concentrates on singling out the effect that can be attributed to the intervention and not to such differences in groups.

Table 5.4: Descriptive Statistics of Outcome Indicators - General

\begin{tabular}{|c|c|c|c|c|c|c|c|}
\hline \multirow[t]{2}{*}{ Variable } & \multicolumn{3}{|c|}{ Customers (B) } & \multicolumn{3}{|c|}{ Control (C) } & \multirow{2}{*}{$\begin{array}{l}\text { ttest B } \\
\text { vs. C } \\
\text { t-stat }\end{array}$} \\
\hline & med & mean & sd & med & mean & sd & \\
\hline \multicolumn{8}{|c|}{ GENERAL OUTCOME INDICATORS - REALIZATIONS } \\
\hline $\begin{array}{l}\text { Total yearly } \\
\text { household income }\end{array}$ & 63,400 & 79,321 & 53,292 & 47,400 & 55,417 & 39,867 & -6.25 \\
\hline Total asset value & 230,100 & 323,665 & 281749 & 153,700 & $\begin{array}{c}214,51 \\
6 \\
\end{array}$ & 213530 & -5.35 \\
\hline Savings & 500 & 2,023 & 3,520 & 0 & 1,616 & 2,964 & -1.53 \\
\hline $\begin{array}{l}\text { Total yearly food } \\
\text { consumption } \\
\text { expenditure }\end{array}$ & 36,374 & 40,119 & 18,337 & 28,938 & 32,687 & 17,791 & -5.27 \\
\hline $\begin{array}{l}\text { Total yearly other } \\
\text { non-durable } \\
\text { consumption exp. }\end{array}$ & 10,400 & 17,010 & 20,088 & 6,760 & 11,763 & 16,258 & -3.58 \\
\hline $\begin{array}{l}\text { durable consumption } \\
\text { exp. }\end{array}$ & 13,900 & 16,903 & 11,410 & 10,250 & 12,403 & 9,214 & -5.42 \\
\hline \multicolumn{8}{|c|}{ GENERAL OUTCOME INDICATORS - EXPECTATIONS } \\
\hline $\begin{array}{l}\text { Total yearly } \\
\text { household income }\end{array}$ & 61,275 & 77,512 & 53,275 & 50,000 & 56,975 & 36,247 & -5.34 \\
\hline
\end{tabular}

\subsection{Evaluation Technique}

The study uses Propensity Score Matching (PSM) techniques to estimate the effect of programme participation on above described outcome variables. This technique has been widely applied in the non-experimental evaluation literature, especially in the context of labour market policies. The key idea and assumption is that conditional on observable variables, the assignment of a programme is random. Since conditioning on all relevant variables implies in most settings a high dimensional covariate vector, it is common practice to make use of a result by Rosenbaum and Rubin (1983) which suggests that instead of conditioning on all covariates one can use a single function of these same variables - such as the propensity score. A propensity score of which the distribution is the same for treated as well as non-treated individuals can be used to 
match pairs within the two groups. The average difference in outcomes between these pairs is then the so-called average treatment effect on the treated.

PSM improves over OLS Regressions that include a dummy variable to estimate treatment in three respects: For one, it is a semi-parametric estimation method and hence avoids distributional and functional form assumptions; second, one does not need to assume homogeneous effects and third, the method does not extrapolate outside the common support, meaning that one avoids comparing the incomparable.

The crucial aspect of propensity score matching is hence the estimation of the propensity score itself. As is usual in practice, this study estimates the probability of programme participation using a probit model. Variable selection followed mainly theoretical consideration, including only those variables that are hypothesized to influence simultaneously the participation decision as well as the outcome of interest and that are not affected by the treatment. This latter is especially important given the drawback that no baseline data is available for outcome indicators. The set of variables that has been used to estimate propensity scores in this study can be seen in Appendix $B$, which provides detailed information on the propensity score model used in the analysis of the overall effect of the intervention ${ }^{97}$.

For one, predetermined variables such as education and caste and household composition are included in the participation equation. Also considered are variables related to BASIX's appraisal policy as well as the program placement decision. Loan appraisal includes for example a brief assessment of household indebtedness (in terms of present sources and amount of credit) as well as an estimate of household income from different sources. The institutions also prefers to give loans to households that are less likely to move - such as for example married women or those households that have lived in the village all their life. Furthermore, the institution works in poorer districts, but where certain factor conditions are met (see Datta et al (2005) for a more detailed discussion). To the extend possible, such variables were accounted for as well by including mandal-level ${ }^{98}$ characteristics such as for example the percentage of villages on a main road. The importance of accounting for geographical conditions will also be taken up in the following chapter.

Propensity score matching has the advantage of being able to discard those individuals from the analysis for which the control group does not offer a suitable counterfactual. Since the effect of treatment cannot be estimated for the discarded individuals the results of the evaluation will be more meaningful, the lower the decrease in sample size due to this exclusion. Checking the overlap and the region of common support

\footnotetext{
${ }^{97}$ Regression results for the other models (where treatment are participation with additional financial and/or non-financial services) can be obtained from the author on request.

${ }^{98}$ Mandals are the third subnational administrative units below states and districts in India.
} 
between treatment and comparison group is therefore an important step in the analysis. These indicators as well as graphs of the propensity score distribution for the treated and for the untreated are provided together with the propensity score estimates in Appendix B. For estimated scores, the overlap is around 87 per cent, implying that estimated effects is close but not totally representative for the impact of the program. But, the graphs also indicate that the propensity score distributions are still quite different between the groups. To bring the means closer together and thereby find better matches, the tails are trimmed in the analysis. Doing so, a further 28 per cent of observations on the common support are discarded. Overall, about 60 per cent of observations on the common support are used in the analysis. This is important to be kept in mind as it influences the generalizability of results.

Once the propensity score is specified, several matching estimators can be applied. Results presented in this study are Kernel estimates. In this setting, all treated units are matched with a weighted average of all controls with weights that are inversely proportional to the distances between the propensity scores of treated and comparisons. ${ }^{99}$ A major advantage of Kernel matching over for example Nearest Neighbour matching is the lower variance resulting from more information being used. Nevertheless, one risks using 'bad' matches, which again stresses the importance of the common support condition. ${ }^{100}$

The standard errors presented are bootstrapped, taking into account the clustered nature of the data on village-level. Note that some caution has to be taken when making inference based on these standard errors. To date, no formal evidence to justify bootstrapping in this context seems to exist. ${ }^{101}$ Yet, studies do report and base their inference on them (see for example Heckman et al., 1997a; Black and Smith, 2004; Sianesi, 2004).

\footnotetext{
${ }^{99}$ Results for Nearest Neighbour estimates are available on request. Note that interpretations of results do not change.

${ }^{100}$ One might furthermore choose a narrower bandwidth which then places more weight on 'close' observations. The bandwith used throughout the following analysis is 0.06 .

${ }^{101}$ Abadie and Imbens (2008) developed a formula for standard errors, which only applies though when the true propensity score is known. This implies that the smaller the original sample, the more unlikely it is that the distribution of the sample represents the entire population. This makes it quite difficult to compute trustable confidence intervals as bootstraps rely heavily on the tails of the distribution for the computations. Hence, unless one is confident about the quality of the data and its ability to reflect the characteristics of the population being sampled, one should not accept unquestioningly the validity of the computations. Invalid statistical estimations are possible due to sampling error when performing the random sampling in the bootstrap procedure.
} 


\subsection{Impact evaluation of BASIX's dairy intervention}

The interest lies in the impact of BASIX's intervention in the dairy sub-sector. To The interest lies in the impact of BASIX's intervention in the dairy sub-sector. To begin with, the overall effect of participating in the programme is considered. The 'overall effect' hence looks at participants that took a loan for the purpose of buying a cow or a buffalo. Here, no distinction is being made as to whether the participant receives credit only or whether they opted for additional (non) financial services. This will be considered later, estimating first the effect of receiving (and having paid for) Agricultural and Business Development Services (Ag/BDS) and then narrowing the treatment sample further to those participants that have $\mathrm{Ag} / \mathrm{BDS}$ as well as livestock insurance.

The main considerations led to the choice of putting more emphasize on Ag/BDS services rather than on livestock insurance is that with $\mathrm{Ag} / \mathrm{BDS}$ one can be more certain that whether a participant has these services or not actually reflects a choice. It is not uncommon to bundle products with the loan to reach targets. Nevertheless, experience showed that making $\mathrm{Ag} / \mathrm{BDS}$ mandatory (in practise rather than on paper) resulted in a higher probability of loan default, which is risky and obviously not desirable for the organisation. In addition, an increase in $\mathrm{Ag} / \mathrm{BDS}$ registration for nonloan participants is observed. ${ }^{102}$

\subsubsection{Impact of being a dairy customer of BASIX (in Anantapur)}

Table 5.5a displays results for the impact analysis of being a dairy customer of the LPI on outcomes indicators directly related to the intervention, the investment returns.

The average treatment effect on the treated (ATT) is shown in column (i). The signs of the estimated effects on income from selling milk and on veterinarian costs indicate that customers, while incurring lower costs, also earn less from this activity when compared to the control group. The effect of lower costs is statistically insignificant. Surprisingly, the lower return from the activity is on the other hand significant participants earn on average Rs. 11,900 per year less than comparable nonparticipating households. As was already seen in the simple summary statistics, the difference between groups is considerably smaller when considering the respondents' subjective future outlook, show in the lower panel of Table 5a.

Several possible explanations can be brought forward for this unexpected negative effect on income from the intervention activity.

\footnotetext{
${ }^{102}$ I would like to thank Mendu Sreenivasulu, (Manager-Samruddhi Centre for Livelihood Promotion, KBS BANK, BASIX Group) for a discussion and information on this issue.
} 
First, it is possible that as a result of the intervention, less productive and less efficient households engage in the dairy activity. These lower skills could result in households earning on average less than the more productive households in control villages, who engaged in the activity without the support of BASIX. This observation is underlined by the sample size - the control group consists here only of around 40 households only those households that do have milk-producing animals.

Table 5.5a: Effect of participating in BASIX's Dairy Intervention

\begin{tabular}{|c|c|c|c|c|c|c|c|c|}
\hline \multicolumn{9}{|c|}{ Effect of participating in the Dairy Intervention (vs. CONTROL) } \\
\hline Outcome & Group & Obs & Mean & Std.Dev. & $\begin{array}{c}\text { ATT } \\
\text { (i) } \\
\end{array}$ & $\begin{array}{l}\text { se. } \\
\text { (ii) } \\
\end{array}$ & $\begin{array}{c}\text { t-stat } \\
\text { (iii) } \\
\end{array}$ & $\begin{array}{c}\text { bias corr CI } \\
\text { (iv) } \\
\end{array}$ \\
\hline \multicolumn{9}{|l|}{ Realizations } \\
\hline \multirow{2}{*}{$\begin{array}{l}\text { income from } \\
\text { dairy }\end{array}$} & BASIX & 238 & 18498 & 12907 & \multirow[t]{2}{*}{$-11,900 *$} & \multirow[t]{2}{*}{3203} & \multirow[t]{2}{*}{-3.72} & \multirow[t]{2}{*}{$(-16639 ;-5004)$} \\
\hline & Control & 42 & 30404 & 16230 & & & & \\
\hline \multirow{2}{*}{$\begin{array}{l}\text { total health } \\
\text { costs for } \\
\text { animal }\end{array}$} & BASIX & 239 & 2083 & 3653 & \multirow[t]{2}{*}{$-1,210$} & \multirow[t]{2}{*}{1416} & \multirow[t]{2}{*}{-0.85} & \multirow[t]{2}{*}{$(-3444 ; 1831)$} \\
\hline & Control & 43 & 3293 & 5238 & & & & \\
\hline \multicolumn{9}{|l|}{ Expectations } \\
\hline \multirow{2}{*}{$\begin{array}{l}\text { income from } \\
\text { dairy }\end{array}$} & BASIX & 231 & 2585 & 2065 & \multirow[t]{2}{*}{$-1,051$} & \multirow[t]{2}{*}{1053} & \multirow[t]{2}{*}{-1} & \multirow[t]{2}{*}{$(-4466 ; 75)$} \\
\hline & Control & 40 & 3637 & 3303 & & & & \\
\hline \multirow{2}{*}{$\begin{array}{l}\text { total health } \\
\text { costs for } \\
\text { animal }\end{array}$} & BASIX & 223 & 1164 & 1245 & \multirow[t]{2}{*}{-300} & \multirow[t]{2}{*}{284} & \multirow[t]{2}{*}{-1.06} & \multirow[t]{2}{*}{$(-785 ; 310)$} \\
\hline & Control & 38 & 1463 & 1279 & & & & \\
\hline $\begin{array}{l}\text { Kernel estimat } \\
\text { village level } \\
\text { balancing prot }\end{array}$ & $\begin{array}{l}\text { over com } \\
0 \text { replica } \\
\text { ty, and is }\end{array}$ & on sl & $\begin{array}{l}\text { ort, bo } \\
\text { opensit } \\
\text { at its ta }\end{array}$ & $\begin{array}{l}\text { strapped } \\
\text { score incl } \\
\text { (pscore }<0\end{array}$ & $\begin{array}{l}\text { dard er } \\
\text { es geog }\end{array}$ & $\begin{array}{l}\text { that } \\
\text { hical }\end{array}$ & $\begin{array}{l}\text { ount for } \\
\text { racteris }\end{array}$ & $\begin{array}{l}\text { clustering on the } \\
\text { ics, satisfies the }\end{array}$ \\
\hline
\end{tabular}

Another reason is related to the establishment of market linkages that is sometimes part of the intervention. Personal observations and preliminary primary data collection indicated that intervention participants would sometimes sell their milk to milk-agents established by BASIX despite receiving a lower price ${ }^{103}$. They did so in order not to jeopardize the presence of BASIX in the village. This could result in a lower income from dairy in comparison to households selling their milk to local vendors. This issue will be picked up again when looking more specifically at customers that have additionally (non)financial services.

\footnotetext{
${ }^{103}$ A milk agent collects milk from customers and sells it on to a milk chilling plant. Mostly, these agents use - or are supposed to use - an instrument for fat and SNF-testing which is purchased through a loan from the LPI. The higher the fat and SNF percentage of the milk, the higher the price per litre should be.
} 
Finally, it is possible that participants consume more and sell less of their produced milk. This mechanism would imply an increase in the households' food consumption. Some descriptive statistics support this hypothesis: The ratio of yearly home consumption of milk to milk production is 0.09 for participants as compared to only 0.03 for controls. The same conclusion holds for absolute numbers: Participants consume 0.95 litres of milk per day while controls consume only 0.8 .

The next results presented - effects on general outcome indicators - show that participants have indeed a significant increase in their consumption.

Table 5.5b: Effect of participating in BASIX's Dairy Intervention - General

\begin{tabular}{|c|c|c|c|c|c|c|c|c|}
\hline \multicolumn{9}{|c|}{ Effect of participating in BASIX's Dairy Intervention (vs. CONTROL) } \\
\hline Outcome & Group & Obs & Mean & Std.Dev. & $\begin{array}{c}\text { ATT } \\
\text { (i) } \\
\end{array}$ & $\begin{array}{l}\text { se. } \\
\text { (ii) }\end{array}$ & $\begin{array}{c}\text { t- } \\
\text { stat } \\
\text { (iii) } \\
\end{array}$ & $\begin{array}{c}\text { bias corr CI } \\
\text { (iv) } \\
\end{array}$ \\
\hline \multicolumn{9}{|l|}{ Realizations } \\
\hline \multirow{2}{*}{$\begin{array}{l}\text { total hh } \\
\text { income }\end{array}$} & BASIX & 283 & 77163 & 50705 & \multirow{2}{*}{16,011} & \multirow{2}{*}{9726} & \multirow{2}{*}{1.65} & \multirow{2}{*}{$(-3794 ; 32714)$} \\
\hline & Control & 164 & 61152 & 40854 & & & & \\
\hline \multirow{2}{*}{ assets } & BASIX & 275 & 322717 & 288742 & \multirow{2}{*}{90,702} & \multirow{2}{*}{43956} & \multirow{2}{*}{2.06} & \multirow{2}{*}{$(-15995 ; 155014$} \\
\hline & Control & 161 & 232116 & 226164 & & & & \\
\hline \multirow{2}{*}{ savings } & BASIX & 264 & 1926 & 3725 & \multirow{2}{*}{345} & \multirow{2}{*}{613} & \multirow{2}{*}{0.56} & \multirow{2}{*}{$(-753 ; 1502)$} \\
\hline & Control & 157 & 1579 & 2231 & & & & \\
\hline \multirow{2}{*}{$\begin{array}{l}\text { food } \\
\text { consumption }\end{array}$} & BASIX & 281 & 39690 & 15775 & \multirow{2}{*}{ 8,868* } & \multirow{2}{*}{2732} & \multirow{2}{*}{3.25} & \multirow{2}{*}{$(3986 ; 14304)$} \\
\hline & Control & 163 & 30822 & 13619 & & & & \\
\hline \multirow{2}{*}{$\begin{array}{l}\text { other non- } \\
\text { durable } \\
\text { consumption }\end{array}$} & BASIX & 286 & 17336 & 22857 & \multirow{2}{*}{$6,852 *$} & \multirow{2}{*}{1541} & \multirow{2}{*}{4.45} & \multirow{2}{*}{$(3623 ; 9699)$} \\
\hline & Control & 165 & 10484 & 15225 & & & & \\
\hline \multirow{2}{*}{$\begin{array}{l}\text { durable } \\
\text { consumption }\end{array}$} & BASIX & 283 & 17309 & 11637 & \multirow{2}{*}{$3,954 *$} & \multirow{2}{*}{1637} & \multirow{2}{*}{2.42} & \multirow{2}{*}{$(-579 ; 6106)$} \\
\hline & Control & 164 & 13356 & 9484 & & & & \\
\hline \multicolumn{9}{|l|}{ Expectations } \\
\hline \multirow{2}{*}{$\begin{array}{l}\text { total hh } \\
\text { income }\end{array}$} & BASIX & 269 & 76934 & 52554 & \multirow{2}{*}{15,270} & 10274 & 1.49 & $(-6485 ; 32688)$ \\
\hline & Control & 155 & 61664 & 38150 & & & & \\
\hline $\begin{array}{l}\text { Kernel estima } \\
\text { village level } \\
\text { balancing pro }\end{array}$ & $\begin{array}{l}\text { over cor } \\
300 \text { replic }\end{array}$ & imon s & $\begin{array}{l}\text { port, boo } \\
\text { ropensity }\end{array}$ & $\begin{array}{l}\text { rapped sta } \\
\text { core incluc }\end{array}$ & lard err & $\begin{array}{l}\text { s that a } \\
\text { shical c }\end{array}$ & ount $f$ & $\begin{array}{l}\text { clustering on the } \\
\text { tics, satisfies the }\end{array}$ \\
\hline
\end{tabular}

It can be seen in Table $5.5 \mathrm{~b}$ that all estimated programme impacts are positive: total household income, the asset base and savings are estimated to be higher due to participation, but the effects are not significant. As hypothesized above, participants do experience a significant increase in their consumption pattern though. This holds for 
all three categories considered: food, other non-durable and durable consumption. The quantitatively biggest effect is found for food consumption: the estimated effect translates into a food consumption increase equivalent to Rs. 24 per household per day. This is a considerable amount when keeping in mind that the average daily wage for an agricultural wage labourer is about Rs. 90 for men and Rs. 60 for women. This result stresses the importance of programmes like the one under consideration in helping families to self-insure consumption

The lower panel of Table 5.5b shows that participants themselves expect the positive impact of participating in the intervention on their household income to prevail in the coming year. This expected return is slightly smaller than the estimated impact on realization data and also insignificant.

The increase in household income is at first sight a counterintuitive result given that the intervention activity does not seem to yield a positive impact on income from selling milk. This might be explained by a substitution effect taking place: no data was collected on this issue but experiences during field work, discussion with LPI stuff and participants, confirmed that often women who stayed otherwise at home (either without working or undertaking an activity with lesser return such as for example bidi rolling) now contribute to household income through the dairy activity. Hence, total household income increases but income from dairy might still be less compared to people that engage in the activity and did not borrow from the LPI to do so.

The differences between effects on realizations and expectations are much sharper for income from dairy than for overall household income. As can be seen in Figure 1, participants earned much less from selling dairy in comparison to the control group but they expect this difference to almost disappear in the coming year.

Figure 5.1: Effect on Realized and Expected Incomes

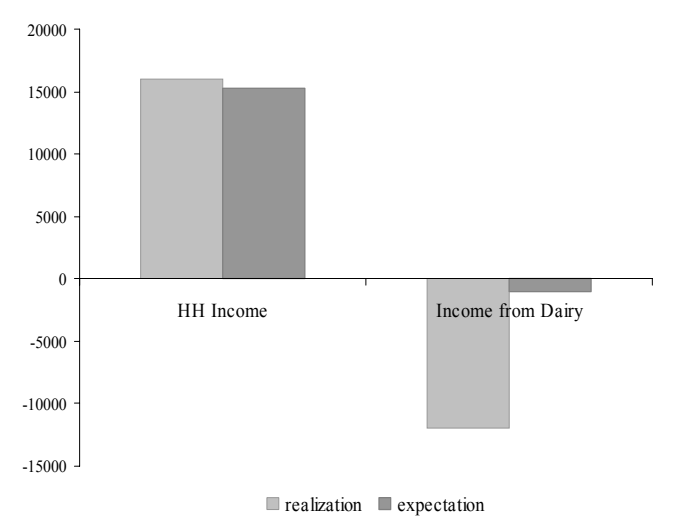


Two reasons can be brought forward to explain this difference. On the one hand, the optimism bias is expected to play a greater role for variables that are directly linked to the intervention - income from dairy being the most obvious one. On the other hand, since the expectations refer to the coming year and the realizations to the previous year, it is possible that the differences in effects reflect a perceived long-term effect of the program. If this is the case, estimated results suggest that income generated from the supported activity is currently lower for participants than for controls but that this changes with time and experience. In the discussion to follow it will be argued that the second reason seems more plausible.

\subsubsection{Average versus Intention to Treatment Effect)}

In the just presented results, intervention participants are compared to households living in villages where, at the time of the survey, BASIX was not operating. This implies that it is not known which of the households in these control villages would choose to participate in the intervention if they had the possibility to do so. Therefore, in the previous analysis, households that decided to participate are compared to households similar in characteristics, but of which it is not known whether they would actually self-select themselves into the intervention as well.

This section addresses the issue by looking at the Intention to Treatment Effect (ITT) rather than the Average Treatment Effect (ATT). Such an intention to treat analysis provides information on the potential effects of the intervention - the potential effect of the LPI offering its services in a village on households.

To do so, the treatment group considered now consists not only of participants of the intervention but includes also other households living in the same villages. These are compared to households living in non-intervention villages (the same control group as above).

Table 5.6 shows the ATTs from Tables 5.5a and 5.5b alongside the newly estimated ITTs. It can be seen that for all variables the effects are remarkably similar; this holds especially for the investment returns and costs: the ATTs and ITTs for expectations of investment returns and costs are almost identical. This gives indication that participants do not decide to participate in the intervention because they are overly optimistic about the returns to the investment.

For the more general outcome indicators, the ATTs is slightly higher than the ITTs. This is not an unexpected finding as it can be attributed to self-selection into the programme. Note though that none of the effects are statistically significant different from each other - this holds for investment return and general variables. From this, it can be concluded that the propensity score matching accounts well for the possible self-selection into the intervention. Therefore, the remaining results presented in this paper - the effects of having additionally (non)financial services - will be ATTs rather than ITTs. 
Table 5.6: ATT versus ITT

\begin{tabular}{|c|c|c|c|c|c|}
\hline \multicolumn{3}{|r|}{ Outcome } & \multicolumn{2}{|c|}{ ATT \& ITT } & bias corr $\mathrm{CI}$ \\
\hline \multirow{8}{*}{ 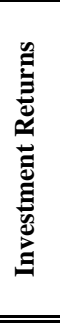 } & \multirow{4}{*}{ 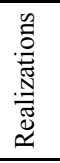 } & \multirow{2}{*}{ income from dairy } & ATT & $-11,900 *$ & $(-16639 ;-5004)$ \\
\hline & & & ITT & $-10,700 *$ & $(-15052 ;-5228)$ \\
\hline & & \multirow{2}{*}{$\begin{array}{l}\text { total health costs for } \\
\text { animal }\end{array}$} & ATT & $-1,210$ & $(-3444 ; 1831)$ \\
\hline & & & ITT & $-1,083$ & $(-3003 ; 1542)$ \\
\hline & \multirow{4}{*}{ 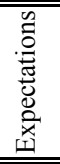 } & \multirow{2}{*}{ income from dairy } & ATT & $\begin{array}{l}-1,051 \\
\end{array}$ & $(-4466 ; 75)$ \\
\hline & & & ITT & $-1,091 *$ & $(-2923 ;-57)$ \\
\hline & & \multirow{2}{*}{$\begin{array}{l}\text { total health costs for } \\
\text { animal }\end{array}$} & ATT & -300 & $(-785 ; 310)$ \\
\hline & & & ITT & -293 & $(-815 ; 280)$ \\
\hline \multirow{14}{*}{ 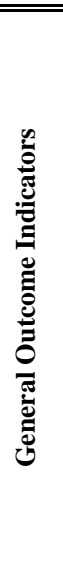 } & \multirow{12}{*}{ 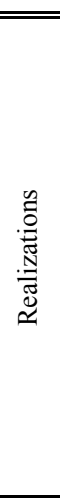 } & \multirow{2}{*}{ total hh income } & ATT & 16,011 & $\overline{(-3794 ; 32714)}$ \\
\hline & & & ITT & 12,883 & $(-5463 ; 27159)$ \\
\hline & & \multirow{2}{*}{ assets } & ATT & 90,702 & $(-15995 ; 155014)$ \\
\hline & & & ITT & 62,800 & $(-12605 ; 140116)$ \\
\hline & & \multirow{2}{*}{ savings } & ATT & 345 & $(-753 ; 1502)$ \\
\hline & & & ITT & 130 & $(-935 ; 1054)$ \\
\hline & & \multirow{2}{*}{ food consumption } & ATT & 8,868 & $(3986 ; 14304)$ \\
\hline & & & ITT & 7,033 & $(1640 ; 11727)$ \\
\hline & & \multirow{2}{*}{$\begin{array}{l}\text { other non-durable } \\
\text { consumption }\end{array}$} & ATT & 6,852 & $(3623 ; 9699)$ \\
\hline & & & ITT & 5,280 & $(2167 ; 8324)$ \\
\hline & & \multirow{2}{*}{$\begin{array}{l}\text { durable } \\
\text { consumption }\end{array}$} & $\mathrm{ATT}$ & 3,954 & $(-579 ; 6106)$ \\
\hline & & & ITT & 3,649 & $(371 ; 5863)$ \\
\hline & \multirow{2}{*}{ 离 } & \multirow{2}{*}{ total hh income } & בATT & 15,270 & $\begin{array}{l}(-6485 ; 32688) \\
\end{array}$ \\
\hline & & & ITT & 12,355 & $(-3941 ; 26811)$ \\
\hline \multicolumn{6}{|c|}{$\begin{array}{l}\text { Kernel estimates over common support, bootstrapped standard errors that account } \\
\text { for clustering on the village level ( } 300 \text { replications), propensity score includes } \\
\text { geographical characteristics, satisfies the balancing propoerty, and is trimmed at its } \\
\text { tail (pscore }<0.85) \text {. }\end{array}$} \\
\hline
\end{tabular}

\subsubsection{Impact of receiving additional (non-financial) Services}

This section discussed estimated effects on the same outcome variables as above, now the treatment group being those participants that not only have a loan but also paid Rs. 300 to receive additional services over the period of the loan. As described in section 2, these services include for example regular check-up by a veterinarian and training on how to keep and feed the animal. Some of these clients might additionally have livestock insurance, which will be discussed further in the next section. Table 5.7a presents results for those participants who had these services at the time of the survey. ${ }^{104}$

${ }^{104}$ Results where the treatment group consists of participants who ever had these additional services (whether at the time of the survey or at any time before) are available on request. They are not presented here as they are very comparable. 
Also for customers with additional services, income from selling milk (products) is estimated to be significantly negative. Explanations for this negative effect were already discussed above. To recap, it is likely that especially participants who decide to take non-financial services alongside the loan are those less experienced and less productive in dairy activities and would experience a lower income due to this. The second explanation - the one related to the established market linkages deserves a more detailed account at this point. It was argued that field work revealed indication of some milk-agents operating on milk routes initiated by the LPI paying a lower price per litre of milk than local vendors. In addition, in some villages the milk agent would take a sample of the participants' milk for testing but would not return it to the participant. By doing so, the agent could make a personal profit through selling the samples as his own milk but would at the same time reduce the participants' income.

Such practices led to an average loss of Rs. 2 per litre of milk for the participant. While Rs. 2, which is just 0.05 US Dollar might sound like a negligible amount, it is not considering the price of milk: A milk agent pays on average Rs. 10 for one litre of buffalo milk and Rs. 8 for one litre of cow's milk - a participant can consequently experience losses of up to 20-25 per cent. Why would a participant still sell milk to the milk-agent and not directly to the local vendor? In an interview one woman explained that she sold some of her milk to the local vendor - since he would pay a higher price and some to the milk agent - in order not to jeopardize BASIX's presence in the village. ${ }^{105}$

Table 5.7a: Effect of additional Non-financial services - Investment Returns

\begin{tabular}{|c|c|c|c|c|c|c|c|c|}
\hline \multicolumn{9}{|c|}{ Effect of participating in the AgBDS Dairy Intervention (vs. CONTROL) } \\
\hline Outcome & Group & Obs & Mean & Std.Dev. & $\begin{array}{c}\text { ATT } \\
\text { (i) }\end{array}$ & $\begin{array}{l}\text { se. } \\
\text { (ii) }\end{array}$ & $\begin{array}{c}\text { t-stat } \\
\text { (iii) }\end{array}$ & $\begin{array}{l}\text { bias corr } \mathbf{C I} \\
\text { (iv) }\end{array}$ \\
\hline \multicolumn{9}{|l|}{ Realizations } \\
\hline \multirow{2}{*}{ income from dairy } & AgBDS & 161 & 18852 & 13605 & \multirow{2}{*}{$-10,600 *$} & \multirow{2}{*}{3192} & \multirow{2}{*}{-3.331} & \multirow{2}{*}{$(-15968 ;-2226)$} \\
\hline & Control & 45 & 29484 & 15552 & & & & \\
\hline \multirow{2}{*}{$\begin{array}{l}\text { total health costs } \\
\text { for animal }\end{array}$} & AgBDS & 159 & 2271 & 4623 & \multirow{2}{*}{-821} & \multirow{2}{*}{1252} & \multirow{2}{*}{-0.656} & \multirow{2}{*}{$(-2693 ; 2232)$} \\
\hline & Control & 46 & 3092 & 5399 & & & & \\
\hline \multicolumn{9}{|l|}{ Expectations } \\
\hline \multirow{2}{*}{ income from dairy } & AgBDS & 154 & 2721 & 2209 & \multirow{2}{*}{$-1,046$} & \multirow{2}{*}{962} & \multirow{2}{*}{-1.087} & \multirow{2}{*}{$(-3878 ;-98)$} \\
\hline & Control & 44 & 3767 & 3278 & & & & \\
\hline \multirow{2}{*}{$\begin{array}{l}\text { total health costs } \\
\text { for animal }\end{array}$} & AgBDS & 150 & 1171 & 1314 & \multirow{2}{*}{-304} & \multirow{2}{*}{321} & \multirow{2}{*}{-0.948} & \multirow{2}{*}{$(-900 ; 398)$} \\
\hline & Control & 42 & 1475 & 1289 & & & & \\
\hline \multicolumn{9}{|c|}{$\begin{array}{l}\text { Kernel estimates over common support, bootstrapped standard errors that account for clustering on the village } \\
\text { level (300, for border cases } 1000 \text { replications), propensity score includes geographical characteristics and is } \\
\text { trimmed at its tails (pscore }<0.82) \text {. }\end{array}$} \\
\hline
\end{tabular}

${ }^{105}$ An impact analysis combining administrative of the LPI and geographical data (Augsburg, 2009) addresses the issue further and finds quantitative confirmation of this hypothesis. 
Further, results presented in Table 5.7a suggest that receiving a loan and non-financial services reduces costs and foregone earnings experienced when the milk animals fall ill - as before, the effect is insignificant for participants that have non-financial services. As before, expectations indicate that the difference in outcomes between groups will become much smaller for both outcome variables.

The most important difference to the overall program effect (when looking at general outcomes indicators as presented in Table 5.7b) is that the effect on household income is less than half in size. The most plausible explanation for this is the higher effect on consumption that is found. Households that have added services to the loan consume for example food worth Rs. 28 more per day than the control group - this number was estimated to be Rs. 24 for the average customer as presented above.

Also in line with previous findings are positive but insignificant effects on savings and assets.

Table 5.7b: Effect of Add. Non-financial Services - General

\begin{tabular}{|c|c|c|c|c|c|c|c|c|}
\hline \multicolumn{9}{|c|}{ Effect of participating in the AgBDS Dairy Intervention (vs. CONTROL) } \\
\hline Outcome & Group & Obs & Mean & Std.Dev & $\begin{array}{l}\text { ATT } \\
\text { (i) }\end{array}$ & $\begin{array}{l}\text { se. } \\
\text { (ii) }\end{array}$ & $\begin{array}{l}\text { t-stat } \\
\text { (iii) }\end{array}$ & $\begin{array}{c}\text { bias corr CI } \\
\text { (iv) } \\
\end{array}$ \\
\hline \multicolumn{9}{|l|}{ Realizations } \\
\hline \multirow{2}{*}{$\begin{array}{l}\text { total hh } \\
\text { income }\end{array}$} & AgBDS & 183 & 76100 & 49877 & \multirow{2}{*}{7,892} & \multirow{2}{*}{11764} & \multirow{2}{*}{0.671} & \multirow{2}{*}{$(-12371 ; 30871)$} \\
\hline & Control & 162 & 68208 & 44364 & & & & \\
\hline \multirow{2}{*}{ assets } & AgBDS & 178 & 317176 & 248669 & \multirow{2}{*}{69,914} & \multirow{2}{*}{58338} & \multirow{2}{*}{1.198} & \multirow{2}{*}{$(-24574 ; 192026)$} \\
\hline & Control & 159 & 247262 & 224781 & & & & \\
\hline \multirow[t]{2}{*}{ savings } & AgBDS & 169 & 2475 & 4254 & \multirow[t]{2}{*}{691} & \multirow[t]{2}{*}{722} & \multirow[t]{2}{*}{0.958} & \multirow{2}{*}{$(-657 ; 1997)$} \\
\hline & Control & 156 & 1784 & 2405 & & & & \\
\hline \multirow{2}{*}{$\begin{array}{l}\text { food } \\
\text { consumption }\end{array}$} & AgBDS & 181 & 40395 & 16175 & \multirow{2}{*}{$10,280 *$} & \multirow{2}{*}{3038} & \multirow{2}{*}{3.384} & \multirow{2}{*}{$(4142 ; 15431)$} \\
\hline & Control & 162 & 30115 & 13230 & & & & \\
\hline \multirow{2}{*}{$\begin{array}{l}\text { other non- } \\
\text { durable } \\
\text { consumption }\end{array}$} & AgBDS & 183 & 17363 & 22405 & \multirow{2}{*}{$6,589 *$} & \multirow{2}{*}{2181} & \multirow{2}{*}{3.021} & \multirow{2}{*}{$(2485 ; 11289)$} \\
\hline & Control & 163 & 10773 & 15782 & & & & \\
\hline \multirow{2}{*}{$\begin{array}{l}\text { durable } \\
\text { consumption }\end{array}$} & AgBDS & 183 & 17332 & 11759 & \multirow{2}{*}{3,624} & \multirow{2}{*}{2034} & \multirow{2}{*}{1.782} & \multirow{2}{*}{$(-1340 ; 6541)$} \\
\hline & Control & 162 & 10708 & 9680 & & & & \\
\hline \multicolumn{9}{|l|}{ Expectations } \\
\hline \multirow{2}{*}{$\begin{array}{l}\text { total hh } \\
\text { income }\end{array}$} & AgBDS & 170 & 72321 & 50858 & \multirow{2}{*}{4,609} & 11273 & 0.409 & $(-13103 ; 27958)$ \\
\hline & Control & 154 & 67712 & 39206 & & & & \\
\hline $\begin{array}{l}\text { Kernel estimat } \\
\text { village level } \\
\text { characteristics }\end{array}$ & $\begin{array}{l}\text { over col } \\
300, \text { for } \\
\text { ind is trim }\end{array}$ & $\overline{\text { mons }}$ & port, bo & trappeds & idard e & s that & $\begin{array}{l}\text { count } f \\
\text { re inc }\end{array}$ & $\begin{array}{l}\text { clustering on the } \\
\text { des geographical }\end{array}$ \\
\hline
\end{tabular}




\subsubsection{Impact of having Livestock Insurance and receiving $A g / B D S$}

In this section, treatment is defined as having Livestock Insurance together with $\mathrm{Ag} / \mathrm{BDS}$ and the loan from BASIX. Tables 5.8a and 5.8b show the results.

Three important differences to the previous results are to be pointed out.

Table 5.8a: Effect of having loan, livestock insurance \& Ag/BDS - Investment Return

Effect of participating in the Livestock Insurance and AgBDS Dairy Intervention (vs. CONTROL)

\begin{tabular}{lllllllll}
\hline \hline & & & & ATT & se. & t-stat & bias corr CI \\
Outcome & Group & Obs & Mean & Std.Dev. & (i) & (ii) & (iii) & (iv) \\
\hline \hline Realizations & & & & & & & & \\
\hline $\begin{array}{l}\text { income from } \\
\text { dairy }\end{array}$ & BASIX-LI & 100 & 18455 & 12985 & $\mathbf{- 1 0 , 3 0 0 *}$ & 3282 & -3.136 & $(-17579 ;-4370)$ \\
\hline $\begin{array}{l}\text { total health } \\
\text { costs for } \\
\text { animal }\end{array}$ & BASIX-LI & 98 & 2992 & 5597 & $\mathbf{7}$ & 1291 & 0.005 & $(-2422 ; 2365)$ \\
\hline \hline Expectations & Control & 45 & 2985 & 5209 & & & & \\
\hline $\begin{array}{l}\text { income from } \\
\text { dairy }\end{array}$ & BASIX-LI & 97 & 3032 & 2468 & -589 & 809 & -0.729 & $(-2216 ; 682)$ \\
\hline $\begin{array}{l}\text { total health } \\
\text { costs for } \\
\text { animal }\end{array}$ & Control & 43 & 3622 & 2925 & & & & \\
\hline
\end{tabular}

Firstly, in terms of investment returns it can be seen that customers who have life insurance for their animal experience a quantitatively similar negative effect on income from selling milk. Nevertheless, they at the same time have higher veterinarian costs and expect these to further increase in the coming year as compared to the control group. This finding might be explained by the fact that many customers decide to take up the insurance product only when they anticipate a higher risk: talking to insurance clients, it became clear that many of them for example only chose to pay the premium when their animal was (or was about to be) in calf. The risk of the animal dying increases under these circumstances. It is hence likely that those livestock owners with insurance also experienced more health shocks to their animals. This is confirmed when looking at the percentage of households of whom an animal died in the previous year -17 per cent of households with livestock insurance experienced a loss in the previous year compared to three per cent of households in the control group (conditional on having animals). This percentage is slightly smaller when excluding calves but the difference remains with 12 compared to three per cent. 
Table 5.8b: Effect of having a loan \& Livestock Insurance \& Ag/BDS - General

Effect of participating in the Livestock Insurance and AgBDS Dairy Intervention (vs. CONTROL)

\begin{tabular}{|c|c|c|c|c|c|c|c|c|}
\hline Outcome & Group & Obs & Mean & Std.Dev. & $\begin{array}{l}\text { ATT } \\
\text { (i) }\end{array}$ & $\begin{array}{l}\text { se. } \\
\text { (ii) }\end{array}$ & $\begin{array}{l}\text { t-stat } \\
\text { (iii) }\end{array}$ & $\begin{array}{c}\text { bias corr } \mathbf{C I} \\
\text { (iv) } \\
\end{array}$ \\
\hline \multicolumn{9}{|l|}{ Realizations } \\
\hline \multirow{2}{*}{$\begin{array}{l}\text { total hh } \\
\text { income }\end{array}$} & BASIX-LI & 104 & 75186 & 51289 & \multirow{2}{*}{4,848} & \multirow{2}{*}{12550} & \multirow{2}{*}{0.386} & \multirow{2}{*}{$(-17369 ; 29489)$} \\
\hline & Control & 157 & 70338 & 42933 & & & & \\
\hline \multirow{2}{*}{ assets } & BASIX-LI & 101 & 383861 & 322751 & \multirow{2}{*}{122,000} & \multirow{2}{*}{58731} & \multirow{2}{*}{2.081} & \multirow{2}{*}{$(13376 ; 237752)$} \\
\hline & Control & 154 & 261661 & 237088 & & & & \\
\hline \multirow[t]{2}{*}{ savings } & BASIX-LI & 97 & 1798 & 2954 & \multirow[t]{2}{*}{8} & \multirow[t]{2}{*}{822} & \multirow[t]{2}{*}{0.01} & \multirow[t]{2}{*}{$(-1689 ; 1471)$} \\
\hline & Control & 150 & 1790 & 2460 & & & & \\
\hline \multirow{2}{*}{$\begin{array}{l}\text { food } \\
\text { consumption }\end{array}$} & BASIX-LI & 105 & 39320 & 16317 & \multirow[t]{2}{*}{8041} & \multirow[t]{2}{*}{3166} & \multirow{2}{*}{2.54} & \multirow{2}{*}{$(1015 ; 13012)$} \\
\hline & Control & 157 & 31279 & 13679 & & & & \\
\hline \multirow{2}{*}{$\begin{array}{l}\text { other non- } \\
\text { durable } \\
\text { consumption } \\
\end{array}$} & BASIX-LI & 107 & 19743 & 24350 & \multirow[t]{2}{*}{8906} & \multirow[t]{2}{*}{2771} & \multirow[t]{2}{*}{3.214} & \multirow{2}{*}{$(4585 ; 16139)$} \\
\hline & Control & 158 & 10837 & 15655 & & & & \\
\hline \multirow{2}{*}{$\begin{array}{l}\text { durable } \\
\text { consumption }\end{array}$} & BASIX-LI & 104 & 17086 & 11605 & \multirow{2}{*}{2,854} & \multirow{2}{*}{2552} & \multirow{2}{*}{1.118} & \multirow{2}{*}{$(-5121 ; 6292)$} \\
\hline & Control & 157 & 14231 & 9450 & & & & \\
\hline \multicolumn{9}{|l|}{ Expectations } \\
\hline \multirow{2}{*}{$\begin{array}{l}\text { total hh } \\
\text { income }\end{array}$} & BASIX-LI & 99 & 70114 & 48462 & \multirow[t]{2}{*}{1,667} & \multirow[t]{2}{*}{11992} & \multirow[t]{2}{*}{0.139} & $(-17209 ; 25471)$ \\
\hline & Control & 148 & 68448 & 37875 & & & & \\
\hline $\begin{array}{l}\text { Kernel estima } \\
\text { level (300, for } \\
\text { its tails (pscor }\end{array}$ & $\begin{array}{l}\text { over commo } \\
\text { rder cases } 1 \\
.82) \text {. }\end{array}$ & uppor & $\begin{array}{l}\text { bootstra } \\
\text { oropensi }\end{array}$ & $\begin{array}{l}\text { ed standa } \\
\text { score incli }\end{array}$ & errors th & acou & for clu & $\begin{array}{l}\text { ing on the village } \\
\text { and is trimmed at }\end{array}$ \\
\hline
\end{tabular}

The two other differences with respect to previous results are to be found in the general outcome indicators to be seen in Table 5.8b. For one, the effect on household income is much smaller in magnitude - about one fourth of the overall program effect on the same variable. And second the effect on assets is bigger - and contrary to the effect on household income, the effect on assets turns to be significant for participants with livestock insurance. This could be explained by the fact that household who have insurance and lost an animal get the premium and are able to buy a new (and maybe even more valuable) animal. This is again supported when looking at how many of those households that had an animal dying bought a new one - 55 per cent of those with livestock insurance did as compared to eight per cent without. 


\subsection{Conclusion}

This chapter is concerned with evaluating the impact of BASIX's intervention in the dairy sub-sector. This intervention falls under the umbrella of integrated microfinance services, offering non-financial services alongside the loan and insurance services. Given the specific feature of this microfinance intervention, special emphasise is placed on estimating the effect of the additional non-financial services. Several outcome indicators are considered to accredit the holistic approach that focuses not only on income-generation.

The results indicate a positive program effect on the conventional five per cent significance level on consumption of participants as well as on the income they receive from selling milk (products). These significant effects are consistent for all treatment groups considered - are hence independent on whether the customer takes only a loan or in combination with (non)financial services.

This finding confirms that the primary goal of integrated microfinance services is reached, namely reducing risk and uncertainty and by doing so helping to smooth the participants' consumption and in increasing the ability to cope with shocks.

In the intervention under consideration, it is foremost the Agricultural and Business Development Services that are supposed to serve these latter purposes and indeed, the effects on consumption are highest for those participants that had Ag/BDS at the time of the survey. Also results on participants who have livestock insurance indicate that this service effectively insures household against the loss of one of an extremely important asset in the context of the respondents' households' livelihoods - the milkanimal.

An unexpected result is the finding that program participants experience a negative impact on their income from engaging in milk selling as an extra income-generating activity. Possible explanations for this result (relating to the productivity of households as well as the available market linkages) were brought forward in the discussion of these results. An additional issue could be the fact that the analysis conducted lacks information that is obtainable but not available. The first set of information is a baseline survey. The potential bias that results from having no baseline and therefore not being able to account for differing starting values was discussed in the first section. The technique applied in the analysis, propensity score matching, minimizes this type of bias by matching closely resembling observations but it is possible that some bias remains.

The second set of information that is not accounted for is information on the village level. This issue is taken up on the next chapter, which is also concerned with evaluating the effect of $\mathrm{Ag} / \mathrm{BDS}$ on the customers' income. It will be seen there that not including information on a village level (such as the availability of market linkages) results in an underestimation of the program effect. Also this type of bias 
was addressed as far as possible by including regional information on the mandal level. Unfortunately, data collected about the survey villages was found to be too unreliable to be used in the analysis.

This study goes further than purely estimating the effect on realized indicators as is typically done in evaluation studies.

The availability of information on subjective expectations allows estimating the subjective return to investment into a milk-producing animal with a loan from the LPI. Estimates reveal that participants themselves expect a positive return on their household income from participating in the intervention in the future. They further expect to also in the coming year earn less from selling dairy in the coming than the control group. Nevertheless, the effect on expected income from dairy is much smaller in magnitude, almost approaching zero, than the one on realized income from dairy. 
Appendix 5a-Table 5.A1: Household Characteristics - by Group

\begin{tabular}{|c|c|c|c|c|c|c|c|}
\hline \multirow[t]{2}{*}{ Variable } & \multicolumn{3}{|c|}{ Customer (B) } & \multicolumn{3}{|c|}{ Control (C) } & \multirow{2}{*}{$\begin{array}{c}\text { ttest B vs. } \\
\text { C } \\
\text { t-stat } \\
\end{array}$} \\
\hline & median & mean & std.dev & median & mean & std.dev & \\
\hline hh-head - gender (1=male $)$ & 1.0 & 0.91 & 0.28 & 1.0 & 0.91 & 0.29 & -0.20 \\
\hline hh-head - age & 42 & 44 & 12 & 45 & 46 & 12 & 2.79 \\
\hline Education hh head: none & 1.0 & 0.58 & 0.49 & 1.0 & 0.73 & 0.44 & 4.19 \\
\hline Education hh head: some primary & 0.0 & 0.10 & 0.30 & 0.0 & 0.12 & 0.32 & 0.68 \\
\hline Educ. hh head: some secondary & 0.0 & 0.10 & 0.30 & 0.0 & 0.03 & 0.18 & -3.37 \\
\hline Educ. hh head: some high school & 0.0 & 0.15 & 0.35 & 0.0 & 0.07 & 0.26 & -2.97 \\
\hline spouse - age & 35 & 36.4 & 11.1 & 36 & 38.8 & 11.4 & 2.67 \\
\hline education spouse: none & 1.0 & 0.67 & 0.47 & 1.0 & 0.76 & 0.42 & 2.63 \\
\hline education spouse: some primary & 0.0 & 0.07 & 0.26 & 0.0 & 0.06 & 0.24 & -0.54 \\
\hline Educ. spouse: some secondary & 0.0 & 0.08 & 0.27 & 0.0 & 0.02 & 0.13 & -3.41 \\
\hline Educ. spouse: some high school & 0.0 & 0.07 & 0.26 & 0.0 & 0.02 & 0.13 & -3.26 \\
\hline no. of hh members & 4.0 & 4.72 & 1.80 & 5.0 & 4.92 & 1.84 & 1.49 \\
\hline no of kids between 0 and 5 & 0.0 & 0.28 & 0.55 & 0.0 & 0.27 & 0.56 & -0.41 \\
\hline no of kids between 5 and 10 & 0.0 & 0.42 & 0.68 & 0.0 & 0.37 & 0.62 & -0.92 \\
\hline no of kids between 10 and 15 & 0.0 & 0.66 & 0.86 & 0.0 & 0.68 & 0.86 & 0.22 \\
\hline caste: forward caste & 0.0 & 0.36 & 0.48 & 0.0 & 0.27 & 0.45 & -2.46 \\
\hline caste: backward caste & 0.0 & 0.45 & 0.50 & 0.0 & 0.48 & 0.50 & 0.71 \\
\hline caste: scheduled caste & 0.0 & 0.11 & 0.31 & 0.0 & 0.17 & 0.38 & 2.34 \\
\hline caste: scheduled tribe & 0.0 & 0.04 & 0.20 & 0.0 & 0.05 & 0.22 & 0.57 \\
\hline hh: vegetarian & 0.0 & 0.07 & 0.25 & 0.0 & 0.10 & 0.31 & 1.68 \\
\hline primary activity: farmer & 0.0 & 0.28 & 0.45 & 0.0 & 0.27 & 0.44 & -0.46 \\
\hline primary activity: agric. labour & 1.0 & 0.62 & 0.49 & 1.0 & 0.64 & 0.48 & 0.58 \\
\hline primary activity: selfemployed & 0.0 & 0.05 & 0.21 & 0.0 & 0.01 & 0.11 & -2.46 \\
\hline hh lived in village all life & 1.0 & 0.95 & 0.23 & 1.0 & 0.96 & 0.19 & 1.13 \\
\hline hh plans to move & 0.0 & 0.01 & 0.09 & 0.0 & 0.00 & 0.06 & -0.81 \\
\hline house ownership: own & 1.0 & 0.86 & 0.34 & 1.0 & 0.94 & 0.23 & 3.23 \\
\hline no. of rooms & 2.0 & 2.11 & 0.81 & 2.0 & 1.95 & 0.61 & -2.72 \\
\hline roof material: cement/RCC & 0.0 & 0.06 & 0.25 & 0.0 & 0.04 & 0.19 & 0.95 \\
\hline roof material: stone/slab & 1.0 & 0.78 & 0.42 & 1.0 & 0.81 & 0.39 & 1.13 \\
\hline roof material: sheet/tin & 0.0 & 0.04 & 0.21 & 0.0 & 0.06 & 0.24 & 0.91 \\
\hline floor material: cement & 0.0 & 0.06 & 0.24 & 0.0 & 0.04 & 0.21 & -0.86 \\
\hline floor material: stone & 1.0 & 0.89 & 0.31 & 1.0 & 0.91 & 0.29 & 0.69 \\
\hline bath: closed inside/outside house & 0.0 & 0.36 & 0.48 & 0.0 & 0.41 & 0.49 & 1.31 \\
\hline bath: enclosure in/outside house & 0.0 & 0.46 & 0.50 & 0.0 & 0.49 & 0.50 & 0.78 \\
\hline bath: shielded/thatched outside & 0.0 & 0.17 & 0.38 & 0.0 & 0.09 & 0.29 & -2.92 \\
\hline cooking fuel: $\mathrm{LPG}$ & 0.0 & 0.10 & 0.30 & 0.0 & 0.08 & 0.27 & -0.99 \\
\hline cooking fuel: Firewood & 1.0 & 0.83 & 0.38 & 1.0 & 0.91 & 0.29 & 2.96 \\
\hline drink water :publ outdoortab close & 1.0 & 0.72 & 0.45 & 1.0 & 0.82 & 0.38 & 3.27 \\
\hline drink water: publ outdoor tab far & 0.0 & 0.15 & 0.36 & 0.0 & 0.13 & 0.34 & -0.67 \\
\hline Asset: Agric Land & 1.0 & 0.80 & 0.40 & 1.0 & 0.77 & 0.42 & -0.88 \\
\hline Asset: Chair(s) & 2.0 & 2.28 & 1.47 & 2.0 & 1.82 & 1.16 & -4.32 \\
\hline Asset: Table(s) & 0.0 & 0.28 & 0.50 & 0.0 & 0.10 & 0.29 & -5.48 \\
\hline Asset: $\operatorname{Bed}(\mathrm{s})$ & 1.0 & 1.16 & 0.70 & 1.0 & 0.98 & 0.50 & -3.50 \\
\hline Asset: Cupboard(s) & 1.0 & 0.80 & 0.53 & 1.0 & 0.77 & 0.44 & -0.58 \\
\hline Asset: Radio & 0.0 & 0.04 & 0.20 & 0.0 & 0.03 & 0.18 & -0.77 \\
\hline Asset: Telephone / cell & 0.0 & 0.43 & 0.59 & 0.0 & 0.25 & 0.44 & -4.15 \\
\hline Asset: Sewing machine & 0.0 & 0.10 & 0.32 & 0.0 & 0.04 & 0.20 & -2.54 \\
\hline Asset: Electric iron & 0.0 & 0.24 & 0.43 & 0.0 & 0.16 & 0.36 & -2.78 \\
\hline
\end{tabular}




\begin{tabular}{|l|c|c|c|c|c|c|c|}
\hline \multicolumn{1}{|c|}{ Variable } & \multicolumn{3}{c|}{ Customer (B) } & \multicolumn{3}{c|}{ Control (C) } & test B vs. \\
C \\
\hline Asset: Electric Fans & 1.0 & 1.09 & 0.49 & 1.0 & 1.01 & 0.41 & -2.24 \\
\hline Asset: Steel Utensils & 1.0 & 1.19 & 0.87 & 1.0 & 1.38 & 1.14 & 2.59 \\
\hline Asset: Jewellery & 1.0 & 1.98 & 7.84 & 0.0 & 0.83 & 4.48 & -2.15 \\
\hline Asset: Bullock & 0.0 & 0.62 & 1.00 & 0.0 & 0.58 & 1.01 & -0.55 \\
\hline Asset: Buffalo & 1.0 & 1.66 & 1.50 & 0.0 & 0.51 & 1.04 & -10.9 \\
\hline Asset: Irrigation Equipment & 0.0 & 0.16 & 0.71 & 0.0 & 0.04 & 0.20 & -2.68 \\
\hline Asset: Modern agric. equipment & 0.0 & 0.16 & 0.40 & 0.0 & 0.06 & 0.26 & -3.60 \\
\hline Asset: other agricultural equip. & 0.0 & 0.23 & 0.43 & 0.0 & 0.18 & 0.40 & -5.01 \\
\hline
\end{tabular}

APPENDIX 5.B - Table 5.B1: Propensity Score of being a participant vs. Control

\begin{tabular}{lccc}
\hline \multicolumn{4}{c}{ Probit Model for being a dairy customer of BASIX } \\
\hline variable & coef & std.err & $\mathbf{z}$ \\
\hline \hline No of kids under 5 & -0.027 & 0.114 & -0.23 \\
No of kids between 5 and 10 & -0.017 & 0.070 & -0.25 \\
Vegetarian household (0/1) & -0.057 & 0.204 & -0.28 \\
hh head: age & -0.015 & 0.041 & -0.36 \\
hh head: age & 0.000 & 0.000 & 0.29 \\
hh head: gender (1=male) & -0.962 & 0.550 & -1.75 \\
hh head education: none & -0.310 & 0.139 & -2.22 \\
spouse: age & 0.013 & 0.040 & 0.34 \\
spouse: age & 0.000 & 0.000 & -0.51 \\
spouse education: none & -0.251 & 0.167 & -1.5 \\
caste: backward & 0.212 & 0.155 & 1.36 \\
caste: forward & 0.216 & 0.175 & 1.23 \\
hh primary activity: farmer & 0.378 & 0.255 & 1.48 \\
hh primary activity: agricultural labour & 0.272 & 0.242 & 1.13 \\
hh primary activity: self-employed & 0.975 & 0.461 & 2.12 \\
lived in village all life (0/1) & 0.783 & 1.411 & 0.55 \\
hh plans to move (0/1) & 0.181 & 0.849 & 0.21 \\
risk experienced: illness (0/1) & 0.129 & 0.145 & 0.89 \\
female population per area & -1.896 & 0.512 & -3.7 \\
distance to Anantapur & -0.048 & 0.010 & -4.58 \\
average landholding & 3.491 & 0.916 & 3.81 \\
no. of workers per household & -22.812 & 4.247 & -5.37 \\
no. of veterinarian staff per household & 1.608 & 1.576 & 1.02 \\
grazingland per area & -6.154 & 1.635 & -3.76 \\
villages on main road (\%) & 6.338 & 1.872 & 3.39 \\
villages with bus stop (\%) & 3.391 & 1.111 & 3.05 \\
irrigated area used for paddy (\%) & -5.508 & 2.524 & -2.18 \\
bankbranches per population & 0.000 & 0.000 & 3.8 \\
literates (\%) & -52.737 & 18.859 & -2.8 \\
Constant & 70.925 & 16.411 & 4.32 \\
\hline \hline Common support was chosen and yielded the following region: & & & \\
Indications: LR Chi ${ }^{2}(194.5)=$, Pseudo $R^{2}=0.24$. & $0.99] ;$ & Model \\
& & &
\end{tabular}


Table 5.B2: Balancing Property

\begin{tabular}{|c|c|c|c|}
\hline Inferior of block of pscore & Conrtol & LPI & Total \\
\hline 0.20 & 27 & $\overline{111}$ & 38 \\
\hline 0.40 & 37 & 17 & 54 \\
\hline 0.50 & 29 & 46 & 75 \\
\hline 0.60 & 60 & 168 & 228 \\
\hline 0.80 & 16 & 90 & 106 \\
\hline 0.9 & 4 & 108 & 112 \\
\hline Total & 173 & 440 & 613 \\
\hline
\end{tabular}

Figure 5.B1: Histogram of Propensity Score of being a participant

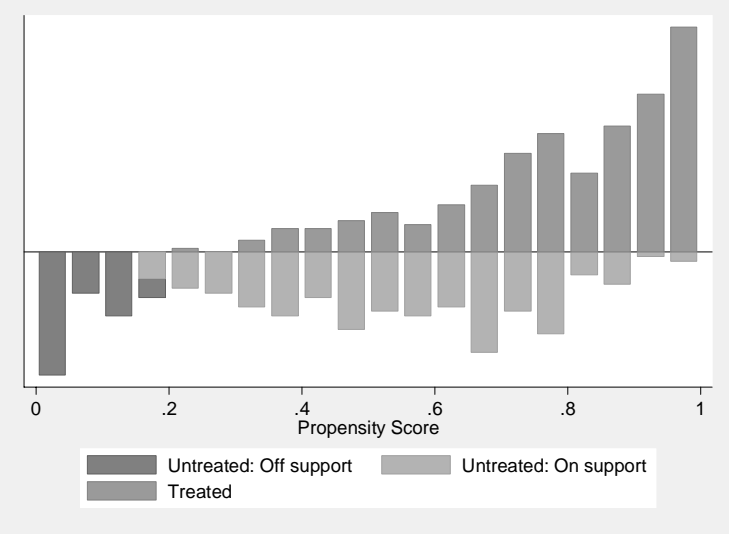




\section{Microfinance Plus: Impact of the 'plus' on customers' income in rural India}

\subsection{Introduction}

Like the previous chapter, this chapter is concerned with estimating the impact of BASIX's dairy intervention on its customers, more specifically the effect of having additional services with the loan. Also, this chapter gives new insights into whether microfinance credit has a higher impact on the customers' productivity if non-financial support related to that activity is provided as well. The crucial difference to the previous chapter lies in the data used: while the earlier analysis used data from a survey that was specifically designed to be able to conduct an impact analysis, this chapter deals with data that is readily available. More specifically, information on households is taken from the organisation's Management Information System (MIS). This data is merged with regional information that is made publicly available by the Department of Economics and Statistics, Andhra Pradesh.

This latter data on regional characteristics is used to address the problem of endogeneity that is inherent in every evaluation study other than randomized control trials. The endogeneity bias one has to deal with typically results from unobservable characteristics of a borrower or issues such as programme placement. A classical example is that income of a borrower might be higher not due to having been able to engage in an extra income generating activity, but because he had higher motivation and entrepreneurial spirit to begin with. McKernan (2002) finds that such (selfselection) bias can result in an overestimation of programme benefits of up to 200 per cent. One of the perhaps most often cited impact assessment that accounts for such selection bias is that of the Grameen Bank in Bangladesh. The authors, Pitt and Khandker (1998), investigate the impact of a microfinance programme on poor households, focussing on female participants. They rely on a quasi-experimental survey design to account for self-selection. One of their findings is that both men and women benefit from the programme, but women do to a greater extent. Other interesting studies with similar results include Coleman (1999, 2002), Binswanger and Khandker (1995) and Khandker \& Feruqee (2003). ${ }^{106}$

${ }^{106}$ For a review of impact evaluations of additional microfinance services see the Introduction of chapter five. 
This chapter relies on an instrumental variable approach to account for endogeneity in estimated effects. The estimated effect is the one of having additional services alongside the loan. Since the loan is for the purpose of buying a bovine animal, the additional services for example include how to feed and keep the animal and regular check-up visits by a veterinarian. ${ }^{107}$ Findings of this study suggest that such additionally offered services alongside the microfinance loan have no significant effect in the context of the intervention. In other words, customers who purchase nonfinancial services designed to support their loan-related income generating activity experience no difference in their income compared to customers that only avail credit. Comparing to simple ordinary least square regression results, not accounting for endogeneity would overestimate this effect significantly: When taking having the services as random, the estimated effect is estimated to be positive and highly significant. Of further interest is the result that not accounting for market linkages in the estimation underestimates the effect: the estimate is negative (still insignificant though) when not taking information on availability or non-availability of different buyers of the milk product into account.

The non-availability of information on non-clients as well as a very constrained set of outcome indicators set limits to the analysis. Due to these constraints, only the effect of a component of the programme on household income can be estimated. As could be seen in the previous analysis, finding no significantly positive effect on income does not imply a failure of the program. Many other indicators play a role when talking about successful or unsuccessful livelihood promotion. This caveat is acknowledged but it needs to be stressed that the main purpose of this chapter is to explore the possibilities of evaluating a programme - or a component of a programme - with data readily available and hence much more cost-efficient than when collecting survey data. It gives insight into possibilities as well as limitations that one has based on information that the microfinance institution collects anyway in their daily activities in combination with data that can be attained from official statistics departments.

Comparing results from this analysis with those presented in the previous chapter gives confidence in the estimates presented here. Both evaluations - the one with readily available data as well as the one making use of household survey data - find an insignificant effect.

Since the programme under consideration was described in detail in section two of the previous chapter, the next section jumps directly to the description of the data used in this analysis. The third section goes on describing the strategy to address the problem of endogeneity. Thereafter, estimation results are presented and the final section concludes.

\footnotetext{
${ }^{107}$ See chapter five, Section 2 for details on the intervention under consideration.
} 


\subsection{The Data}

In order to assess the impact these additional non-financial dairy services have on BASIX's clients' income, a data set was constructed from four different sources. The first source is the Management Information System (MIS) of BASIX. This system collects data on all of the organisation's clients, including socio-economic information as well as all data related to the loan, its repayment and on insurance or other services taken by the client. The second source is a separate list from BASIX, providing the name, village and application date of customers who bought Ag/BDS-dairy services. This information was at the time not integrated into the MIS and needed therefore to be matched with loan information of the client.

This data was then merged with official statistics ${ }^{108}$ of Anantapur district as provided in the "District Hand Book of Statistics". These statistics are available from the Directorate of Economics and Statistics, Government of Andhra Pradesh, Hyderabad. It is an extensive data set on population, industries, housing, employment, price indices, state finance, five year plans, tourism, environment and almost any other area, some of which is disaggregated on the mandal level. ${ }^{109}$ The data is collected from various central/state government departments, public sector undertakings, corporations and other agencies and is available on a yearly basis from 2000 to 2006. For this study, data from the financial years 2003/04 and 2004/05 was used in the analysis.

Finally, the fourth data source used is information collected on alternative (nonBASIX) milk vendors it was collected specifically for this study and integrated in the analysis. ${ }^{110}$

The client data was extracted in January 2007 so that the final sample consisted of clients, who became customers of BASIX in the time period from the first of April 2003 to the $30^{\text {th }}$ of December 2006 (reducing the sample from 15,557 to 12,570 observations). While BASIX offers loans for different investment purposes ${ }^{111}$, only clients that took a loan for the purpose of buying a cow or a buffalo were considered as these had the possibility to opt for additional services ${ }^{112}$ (reducing the sample to 4,410 observations). The sample needed to be restricted further due to non-availability of income figures (416 observations had a stated annual income of zero Rupees, 468 of less than 1,000 Rupees, and 63 of more than 500,000 Rupees) as well as the nonavailability of the loan size (for 131 clients the loan size was stated to be below 500

\footnotetext{
${ }^{108}$ Handbook of Statistics, 2004-05 Anantapur District, available for purchase at the Directorate of Economics and Statistics, Hyderabad, Andhra Pradesh, India.

${ }^{109}$ India is divided into several subnational administrative units. Mandals form the third subdivision below states and districts (www.wikipedia.org).

${ }^{110}$ I would like to thank Ramanjaneya Reddy P., unit head Anantapur, for making this extra data collection possible.

${ }^{111}$ See Appendix 6.A Table 1 for the different loans and their distribution given the final sample and Table 2 for comparative statistics on dropped and kept observations.

${ }^{112} \mathrm{Ag} / \mathrm{BDS}$ is also offered for crop-loans which make up only $7.5 \%$ of all $\mathrm{Ag} / \mathrm{BDS}$-clients though.
} 
Rupees - a loan size not given by BASIX). The final sample consisted of 3332 observations. ${ }^{113}$

Table 6.1 provides information on the customer's socio-economic background as well as on their financial relationship with BASIX, split by whether the customer took on additional services or not.

The great majority (about 65 per cent) are female clients in their mid thirties belonging to Other Backward Classes (OBC) $)^{114}$ or other castes. Only 1.2 per cent of all clients belong to the scheduled castes (ST) and eight per cent to scheduled tribes (SC). On a district basis, these percentages are only available for SC and ST for more recent years. According to the census of 2001, two per cent of Anantapur's population belonged to the ST and eight per cent to SC and proportions are hence almost identical to the sample proportions. ${ }^{115,116}$

Table 6.1: Socio-Economic Characteristics of sample

\begin{tabular}{|c|c|c|c|c|c|}
\hline \multirow{3}{*}{ Variable } & \multicolumn{4}{|c|}{ Dairy } & \multirow{3}{*}{$\begin{array}{c}\text { t-stat } \\
\text { for equivalence } \\
\text { of means across } \\
\text { two groups }\end{array}$} \\
\hline & \multicolumn{2}{|c|}{ WithOUT Ag/BDS } & \multicolumn{2}{|c|}{ WITH Ag/BDS } & \\
\hline & mean & sd & mean & sd & \\
\hline Observations & 2,056 & & 1,397 & & \\
\hline Yearly income (Rs.) & 86,451 & 1,460 & 108,080 & 1,908 & -9.13 \\
\hline Age & 35.89 & 0.18 & 35.03 & 8.34 & -2.08 \\
\hline Female & 0.67 & 0.01 & 0.71 & 0.01 & -2.31 \\
\hline Familysize & 4.19 & 0.03 & 1.66 & 0.04 & 51.2 \\
\hline Other Backward Caste, $\%$ & 0.40 & 0.01 & 0.36 & 0.01 & 2.62 \\
\hline Other Caste, $\%$ & 0.47 & 0.01 & 0.51 & 0.01 & -2.59 \\
\hline Scheduled Caste, $\%$ & 0.09 & 0.01 & 0.10 & 0.01 & -1.38 \\
\hline Scheduled Tribes, $\%$ & 0.02 & 0.00 & 0.01 & 0.00 & 3.46 \\
\hline Minority caste, $\%$ & 0.02 & 0.00 & 0.02 & 0.00 & -0.97 \\
\hline
\end{tabular}

It can be seen that clients with $\mathrm{Ag} / \mathrm{BDS}$ tend to be wealthier than those without, while on the other hand they are more likely to have a thatched roof as compared to one made of stone for clients without Ag/BDS.

\footnotetext{
${ }^{113}$ Appendix A includes a table on descriptive statistics and t-tests of the variables dropped and kept. Customer Characteristics are in general comparable. Exceptions are that of the dropped observations, customers have on average statistically significant bigger families and are younger if they have Ag/BDS; more are male and belong to Backward Castes, Scheduled Case or Scheduled Tribes if they do not have $\mathrm{Ag} / \mathrm{BDS}$. Income figures and variables that give information on the loan are almost all significantly different between dropped and kept observations, no matter whether customers have Ag/BDS or not. This is not surprising given that these relate to reasons for dropping observations.

${ }^{114}$ Other backward classes - as well as scheduled tribes and scheduled castes - are Indian communities that are granted a special status by the constitution of India in order to extend positive discrimination against these groups.

${ }^{115}$ Data on OBC are available only in the 1931 census. There, OBCs are estimated to make up 52 per cent of the population, as compared to 60 per cent of the client sample under consideration.

${ }^{116}$ Note that variables are also in line with sample averages of the survey data set used in the previous chapter.
} 
Table 6.2 shows the average loan size of clients is about 11,500 Rupees (approximately US\$290) - covering the cost of a cow or a buffalo. On average, clients with $\mathrm{Ag} / \mathrm{BDS}$ repay the loan in less instalments than those without, all other loan characteristics (security amount, amount overdue and number of days overdue) do not seem to differ systematically between the two groups. Most of the observations in the sample have taken only one loan, while clients without Ag/BDS are more likely to have had an earlier loan with BASIX.

Table 6.2: Loan information of sample

\begin{tabular}{|c|c|c|c|c|c|}
\hline \multirow{3}{*}{ Variable } & \multicolumn{4}{|c|}{ Dairy } & \multirow{3}{*}{$\begin{array}{c}\text { t-stat } \\
\text { for equivalence } \\
\text { of means } \\
\text { across two } \\
\text { groups }\end{array}$} \\
\hline & \multicolumn{2}{|c|}{ WithOUT Ag/BDS } & \multicolumn{2}{|c|}{ WITH Ag/BDS } & \\
\hline & mean & sd & mean & sd & \\
\hline Observations & 2,056 & & 1,397 & & \\
\hline Loan size (Rs.) & 11,489 & 109 & 11,573 & 82 & -0.57 \\
\hline No. of Loans with BASIX & 1.11 & 0.01 & 1.00 & 0.00 & 10.64 \\
\hline Number of instalments & 18.76 & 0.13 & 15.75 & 0.10 & 16.94 \\
\hline Amount overdue (Rs.) & 20.66 & 6.87 & 5.03 & 3.81 & 1.76 \\
\hline No. of Days overdue & 5.49 & 1.19 & 3.55 & 0.25 & 1.34 \\
\hline Security Amount & 1149 & 10.85 & 1157 & 8.22 & -0.56 \\
\hline
\end{tabular}

\subsection{Strategy to address endogeneity}

The fact that a programme itself, as well as participation in the program, is not assigned randomly, can create substantial problems in assessing the effect of an intervention. In this setting, a comparison between villagers lending from BASIX that receive $\mathrm{Ag} / \mathrm{BDS}$ and villagers lending from BASIX that do not receive $\mathrm{Ag} / \mathrm{BDS}$, even when controlling for observed characteristics, can yield very misleading results - as highlighted by McKernan (2002). This is due to participation in an intervention being neither on the demand nor on the supply side at random. Both, the placement of the intervention by the institution and participation by clients are choice variables that give rise to endogeneity problems.

Several strategies can be followed to tackle (and solve) this problem of endogeneity, one of which is an instrumental variable approach, as applied in this chapter. That is, at least one variable will be identified that is likely to affect the participation in the intervention of interest but is unlikely to affect the outcomes of interest directly.

Typically, one looks either on the demand or supply side for appropriate instruments.

According to demand theory, price can be a good instrument for predicting a product's demand. The price of BASIX charges for the Ag/BDS services changed twice during the sample period: in the initial testing phase, the fees were set at 50 rupees, then 100 
rupees and 200 rupees per year, in 2004-05 at the end of financial year Ag/BDS took off with a fee of Rs 150 and was standardized to Rs 300/- in 2006-07. Since it is not apparent from the data who was charged with which amount, this variation in costs is not a useful predictor of demand for the service.

This study turns to the supply side for identifying instrumental variables. Most often, eligibility criteria are used as instruments (see for example Pitt and Khandker, 1998). Nevertheless, since BASIX does not have any exogenous eligibility criteria for $\mathrm{Ag} / \mathrm{BDS}$, a different instrumental strategy will have to be adopted which was first proposed by Khandker and Faruqee (2003). It is based on the assumption that resources of an organisation, in this case BASIX, ${ }^{117}$ as well as other resources (such as milk-chilling plants in the area) are constrained, and the demand for services exceeds the supply. This implies that BASIX needs to make two sets of choices in the process of lending and delivering services. The first set of choices relates to where to operate. The second set of choices relates to whom to take on as customers within the chosen areas. This latter choice becomes irrelevant for matters of this study as only customers rather than non-customers are considered in this study.

It is the first set of choices made by the organisation, i.e. where to operate, which is made use of in this study in order to identify suitable instruments, which can account for the endogeneity of dairy $\mathrm{Ag} / \mathrm{BDS}$ services.

The idea is that given the fixed resources, BASIX can only operate in a constrained number of areas and hence chooses those that have greatest potential for the intervention to be successful. BASIX staff calls such areas 'areas with dairy potential'. Phansalkar \& Gosh (2001) point out that BASIX strives to allocate resources to the best possible borrowers and to operate in areas with favourable factor conditions (like availability of power, roads, milk chilling plants, etc.), demand conditions (size of domestic/local market, presence of buyers, general growth rate of domestic demand, etc.) and related supporting industries.

The approach of choosing certain areas to operate in implies that potential clients who live in more promising areas (as perceived by BASIX) are also more likely the additional services from BASIX. In other words, given the available resources of BASIX, whether a client receives additional services or not depends not only on the own demand but also on the area the client is living in. In the same vein, and this is the crucial aspect for the identification strategy in this chapter, it also depends on the area other clients live in; these 'other areas' can hence be seen as competitors to one's own.

The proposed instruments in this study are hence characteristics of these 'competing' areas. To give an example: In BASIX's choice of where to establish and hence offer additional services related to dairy activities, the number of veterinarians per

\footnotetext{
${ }^{117}$ Resources in the form of staff, such as number of field executives and hence nr of villages they are able to cover; in the form of veterinarians that can serve the village and so on.
} 
household can be seen as one determining factor. Nevertheless, once services are in place, the impact of BASIX's intervention on customers' income will not be dependent on the number of veterinarians (per household) in another area. The characteristics of other areas therefore fulfil the requirements of valid instruments namely that they are correlated with the endogenous explanatory variable but are uncorrelated with the error term of the regression equation.

As described in the data section, the smallest area unit for which official statistics are available are mandals. The district Anantapur is divided into 63 mandals. In 29 out of these BASIX offers loans for the purpose of buying a cow or a buffalo.

Information on these mandals $m, X_{\mathrm{m}}$, are to be included as explanatory variables in the model. Averages of these same indicators for all mandals except for the one the subject lives in, contribute to the proposed instruments, $\bar{X}_{A-m} \cdot{ }^{118}$

The basic point of departure for impact estimation is then the following equation:

$$
y_{i m}=\alpha_{1} X_{i m}+\beta S_{i m}+\varepsilon_{i m},
$$

with $y_{i m}$ indicating the outcome variable of interest (here income) for client $i$ in mandal $m, X_{i m}$ are customer characteristics as well as mandal characteristics, $S_{i m}$ denoted whether a client receives $\mathrm{Ag} / \mathrm{BDS}$ or not and $\varepsilon_{i m}$ is an unsystematic error term. $\alpha_{I}$ and $\beta$ are unknown parameters to be estimated. If no problem of endogeneity was encountered and all determining variables were observed, estimated $\beta$ by OLS would measure the impact of having $\mathrm{Ag} / \mathrm{BDS}$ on income without any bias. Nevertheless, receiving $\mathrm{Ag} / \mathrm{BDS}$ or not, $S_{i m}$, and the error term of the equation, $\varepsilon_{i m}$, are correlated the source of the described endogeneity bias.

In the Instrumental Variable approach that accounts for this bias and that is applied in this chapter, the determinants of $\mathrm{Ag} / \mathrm{BDS}$ are estimated in a first stage; $\mathrm{Ag} / \mathrm{BDS}$ being modelled as follows:

$$
S_{i m}=\alpha_{2} X_{i m}+\alpha_{3} \bar{X}_{A-m}+v_{i m}
$$

where $\alpha_{2}$ and $\alpha_{3}$ are again unknown parameters, $\bar{X}_{A-m}$ is as defined above and $v_{\text {im }}$ is the error term, assumed to have an expectation of zero given the explanatory variables. As mentioned, $\bar{X}_{A-m}$ are average mandal information for all mandals other than the one the observation lives in. The characteristics chosen are those that influence

${ }^{118}$ Within-area competitor's characteristics can be dismissed as most likely being poor instruments because of 'spill-over' and 'social capital' arguments. 
BASIX's decision of where to offer the services but the income of the observation is not influenced by these variables and can hence be excluded from equation (1).

\subsection{Estimation Results}

6.4.1. Estimates of Ag/BDS Impact on income - Simple OLS Results and Testing for
Endogeneity

Observable customer characteristics included in the model are the age (squared) and sex of the customer, information on the family size, an interaction term between the latter two variables and one between age (squared) and being female. Information on the caste of the household is included as well as information on the type of the household's roof. All other customer characteristics captured in the MIS (such as primary occupation and asset value) could not be used as the number of clients for whom this was recorded is very limited.

Further included were variables providing information on the borrowing-relationship between the client and BASIX, namely the number of loans taken, the size of the latest loan and whether or not a customer was active at the time the data was extracted from the MIS.

Finally, mandal characteristics used in the model include information on percentage deviation from normal rainfall in the mandal over the last four years, as well as government expenditure and receipts in the mandal in the financial year 2004-05 per 1,000 households. The variables on rainfall were chosen due to the strong dependence on agriculture in the study area in combination with low availability of irrigation facilities for poor households. Government receipts and expenditures can be interpreted as a proxy of wealth as well as availability of other services and infrastructure in the region.

The other regional characteristics included are counter-parts to the instrumental variables. More details are given below when describing the instruments used.

The dependent variable is the logarithm of overall annual household income. BASIX reports annual income of the household in its MIS due to most households being, as already stated, highly dependent on agriculture - and hence on seasonal income. This makes annual income much more informative in terms of wealth of the household than monthly income.

As a first step, equation (1) is estimated by simple OLS, which takes the services as randomly given. Results are presented in Table 6.4.

The results suggest that taking the additional services has a positive and highly significant effect on household income. Nevertheless, these results are likely to be biased due to a correlation of the indicator of whether a customer receives $\mathrm{Ag} / \mathrm{BDs}$ or 
not and the error term of (1). The Wu-Hausman as well as the Durbin-Wu-Hausman tests were applied in order to test for this endogeneity. Results are presented in Table 6.5. Both of these tests indicate that there are systematic differences between the two models. This means the OLS results show that whether a client receives Ag/BDS or not cannot be taken as given and IV estimates are to be preferred over the simple OLS estimates.

Table 6.4: Simple OLS regression Results

\begin{tabular}{|l|cc|}
\hline & Ordinary Least Squares \\
\hline \hline Dependent Var: log(Income) & coeff. & t-stat \\
\hline Ag/BDS & $\mathbf{0 . 1 2 8}$ & $\mathbf{3 . 7 9 0}$ \\
\hline Age $^{2}$ & 0.000 & 1.430 \\
Female & -0.394 & -5.910 \\
Female*Familysize & 0.072 & 6.460 \\
Female*Age ${ }^{2}$ & 0.000 & 1.140 \\
log(Familysize) & -0.080 & -2.650 \\
Caste: OC & -0.086 & -3.760 \\
Caste: ST & -0.187 & -2.180 \\
Caste: SC & -0.135 & -3.390 \\
Roof: Stones & -0.096 & -3.190 \\
Roof: Tiles & -0.085 & -1.230 \\
\hline log(Loansize) & 0.404 & 9.600 \\
no. Of loans taken with BASIX & -0.359 & -9.800 \\
Active customer & 0.256 & 8.230 \\
\hline \% deviation rainfall 2005 & 0.274 & 1.870 \\
\% deviation rainfall 2004 & -0.402 & -3.390 \\
\% deviation rainfall 2003 & 0.362 & 2.090 \\
\% deviation rainfall 2002 & -0.024 & -0.450 \\
Gvnmt expenditure per 1,000 households (04-05) & 25.32 & 1.57 \\
Gvnmt receipts per 1,000 households (04-05) & -4.663 & -0.3 \\
Average difference in rural domestic electrification per household & -0.008 & -0.11 \\
Average difference of veterinarian staff per household & 0.067 & 0.83 \\
Average growth in area used for agriculture & 0.227 & 3.74 \\
Average growth in area used food production & -0.056 & -0.85 \\
Average growth in area used non-food production & 0.005 & 0.07 \\
log(landrevenue per household) & -0.004 & -1.1 \\
No. of banks per household & 0.630 & 4.06 \\
\hline Constant & 7.066 & 17.19 \\
\hline \hline Number of obs.: 3370 & $\mathbf{F ( 2 7 , 3 3 4 3 )}$ & 24.43 \\
& $\mathbf{P r o b}>\mathbf{F}$ & 0.00 \\
$\mathbf{R}^{2}$ & 0.165 \\
& Adj. $\mathbf{R}^{2}$ & 0.158 \\
\hline \hline Notes: OLS estimates with bootstrapped standard errors at the village level & \\
\hline
\end{tabular}

Table 6.5: Test statistics for the endogeneity of $\mathrm{Ag} / \mathrm{BDS}$

\begin{tabular}{llllll}
\hline Tests of endogeneity of: Dairy-Ag/BDS services & & & & \\
\hline \hline H0: Regressor is exogenous & 6.964 & $\mathrm{~F}(1,3312)$ & p-value: & 0.008 \\
Wu-Hausman F test: & 6.992 & Chi-sq(1) & p-value: & 0.008 \\
Durbin-Wu-Hausman chi-sq test: & & & & \\
\hline
\end{tabular}




\subsubsection{Estimates of Ag/BDS Impact on income - Instrumental Variable Regression}

Given the confirmation of $\mathrm{Ag} / \mathrm{BDS}$ being an endogenous variable, the instrumental variable approach is now estimated. ${ }^{119}$

The first stage regression includes - in addition to all variables used in the OLSmodel, average 'competitors' characteristics as instruments. As described above, these are variables that influence whether services are being made available in a certain area or not, but have no influence on the customer's income. Table 6.6 lists the variables used in the final model and provides a brief explanation of why they were chosen and an interpretation of the sign of the estimated coefficient. Note that all these variables are averages in other mandals than the one a customer lives in.

\section{Table 6.6: Instrumental Variables}

\begin{tabular}{|c|c|}
\hline Instrument & Explanation \\
\hline $\begin{array}{l}\text { difference of } \\
\text { veterinarian staff in } \\
2003-04 \text { and } 2004-05 \\
\text { per } 1,000 \text { hhs }\end{array}$ & $\begin{array}{l}\text { Also part of } \mathrm{Ag} / \mathrm{BDS} \text { are regular check-ups for the animals. The } \\
\text { estimated coefficient suggests that if the difference in veterinarian } \\
\text { staff between two financial years is on average bigger in other } \\
\text { mandals than in the one the customers lives in, he/she is more likely } \\
\text { to have } \mathrm{Ag} / \mathrm{BDS} \text { services. }\end{array}$ \\
\hline $\begin{array}{l}\text { average number of } \\
\text { milk animals per } \\
1,000 \text { households, }\end{array}$ & $\begin{array}{l}\text { BASIX does not offer dairy-loans in areas where hardly any } \\
\text { households are engaged in dairy activities. A certain presence of } \\
\text { these is important for the success of the intervention. Nevertheless, } \\
\text { a part of the service in the dairy intervention includes the } \\
\text { establishment of market linkages in areas where BASIX sees } \\
\text { potential. This explains the positive coefficient of the variable in the } \\
\text { model. }\end{array}$ \\
\hline $\begin{array}{l}\text { growth in area used } \\
\text { for food production } \\
\text { from } 2003-04 \text { to } \\
2004-05\end{array}$ & $\begin{array}{l}\text { Availability of fodder for the animals is a big risk factor for many } \\
\text { customers. Some customers get fodder from their own land or } \\
\text { purchase it. However, most collect fodder which makes the } \\
\text { availability of grazing or undeveloped land important. The growth } \\
\text { in land, which is used for food production can be seen as a proxy of } \\
\text { how much land is unused and hence available for fodder collection. }\end{array}$ \\
\hline $\begin{array}{l}\text { average growth in } \\
\text { area used for } \\
\text { agriculture }\end{array}$ & $\begin{array}{l}\text { This variable is seen as important since most of BASIX customers } \\
\text { are engaged in agriculture as their main source of income - either } \\
\text { owning some land themselves or working as agricultural wage } \\
\text { labourers. Furthermore, 'waste' from harvests often serves as an } \\
\text { additional source for fodder for animals. }\end{array}$ \\
\hline $\begin{array}{l}\text { average difference in } \\
\text { rural domestic } \\
\text { electrification per } \mathrm{hh}\end{array}$ & $\begin{array}{l}\text { This variable can be seen as a proxy for the level of development in } \\
\text { an area. Having electricity is still not an issue in areas where } \\
\text { BASIX operates of course. }\end{array}$ \\
\hline $\begin{array}{l}\text { number of } \\
\text { households per area }\end{array}$ & $\begin{array}{l}\text { The number of households per area can be seen as important in an } \\
\text { organisation's service supply decision in terms of having enough } \\
\text { demand for the product offered. }\end{array}$ \\
\hline
\end{tabular}

\footnotetext{
${ }^{119}$ Limited Information Maximum Likelihood is applied. See Greene (2005), Chapter 15 for a review.
} 
In addition to the competitors' characteristics, one further variable was used as an instrument. This is the distance of the mandal capital to Anantapur - the district capital and at the same time the town where BASIX has its main office in the district. This variable is an important variable in BASIX service supply decision. The typical approach is to first serve areas that are closer to the main office and then expand into areas further away. Once the distance gets too big, a branch is established in those respective areas. This approach is reflected in the estimated coefficient of the variable: the further away a customer lives, the less likely it is that he or she has access to $\mathrm{Ag} / \mathrm{BDS}$ services.

Note that although the dependent variable is a binary indicator, a linear model is used for estimation. Angrist (2001) provides evidence that a linear instrumental variable approach can be used in the context of a binary endogenous variable.

The last two columns of Table 6.7 display estimation results of the instrumental variable approach - the approach that was shown to be preferred over simple OLS estimates.

When accounting for the endogeneity of the additional (Ag/BDS) services, the effect of having $\mathrm{Ag} / \mathrm{BDS}$ on a customer's income is estimated to be negative but insignificant. The estimated coefficient changes from a positive value of 0.128 to a negative one of 0.188 . This is a considerable change and shows by how much a programme effect might be overestimated when not accounting for endogeneity. While insignificant the negative effect is considerably counterintuitive and calls for more attention. The issue will be looked at in more detail in the next section.

Most other estimated coefficients in the model have the expected sign given the cultural setting of the area. Belonging to scheduled tribes or a scheduled caste for example has a negative effect and also being female translates into lower income. Being older on the other hands increases income, all else equal.

One unexpected result is the coefficient on the number of loans a client took out. This variable is estimated to have a highly significant negative effect, which is unexpected in the sense that one would assume long-term benefits from taking part in such a programme (with time the loan size increases and opens up more opportunities, and clients would be expected to slowly mature into higher income brackets). Nevertheless, some support for the finding comes from Khandker and Pitt (2003). In their paper they examine the impacts of microfinance on a number of outcomes using a panel household survey from Bangladesh. More specifically, they consider issues such as whether the effects of microfinance are saturated or crowded out over time, whether programmes generate externalities, and whether the estimated impacts of microfinance found earlier with cross-section data analysis can be corroborated using an alternative method. They find a declining long-term impact of microfinance as well as the possibility of village saturation from microfinance loans. Since the average number of 
loans taken out by the clients under consideration is only 1.1 loans it is unlikely that customers would actually already experience declining long-term effects, but village saturation might be what drives the results.

Table 6.7: First Stage \& 2SLS (IV) Regression Results

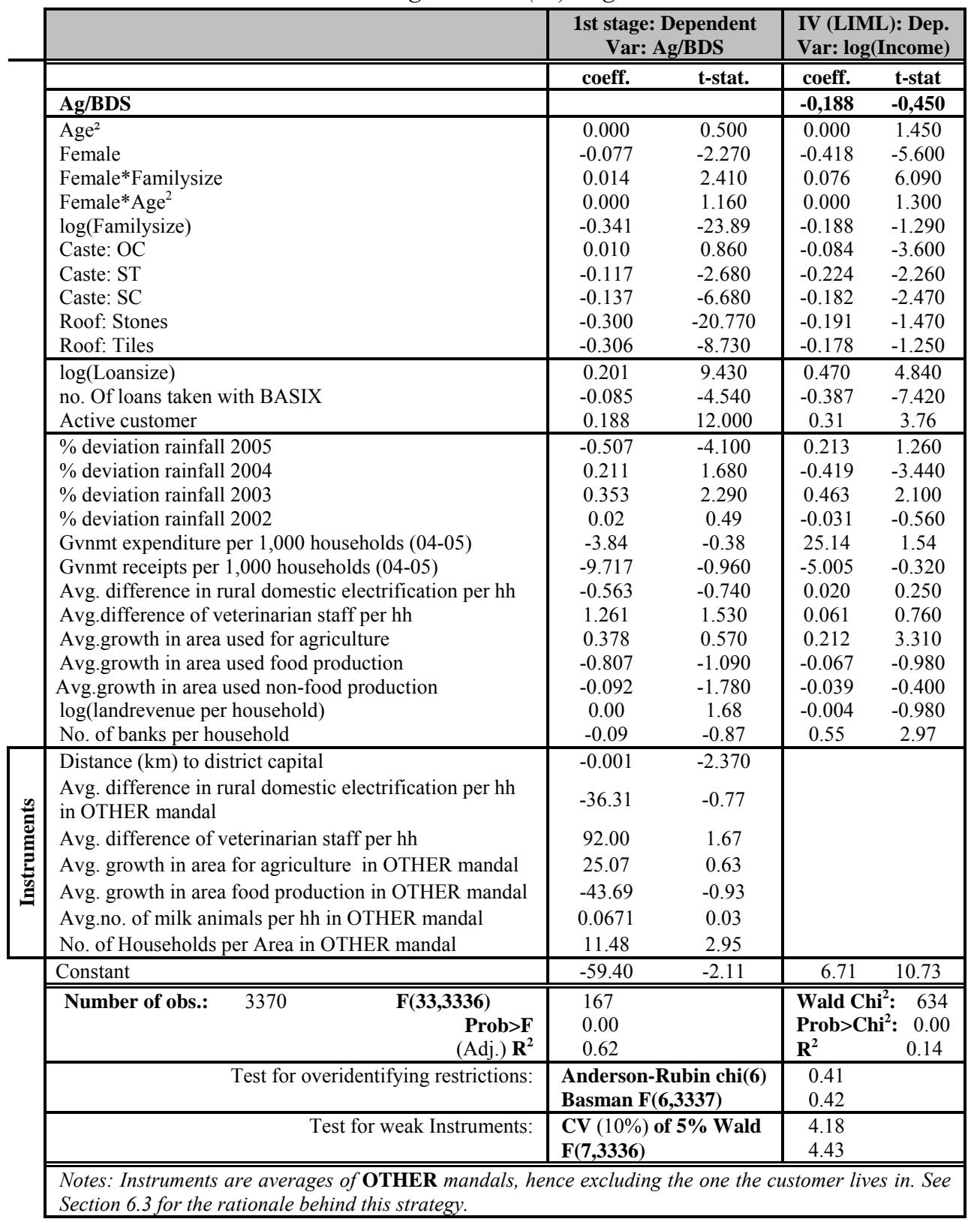




\subsubsection{Estimates of Ag/BDS Impact on income - Including information on milk vendors}

In this section, the unexpected negative effect of $\mathrm{Ag} / \mathrm{BDS}$ on income is investigated further.

Personal observations and preliminary primary data collection in autumn 2006 for the household survey used for the analysis in the previous chapter had indicated that in some cases milk agents ${ }^{120}$ that operate on milk routes and initiated by BASIX pay a lower price per litre of milk than local vendors. In addition, in some villages the milk agent would take a sample of the customers' milk for testing but would not return it to the customer. By doing so, he could make a personal profit through selling the samples as his own milk but would at the same time reduce the customers' income.

Such practices led to an average loss of two Rupees per litre of milk for the customer. While two Rupees, which is just 0.05 US Dollar might sound like a negligible amount, it is not considering the price of milk: A milk agent on average pays ten Rupees for one litre of buffalo milk and eight for one litre of cow's milk - a customer can consequently experience losses up to 20-25 per cent. Why would a customer still sell milk to the milk-agent and not directly to the local vendor? In an interview one woman explained that she sold some of her milk to the local vendor - since he would pay a higher price - and some to the milk agent - in order not to jeopardize BASIX's presence in the village.

Based on these observations in combination with the above mentioned estimation results, BASIX staff in Anantapur were asked to collect data on the presence of local and private milk vendors in intervention villages. Due to the heavy workload of field staff, only 21 out of 30 mandals could be covered. Therefore, including the collected information resulted in a further loss of observations, reducing the sample size to 2,150 customers. $^{121}$

Table 6.8 gives information on average numbers of private milk vendors in villages where BASIX customers have Ag/BDS and where they do not. No significant differences between the villages in terms of the number of private vendors as well as the number of all vendors before and after BASIX started operations are to be observed.

\footnotetext{
${ }^{120}$ A milk agent collects milk from customers and sells it on to a milk chilling plant. Mostly, these agents use - or are supposed to use - an instrument for fat and SNF-testing which is purchased through a loan from BASIX. The higher the fat and SNF percentage of the milk, the higher the price per litre should be.

${ }^{121}$ See Appendix 6.B Table 1 for a comparison of the sample for the model with and without information on milk-vendors.
} 
Table 6.8: Information on Milk Vendors in Sample Villages

\begin{tabular}{|l|c|c|c|c|c|}
\hline \multirow{2}{*}{ Variable } & \multicolumn{4}{c|}{ Dairy-Villages } & \multicolumn{2}{c|}{ t-stat } \\
& WithOUT Ag/BDS & \multicolumn{2}{c|}{ WITH Ag/BDS } & equivalence of \\
& mean & sd & mean & sd & means for groups \\
\hline \hline Observations & $\mathbf{5 6}$ & & $\mathbf{2 8}$ & & \\
\hline private vendor present in the village & 0.86 & 0.35 & 0.89 & 0.31 & -0.45 \\
\hline number of private vendors in the village & 4.70 & 4.59 & 4.64 & 5.04 & 0.05 \\
\hline nr of vendors before BASIX started operations & 2.91 & 3.32 & 2.89 & 3.55 & 0.02 \\
\hline nr of vendors after BASIX started operations & 1.91 & 2.03 & 1.81 & 2.09 & 0.19 \\
\hline nr of years BASIX is in operation & 4.64 & 1.93 & 4.38 & 1.70 & 0.59 \\
\hline
\end{tabular}

The previous analysis was repeated with the reduced sample, integrating information on milk vendors.

First Step estimation results as well as test results for the endogeneity of $\mathrm{Ag} / \mathrm{BDS}$ are to be found in Appendix 6.C Table 1 and 2. The same explanatory variables and instruments as in the previous model are used - all estimated coefficients having the same sign.

Table 6.9 presents OLS and IV results.

The effects of milk vendors being present in a village on customers' income are highly significant. The presence of a local vendor is estimated to be positive while customers' income decrease the more private vendors operate in a village. These are results in line with the observations from the field.

The negative coefficient on the number of private vendors in the village can be interpreted as additional support for the hypothesis that village saturation might drive the negative effect of the number of loans taken, as mentioned in the previous section.

As before, when taking $\mathrm{Ag} / \mathrm{BDS}$ as randomly given, the interventions impact on customer's income is estimated to be positive and highly significant. Nevertheless, by accounting for market linkages and endogeneity, the estimated effect does not change its sign and remains positive; it does however become insignificant.

As was discussed in the previous chapter, the insignificant intervention impact does not lead to the conclusion of the services being superfluous. It may well be that customers with additional services do indeed not experience an increase in their income due to the services but they can nevertheless expect to have a lower variability in their income streams. This would translate into lower risk and vulnerability, which is one desired result from such an integrated microfinance intervention. Whether this process is taking place can unfortunately not be tested with the data used in this analysis. 
Table 6.9: Estimation Results - Model including Information on milk vendors

\begin{tabular}{|c|c|c|c|c|}
\hline & \multicolumn{2}{|c|}{ Ordinary Least Squares } & \multicolumn{2}{|c|}{ IV (LIML) } \\
\hline & coeff. & se & coeff. & se \\
\hline Ag/BDS & 0.093 & 2.290 & 0.290 & 0.660 \\
\hline $\mathrm{Age}^{2}$ & 0.000 & 1.090 & 0.000 & 1.090 \\
\hline Female & -0.520 & -6.030 & -0.496 & -4.930 \\
\hline Female*Familysize & 0.101 & 7.110 & 0.095 & 5.180 \\
\hline Female $^{*}$ Age $^{2}$ & 0.000 & 2.040 & 0.000 & 1.780 \\
\hline $\log ($ Familysize $)$ & -0.137 & -3.550 & -0.064 & -0.390 \\
\hline Caste: $\mathrm{OC}$ & -0.023 & -0.780 & -0.024 & -0.820 \\
\hline Caste: ST & -0.109 & -1.070 & -0.089 & -0.800 \\
\hline Caste: SC & -0.098 & -2.010 & -0.066 & -0.760 \\
\hline Roof: Stones & -0.139 & -3.730 & -0.080 & -0.590 \\
\hline Roof: Tiles & -0.098 & -1.140 & -0.035 & -0.210 \\
\hline $\log ($ Loansize $)$ & 0.381 & 6.930 & 0.335 & 2.920 \\
\hline no. Of loans taken with BASIX & -0.362 & -7.830 & -0.344 & -5.620 \\
\hline Active customer & 0.241 & 5.980 & 0.20 & 2.18 \\
\hline$\%$ deviation rainfall 2005 & 0.144 & 0.660 & 0.199 & 0.790 \\
\hline$\%$ deviation rainfall 2004 & 0.168 & 0.750 & 0.168 & 0.750 \\
\hline$\%$ deviation rainfall 2003 & -0.309 & -1.280 & -0.381 & -1.320 \\
\hline$\%$ deviation rainfall 2002 & 0.10 & 1.34 & 0.117 & 1.420 \\
\hline Gvnmt expenditure per 1,000 households (04-05) & 43.69 & 1.34 & 48.09 & 1.39 \\
\hline Gvnmt receipts per 1,000 households $(04-05)$ & -34.616 & -1.170 & -38.195 & -1.230 \\
\hline $\begin{array}{l}\text { Average difference in rural domestic } \\
\text { electrification per household }\end{array}$ & 0.035 & 0.360 & 0.024 & 0.240 \\
\hline Average difference of veterinarian staff per hh & -0.003 & -0.020 & 0.027 & 0.180 \\
\hline Average growth in area used for agriculture & 0.199 & 1.880 & 0.207 & 1.920 \\
\hline Average growth in area used food production & -0.302 & -2.140 & -0.297 & -2.100 \\
\hline Average growth in area used non-food production & -0.110 & -0.580 & -0.055 & -0.240 \\
\hline $\log ($ landrevenue per household $)$ & 0.01 & 1.27 & 0.008 & 1.230 \\
\hline No. of banks per household & 0.12 & 0.43 & 0.18 & 0.58 \\
\hline Presence of local vendor & 0.190 & 2.380 & 0.202 & 2.410 \\
\hline No pf private vendors & -0.011 & -3.090 & -0.01 & -3.06 \\
\hline Constant & 7.961 & 13.51 & 8.188 & 10.69 \\
\hline Number of obs.: & 16.39 & & "WaldChi(29) & 471 \\
\hline Prob $>$ F & 0.00 & & Prob $>$ Chi & 0.00 \\
\hline Adjusted $\mathbf{R}^{2}$ & 0.17 & & $\mathbf{R}^{2}$ & 0.17 \\
\hline Test for overidentifying restrictions: & $\begin{array}{l}\text { Anderson- } \\
\text { Basman F }\end{array}$ & $\begin{array}{l}\text { n chi(6): } \\
\text { 37): }\end{array}$ & $\begin{array}{l}0.08 \\
0.08 \\
\end{array}$ & \\
\hline Test for weak Instruments: & $\begin{array}{l}\text { CV }(10 \%) \\
\text { F(7,2222): }\end{array}$ & ( Wald: & $\begin{array}{l}4.18 \\
5.17\end{array}$ & \\
\hline $\begin{array}{l}\text { Notes: Instruments are averages of OTHER mand } \\
\text { Section } 6.3 \text { for the rationale behind this strategy. }\end{array}$ & hence excl & the one & omer liv & in. See \\
\hline
\end{tabular}

\subsection{Conclusion}

Microfinance and its impact have received considerable attention over the last few decades, with most studies confirming a positive impact on the customers. However, almost exclusively these studies only consider the effect of credit and make use of data that was specifically collected to conduct an evaluation on the other hand - something timely and costly to do. 
This study has addressed both of these issues.

As was already explained in the previous chapter, today, the term 'Microfinance', and going beyond financial services 'microfinance plus', involves much more than just giving someone financial credit. Over the last decades enormous developments and innovations have taken place in the microfinance sector, resulting in a much broader approach taken. Training is being given, insurance products and saving possibilities are offered, market linkages are being established - to name just a few of the developments that can be observed.

General consensus exists that these are services which are needed by the poor - though not much quantitative evidence exists to support this view.

The programme under consideration in this study takes this recently developed holistic approach. The effect of services offered for customers engaging in the dairy sector have been estimated. Customers of the microfinance institution BASIX India who take a loan for the purpose of buying a cow or a buffalo can choose to additionally purchase so-called Agricultural/Business Development Services. These for example include training on how to keep and feed the animal or a monthly check-up of the animal by a veterinarian.

Estimating the effect of these services on the customer's income by simple OLS, hence taking them at random, overestimates the effect significantly. The bias which results from the program-variable being endogenous leaves one to believe that the services influence income in a significant way. Nevertheless, taking account of this endogeneity shows that the customers actually experience no noteworthy effect on their income as compared to customers who only avail themselves of credit.

This might reflect that these customers pay a price for a lower variability in their income, which can hence be interpreted as a form of insurance. The analysis in chapter four revealed that this is actually true. The standard deviation of typical income is lowest if a customer has $\mathrm{Ag} / \mathrm{BDS}$ (whether in combination with livestock insurance or not) and highest if he/she has no additional services. This implies that the additional services might not have an immediate effect on the income of the clients themselves, but that they influence the health of the animal and by doing so reduce risk. Given the context in which the programme is being offered, this result is probably of higher importance than an increase in income, as an animal falling ill or dying can have severe consequences for the people that are the subject of this study. These individuals are extremely poor, owning hardly any assets so that incurring medical expenses for their animal or losing them is very difficult to cope with. 
The chapter further points to the importance of the establishment of market linkages: the profit margin of dairy activities is typically very small ${ }^{122}$ so that even a minute reduction in prices can significantly reduce profits for producers.

The second issue addressed in this chapter is the exploration of evaluating a microfinance intervention with data readily available and hence doing so in a cost efficient manner. Since data from the Management Information System does not provide any information on non-customers it was not possible to estimate the overall effect of the program. The analysis was constrained to comparing customers to customers, i.e. those that use additional services to those that do not. To overcome problems of endogeneity, official statistics and data on market linkages was turned to in the analysis. While results are very dependent on the quality of data collected by field agents of the microfinance institution, this analysis- in combination with results from the previous chapter - shows that getting insight into the effectiveness of a programme is possible without conducting a specific survey. It also becomes clear though, that the type of information one gets is very limited. Looking at overall household income as a dependent variable is very constrained when talking about livelihood promotion. If the organisation is hence interested in getting a broader picture, the collection of other outcome indicators should be integrated into their loanappraisal forms.

${ }^{122}$ In rural areas for example, where customers need to purchase fodder for the animal, profit can only be attained when mixing milk with water one to one. 


\section{APPENDIX 6.A}

Table 6.A1: Distribution of Customers by Purpose of Loan

\begin{tabular}{|l|c|c|c|}
\hline Purpose of loan & freq. & \% & cum. \\
\hline \hline House Repairs / Extensions & 2 & 0.02 & 0.02 \\
\hline General Purpose - S.H.G & 4 & 0.04 & 0.06 \\
\hline S.H.G.S without C.S & 4 & 0.04 & 0.1 \\
\hline Federation of S.H.G.S/MACTS & 8 & 0.08 & 0.18 \\
\hline Vehicle loans for employees/LSAs & 9 & 0.09 & 0.27 \\
\hline Agri Investment loans & 11 & 0.12 & 0.39 \\
\hline Housing \& Infrastructure loans & 42 & 0.44 & 0.83 \\
\hline Crop Loans (JLGS) & 510 & 5.37 & 6.2 \\
\hline General Purpose Women (JLG) & 521 & 5.49 & 11.69 \\
\hline AGRI-ALLIED LOANS & 3,454 & 36.4 & 48.09 \\
\hline Non-farm Micro-Enterprises & 4,924 & 51.89 & 100 \\
\hline Total & 9,490 & & \\
\hline
\end{tabular}

Table 6.A2: Comparison of Dropped and Kept observations

\begin{tabular}{|c|c|c|c|c|c|c|c|c|c|c|}
\hline \multirow[b]{3}{*}{ Variable } & \multicolumn{5}{|c|}{ WITH Ag/BDS } & \multicolumn{5}{|c|}{ WithOUT Ag/BDS } \\
\hline & \multicolumn{2}{|c|}{ dropped obs. } & \multicolumn{2}{|c|}{ kept obs. } & \multirow{2}{*}{ t-test } & \multicolumn{2}{|c|}{ dropped obs. } & \multicolumn{2}{|c|}{ kept obs. } & \multirow{2}{*}{ t-test } \\
\hline & mean & $\mathrm{sd}$ & mean & $\mathrm{sd}$ & & mean & sd & mean & $\mathrm{sd}$ & \\
\hline No. Of Obs. & \multicolumn{2}{|c|}{34} & \multicolumn{2}{|c|}{1443} & & \multicolumn{2}{|c|}{901} & \multicolumn{2}{|c|}{2140} & \\
\hline Income & 536718 & 408618 & 108080 & 72493 & 26.23 & 18594 & 113445 & 86451 & 67013 & -20.38 \\
\hline Age & 33.15 & 7.56 & 36.49 & 8.51 & -2.27 & 36.05 & 8.63 & 35.89 & 8.35 & 0.48 \\
\hline $\begin{array}{l}\text { Sex } \\
(\text { Female }=1)\end{array}$ & 0.559 & 0.504 & 0.708 & 0.455 & -1.89 & 0.527 & 0.500 & 0.672 & 0.470 & -7.57 \\
\hline Family size & 2.735 & 1.864 & 1.663 & 1.348 & 4.54 & 4.284 & 1.854 & 4.195 & 1.510 & 1.38 \\
\hline Caste: OBC & 0.471 & 0.507 & 0.356 & 0.479 & 1.37 & 0.483 & 0.500 & 0.400 & 0.490 & 4.23 \\
\hline Caste: OC & 0.412 & 0.500 & 0.512 & 0.500 & -1.16 & 0.424 & 0.494 & 0.468 & 0.499 & -2.23 \\
\hline Caste: SC & 0.059 & 0.239 & 0.101 & 0.302 & -0.81 & 0.074 & 0.263 & 0.087 & 0.283 & -1.19 \\
\hline Caste: ST & 0.000 & 0.000 & 0.006 & 0.079 & -0.46 & 0.002 & 0.047 & 0.020 & 0.142 & -3.77 \\
\hline $\begin{array}{l}\text { Caste: } \\
\text { Minority }\end{array}$ & 0.059 & 0.239 & 0.024 & 0.154 & 1.27 & 0.017 & 0.128 & 0.024 & 0.154 & -1.30 \\
\hline Loan size & 13853 & 5235 & 11573 & 3126 & 4.12 & 12021 & 6299 & 11490 & 4978 & 2.47 \\
\hline $\begin{array}{l}\text { No. of } \\
\text { Loans }\end{array}$ & 1.059 & 0.239 & 1.003 & 0.070 & 4.12 & 1.560 & 0.839 & 1.110 & 0.375 & 20.34 \\
\hline $\begin{array}{l}\text { No. of } \\
\text { Instalments }\end{array}$ & 18.56 & 2.98 & 15.75 & 3.79 & 4.29 & 18.82 & 6.18 & 18.76 & 5.98 & 0.25 \\
\hline $\begin{array}{l}\text { Amount } \\
\text { overdue }\end{array}$ & 0.18 & 0.46 & 5.04 & 144.58 & -0.20 & 122.95 & 895.12 & 20.66 & 315.39 & 4.61 \\
\hline $\begin{array}{l}\text { Days } \\
\text { overdue }\end{array}$ & 3.50 & 8.57 & 3.55 & 9.69 & -0.03 & 18.84 & 123.97 & 5.49 & 54.46 & 4.10 \\
\hline $\begin{array}{l}\text { Security- } \\
\text { amount }\end{array}$ & 1385.29 & 523.47 & 1157.31 & 312.58 & 4.12 & 1202.04 & 629.94 & 1148.95 & 497.85 & 2.47 \\
\hline
\end{tabular}




\section{APPENDIX 6.B}

Table 6.B1: Comparison of observations in Model with and without information on milk-vendors

\begin{tabular}{|c|c|c|c|c|c|}
\hline & \multirow{2}{*}{\multicolumn{2}{|c|}{ in both samples }} & \multirow{2}{*}{\multicolumn{2}{|c|}{$\begin{array}{c}\text { not in milk- } \\
\text { vendor model }\end{array}$}} & \multirow[b]{3}{*}{ t-test } \\
\hline & & & & & \\
\hline & mean & sd & mean & sd & \\
\hline & \multicolumn{5}{|c|}{ WITH Ag/BDS } \\
\hline No. Of Obs. & \multicolumn{2}{|c|}{1000} & \multicolumn{2}{|c|}{443} & \\
\hline Income & 108176 & 69041 & 107862 & 79821 & 0.08 \\
\hline Age & 37.07 & 8.65 & 35.18 & 8.03 & 3.91 \\
\hline Sex $($ Female $=1)$ & 0.741 & 0.438 & 0.634 & 0.482 & 4.13 \\
\hline Family size & 1.676 & 1.359 & 1.634 & 1.324 & 0.54 \\
\hline Caste: OBC & 0.373 & 0.484 & 0.318 & 0.466 & 2 \\
\hline Caste: OC & 0.48 & 0.5 & 0.585 & 0.493 & -3.68 \\
\hline Caste: SC & 0.123 & 0.329 & 0.052 & 0.222 & 4.15 \\
\hline Caste: ST & 0.005 & 0.071 & 0.009 & 0.095 & -0.89 \\
\hline Caste: Minority & 0.019 & 0.137 & 0.036 & 0.187 & -1.95 \\
\hline Loan size & 12047 & 1991 & 10503 & 4611 & 8.88 \\
\hline No. of Loans & 1.003 & 0.055 & 1.005 & 0.095 & -0.38 \\
\hline No. of Installments & 16.48 & 1.95 & 14.1 & 5.87 & 11.46 \\
\hline Amount overdue & 1.97 & 56.96 & 11.96 & 246.57 & 1.21 \\
\hline Days overdue & 2.69 & 7.87 & 5.5 & 12.67 & -5.13 \\
\hline \multirow[t]{2}{*}{ Security-amount } & 1204.7 & 199.07 & 1050.34 & 461.13 & 8.88 \\
\hline & \multicolumn{5}{|c|}{ WithOUT Ag/BDS } \\
\hline No. Of Obs. & \multicolumn{2}{|c|}{1324} & \multicolumn{2}{|c|}{780} & \\
\hline Income & 85299 & 64094 & 88406 & 71695 & -1.03 \\
\hline Age & 35.53 & 8.33 & 36.51 & 8.37 & -2.6 \\
\hline Sex $($ Female $=1)$ & 0.704 & 0.457 & 0.617 & 0.487 & 4.13 \\
\hline Family size & 4.147 & 1.55 & 4.277 & 1.438 & -1.91 \\
\hline Caste: OBC & 0.356 & 0.479 & 0.473 & 0.5 & -5.31 \\
\hline Caste: OC & 0.489 & 0.5 & 0.433 & 0.496 & 2.46 \\
\hline Caste: SC & 0.106 & 0.308 & 0.056 & 0.231 & 3.88 \\
\hline Caste: ST & 0.024 & 0.154 & 0.014 & 0.118 & 1.58 \\
\hline Caste: Minority & 0.025 & 0.156 & 0.023 & 0.15 & 0.27 \\
\hline Loan size & 11514 & 4941 & 11447 & 5043 & 0.3 \\
\hline No. of Loans & 1.109 & 0.367 & 1.112 & 0.388 & -0.16 \\
\hline No. of Installments & 18.75 & 6.21 & 18.77 & 5.57 & -0.08 \\
\hline Amount overdue & 26.69 & 373.59 & 10.43 & 177.03 & 1.14 \\
\hline Days overdue & 6.18 & 56.89 & 4.3 & 50.09 & 0.77 \\
\hline Security-amount & 1151.44 & 494.14 & 1144.73 & 504.36 & 0.3 \\
\hline
\end{tabular}


APPENDIX 6.C - Test for Endogeneity and $1^{\text {st }}$ Stage Regression Results: Model including information on Milk Vendors

Table 6.C1: Test statistics for the endogeneity of $\mathrm{Ag} / \mathrm{BDS}$

\begin{tabular}{lllll}
\hline \multicolumn{1}{l}{ Tests of endogeneity of: Dairy-Ag/BDS services } & & & \\
\hline \hline H0: Regressor is exogenous & & & & \\
Wu-Hausman F test: & 4.917 & $\mathrm{~F}(1,2127)$ & p-value: & 0.027 \\
Durbin-Wu-Hausman chi-sq test: & 4.959 & Chi-sq(1) & p-value: & 0.026 \\
\hline
\end{tabular}

Table 6.C2: 1st Stage Regression Results

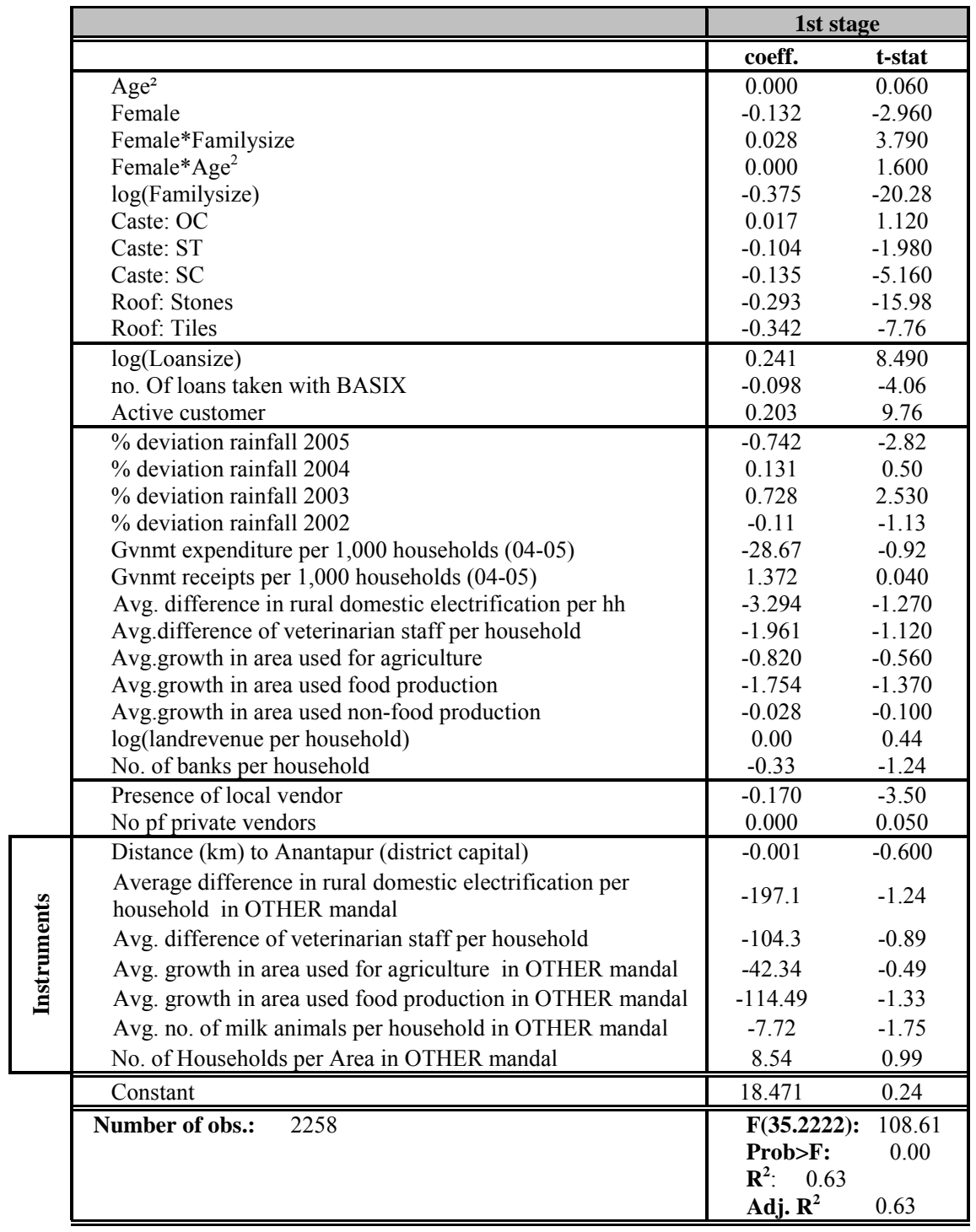




\section{Overall Conclusion}

"The achievement we celebrate today is but a step, an opening opportunity, to the greater triumphs and achievements that await us. Are we brave enough and wise enough to grasp this opportunity and accept the challenge of the future?"

Jawaharlal Nehru, speech on the granting of independence, August 14, 1947.

In many ways India was indeed brave and wise enough to grasp opportunities it was given over the last two decades. Its economy has become a rising star in the international sphere, with growth rates of more than nine per cent for the third year in a row. This remarkable economic growth is attributed to science, technology and innovation-led development, primarily in sectors such as IT and pharmaceuticals. Growth in the agricultural sector on the other hand fell far behind. This is worrisome given that agricultural activity is the main means of livelihood for almost two thirds of the Indian workforce, currently contributing about one fourth to GDP. And the absolute population dependent on agriculture is increasing rather than decreasing in the Indian context (Business Standard India 2008).

The Indian government is aware of the graveness of the situation and is taking measures accordingly. The Eleventh Five-Year Plan (2007-2012) urges attention to the stagnation in the agricultural sector, which is recognised by most as a crisis. The Government's plan says: "It is necessary to double the growth rate achieved in the $10^{\text {th }}$ Plan and put agriculture on a growth path of around 4 percent."

"So far as I am able to judge, nothing has been left undone, either by man or nature, to make India the most extraordinary country that the sun visits on his rounds. Nothing seems to have been forgotten, nothing overlooked."

Mark Twain, Following the Equator, 1897.

The Indian microfinance economy observed a similar - if not much brighter - growth than the overall economy. Chapter two gives an overview of the immense spread of the major microfinance model in India, the SHG Bank Linkage Programme, but it also 
shows that the microfinance institution model is expanding rapidly. Ghatak's (2007) estimates for 2006 are that the MFI model served about 7.3 million households and the SHG model 14 million households; allowing for overlap, this adds up to approximately one fifth of all poor Indian households.

These are impressive numbers, but small within a populous country the size of India with people living below and just above the poverty line numbering in hundreds of millions. As is the case in the overall economy, the major backbone of the microfinance economy is lagging behind; the backbone being the very remote areas, the very backward areas, the very poor people, and - uniquely so in India - the urban poor. And, contrary to the agricultural sector, a lot has been forgotten and a lot has been overlooked.

The first part of this dissertation deals with such forgotten and overlooked factors of microfinance in India. Fortunately, most of these are not forgotten and overlooked by all. A book edited by Dichter \& Harper (2007) repeatedly points to the fact that "microfinance can 'crowd out' other initiatives" (p. 258). Hulme for example states in the second chapter that:

"MFI and donor hype has created the impression that microfinance is a cure to poverty. [...] This is a potentially dangerous line of argument as it distracts attention from the fact that poverty reduction requires action on many fronts: social safety nets for the poorest and most vulnerable, an effective education system, low-cost and reliable health services, governments that can provide social inclusion (and thus maintain law and order) and sound macroeconomic policies, and many other issues" (Hulme, 2007, p. 21)

While such observations are being made, little if any quantitative support exists to corroborate them. Chapter two of this dissertation gives evidence to the claim by undertaking a quantitative analysis of the determinants of the spread of the SHG model. Amongst others it is found that the SHG model is predominantly active in areas where a banking network is available - and as of yet not in areas devoid of a formal financial sector. Also, indication is given that the focus on SHGs seems to be a tradeoff with other social schemes - leaving many underprivileged groups unattended to.

In fact, the SHG model seems to grow ahead of its capacity, an issue also taken up in the third chapter. This chapter goes deeper into implications of the growth and the microfinance hype it brings about. The lesson is clear: There is an unquestionable need for greater transparency as well as greater awareness.

The greater awareness that is called for is public awareness - public awareness of issues related to financial indicators. A lot has been written about the high costs of microfinance loans and especially practitioners of the microfinance institution model in particular argue for the need of high interest rates to cover these costs. Chapter three gives an account of what can happen in circumstances of lacking awareness - when 
real costs are not known by the public and beliefs reside that high interest rates are a result of greed and money-making and not a necessity to cover costs. Institutions find ways to lower the interest rates, but what is saved on one side needs to be recovered somewhere else - be it in additional charges to the customer or near to perfect recovery rates, which often do not come without pressure. The crisis in Andhra Pradesh is just one example of the severe consequences.

Contrary to what is usually promoted, the transparency called for in this dissertation relates to consumer protection. Typically in the context of finance, discussions evolve around asymmetric information in terms of what the institutions do not know about the clients. The success of microfinance is partly based on finding solutions to this problem, such as the joint-liability model. The asymmetries that run in the other direction are much less talked about are- all the information that the institution possesses and knowingly or unknowingly withholds from the clients; with the real costs of credit topping the list.

As argued in chapter three, the focus to date lies too much on economic indicators of the institution, pushing for financial sustainability and neglecting the consequences of such one-sided attention. Of course, facts and figures are important when for example considering funding decisions. But an effort should be made to go beyond the standard ratings and financial performance indicators - especially when the aim is poverty alleviation.

And this is in fact less difficult than it might appear at first sight - little by little, possibilities are being given that facilitate paying attention to social performance. ${ }^{123} \mathrm{In}$ March 2005, a Social Performance Task Force was created based on the initiative of the Consultative Group to Assist the Poor (CGAP), the Argidius Foundation, and the Ford Foundation. Their aim is to define social performance and to decide on how to measure and monitor it. ${ }^{124}$ Four rating institutions ${ }^{125}$ already conducted social ratings of some microfinance institutions. The percentage of microfinance institutions that has such ranking is more than negligible, and a lot can be said about the difficulty in measuring and the missing accuracy of such social indicators. Nevertheless, the crucial aspect is to put weight and emphasis on the issue.

And it is donors who can - and should - play a major role in pushing for greater rights of microfinance consumers by encouraging and spreading these types of indicators. Clear signals need to be given that support is provided to institutions that are not only performing well in terms of financial indicators but that the social aspect is at least as important.

\footnotetext{
${ }^{123}$ The Social Performance Task Force initiated by CGAP defines social performance as "the effective translation of an institution's social mission into practice in line with accepted social values."

${ }^{124}$ More recently (November 2007), ACCION International published its report "Guidelines to Evaluate Social Performance", which develops a framework for MFIs of how to assess and report social performance.

${ }^{125}$ These are MCRIL, MicroFinanza Rating, MicroRate and Planet Rating.
} 
In fact, as results from the third chapter, donors should not even focus on funding institutions with an excellent track record of financial indicators.

The success of micro"financial"services in their original purpose (such as a loan for investment into an income-generating activity) came about because returns of financed activities were high enough to cover costs of such loans and for customers to still benefit on several levels (household, empowerment...). Microfinancial services do not need to be dependent on donor money. Organisations that demonstrate to be able to work on financially self-sustainable basis are nowadays able to attract investment from other sources - a new market develops in which investors look for possibilities to combine capitalism with altruism; such as investing in microfinance institutions that yield a competitive rate if return to its investors.

One example is the Bangladeshi microfinance organisation Association for Social Advancement (ASA). Its founder and president Shafiqual Haque Choudhury managed to attract 500 billion Euros from investors such as the Dutch pension fund ABP or the American one TIAA-CREF, offering a yearly interest yield of ten per cent over ten years. Another example that has been recently widely discussed is Compartamos, a Mexican microfinance bank. This microfinance organisation which was founded in 1990 went public in April 2007, the original investors offering 30 per cent of their shares. They walked away with US\$ 450 million. That altruism fell far behind in this incidence - original investors making an enormous profit and keeping most of it for themselves - is of course a not to be neglected issue and relates back to the discussion of pushing for the importance of placing emphasis on the altruistic motives. Chapter three elaborates on possible consequences that evolve when the social objective are lost out of sight. Muhammed Yunus voiced his concern in an interview with the German magazine the Spiegel saying that: "It was our goal to crowd out usurers. Now they are coming back, dressed up as benefactors". ${ }^{126}$

The point these examples are supposed to make is that donors do not need to play a role in microfinance - for sure not in the long-run, maybe not even today.

The emphasis is, however, on finance.

As was detailed in chapter five, over recent decades a broader approach to microfinance developed. This was mainly a reaction to observations that the very poor need more than just loans and that microfinance - the tool for poverty eradication would neglect this part of the population if it did not adapt to their needs.

Many microfinance institutions now offer services alongside the loan that are aimed at increasing efficiency and productivity. Of course, these services increase costs - costs that are already high given the peculiarities of the clients and hence the financial services provided. Given that microfinance institutions are filling a hole; that they are

\footnotetext{
${ }^{126}$ Buse (2008). "Die Grenzen des Anstands“. Der Spiegel (33/2008), own translation.
} 
playing a role that should be someone else's to play, this is where donors' money can be meaningfully invested.

What non-financial services are MFIs offering and whose role would it actually be to do so?

The range of additional services as offered today is very broad. Chapters five and six go into more detail of one such an integrated approach, looking at a program that provides a loan for the purpose of buying a cow or a buffalo to engage in milk-selling as an extra-income generating activity. With the loan comes a health and life insurance for the client and the spouse. Additionally livestock insurance is being offered as well as a non-financial-services-package that includes, among others, training on how to keep and feed the animal, regular check-ups by a veterinarian as well as health camps. Furthermore, market linkages are established in areas where needed and fat-testing of the milk is introduced to guarantee fair prices for the product. This is just one example. Many other microfinance programs offer skills training in income-generating activities and capacity building, business skills development courses, ongoing business support, courses in functional literacy, health and sanitation awareness sessions and even healthcare services, they address issues of social empowerment and gender sensitization, give food grain assistance and sometimes even provide grants before giving loans.

The list is long and it is clear that these are not services that one would imagine a financial institution to have an expertise in. These are services that the government or maybe some private institutions are expected to provide - basic education, building of infrastructure, healthcare. If these institutions fail, one would expect NonGovernmental Organisations (NGOs) and Donors to step in. Not, however, "banks".

Well, why not? Let microfinance develop into "microfinance plus", "integrated microfinance", "holistic microfinance" - but give them the needed support. Do not expect financial experts to know when the buffalo should be inseminated for the milkproduction cycle to be maximized or to teach their clients how to read and write numbers so that they can actually keep track of their sales.

By supporting such non-financial activities donors can further place emphasis on the social mission of microfinance institutions, which - as argued above - is an important role for them to play.

Hence, instead of looking for supporting "microfinance-stars" in terms of financial indicators donors should rather turn to support NGO-MFI type of microfinance providers. These are NGOs that took up lending activities. Besides placing greater emphasis on non-financial services and hence being a more appropriate provider for the very poor, the encouragement of this more grassroot form of credit delivery is also an important step in the development of the Indian microfinance sector. 
Two main reasons can be brought forward to explain this view: For one, given their smaller size and stronger focus on social objectives, NGO-MFIs are much closer to the ground, in more direct contact and discussion with the clients and therefore serve as an important source of innovation with respect to microfinance services. Furthermore, NGO-MFIs are much more likely to operate in remote and underserved areas, not at last because of their smaller size. Given the results from chapter two, that the SHG Bank Linkage Programme is much less dominant in for example remote hill tribe areas the distinguishing feature of the NGO-MFI to operate in such un(der)served areas obviously fills the observed gap.

One of the most convincing arguments to support such integrated programs remains evidence of course that they actually do the participants good.

The second part of the dissertation looks at the benefits to the customers of such an approach, by analyzing the livelihood promotion intervention in the dairy sub-sector previously described. The providing organization, BASIX India, is not an NGO-MFI but a Non-Banking Finance Company. Nevertheless, it is one of the drivers of the integrated sector approach to microfinance in India. They are seen as one of the most innovative institutions - almost an experimental microfinance laboratory, following their strategy of the livelihood triad as explained in chapter five. BASIX is a remarkable institution with unique leadership, which needs to be acknowledged as one of the driving forces behind the institution's successes in working with the poor, which are also reflected in the results of the impact analysis conducted in this dissertation. This raises the question of replicability of their initiatives. While it is beyond the scope of this dissertation to answer this question, it is without doubt that personality and commitment are crucial when mixing banking with non-banking services. And even an institution like BASIX can and did fail as can be seen from their effort to potatogrowers in Jharkand with the snack-food company Frito Lays. ${ }^{127}$

Before going into the evaluation of BASIX's specific program, the fourth chapter of this dissertation is devoted to analysing the benefits of engaging in dairy as an extra income generating activity in general terms. Results show that households do derive economic benefits from selling dairy products: they had in the previous year, typically have and also expect a significantly higher overall income stream than people whose household income sources do not include milk-selling. These results are confirmed in a Lorenz-curve analysis, which shows that engaging in dairy activities is indeed welfare-improving.

This positive result on the role of dairy-activities links back to the concern about the agricultural sector raised in the beginning of the conclusion. While the sector's growth is stagnating at 3.3 per cent, the livestock sector, which contributes to about 25 per cent to agricultural GDP, is growing at an annual rate of 5.6 per cent. With 66.6 per

\footnotetext{
${ }^{127}$ See Harper (2009).
} 
cent in 2001-03, the greatest contribution to the livestock sector came from milk and milk products. Livestock and especially milk production is showing great potential to be the main driver of agricultural growth and hence also to be the potential solution to the currently observed stagnation in this backbone of the Indian economy.

India is at present in fact the largest producer of milk in the world with an annual production of 88.1 million tones in 2003-04 (Ali, 2007). This translates into a production of approximately $1,123 \mathrm{~kg} /$ year per animal as compared to $9,306 \mathrm{~kg} /$ year in the United States and 5,529 kg/year in the European Union (FAPRI, 2008). Productivity in India lies much below the world average of approximately 3,882 $\mathrm{kg} /$ year per cow, which calls for further policy interventions, developments and innovations within this sector. Chapters five and six go into more detail of such an intervention.

A further important result that comes out of chapter four is that, while greater heterogeneity in income is observed for households that derive income from selling milk, they face lower uncertainty in their future income streams.

This latter observation is possible despite the fact that only cross-sectional data is available for analysis. Data on subjective expectations of the customers allows distinguishing between heterogeneity and uncertainty, as was detailed in chapter four. The work of subjective expectations is a relatively new but growing field. This dissertation adds to the literature by collecting new data in a developing country on a population that faces above average uncertainty as well as by eliciting expectations on investment-specific returns. These latter expectations on returns directly linked to the intervention are more elaborated on in the evaluation studies presented in chapters five and six.

The results of these evaluation analyses indicate a positive program effect on considered economic outcome indicators. This suggests that the just described analysis of engaging in dairy activities might inherit a bias given that the greater part of the respondents is clients of the organisation BASIX India. This needs to be kept in mind when interpreting the results. Nevertheless, they are in line with other studies that show dairy to be a welfare improving activity (for references see chapter four) and it is therefore believed that the possible bias is not extensive.

Significant positive programme impact is found on household income, assets and consumption categories (food, other non-durables and durables) of customers. The positive and significant effect on consumption holds for all sub-groups of customers considered (looking at additional (non-)financial services). This finding supports the statement of Monique Cohen (2003) that microfinance should be seen as a "necessary but not sufficient condition for development"; that credit to the (income) poor might not necessarily lift them above the poverty line but that it plays a crucial role in vital 
issues such as consumption smoothing, in reducing risk and uncertainty and in the ability to cope with shocks.

In fact, the Agricultural and Business Development Services as well as Livestock Insurance that BASIX offers alongside the loan, serve exactly these latter purposes of among others productivity enhancement and risk mitigation. And indeed, the effects on consumption are highest for those customers that had $\mathrm{Ag} / \mathrm{BDS}$ at the time of the survey.

An unexpected result is the finding that program participants have a negative impact on their income from engaging in milk selling as an extra income-generating activity. This effect is significant for customers who have livestock insurance.

Several explanations can be brought forward for this result. One lies in data constraints that the applied statistical techniques fail to account for and that hence lead to biases in the results. Of course, one always has to deal with unobservables that are difficult if not impossible to measure and where additional data collection effort would not lead to a solution. Nevertheless, the two sets of information that are obtainable but are missing in the analysis are village as well as baseline data. The potential bias that results from having no baseline was discussed in chapter five, stressing the problem of missing data on outcome indicators before the intervention started, hence not being able to account for differing starting values. Simple summary statistics as well as discussions with staff of BASIX, indicate that customers who opt for additional nonfinancial services are on average poorer and have less experience with the keeping and rearing of cows or buffaloes than those that only take the loan. The lack of data and hence inability to account for it in the analysis might be driving the insignificant results for customers with additional services as compared to those without. Propensity score matching minimizes this type of bias by matching closely resembling observations but it is nevertheless possible that some bias remains.

Chapter six gives evidence that not including information on a village level (such as the availability of market linkages) results in an underestimation of the effect. While the selection of survey villages followed a thorough process that aimed at minimizing differences between the program and non-program villages, it would be more efficient to include information on village level. For that matter, village information was collected in the course of the survey but unfortunately the quality of the data was not deemed good enough to be included in the analysis. Data on a few villages was collected twice and comparison showed too large differences to be confident with the information. Unfortunately, time (and money) constraints did not allow for recollection of the data.

Throughout the analysis conducted for this dissertation, attention was paid to minimize such biases to the best possible extent and to take limitations into account when 
interpreting results. There is hence confidence that the conclusions presented are a reflection of what is going on in the field.

In the second part of the dissertation, this "what is going on" captures whether customers are better off due to participating in the intervention or not. What remains unanswered and is subject to future research are questions such as whether the additional services reduce the risk of the customers; i.e. make them less vulnerable to shocks.

In order to get a complete (or more complete) picture, one needs to go beyond oneshot level indicators that reflect the current state. As mentioned several times in this dissertation, risk and uncertainty play a major role in the life of microfinance clients, and livelihood promotion is geared at reducing this risk and at the same time increasing the customers' ability to cope with shocks. To capture effects of such forward-looking anti-poverty interventions one needs a measure that reflects a household's future prospects and that by doing so incorporates risk and uncertainty an ex-ante measure of poverty such as vulnerability to poverty is an example.

The measurement of vulnerability is not straightforward. Since it is forward-looking, it involves the measurement of all possible outcomes as well as their likelihood. In other words hypothetical situations of what outcome level (such as consumption level) a household will have in a certain state of nature needs to be measured.

Estimating the first two moments of expected outcome distributions as was done in chapter four, is a first step in analysing vulnerability by looking at uncertainty. The standard deviation of this subjective outcome distribution reflects this uncertainty and can hence serve as a measure of idiosyncratic risk. As mentioned before, descriptive statistics presented in that chapter indicate that households engaging in dairy as an extra income generating activity are less vulnerable - their expected income is higher and their expected standard deviation on average lower than for households not selling any milk.

In order to get deeper insight into the issue of vulnerability, a second survey round is required (and actually planned). With panel data available, measures of vulnerability that are not based on subjective expectations data is possible and hence a comparison of the two approaches can be undertaken. Besides delivering interesting insights into the program under consideration, further contributions to the literature can be made by shedding light on the potential usefulness of expectation data for estimation and identification, here in the context of risk and vulnerability. 


\section{References}

Abadie, A. \& Imbens, G.W. (2008). On the Failure of the Bootstrap for Matching Estimators. Econometrica, Econometric Society, vol. 76(6), pages 1537-1557.

Adams, R.H. Jr. \& He, J.J. (1995). Sources of Income Inequality and Poverty in Rural Pakistan, Research Report 102. International Food Policy Research Institute, Washington, D.C.

Ali, J. (2007). Livestock sector Development and implications for rural poverty alleviation in India. Livestock Research for Rural Development, 19(2).

Angrist, J.D. (2001). Estimation of Limited Dependent Variable Models with Dummy Endogenous Regressors: Simple Strategies for Empirical Practice. Journal of Business \& Economic Statistics, 19(1), 2-16.

Anselin, L. (1992). Space and applied econometrics. Special Issue, Regional Science and Urban Economics, 22.

Anselin, L. \& Hudak, S. (1992). Spatial econometrics in practice: A review of software options. Regional Science and Urban Economics, 22, 509-536.

Anselin, L., Bera, A., Florax, R. \& Yoon, M. (1996). Simple diagnostic tests for spatial dependence. Regional Science and Urban Economics 26, 77-104.

APMAS. (2006). Voice of the people on lending practices of microfinance institutions in Krishna district of Andhra Pradesh, Hyderabad: Andhra Pradesh Mahila Abhivruddhi Society.

Armandariz, B. \& Morduch, J., (2005). The Economics of Microfinance. Cambridge, MA: MIT Press.

Assadi, M. (2006). Agrarian crisis and farmers' suicide in India. Indian Journal of Labour Economics 49(4), 799-820.

Attanasio, O., E. Battistin, E. Fitzsimons, A. Mesnard, and M. Vera-Hernández. (2005). How Effective are Conditional Cash Transfers? Evidence from Colombia. Unpublished, The Institute for Fiscal Studies, London, UK.

Binswanger, H. \& Khandker, S.R. (1995). Impact of Formal Finance on the Rural Economy of India. Journal of Development Studies, 32(2), 234-262.

Birthal, P.S. \& Singh, M.K. (1995). Structure of Rural Income Inequality: A Study on Western Uttar Pradesh, Indian Journal of Agricultural Economics, (30)2, 168-175.

Black,D., J.Smith, A.Jeffrey. (2004). "How robust is the evidence on the effects of college quality? Evidence from matching," Journal of Econometrics, 121(1-2), 99-124.

Boltanski, L. \& Laurent, T. (1991). On Justification. Economies of Worth. Princeton, NJ: Princeton University Press. 
Bourdieu, P. (2000). Making the Economic Habitus. Algerian Workers revisited. Ethnography 1(1), 17-41.

Brown, D.S., Brown, C.J. \& Desposato, S.W. (2002). Left turn on Green? The unintended consequences of international funding for sustainable development in Brazil. Comparative Political Studies 35(7), 814-838

CGAP. (2005). Funding Microfinance Technology. CGAP Donor Brief No. 23.

CGAP. (2002). Microfinance Consensus Guidelines. Guiding Principles on Regulation and Supervision of Microfinance, Washington, DC.

Chandrashekhar, B. (2004). Poor bank credit drives riots to private lenders, The Hindu, 1.07.2004.

Chowdhury, A. (2000). Macro Story of Micro-Credit. Himal South Asia 13(3), 10-20.

Cliff, A. \& Ord, J. K. (1981). Spatial Processes: Models and Applications. London.

Cohen, M. (2002). Making microfinance more client-led. Journal of International Development 14(3), 335-350.

Coleman, B. (1999), The Impact of Group Lending in Northeast Thailand. Journal of Development Economics 60, 105-42

Coleman, B. (2002), Microfinance in Northeast Thailand: Who benefits and how much?. Asian Development Bank, Economics and Research Department Working Paper No. 9, April 2002.

Cull, R., Demingüç-Kunt, A. \& Morduch, J. (2007), Financial performance and outreach: a global analysis of leading microbanks, Economic Journal, 117, F107-F133.

Davidson, A.P. \& Ahmad, M. (2003). Privatization and the crisis of agricultural extension: The case of Pakistan. Ashgate Publishing Limited.

De Vletter, F. (2001). Microfinance in Mozambique: Are Donors Promoting Regional Feminisation of Poverty?. Discussion Paper 16. International Labor Organization/Southern Africa Multidisciplinary Advisory Team, Harare.

Deaton, A.S. (1997). The Analysis of Household Surveys: A Microeconometric Approach to Development Policy. Johns Hopkins University Press, World Bank.

Dehejia, R.H. \& Whaba, S. (2002). Propensity Score Matching Methods for Nonexperimental Causal Studies. The Review of Economics and Statistics. 84(1): 151161.

Delavande, A. (2004). Pill, patch or shot? Subjective expectations and birth control choice. RAND Corporation and Universidade Nova de Lisboa working paper.

Devine, J. (2003). The paradox of sustainability: Reflections on NGOs in Bangladesh. The Annals of the American Academy of Political and Social Science 590, 227-242. 
Diagne, A. (1998). Impact of Access to credit on income and food security in Malawi, International Food Policy Research Institute, Food Consumption and Nutrition Division Discussion Paper No. 46. Economics 22.

Dichter, T. \& M. Harper (2007). What's wrong with Microfinance?. Intermediate Technology Publications Limited.

Dominitz, J. (2001). Estimation of income expectations models using expectations and realization data, Journal of Econometrics, 102, 165-195.

Dominitz, J. \& Manski, C.F. (1997), Using expectations data to study subjective income expectations, Journal of the American Statistical Association, 92(439), 855-67.

FAPRI (2008). US and World Agricultural Outlook. Staff Report 08-FSR 1. ISSN 1534-4533. Food and Agricultural Policy Research Institute.

Ferguson, J. (1994). The Anti-Politics Machine: "Development", Depolitization and Bureaucratic Power in Lesotho. Minneapolis: University of Minnesota Press.

Fernando, J.L. (2006). Microcredit and empowerment of women: visibility without power. In Microfinance perils and prospects, edited by Jude L. Fernando. New-York: Routledge, Pp. 187-237.

Fisher, T. \& Sriram, M.S. (2002). Beyond Microcredit: Putting Development Back into Microfinance. New Delhi: Sage.

Fouillet, C. \& Augsburg, B. (2008). Spread of the SHG Banking Linkage Programme in India. International Conference on Rural Finance Research: Moving Results, held by FAO and IFAD, March 19-21, Rome, Italy.

G8. (2004). Applying the Power of Entrepreneurship to the Eradication of Poverty. Sea Island Summit 2004, Action Plans. June 9. Retrieved May 8, 2008 (http://www.g7.utoronto.ca/summit/2004seaisland/poverty.html).

Garcia O., Saha, A., Mahmood, K., Ndambi, A., Hemme, T. (2006). Dairy Development Programs in Andhra Pradesh, India: Impacts and Risks for Small-scale Dairy Farms, PPLPI Working Paper No. 38

Geary, R. (1954). The contiguity ratio and statistical mapping. The Incorporated statistician, 5.115-145.

Getis, A. \& Ord, J.K. (1992), The analysis of spatial association by use of distance statistics, Geographical Analysis, 24, 189 - 206.

Ghatak, M. \& Guinnane, T.W. (1999). The Economics of Lending with Joint Liability: Theory and Practice. Journal of Development Economics 60, 195-228.

Ghate, P. (2007a). Indian Microfinance - The Challenges of Rapid Growth. SAGE Publications.

Ghate, P. (2007b). Learning from the Andhra Crisis. Published in What's wrong with Mircrofinance?. Edited by T. Dichter \& M. Harper (2007). 
Giné, X., Townsend, R.M., Vickery, J.I. (2007). Statistical Analysis of Rainfall Insurance Payouts in Southern India. American Journal of Agricultural Economics. 89(5): 1248-1254.

Glosser, A. (1994). The Creation of BancoSol in Bolivia. Pp. 229-250 in The New World of Microenterprise Finance, edited by Otera, M. \& Rhynee, E.. London: Kumarian Press.

Goodwin-Groen, R.P. (2007). The National Credit Act and its Regulations in the Context of Access to Finance in South Africa. South-Africa: FinMarkTrust .

Gore, C. (2000). The rise and fall of the Washington consensus as a paradigm for developing countries. World Development 28(5), 789-804.

Guerin I. \& Palier J. (2005). Microfinance challenges: Empowerment or disempowerment of the poor?. Pondicherry: French Institute of Pondicherry.

Guérin, I, Fouillet, C. \& Palier, J. (2007). "La microfinance indienne peut-elle être solidaire ?." Revue Tiers-Monde, 190,291-308.

Guntur (2006). "MPs, MLAs cry for action against MFIs.” The Times of India, April 7.

Halder, S.R. \& Mosley, P. (2004). Working with the ultra poor: learning from BRAC experiences. Journal of International Development. 16(3), 301-330.

Harper, M. (1998). Profit for the poor: Cases in microfinance. London: ITDG Publications.

Harper, M. (2002). Self-help groups and Grameen Bank groups: What are the differences?. Pp. 169-198 in Beyond Microcredit: Putting Development Back into Microfinance, edited by Fisher, T. \& Sriram, M.S.. New Delhi: Sage.

Harper, M. (2009). Inclusive Value Chains in India - Linking the Smallest Producers to Modern Markets. World Scientific Publishing Co.Pte. Ltd. Singapore.

Harper, M. \& M. Nath (no year). Inequity in Self-Help Groups - A View from India's Centre.

http://www.ruralfinance.org/servlet/BinaryDownloaderServlet?filename $=1112217041$

800_Harper_inequity paper.pdf. Accessed: January 2008.Harriss, J. (2001). Depoliticizing Development. The World Bank and Social Capital. Delhi: Left Word.

Hartarska, V. \& Nadolnyak, D. Forthcoming. Does rating help microfinance institutions raise funds? Cross-country evidence. International Review of Economics and Finance.

Heckman, J.J., Ichimura, H. \& Todd, P. (1997). Matching as an Econometric Evaluation Estimator: Evidence from Evaluating a Job Training Programme. Review of Economic Studies, 64(4), 605-54.

Hickson, R. (2005). People's Republic of China: Market Research for Microfinance in jiangkou County. Technical Assistance Consultant's Report, Asian Development Bank, Manila. 
Holvoet, N. (2005). The impact of microfinance on decision-making agency: evidence from South India, Development and Change, 36(1), 75-102.

Hulme, D. \& Mosley, P. (1996). Finance against poverty. London: Routledge.

IMF. (2005). Microfinance: A View from the Fund. Report of the Monetary and Financial Systems Department, Washington, DC: International Monetary Fund.

Isern, J. \& Porteous, D. (2005). Commercial banks and microfinance: Evolving models of success. Focus Note 28. Washington, DC: Consultative Group to Assist the Poor.

Jansen, W. (2007). The Analysis and Evaluation of Organizational Structure, Dissertation, University of Amsterdam.

Jauzelon, C. (2007). Microfinance et pratiques sociales des femmes paraiyars en Inde du sud. Revue Tiers Monde 190, 275-290.

Jha, D.N. (2004). The Myth of the Holy Cow. Verso Books.

Kahneman, D. and A. Tversky, (1979), Prospect Theory of Decisions Under Risk. Econometrica. Vol. 47(2), pp. 263-292.

Kamat, S. (2002). Development Hegemony: Non-Governmental Organizations and the State in India, New York: Oxford University Press.

Kamat, S. (2004). The privatization of public interest: theorizing NGO discourse in a neoliberal era. Review of International Political Economy 11(1), 155-176.

Karlan, D. \& Valdivia, (2006), Teaching Entrepreneurship: Impact of Business Training on Microfinance Clients and Institutions, Yale University Economic Growth Center Discussion Paper, 941.

Khandker, S.R. \& Faruquee, R.R. (2003), The impact of farm credit in Pakistan, Agricultural Economics 28, 197-213.

Kochar, A. (1997). An empirical investigation of rationing constraints in rural credit markets in India. Journal of Development Economics, 53, 339-371.

Kurup M.P.G. (2004). Production structure and cost competitiveness of livestock production in Asia. In: Ahuja, V. (ed), Livestock and livelihoods. Challenges and opportunities for Asia in the emerging market environment. NDDB (National Dairy development Board), Anand, Gujarat, India, and FAO (Food and Agriculture Organization of the United Nations), Rome, Italy. pp. 132-154.

Littlefield, E., Morduch, J. \& Syed, H. (2003). Is microfinance an effective strategy to reach the Millennium Development Goals?. CGAP Focus Note 24. Washington, DC: Consultative Group to Assist the Poor.

Lorenz, M.O. (1905) Methods of measuring the concentration of wealth, Journal of the American Statistical Association, 70, 209-17. 
Luseno, W.K., McPeak, J., Barrett, C.B., Gebru, G. \& Little, P.D. (2003). The Value of Climate Forecast Information for Pastoralists: Evidence from Southern Ethiopia and Northern Kenya, World Development, 31(9), 1477-1494.

Lybbert, T.J., Barrett, C.B., Desta, S. \& Coppock, D.L. (2004). Pastoral Risk and Wealth-Differentiated Herd Accumulation Patterns in Southern Ethiopia. Economic Journal.

Mahajan V. (2005).From Microcredit to Livelihood Finance,Economic Politic Weekly,Oct 8,4416-4419.

Malamoud, C. (1983). Debts and Debtors. New York: Advent Books.

Manor, J. (2000). Small-Time Political Fixers in India's States: 'Towel over Armpit' Asian Survey, 40(5), 816-835.

Manski, C. (2004). Measuring Expectations. Econometrica, 72(5), 1329-1376.

Mayoux, L. (2000). Microfinance and the Empowerment of Women: A Review of the Key Issues. ILO, Social Finance Unit, Geneva: International Labor Organization.

Mayoux, L. 2001a. Tackling the Down Side: Social Capital, Women's Empowerment and Micro-Finance in Cameroon. Development and Change, 32(3), 435-464.

Mayoux, L. 2001b. Women's Empowerment Versus Sustainability? Towards a New Paradigm in Micro-finance Programs. Pp. 245-269 in Women and Credit. Researching the Past, Refiguring the Future, edited by Lemire, B., Pearson, R. \& Campbell, G. New York: Berg.

McIntosh C. \& Wydick, B. (2005). Competition and Microfinance. Journal of Development Economics, 78, 271-298.

McKee, K. (1989). Microlevel Strategies for Supporting Livelihoods, Employment, and Income Generation of Poor Women in the Third World: The Challenge of Significance. World Development, 17(7), 993-1006.

McKernan, S.-M. (2002). The Impact of Microcredit Programmes on Self-employment Profits: Do Noncredit Programme Aspects Matter?. Review of Economics and Statistics 84(1), 93-115.

M-Cril. (2007). India microfinance review 2007, Gurgaon, Micro-Credit Ratings International Limited.

Meghir, C. \& Pistaferri, L. (2004), Income variance dynamics and heterogeneity. Econometrica, 72(1), 1-32.

Menon, P. (2002). Micro-credit and mixed successes. Frontline, 19(19), September 14 -27 .

Microrate. (2002). The Finance of Microfinance. Arlington: Microrate.

Milgram, B.L. (2001). Operationalizing Microfinance: Women and Craftwork in Ifugao, Upland Philippines. Human Organization 60(3), 212-224. 
Moran, P.A.P. (1948), The interpretation of statistical maps, Journal of the Royal Statistical Society, Series B, 37, 243- 251.

Morduch, J. (1999a). The Microfinance Promise. Journal of Economic Literature 37(4), 1569-1614.

Morduch, J. (1999b). The role of subsidies in microfinance: evidence from the Grameen Bank. Journal of Development Economics 60(1), 229-248.

Morduch, J. (2000). The microfinance schism. World Development 28(4), 617-629.

Morgan, B. (2006). Disciplining the developmental subject: neoliberal power and governance through microcredit. Pp. 64-88 in Microfinance perils and prospects, edited by Fernando, J. New York: Routledge.

Mosley P. \& Hulme, D. (1998), Microentreprise finance: Is there a conflict between growth and poverty alleviation. World Development, 26(5), 783-790.

Mosse, D. (2005). Cultivating development. An ethnography of aid policy and practice. London: Pluto Book.

Moulton, B.R. (1987). Diagnostics for Group Effects in Regression Analysis, Journal of Business \& Economic Statistics, (5)2, 275-282.

NABARD (1989). Studies on Self-Help Groups of The Rural Poor. Published on behalf of the Indian member institutions of APRACA. Bombay.

NABARD (2003). Progress of SHG - Bank Linkage in India, 2002-2003, Mumbai.

NABARD (2004). Progress of SHG - Bank Linkage in India, 2003-2004, Mumbai.

NABARD (2005). Progress of SHG - Bank Linkage in India, 2004-2005, Mumbai.

NABARD (2006). Progress of SHG - Bank Linkage in India, 2005-2006, Mumbai.

Nanda, A.S. \& Nakao, T. (2003). Role of Buffalo in the Socioeconomic Development of Rural Asia: Current Status and Future Prospectus. Animal Science Journal, 74, 443 -455 .

National Sample Survey Organisation published a report on the Indebtedness of Farmer Households (January - December 2003). Report No. 498.

Nguyen, C.H., (2007). Determinants of Credit Participation and Its Impact on Household Consumption: Evidence From Rural Vietnam. Discussion Paper 2007/03, Centre for Economic Reform and Transformation, School of Management and Languages, Heriot-Watt University, Edinburgh.

Pace, R. K. \& Barry, R. (1998). Spatial Statistics Toolbox 1.0. Real Estate Research Institute, Lousiana State University, Baton Rouge, LA.

Parekh H.T. (2006), Financial Inclusion: Issues and Challenges, Economic and Politic Weekly, October, 4310-4313. 
Petras, J. (1997). Imperialism and NGOs in Latin America. Monthly Review 49(7), 1033.

Phansalkar \& Ghosh (2001). BASIX Intervention in Milk Sub-sector. In: A Resource Book for Livelihood Promotion, edited by Datta,S., Mahajan, V. \& Thakur, V.. Indian School of Livelihood promotion, BASIX.

Pitt, M. ,\& Khandker, S. (2003). The Impact of Group-Based Credit on Poor Households in Bangladesh: Gender of Participants Matter?, Journal of Political Economy, 106(5).

Pitt, M. ,\& Khandker, S. (1998a). The Impact of Group-Based Credit Programmes on Poor Households in Bangladesh: Does the Gender of Participants Matter?. Journal of Political Economy 106(5), 958-996.

Pitt, M. \& Kandker, S. (1998b). Credit Programmes for the Poor and Seasonality in Rural Bangladesh. Brown University and World Bank, draft, January 9.

Planning commission, Government of India. (2007). Poverty estimates for 2004-05. http://www.planningcommission.gov.in/news/prmar07.pdf. Accessed: June 10, 2007.

Pulley, R. (1989). Making the Poor Credit-worthy: A Case Study of the Integrated Rural Development Programme in India. World Bank Discuss Paper 58, World Bank.

Rahman, A. (1999). Micro-credit initiatives for equitable and sustainable development: Who pays?. World Development 27(1), 67-82.

Rajaram, D. (2001), Working and Impact of Rural Self-Help Groups and other forms of Micro Financing, Jounal of Agricultural Economics, vol. 56(3), 370-386.

Ramkumar, S., Ganesan. R., Heffernan, C., \& Garforth, C. (2003). Diseases affecting cattle in the peri-urban regions of Pondicherry, India: report based on stakeholder's meetings.

Ramnachandran V.K. \& Swaminathan, M. (2005). Financial Liberalization and Rural Credit in India. New-Delhi, Tulika Books.

Ramos, X. \& Schluter, C. (2006). Subjective Income Expectations and Income Risk. IZA Discussion Paper No. 1950.

Rangarajan, C. (2006). Microfinance and its Future. GTZ and SDC.

Rangnekar D.V. (2006). Livestock and livelihoods of the underprivileged communities in India: A review. International Livestock Research Institute, Nairobi, Kenya.

Rao, S. (2005). Women's Self-Help Groups and Credit for the Poor: A Case Study from Andhra Pradesh. Pp. 204-237 in Financial Liberalization and Rural Credit in India, edited by Ramnachandran, V.K. \& Swaminathan, M. New-Delhi: Tulika Books.

Reddy, Y.V. (2005). Micro-Finance: Reserve Bank's Approach. Micro-Finance Conference, Centre for Analytical Finance, Indian School of Business, Hyderabad, August 6. 
Reddy, S.T.S. (2007). Diary of a Moneylender, Economic and Political Weekly, July 21, 2007.

Robinson, M. (2001). The microfinance revolution: sustainable banking for the poor, Washington, DC: The World Bank.

Robinson, M. (1993). Governance, democracy, and conditionality: NGOs and the new policy agenda. Pp. 35-52 in Governance, democracy and conditionality: What role for NGOs?, edited by Clayton, A. Oxford: The International NGO Training and Research Centre.

Rosenbaum, P.R. \& Rubin, D.B. (1983). The Central Role of Propensity Score in Observational Studies for Causal Effects. Biometrika 70(1), 41-55.

Rudner, D.W. (1994). Caste and Capitalism in Colonial India: The Nattukottai Chettiars, Berkeley, University of California Press.

Schümperli, Y., Catherine, D.F. \& Servet, J.-M. (2007). Financer le développement par la mobilisation des ressources locales. Annuaire suisse de politique de développement, 26(2), 11-21.

Schuler, S.R., Hashemi, S.M. \& Riley, A.P.. (1997). The Influence of Women's Changing Roles and Status in Bangladesh's Fertility Transition: Evidence from a Study of Credit Programmes and Contraceptive Use. World Development, 25(4), 563-575.

Scully, N.D. (1997). Micro-credit no panacea for poor women. Retrieved May 9,2008 (http://www.gdrc.org/icm/wind/ micro.html).

Sebstad, J. et al. (1995). Assessing the Impact of Microenterprise Programs: A Framework for Analysis. USAID: MSI, Washington D.C.

Seibel, H.D. \& Dave, H. R. (2002). Commercial Aspects of Self-Help Group Banking in India: a Study of Bank Transaction Costs. Published by Micro Credit Innovations Department, National Bank for Agriculture and Rural Development, Thompson Press, Mumbai 1992.

Shorrocks, A.F. (1983). Ranking income distributions, Economica, 50, 3-17.

Shorrocks, A.F. \& Foster, J.E. (1987). Transfer sensitive inequality measures, Review of Economic Studies, 54, 485-497.

Sianesi, B. (2004). An Evaluation of the Swedish System of Active Labor Market Programmes in the 1990s. The Review of Economics and Statistics, vol. 86(1), 133$155,09$.

Sinha, S. \& Sinha, F. (2002). Sustainability and Development: Evaluating the Performance of Indian Microfinance. Pp. 263-299 in Beyond Microcredit: Putting Development Back into Microfinance, edited by Fisher, T. \&. Sriram, M.S. New Delhi: Sage.

Sokal, R. R., Jacquez, G.M. \&. Wooten, M.C. (1989). Spatial autocorrelation analysis of migration and selection. Genetics 121, 845-855. 
Sreeramulu, G. (2006). Empowerment of Women through Self-Help-Groups. Kalpaz Publications,India

Stata Technical Bulletin, March 2001, STB 60.

Statistical Hand Book of Tamil Nadu. (2005) published by the Department of Economics and Statistics, Chennai-600006.

Stiglitz, J.E. (1990). Peer Monitoring and Credit Markets. The World Bank Economic Review 4(3), 351-366.

Stiglitz, J. (1998). More Instruments and Broader Goals: Moving Toward the PostWashington Consensus. WIDER Annual Lecture presented at the United Nations University, January 7, Helsinki: Finland.

Stiles, K. (2002). International support for NGOs in Bangladesh: Some unintended consequences. World Development 30(5), 835-846.

Tamil Nadu Human Development Report (2003). Government of Tamil Nadu, Social Science Press, Delhi 2003.

Thorat, Y.S.P. (2006). Microfinance in India: Sectoral issues and challenges. in Towards a Sustainable Microfinance Outreach in India, published by NABARD, GTZ and SDC.

Tiefelsdorf M. (2000). Modelling Spatial Processes: The Identification and Analysis of Spatial Relationships in Regression Residuals by Means of Moran's I. Berlin: Springer.

Todd, P. \& Wolpin, K. (2007). Assessing the Impact of a School Subsidy Programme inMexico: Using a Social Experiment to Validate a Dynamic BehavioralModel of Child Schooling and Fertility. forthcoming in American Economic Review. UNCDF (1999). Working Paper on Microfinance, New York: The United Nations Capital Development Found.

Twain, M. (1897). Following the Equator: A journey around the world. The American Publishing Company.

Turner, R.L. (2004). Livestock Production and the Rural Poor in Andhra Pradesh and Orissa States, India. PPLPI Working Paper No. 9.

UNICEF (2006). Progress for Children. A report card on nutrition, New-York: The United Nations Children's Fund.

Vahlhans, M. (1994). The New Popularity of NGOs: Will the enthusiasm last?. Development and Cooperation 3, 20-22.

Vidyasagar, R.M. \& Chandra, K.S. (2004). Farmers' Suicides in Andhra Pradesh and Karnataka. Centre for Social Development, National Institute of Rural Development, Hyderabad.

Vilei, S. \& Chisholm, N. (2003). Impact of credit as perceived by resource-poor Ethiopian households, Discussion Paper, Department of Food Business and Development, National University of Ireland, Cork. 
Walley, P. (1991). Statistical Reasoning with Imprecise Probabilities, London: Chapman and Hall.

Weber, H. (2002). The imposition of a global development architecture: the example of microcrédit. Review of Internation Studies 28, 537-555.

Weber, H. (2004). The new economy and social risk: banking on the poor?. Review of International Political Economy, 11(3), 356-386.

World Development Report 1989.

Zadek, S. (1993). The practice of Buddhist economics?: another view. American Journal of Economics and Sociology 52(4), 433-445. 


\section{9. $\quad$ Appendix}

\subsection{Survey Design}

\subsubsection{Introduction}

This is a description of a survey and its implementation, designed to evaluate an intervention by the microfinance institution BASIX India in the Indian state of Andhra Pradesh.

\subsubsection{The program to be evaluated}

BASIX India started its operation in the second half of the 1990s following the strategy of the so-called 'livelihood triad', the three corners being Institutional Development Services (IDS), Livelihood Financial Services (LFS), and Agricultural and Business Development Services (Ag/BDS). The dairy intervention under consideration in this study encompasses all three of these aspects. IDS in the context of this intervention include for example the formation of producers' groups, federations and cooperatives. The loan itself falls under LFS. The conditions are typically a loan period of on average 18 months, implying 18 loan instalments with an interest rate of 24 per cent per annum. An additional security deposit of 10 per cent of the loan (with an average loan size of 11,500 Rupees, approximately US\$290) is retained. Besides this security deposit no collateral is asked for but the loan is jointliability and it comes with a health and life insurance for the client as well as the spouse. In addition, the customer has the option to buy insurance for the animal, covering its death. In brief, $\mathrm{Ag} / \mathrm{BDS}$ covers credit productivity enhancement, noninsurance risk mitigation and the establishment of alternate market linkages, where needed. Currently, all customers that decide to buy these services are charged a rate of 300 Rupees. For this amount, they can expect timely advisory services on preventive measures to reduce and deal with the risks involved in their selective livelihood at his doorstep/village on fixed dates by a Livelihood Service Provider. ${ }^{128}$ Besides the overall program effect, the aim was to analyse the particular effect of these latter additional services on outcome indicators.

\subsubsection{Design and evaluation methodology}

In the evaluation literature one typically distinguishes between three evaluation designs: experimental, quasi-experimental and non-experimental. When the goal is to

\footnotetext{
${ }^{128}$ In more detail this implies that customers pay for regular and timely access to the physical presence of a Livelihood Service Provider (LSP) on his doorstep for a 12 months period (24 visits by LSP in a year), timely advisory services on their animals management aspects which are appropriate at that time, exposure on latest technologies and market prices connected to his commodity, practical demonstrations on selected themes/activities by LSP (ex. disease identification method), possible facilitation for inputs supply of their choice and also for market linkages, and preventive vaccination for FMD or HS/BQ for 2 animals at free of cost/customer will be done apart from regular health check-ups, first aid treatment on need based, deworming etc..
} 
establish causal relationships and effects, the first of these three, randomized experiments, is considered to be the one with strongest internal validity.

Nevertheless, most often a randomized experiment is not feasible as was the case in this study. The main reasons were ethical considerations by the institution, not wanting to exclude eligible and potential beneficiaries of the intervention under consideration. A quasi-experimental design, using a comparison instead of randomly assigned control group, was therefore opted for. As laid out by Bawden \& Sonenschein ${ }^{129}$ the three most common sources of which comparison groups are chosen are "(1) eligible nonparticipants in the same community, (2) individuals similar to the participants from an existing data base that contains the outcome measures of interest, and (3) individuals in a matched comparison site who would have been eligible for the program if it were in that site."

Considerable thought and effort has to be put into the choice of a valid control group. This becomes especially important in a setting like the current one where data is collected after the program has been in operation for some time.

In this study, the first and the third type of group was chosen. The third type, individuals in similar communities are usually perceived as the most promising comparison group once randomization is ruled out. The choice was made to also sample eligible non-participants as for one, no problem of program placement bias in encountered for such individuals. More importantly though by comparing outcomes of these two comparison groups one can address the issue of spill-over effects.

In addition, when a follow-up survey on the same individuals is considered, this set-up allows studying issues of self-selection and targeting. In the context of this study, the "similar communities" chosen were villages where the microfinance institution BASIX was not operating at the time of the survey but where they considered offering their services in the near future. This implies that the sample includes respondents that did not participate in the program at the time of the first survey but that self-selected into the program before the follow-up.

The main evaluation technique to be applied when data from the first survey round is available is Propensity Score Matching (PSM). This technique has proven reliability in the non-experimental evaluation literature, being for example widely applied in the context of labour market policies. The key idea and assumption is that conditional on observable variables, the assignment of a program is random. Since conditioning on all relevant variables implies in most settings a high dimensional covariate vector, it is common practice to make use of a result by Rosenbaum and Rubin (1983) which suggests that instead of conditioning on all covariates one can use a single function of these same variables - such as the propensity score. A propensity score of which the distribution is the same for treated as well as non-treated individuals can be used to match pairs within the two groups. The average difference in outcomes between these pairs is then the so-called average treatment effect on the treated.

\footnotetext{
${ }^{129} \mathrm{http}: / /$ www.childwelfare.com/courses/Documents/bawden.htm, accessed 7.7.2008.
} 
Propensity Score Matching improves over Ordinary Least Square Regressions (OLS) that include a dummy variable to estimate treatment in three respects: For one, it is a semi-parametric estimation method and hence avoids distributional and functional form assumptions; second, one does not need to assume homogeneous effects and third, the method does not extrapolate outside the common support, meaning that one avoids comparing the incomparable.

A detailed description of this method can be found in Dehejia \& Whaba (2001).

The survey was primarily designed to estimate the impact of the intervention. A second focus was on eliciting subjective expectations of respondents; specifically expectations of outcome indicators. The main motivation for this was the fact that expectations of prospective outcomes are a central component to models of intertemporal choice. Especially the distribution of future income has always been of major concern to economic theory and economic policy. Income and income uncertainty influence among others consumption and savings decisions, schooling decision, insurance purchase, and enrolment into welfare programs.

The importance of taking action in response to beliefs about what will happen increases in environments where future outcomes are extremely uncertain and where insurance markets are typically very imperfect.

Information on respondents' beliefs is hence of major interest.

In what follows the survey design and its implementation are described in greater detail.

\subsubsection{Sample Size and Survey Design}

For reasons outlined above, interviews were conducted in villages where BASIX is operating as well as in comparison (or hereafter referred to as 'control') villages. The targeted number of interviews for this survey was set at 1,000 , spread over three different respondent groups, as indicated in the figure below:

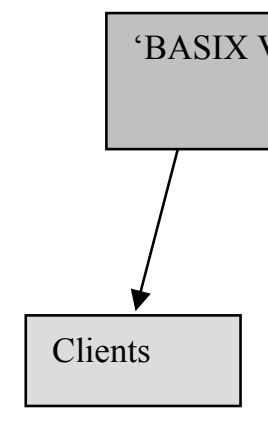

$(500)$

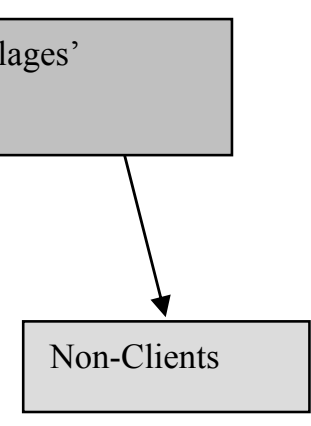

(250)

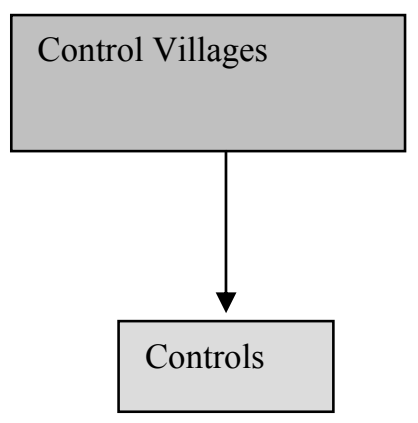

$(250)$

In sum: 1000 interviews 


\subsubsection{Sample Selection}

The survey was based on stratified clustered sample design.

A three-step process was followed to determine the final sample:

(1) Geographical area selection

(2) Village selection

(3) Household (customer, non-customer and control) selection

\subsubsection{Area Selection:}

The geographical coverage was limited to one State only and within this state to one of BASIX's units. These restrictions were opted for mainly in order to be able to work with one survey team and in one language only.

It was decided to conduct the survey in Anantapur district, where one of the oldest units of BASIX is placed. BASIX started its operation in that district due to the opportunity to become involved in the dairy sub-sector and the potential it saw for livelihood promotion. Anantapur unit is hence one of the pioneering units in BASIX's dairy intervention - namely of offering loans for the specific purpose of buying a cow or a buffalo in combination with additional services.

Furthermore, Anantapur is one of the most backward provinces in the state of Andhra Pradesh, which for a great part results from it being the second most drought-affected district of India. ${ }^{130}$ This makes living conditions very hard; people are extremely vulnerable and poverty is highly prevalent. Aspects such as these make holistic microfinance interventions even more important, but at the same time much harder to implement.

\subsubsection{Selection of program and control villages}

Program as well as control villages were randomly selected, while different sources of information will have been used to draw up a list of prospective sample villages for both types.

Program Villages:

Program villages were selected based on information obtained from BASIX's Management Information System. (Note that villages in the system might actually be

\footnotetext{
${ }^{130}$ Anantapur is one of the 23 districts in the state of Andhra Pradesh (AP), India, and was constituted in 1882 from the erstwhile district of Bellary. The district headquarters is Anantapur city. It is the largest district of Andhra Pradesh spanning an area of 19,130 $\mathrm{km}^{2}$ and a population of 3,640,478 of which $25.26 \%$ is urban as of 2001 (Census India, 2001). The district is again split in 68 mandals, which is the unit of administration below a district. The economy is principally agrarian with very few industries. Prominent crops include groundnut, rice, cotton, maize, chillies, sesame, and sugarcane. Silk trade, limestone quarrying, iron and diamond mining constitute the few industries that are there.
} 
hamlets). A list of all active dairy clients was extracted on the $28^{\text {th }}$ of December 2007. Out of the 92 villages that these active clients lived in, only those villages were chosen where BASIX had at least nine customers. Dairy-loans are being given as joint liability with group sizes ranging from four to seven members. Choosing a minimum of nine customers per village hence ensured that at least two different joint-liability groups would be present in the village. Applying this screening process limited the sample to 58 villages in eleven mandals, which made up the final village sample for surveying of customers and non-customers.

A similar screening process was used by Gine, Townsend and Vickery studying rainfall insurance offered by BASIX. They limited their village sample to where at least five households purchase BASIX rainfall insurance, reducing the number of program villages to 25 (out of 37). The higher number of villages (as compared to Gine et al.) seems desirable, since typically, the variation in behaviour and outcomes across Indian villages would be much larger than within villages (Janssen, 2007). This implies that relatively few households are needed to represent a given village, while a larger number of villages will be appropriate in order to reflect the diversity among villages (Deaton, 1997).

\section{Control Villages:}

Control Villages were chosen to be located in areas that are closely comparable in selection criteria to the area where the intervention is being implemented. The strategy that was followed was to have BASIX staff identify villages with 'dairy potential' those that are seen to be suitable for dairy intervention but where no such services were offered at the time of the survey. ${ }^{131}$ Reasons for this absence can be, among others, capacity or time constraints. Gine, Townsend and Vickery followed this strategy of implying a pre-selection. This pre-selection assures that villages are more likely good counterfactuals for the program villages. ${ }^{132}$

Respondents from these thirty villages not served by BASIX contribute to the "control group'.

\footnotetext{
${ }^{131}$ More specifically, the identification of these villages was done by Field Executives (FXs) for the respective areas, since they are the ones identifying villages for BASIX to operate in. Most of the villages surveyed will hence be taken up into BASIX's portfolio in the near future.

${ }^{132}$ Initially, a propensity score was estimated, indicating the likelihood of a village being a BASIX village or not. This was done using data obtained from the Government of Andhra Pradesh and collected for the Rural Poverty Reduction Program. This data will be described in more detail when discussing selection of noncustomers. Explanatory variables that were available and used in the probit estimation were the population in the village as a percentage of the total population in the district, the percentage population below the poverty line, average number of females/males/boys/girls per household, percentage of different castes, the distance to the district capital, as well as area dummies and interaction terms. This led to models with explanatory powers of 10-12 per cent. Intervention and control villages were then paired based on the value of their propensity score. This strategy was abandoned though when it turned out that some control villages chosen turned out to be villages without any dairy potential or so-called 'OD villages', OD standing for Overdue - meaning that BASIX stopped lending in these villages when the repayment culture turned out to be very unsatisfactory.
} 


\subsubsection{Selection of households within villages}

The unit of analysis for the survey was chosen to be a household. The rationale behind choosing a household is that microenterprises "exist as part of a larger portfolio of economic activities, and that decisions with respect to microenterprises - whether made jointly or individually vis à vis other members of the household - can be understood more clearly when considered in relation to tradeoffs within the overall household economy" (Sebstad et al. 1995, p. 1). In other words, economic activities are part of a larger, dynamic household economy - which holds particularly true in the survey area.

\section{Selection of Customers}

550 customers were selected randomly from the list of active dairy clients in the selected 58 villages extracted from the MIS on the $28^{\text {th }}$ of December 2007. No stratification was undertaken along whether a customer has Ag/BDS and or Animal Insurance or not as this information was not integrated in the MIS at the time of sampling.

\section{Selection of Non-Customers and Controls}

The data that was used for the sampling of 250 non-clients and 250 controls stems from the Rural Poverty Reduction Program, a program funded by the World Bank and implemented by the Government of Andhra Pradesh. ${ }^{133}$ As part of the program, an independent society, the Society for Elimination of Rural Poverty (SERP), had been established in 2001. The chairman is the serving Chief Minister of Andhra Pradesh and the CEO is the Senior IAS Officer. The program is implemented in 22 out of 23 districts of Andhra Pradesh, only Hyderabad having been excluded, as it is mainly urban.

The main strategy of the Program is to implement targeted poverty reduction programs. Special effort was hence put into the division of the population into the World Bank Categories, namely (1) Poorest of the poor, (2) Poor, (3) Not so poor and (4) Non-poor. A description of the process is given in Box 1. Most of BASIX's dairy customers fall into the second and third of these categories. Therefore, the random sample of noncustomers was only done from households falling into any of those two categories.

\section{Over-sampling}

All respondent groups were over-sampled to allow for possible problems in either locating borrowers or obtaining their cooperation.

Over-sampling of non-customers and controls needed to be higher as the population data used was collected in 2003. This made it more likely that respondents would not live in the same village anymore or would have died. Furthermore, information that could be provided to locate the respondents was very limited. Interviewers had only the respondent's name, the name of either the husband or the father (given that any of the two was applicable) and the flat number. Especially in bigger villages, this scarcity

\footnotetext{
${ }^{133}$ I would like to greatly thank Mohan Reddy for helping me to obtain this data.
} 
of information made identification difficult. In towns with more than 4,000 households, the help of employees from the Rural Poverty Reduction Program itself was sought.

\section{Box 1: The 'Participatory Identification of the Poor'-Approach}

The poor were identified using the so-called Participatory Identification of the Poor (PIP) approach, which is based on extensive interaction with and participation of all interested villagers.

As a first step, a meeting with villagers was organised to explain the purpose and give information on the program as well as to lay out the process of the 'Social Mapping' that was to follow. This 'Social Mapping' was the main tool to identify the poor and poorest of the poor in villages of Andhra Pradesh.

To start with, villagers were asked to draw their village on the ground - including the main infrastructure such as roads and bus stops as well as other landmarks. Next, a card for each household was written and placed at the appropriate place on the village map.

As a next step, indicators for the World Bank categories were discussed. The categories are (1) Poorest of the poor, (2) Poor, (3) Not so poor and (4) Non-poor, where the first two categories combined make up households living below the poverty line (BPL) and the latter two the ones living above (APL). Villagers were asked to identify which characteristic or indicator would contribute to which category - nonpoor would own their own bathing facility, poorest of the poor would have no access to drinking water facilities and the like. After agreement of these characteristics for each category, card by card, each household was placed into one of the four categories. This was done by taking one card at a time and villagers deciding on a category for the respective household. Once the decision was taken, the characteristics of that category were read out: Housheold XY is.... After doing so, the categorization of the household was reconsidered and finalized. This way, about 45 per cent of all households in rural Andhra Pradesh were identified to live below the poverty line (20 per cent in category one and 25 per cent in category 2).

\subsubsection{Questionnaire Design and Piloting}

\subsubsection{Questionnaire Design:}

A first exploratory field visit took place in March 2006. During this visit, meetings were scheduled with BASIX staff at headquarters as well as field visits organized to two of BASIX units, namely Parbhani in Andhra Pradesh as well as Ramayampet in Maharastra, both very active units in the provision of Agricultural/Business Development Services (Ag/BDS). These visits, which included interviews and discussions not only with BASIX staff but also with customers in the villages, provided a first understanding of BASIX's work. A second, more elaborate field visit followed from October 2006-March 2007. This time was used to develop a deeper 
understanding of the local context, define a set of hypotheses, and to exploratory pilot questions on subjective expectations. Furthermore, data for several units from BASIX's Management Information System was collected, which contained information on all customers. Additional secondary data, including official statistics of potential survey areas, was obtained.

All this information, combined with a literature review, is the basis for the two types of questionnaires administered for the purpose of this study: ${ }^{134,135}$

\section{Village Questionnaire:}

This questionnaire is based on BASIX's village information sheet, and contains information on:

- location (s.a. distance from head office, field office, a main road, the next village),

- demographics (number of households and their caste),

- sectors these households are engaged in (dairy, poultry, leather works...),

- agricultural sector (land under irrigation, number of pumps, main crops),

- kind and number of shops,

- infrastructure (quality of roads, bus service...),

- institutions (banks, SHGs, cooperatives...), and

- reputation of the village (law and order, repayment culture...)

- and prices of consumption goods in the village.

Household Questionnaire:

Household Questionnaire: This questionnaire contains eleven modules, namely:

1. Baseline

2. Household Roster

3. General Household Characteristics

4. Assets

5. Consumption

6. Income

7. Livestock

8. Risk

9. Credit, Savings and Insurance

10. Part for NON-Customers

11. Part for Customers

a. BASIX General

b. BASIX - Agricultural/Business Development Services

c. BASIX - Livestock Insurance

\footnotetext{
${ }^{134}$ Additionally, the questionnaire developed by X. Gine (World Bank, DECRG), R. Townsend (University of Chicago) and J. Vickery (Federal Reserve Bank of New York) for a study n BASIX's rainfall insurance, which was implemented by ICRISAT (International Crops Research Institute for the Semi-Arid Tropics) in late 2004 served as an example. I would like to thank them for providing me with this information.

${ }^{135}$ The detailed questionnaires can be found in Appendix 9.2.
} 
As mentioned, the one aim of the survey was to elicit subjective expectations data from the respondents. This data on expectations was elicited at three times during the interview - in the income section on total expected future household income and in the livestock section on expected future income from dairy activities as well as expected expenditures on health costs for the animal. The question format to elicit the subjective expectations is based on the use of percentages.

\subsubsection{Translation of Questionnaire:}

The questionnaire was translated by an independent translator, recommended by the Centre of Microfinance Research in Hyderabad. No back-translation was undertaken but the quality of translation was checked independently by several staff of BASIX as well as the research assistant and few mistakes found were corrected accordingly. ${ }^{136}$

\subsubsection{Piloting of the Questionnaire:}

A preliminary testing of questions asking about subjective expectations was undertaken in November 2006.

Clients of BASIX (all of which were women ${ }^{137}$ ) were asked on their subjective belief of the expenditures they would have to bear in one year on their animal(s). More precisely, the customers were asked how likely they think it is that they will have to pay a certain threshold. These thresholds (three) were determined on the basis of the number of buffaloes the customer owned, average occurrences of emergencies and costs for health services. ${ }^{138}$ To explain the idea of probabilities a ruler with a scale from 1-100 was used and a "practice round", asking about the probability that it will rain tomorrow (as well as next week and next month), was asked. The client could then point to the number on the ruler corresponding to her belief. Interestingly, women were hesitant in the beginning, but picked up the idea quickly and had no problems answering the questions. They even found it interesting and were very involved. This an important factor since "some economists dismiss subjective data a priori by asserting that survey respondents to surveys have no incentive to answer questions carefully or honestly" (Dominitz \& Manski, 1997).

The piloting of the whole questionnaire was done in December 2007.

Altogether, 26 piloting-interviews were undertaken. The first eight were done by he survey assistant under my presence. The subsequent interviews were partly done by the research assistant together with the interviewers. These interviews were undertaken in the villages close to Anantapur town, where BASIX's unit office is based. The choice was not only made for convenience but also since these villages were chosen

\footnotetext{
${ }^{136}$ A first translation had been done by WASNET - an organisation that BASIX itself collaborates with for translation. Nevertheless, as they could not finish the final translation on time the second translation had to be done from scratch as writing Telugu in one font requires apparently different keyboard combinations than in another font and there is not one general font that people learn to write in.

${ }^{137}$ By the end of 2006, about 67 per cent of all of BASIX's dairy customers were women.

${ }^{138}$ The thresholds were deduced based on information on health expenditures and frequency of animal sicknesses previously experience by animal owners.
} 
not to be part of the sample, given their proximity to the town. All in all, 12 noncustomers and 14 customers were interviewed during the piloting phase.

\subsubsection{Data Collection:}

A research assistant was recruited in December 2007. ${ }^{139}$ The tasks of this assistant included translation during the piloting phase, training of interviewers (initial in-house training as well as in the field), monitoring of field operations related to the project, conducting back-checks in the field, taking reporting from interviewers and scrutiny of questionnaires

A team of fourteen interviewers (eight of which were female) was recruited towards the end of December 2007. They underwent a three-day training course of which two days were classroom training and one day in the field.

The curriculum of the classroom training covered the background, mission and operations of BASIX, including a special section on the dairy intervention and its components. ${ }^{140}$ The purpose of the survey, the conceptual framework and hypotheses were explained, Furthermore, the role and responsibilities of an interviewer were laid out and interviewers were trained on interviewing techniques - in how to conduct an interview and what to do if the respondent was distracted, lost interest, or ran out of time. The second day, the questionnaire was explained in detail, with an extra session on the questions on subjective expectations. Particular attention was paid to the explanation of probabilities as well as the calculation of thresholds.

After the in-house training, the interviewers went to the field in teams of three, accompanied by the research assistant. The research assistant first conducted an interview himself as an example for the interviewers. Thereafter, the interviewers took their turns. The assistant as well as the other team-members would observe and later on discuss what had gone well and what needed improvement. This practice interview improved the comprehension of the questionnaire and accuracy in entering and coding answers.

After about five days of interviews, an extra training session on how to allocate noncustomers was conducted. As briefly mentioned above, scarce information made the task of the interviewers difficult. In order to facilitate their work, Mohan Reddy, [position] with BASIX, who had participated in the data collection for the Rural Poverty Reduction Programme. He explained how respondents could be best allocated, by discussing village dynamics and people that should be contacted first, given their position in and their knowledge of the village.

To carry out the survey, the interviewers worked in teams of two to three, travelling to the villages by bus or rickshaw (or even tractor if no other public transport was

${ }^{139}$ Actually two were recruited - the first needed to be fired.

${ }^{140}$ I would like to thank D. Adinarayana, area representative of BASIX, for a great training session on BASIX. 
available). The first week, each team reported back to the unit office once a day, thereafter approximately every second day in order to reduce their travel time. In the office, they debriefed on their completed interviews, reported on possible difficulties experienced and received their next assignments.

During the survey, the research assistant conducted checks in the field - going back to already interviewed respondents, asking them whether the interview had really taken place. These checks were conducted on several areas as well as for each interviewer. According to these checks, the team of interviewers proved to be quite efficient and diligent.

\subsubsection{Data Entry}

Data Entry was performed by Samruddhi Marketing Assistance for Rural Territory (SMART), established by BASIX to facilitate micro processes of the mainstream service providers while at the same time contributing towards the institution's mission of creating livelihoods. The data was entered Kuppam (Andhra Pradesh) where one of their two Business Process Outsourcing units (BPOs) is located.

The data entry personnel was trained and supervised by myself for the first two days of the entry work. I also checked regularly for mistakes in their entered work, which was send to me about every second evening. The data was entered into Excel and questionnaires were scanned so that the files could be transported easily and also used to answer questions coming up when starting on cleaning the data.

\subsection{Questionnaires}

\subsubsection{Household Questionnaire}

1. Baseline

2. Household Roster

3. General Household Characteristics

4. Assets

5. Consumption

6. Income

7. Livestock

8. Risk

9. Credit, Savings \& Insurance

10. Part for NON-Customers

11. Part for Customers
a. BASIX General
b. BASIX - Agricultural/Business Development Services
c. BASIX - Livestock Insurance 


\subsubsection{Household Questionnaire}

\section{Baseline}

\begin{tabular}{|c|c|c|c|c|c|}
\hline & \multicolumn{3}{|c|}{ WORK DONE } & \multirow{2}{*}{$\begin{array}{c}\text { BY WHOM } \\
\mathrm{d} \\
\text { NAME INTERVIEWER }\end{array}$} \\
\hline & & $\begin{array}{c}\mathrm{a} \\
\text { Day }\end{array}$ & $\begin{array}{c}\mathrm{b} \\
\text { Month }\end{array}$ & $\begin{array}{c}\mathrm{c} \\
\text { Year }\end{array}$ & \\
\hline 1. & Actual interview date & & & & \\
\hline 2. & Data entry Date & & & & \\
\hline
\end{tabular}

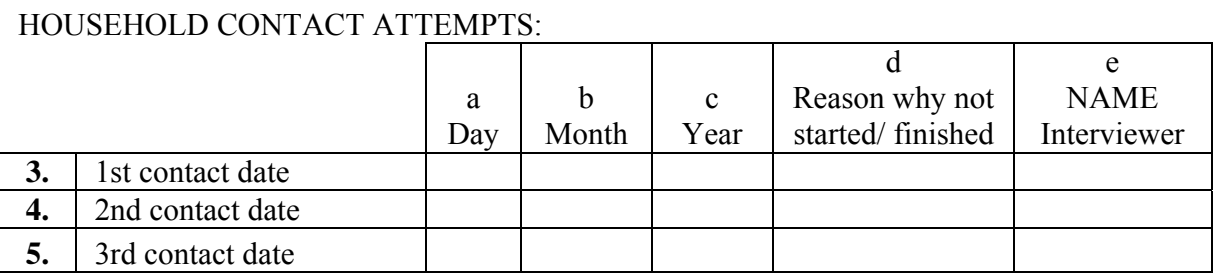

\begin{tabular}{|l|l|l|}
\hline 6. & Interview start time & \\
\hline 7. & Interview end time & \\
\hline 8. & Supervision $\quad$ yes $=1$, no $=0$ & \\
\hline
\end{tabular}

\begin{tabular}{|c|c|c|c|}
\hline & & NAME & ID CODE \\
\hline 9. & District & & \\
\hline 10. & Mandal & & \\
\hline 11. & Village & & \\
\hline 12. & $\begin{array}{l}\text { Household ID number in village sampling } \\
\text { list }\end{array}$ & & \\
\hline 13. & Name of main respondent in household & & \\
\hline
\end{tabular}

\begin{tabular}{|l|l|l|}
\hline 14.a. BASIX CUSTOMERS: yes $=1$, no $=0$ & \\
\hline $\mathbf{1 4 . b}$. & Loan No. & \\
\hline $\mathbf{1 5 .}$ & Loan Cycle with BASIX & \\
\hline $\mathbf{1 6 .}$ & Years with BASIX & \\
\hline $\mathbf{1 7 .}$ & Receives Ag/BDS & \\
\hline $\mathbf{1 8 .}$ & Years receiving Ag/BDS & \\
\hline $\mathbf{1 9 .}$ & Receives Livestock Insurance & \\
\hline $\mathbf{2 0 .}$ & Years receiving livestock insurance & \\
\hline $\mathbf{2 1 .}$ & $\begin{array}{l}\text { Used Loan for buying cow or buffalo } \\
(\text { yes }=1, \text { no }=0)\end{array}$ & \\
\hline
\end{tabular}




\section{HOUSEHOLD ROSTER}

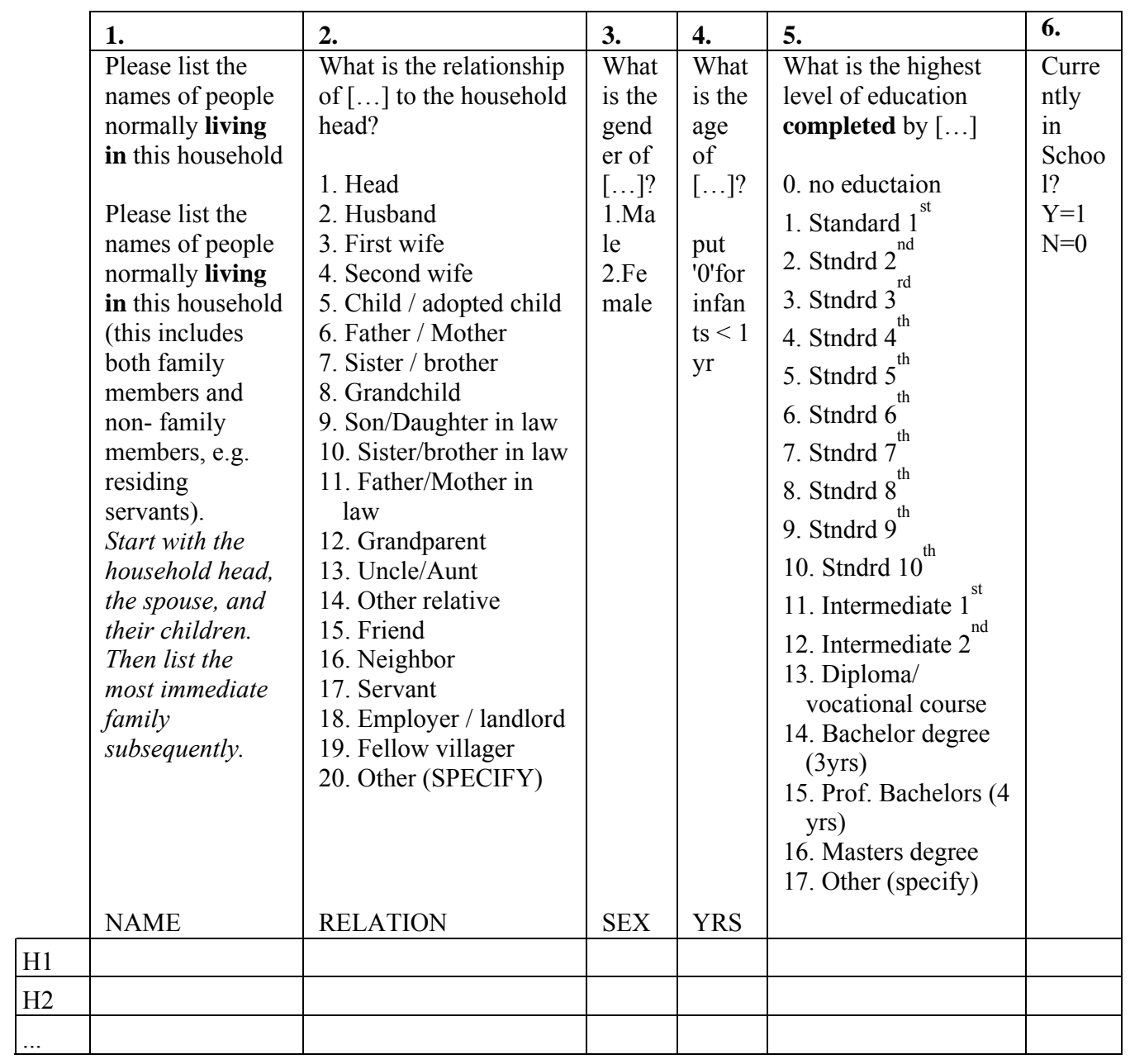

\begin{tabular}{|c|c|c|c|}
\hline \multirow[t]{2}{*}{7.} & $\begin{array}{l}\text { a. Caste or ethnic/religious group of } \\
\text { household head }\end{array}$ & $\begin{array}{l}\text { 1. forward caste } \\
\text { 2. backward caste } \\
\text { 3. scheduled caste }\end{array}$ & $\begin{array}{l}\text { 4. scheduled tribe } \\
5 . \text { minority }\end{array}$ \\
\hline & b. if minority, specify & $\begin{array}{l}\text { 1. Muslim } \\
\text { 2. Christian }\end{array}$ & $\begin{array}{l}\text { 3. Sikh } \\
\text { 4. other (SPECIFY) }\end{array}$ \\
\hline 8. & Is the household vegetarian? & \multicolumn{2}{|l|}{ yes $=1$, no $=0$} \\
\hline
\end{tabular}




\section{GENERAL HOUSEHOLD CHARACTERISTICS}

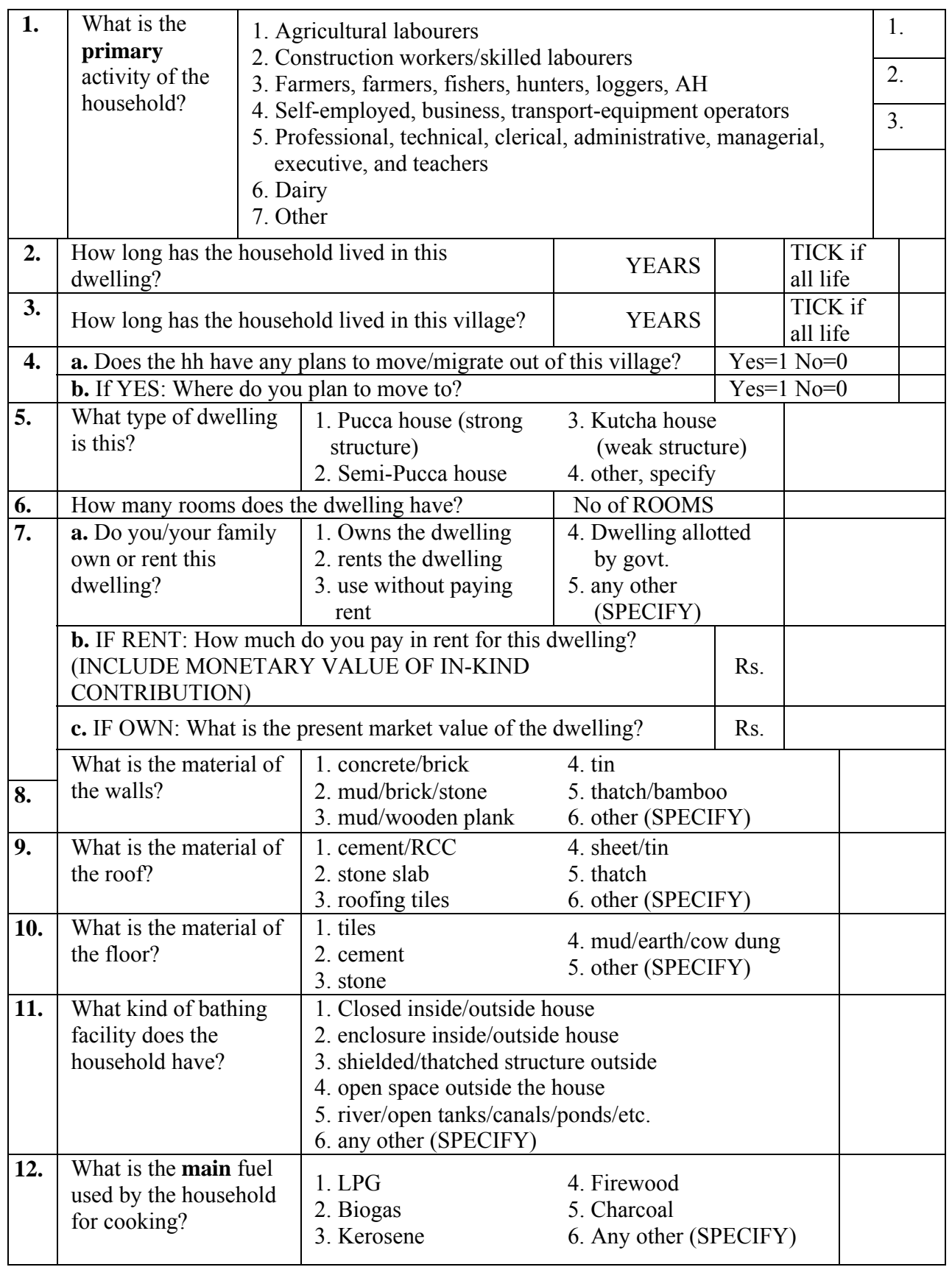




\begin{tabular}{|c|c|c|c|}
\hline 13. & $\begin{array}{l}\text { What is the main fuel } \\
\text { used for household } \\
\text { lighting? }\end{array}$ & \multicolumn{2}{|c|}{$\begin{array}{ll}\text { 1. Electricity } & \text { 4. Kerosene lamps } \\
\text { 2. Generator } & \text { 5. Candles } \\
\text { 3. Battery } & 6 \text { Any other (SPECIFY) }\end{array}$} \\
\hline 14. & $\begin{array}{l}\text { What kind of drinking } \\
\text { water facility does the } \\
\text { household have? }\end{array}$ & \multicolumn{2}{|c|}{$\begin{array}{l}\text { 1. piped into dwelling or compound } \\
\text { 2. protected/unprotected personal well } \\
\text { 3. public outdoor tap or drinking water pump close to } \\
\text { the house } \\
\text { 4. public outdoor tap or drinking water pump far from } \\
\text { the house } \\
\text { 5. (un)protected community well } \\
\text { 6. river/lake/pond } \\
\text { 7. access to another hh's private water source } \\
\text { 8. Govt. water tank } \\
\text { 9. Govt. water tank only in summer } \\
\text { 10. any other (SPECIFY) }\end{array}$} \\
\hline \multirow[t]{2}{*}{15.} & \multirow{2}{*}{\multicolumn{2}{|c|}{$\begin{array}{l}\text { Is there any member of this } \\
\text { household who has ever been or } \\
\text { currently is a ward representative } \\
\text { for local Gram? }\end{array}$}} & $\begin{array}{l}\text { a. } \text { yes }=1 \text { (copy hh member code and } \\
\text { NAME from ROSTER) no }=0\end{array}$ \\
\hline & & & b. CHECK if currently active \\
\hline
\end{tabular}

\section{ASSETS}

\begin{tabular}{|c|c|c|c|}
\hline \multirow[t]{2}{*}{1.} & \multirow{2}{*}{$\begin{array}{l}\text { Do you own any other house elsewhere? If so, } \\
\text { if you were to sell your house today, how } \\
\text { much would you ask for it? }\end{array}$} & a. yes $=1$, no $=0$ & No. \\
\hline & & $\begin{array}{l}\text { b. Present MARKET VALUE } \\
\text { (Rs.) }\end{array}$ & \\
\hline \multirow[t]{2}{*}{2.} & \multirow[t]{2}{*}{ Do you rent it out? } & a. yes $=1$, no $=0$ & \\
\hline & & b. Rent received per month (Rs.) & \\
\hline \multirow[t]{6}{*}{3.} & \multirow{6}{*}{$\begin{array}{l}\text { Does the household own any agricultural } \\
\text { land? }\end{array}$} & a. yes $=1$, no $=0$ & \\
\hline & & b. Acres irrigated & \\
\hline & & c. Acres NOT irrigated & \\
\hline & & d. Acres rented out & \\
\hline & & e. Rent received p. month & \\
\hline & & f. Present market value(Rs.) & \\
\hline 4. & $\begin{array}{l}\text { Did the hh own more/less/same amount of } \\
\text { land one year ago? }\end{array}$ & 1.less 2.same 3 more & \\
\hline \multirow[t]{3}{*}{5.} & \multirow[t]{3}{*}{ Does the household RENT any land? } & a. yes $=1$, no $=0$ & \\
\hline & & b. $\quad$ Acres rented & \\
\hline & & c. Rs. Paid for rent & \\
\hline
\end{tabular}




\begin{tabular}{|c|c|c|c|c|}
\hline & & $\begin{array}{l}\text { 6. How many } \\
{[\ldots] \text { does your }} \\
\text { hh own? }\end{array}$ & $\begin{array}{l}\text { 7. If you sold all o } \\
\text { how much money } \\
\text { Note value of shar } \\
\text { ownership \& state }\end{array}$ & $\begin{array}{l}\text { ur [...] today, } \\
\text { ld you get? } \\
\text { ICK if share } \\
\text { owned }\end{array}$ \\
\hline & TYPE OF ASSET & No. & a. Market Value & b. $\sqrt{ } \quad$ c. $\%$ \\
\hline 1. & Bicycle & & & \\
\hline 2. & Motorcycle & & & \\
\hline 3. & Scooter & & & \\
\hline 4. & Four wheeler & & & \\
\hline 5. & Furniture: a. Chair(s) & & & \\
\hline & b. Table(s) & & & \\
\hline & c. $\operatorname{Bed}(\mathrm{s})$ & & & \\
\hline & d. Cupboard(s) & & & \\
\hline & e. Other & & & \\
\hline 6. & Refrigerator & & & \\
\hline 7. & TV - colour & & & \\
\hline 8. & TV - black and white & & & \\
\hline 9. & Radio & & & \\
\hline 10. & Telephone / cell & & & \\
\hline 11. & Sewing machine & & & \\
\hline 12. & Electric iron & & & \\
\hline 13. & Pressure cooker & & & \\
\hline 14. & Electric Fans & & & \\
\hline 15. & Clock & & & \\
\hline 16. & Steel Utensils & & & \\
\hline 17. & Jewellery & & & \\
\hline 18. & Livestock total: a. Bullock & & & \\
\hline & b. Buffalo & & & \\
\hline & c. Cow & & & \\
\hline & d. Calf & & & \\
\hline & e. Goat & & & \\
\hline & f. Sheep & & & \\
\hline & g. Pig & & & \\
\hline & h. Chicken & & & \\
\hline & i. Other & & & \\
\hline 19. & Irrigation Equipment & & & \\
\hline 20. & $\begin{array}{l}\text { Dairy Assets (shed, milking } \\
\text { machine...) }\end{array}$ & & & \\
\hline 21. & $\begin{array}{l}\text { Modern agricultural equipment } \\
\text { (tractor...) }\end{array}$ & & & \\
\hline 22. & other agricultural equipment & & & \\
\hline 23. & any others (SPECIFY) & & & \\
\hline
\end{tabular}




\section{CONSUMPTION}

INTERVIEWER: HERE IT IS VERY IMPORTANT THAT YOU GUIDE THE RESPONDENT THROUGH THE CALCULATIONS AND HELP IF NECESSARY IN THINKING ABOUT HOW OFTEN THEY BUY SOMETHING, THE PRICE PAID PER UNIT AND THEN MULTIPLY UP FOR THE PRICE PER PAST WEEK OR PAST YEAR.

Now I would like to talk to you about various items the entire household (including all household members, regardless of who made the purchase) acquired (bought, received, from its own business or parcel of land, or a payment in kind) within the last week (year). To make it easier to remember, we will talk about different groups of goods that you might be consuming, regardless of whether you have bought them or they are home produced.

\begin{tabular}{|c|c|c|c|c|c|c|c|}
\hline \multicolumn{3}{|c|}{$\begin{array}{c}1 \text { In the last WEEK, did any member of } \\
\text { the household acquired any of the } \\
\text { following food items? }\end{array}$} & \multirow{2}{*}{ 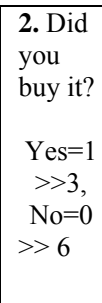 } & \multicolumn{3}{|c|}{ Share Bought } & \multirow{2}{*}{$\begin{array}{c}\mathbf{1 0} \text { How } \\
\text { does this } \\
\text { quantity } \\
\text { compare to a } \\
\text { typical } \\
\text { week? } \\
\text { 1-same, } \\
\text { 2-higher, } \\
\text { 3-lower }\end{array}$} \\
\hline \multicolumn{3}{|c|}{$\mathrm{Yes}=1, \mathrm{No}=0$ (next item) } & & $\begin{array}{l}3 . \\
\text { Quantity } \\
\text { bought }\end{array}$ & $\begin{array}{l}4 . \\
\text { Unit }\end{array}$ & $\begin{array}{l}\mathbf{5 .} \\
\text { Amount } \\
\text { (Rs.) }\end{array}$ & \\
\hline 1 & Rice from market & & & & & & \\
\hline 2 & Rice from PDS shop & & & & & & \\
\hline 3 & Sugar from market & & & & & & \\
\hline 4 & Sugar from PDS shop & & & & & & \\
\hline 5 & Wheat flower & & & & & & \\
\hline 6 & $\begin{array}{l}\text { Wheat Flower } \\
\text { fromPDS shop }\end{array}$ & & & & & & \\
\hline 7 & Dal & & & & & & \\
\hline 8 & Other pulses & & & & & & \\
\hline 9 & Sorghum & & & & & & \\
\hline 10 & Millets & & & & & & \\
\hline 11 & Other cereals & & & & & & \\
\hline 12 & Edible oils & & & & & & \\
\hline 13 & Vegetables & & & & & & \\
\hline 14 & Fruits & & & & & & \\
\hline 15 & Milk & & & & & & \\
\hline 16 & Milk Products & & & & & & \\
\hline 17 & Meat (Beef, chicken...) & & & & & & \\
\hline 18 & Fish & & & & & & \\
\hline 19 & Eggs & & & & & & \\
\hline 20 & Spices and condiments & & & & & & \\
\hline 21 & $\begin{array}{l}\text { Other food expenses } \\
\text { (bread, sweets, } \\
\text { snacks...) }\end{array}$ & & & & & & \\
\hline 22 & $\begin{array}{l}\text { Beverages (incl. tea, } \\
\text { coffee, soft drinks) }\end{array}$ & & & & & & \\
\hline 23 & Alcohol beverages and & & & & & & \\
\hline
\end{tabular}




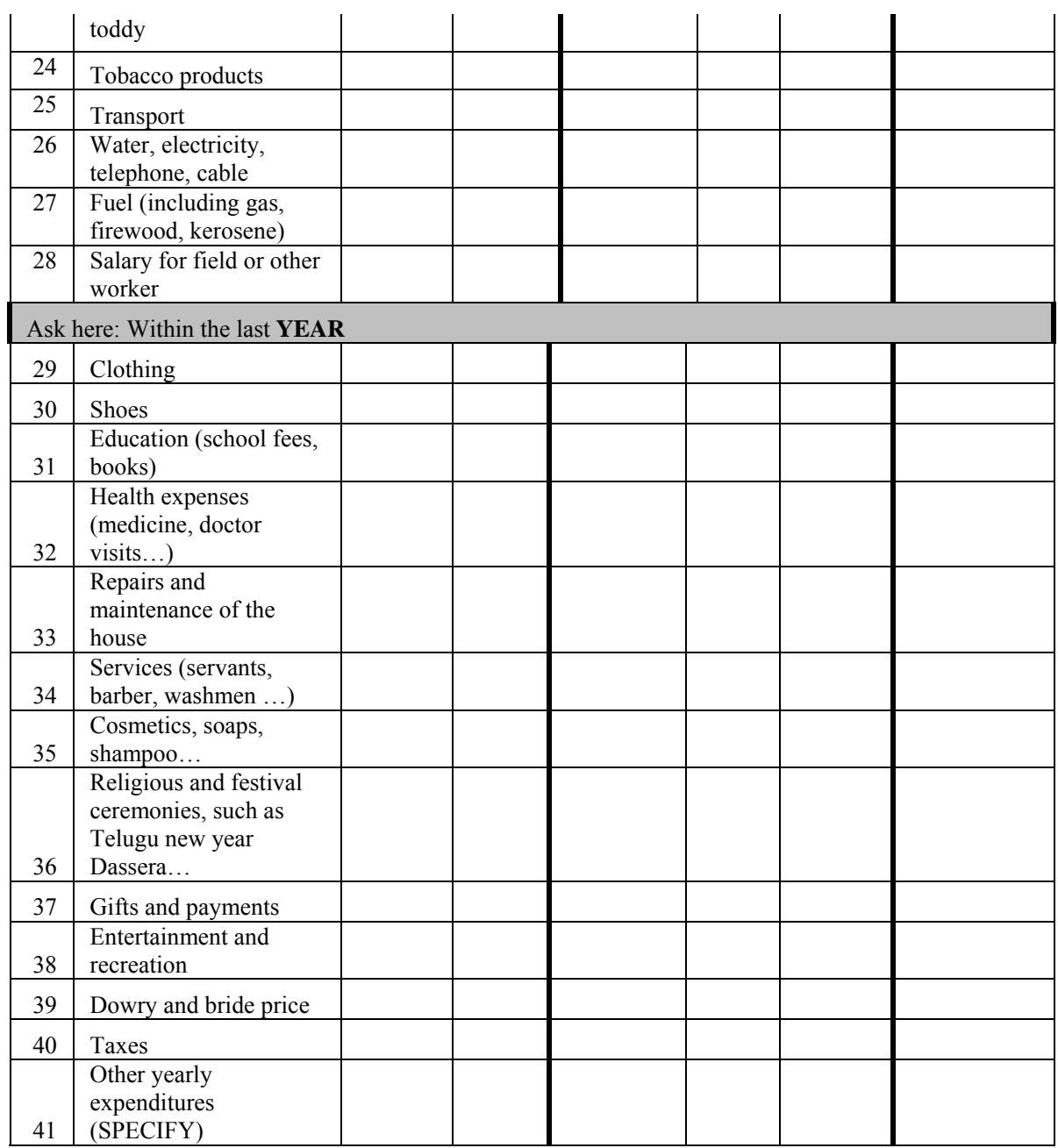

\begin{tabular}{|c|c|c|c|c|c|}
\hline $\begin{array}{l}\text { 6. In this hou } \\
\text { needing to pa }\end{array}$ & $\begin{array}{l}\text { hold did you acquire }[\ldots] \text { without } \\
\text { for it? } \\
\qquad \begin{array}{l}\text { Yes }=1 \gg>7 \\
\text { No }=0>>10\end{array}\end{array}$ & \multicolumn{3}{|c|}{$\begin{array}{c}\text { Share obtained WITHOUT } \\
\text { buying it }\end{array}$} & \multirow{2}{*}{ 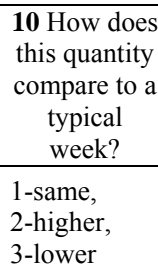 } \\
\hline & & $\begin{array}{l}\text { 7. Quantity } \\
\text { consumed }\end{array}$ & $\begin{array}{l}\mathbf{8 .} \\
\text { Unit }\end{array}$ & $\begin{array}{l}\mathbf{9 .} \\
\text { Amount } \\
\text { (Rs.) }\end{array}$ & \\
\hline 1 & Rice from market & & & & \\
\hline 2 & Rice from PDS shop & & & & \\
\hline$\ldots$ & & & & & \\
\hline
\end{tabular}




\section{INCOME}

INTERVIEWER: IF THE HOUSEHOLD'S PRIMARY ACTIVITY IS FARMING, ASK ABOUT YEARLY INCOME. OTHERWISE, ASK ABOUT MONTHLY INCOME.

\begin{tabular}{|c|c|c|c|c|c|c|}
\hline & \multicolumn{2}{|l|}{1.} & \multicolumn{3}{|l|}{2.} & \multirow{2}{*}{$\begin{array}{l}\text { Did income } \\
\text { from } \\
\text { (INCOME } \\
\text { SOURCE) }\end{array}$} \\
\hline & \multicolumn{2}{|c|}{$\begin{array}{l}\text { Within the last MONTH (Year), has } \\
\text { anyone in your household earned any } \\
\text { income paid as cash or in-kind from }[\ldots] \text { ? }\end{array}$} & \multicolumn{3}{|c|}{$\begin{array}{l}\text { How much income was } \\
\text { earned by those members on } \\
\text { (INCOME SOURCE) per } \\
\text { month (year)? }\end{array}$} & \\
\hline & $\begin{array}{l}\text { ASK RESPONDENT TO } \\
\text { TRANSLATE IN-KIND INCOME } \\
\text { TO MONETARY VALUE }\end{array}$ & $\begin{array}{c}\text { yes }= \\
1 \\
>>2 \\
\text { no }=0\end{array}$ & $\begin{array}{l}\text { a. } \\
\text { Rs. / } \\
\text { MONTH } \\
\text { (Year) }\end{array}$ & $\begin{array}{l}\text { b. } \\
\text { tick if } \\
\text { CASH }\end{array}$ & $\begin{array}{l}\text { c. } \\
\text { Tick if } \\
\text { IN- } \\
\text { KIND }\end{array}$ & $\begin{array}{l}\text { change as } \\
\text { compared to } 1 \\
\text { yr ago? } \\
\text { 1. increase } \\
\text { 2. same } \\
\text { 3. decrease }\end{array}$ \\
\hline 1 & $\begin{array}{l}\text { Wages from agricultural labour } \\
\text { (not on own farm) }\end{array}$ & & & & & \\
\hline 2 & $\begin{array}{l}\text { Wages from non-agricultural sector } \\
\text { - formal sector, (salary...) }\end{array}$ & & & & & \\
\hline 3 & $\begin{array}{l}\text { Wages from non-agricultural sector } \\
\text { - informal sector }\end{array}$ & & & & & \\
\hline 4 & $\begin{array}{l}\text { Wages (possibly in-kind) from } \\
\text { public relief work, e.g. food for } \\
\text { work or other similar programs }\end{array}$ & & & & & \\
\hline 5 & $\begin{array}{l}\text { Non-farm self-employment (net- } \\
\text { income) }\end{array}$ & & & & & \\
\hline 6 & Farm profit & & & & & \\
\hline 7 & Income from Dairy Activities & & & & & \\
\hline 8 & $\begin{array}{l}\text { Sales of handicrafts or other non- } \\
\text { agricultural goods at market (net } \\
\text { income) }\end{array}$ & & & & & \\
\hline 9 & Traditional hereditary occupation & & & & & \\
\hline 10 & migration income / remittances & & & & & \\
\hline 11 & $\begin{array}{l}\text { Benefits from government } \\
\text { schemes, such as social assistance, } \\
\text { child benefits, assistance from } \\
\text { development or welfare programs, } \\
\text { subsidies }\end{array}$ & & & & & \\
\hline 12 & Pensions & & & & & \\
\hline 13 & Dowry income & & & & & \\
\hline 14 & $\begin{array}{l}\text { Other income sources, not } \\
\text { previously mentioned (e.g. } \\
\text { gambling), SPECIFY }\end{array}$ & & & & & \\
\hline & $\begin{array}{l}\text { ERVIEWER: Add all income source } \\
\text { hly (yearly) income (Rs) }\end{array}$ & the & ded col & $\mathrm{bca}$ & & \\
\hline
\end{tabular}




\begin{tabular}{|l|l|l|l|}
\hline 4. & $\begin{array}{l}\text { READ OUT CALCULATED MONTHLY (Yearly) INCOME } \\
\text { Is this a typical monthly income? }\end{array}$ & $\begin{array}{l}\text { 1. yes } \\
\text { 2. no, higher } \\
\text { 3. no, lower }\end{array}$ & \\
\hline 5. & What would be a typical monthly (yearly) income for your household? (Rs) & \\
\hline
\end{tabular}

\section{IF ONLY INCOME SOURCE IS FROM DAIRY ACTIVITIES (7) >> GO TO NEXT SECTION! Else, go on to 6.}

\begin{tabular}{|l|l|c|c|}
\hline 6. & $\begin{array}{l}\text { Imagine that you have a very good month (year), every member of } \\
\text { working age in the household managed to have work, and there were no } \\
\text { droughts or anything the like. What would be the maximum amount of } \\
\text { income your household would receive in such a situation in one month? }\end{array}$ & Y & Rs. \\
\hline $\begin{array}{l}\text { 7. } \\
\text { Now imagine the total opposite: the harvest is bad, animals get sick, } \\
\text { finding work is not possible. What would be the monthly (yearly) income } \\
\text { of your household in such a situation? }\end{array}$ & $\mathrm{X}$ & $\mathrm{Rs}$. \\
\hline $\begin{array}{l}\text { INTERVIEWER: Calculate the expected income (threshold } \mathrm{B}-\text { this should } \\
\text { be close to the typical monthly (yearly) income in question 5). }\end{array}$ & $\mathrm{B}=(\mathrm{X}+\mathrm{Y}) / 2$ & $\mathrm{~A}=(\mathrm{B}+\mathrm{X}) / 2$ \\
\hline INTERVIEWER: Calculate threshold A. & $\mathrm{C}=(\mathrm{B}+\mathrm{Y}) / 2$ & \\
\hline INTERVIEWER: Calculate threshold C. & \\
\hline
\end{tabular}

\section{Please explain the rainfall question to the respondent (See extra sheet!).}

\begin{tabular}{|l|l|}
\hline So, what do you think how likely it is that it will rain tomorrow? & \\
\hline $\begin{array}{l}\text { So, what do you think how likely it is that it will rain within the } \\
\text { coming week? }\end{array}$ & \\
\hline $\begin{array}{l}\text { So, what do you think how likely it is that it will rain within the } \\
\text { coming month? }\end{array}$ & \\
\hline
\end{tabular}

We will now use the same rules as with the rain-question.

\begin{tabular}{|c|l|l|}
\hline 8. & $\begin{array}{l}\text { How likely do you think it is that your monthly (yearly) income in the } \\
\text { coming month will be higher than }\end{array}$ & \\
\hline 9. & $\begin{array}{l}\text { How likely do you think it is that your monthly (yearly) income in the } \\
\text { coming month will be higher than }\end{array}$ & (B) Rupees? \\
\hline $\mathbf{1 0}$ & $\begin{array}{l}\text { How likely do you think it is that your monthly (yearly) income in the } \\
\text { coming month will be higher than }\end{array}$ & (C) Rupees? \\
\hline
\end{tabular}




\section{LIVESTOCK}

\begin{tabular}{|c|l|l|l|}
\hline \multirow{2}{*}{ 1. } & a. Does your household own any cows or buffalos? & $\begin{array}{l}\text { yes }=1 \\
\text { no }=0>\text { NEXT SECTION }\end{array}$ & \\
\cline { 2 - 4 } & IF YES: $\quad$ b. No. of Milk-animals & \\
\hline c. No. of non-milk animals & \\
\hline d. No. of Calves & \\
\hline
\end{tabular}

For CALVES (Milk and non-milk):

\begin{tabular}{|c|c|c|c|}
\hline \multirow[t]{2}{*}{2.} & \multirow[t]{2}{*}{ How many were born/died the last year? } & No. BORN & \\
\hline & & No. DIED & \\
\hline \multirow[t]{4}{*}{3.} & \multirow[t]{4}{*}{ How many did you buy/sell within the last year? } & No. BOUGHT & \\
\hline & & b. Rs. Value bought & \\
\hline & & c. $\quad$ No. SOLD & \\
\hline & & Rs. Value Sold & \\
\hline
\end{tabular}

For NON-MILK Animals:

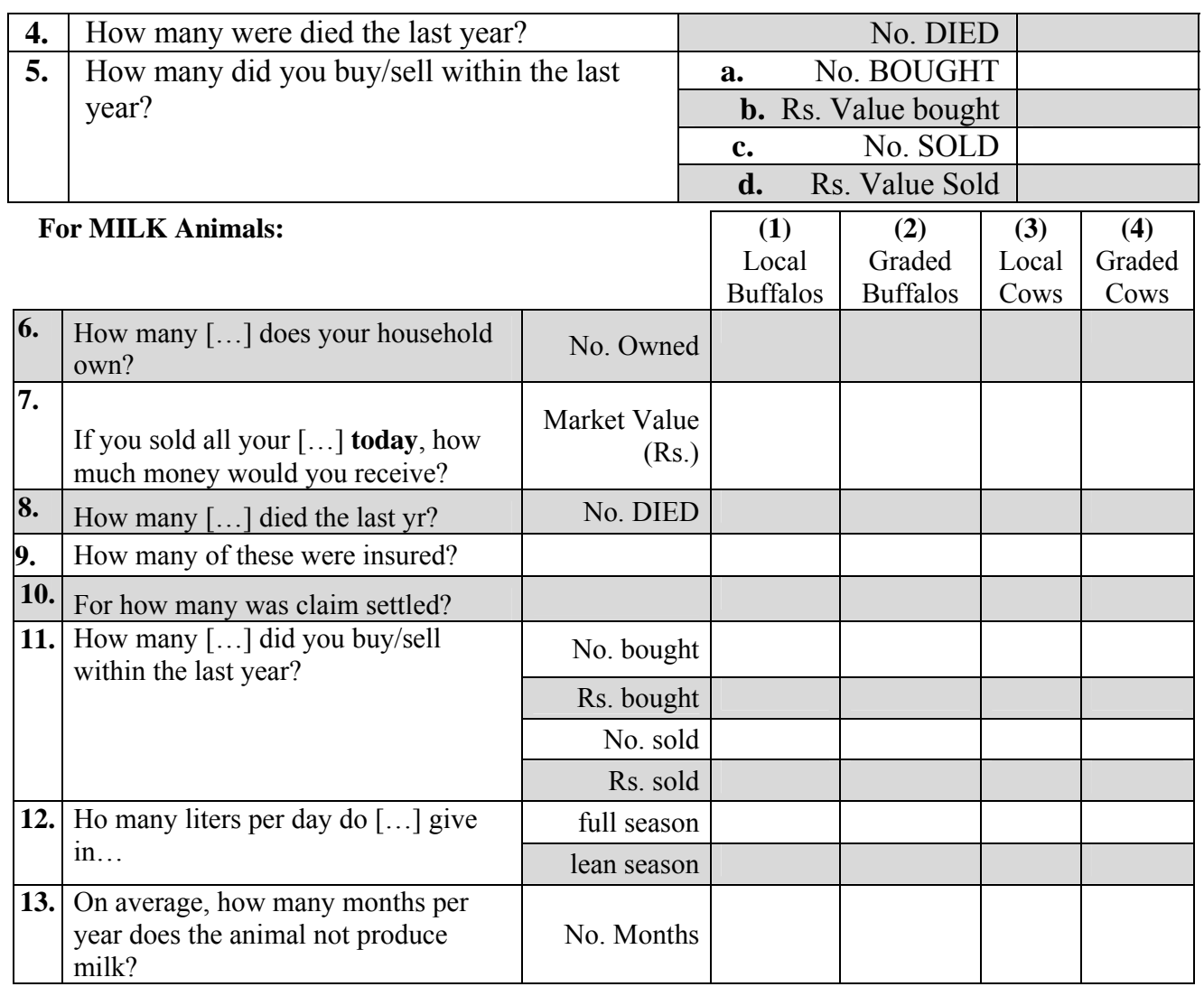

\begin{tabular}{|l|l|l|l|}
\hline \multirow{2}{*}{ a. Is there a cooperative in your village $/$ local area? } & Yes $=1, \mathrm{No}=0$ & \\
\cline { 2 - 4 } & b. IF YES: Are you a member of this cooperative? & Yes $=1, \mathrm{No}=0$ & \\
\hline
\end{tabular}




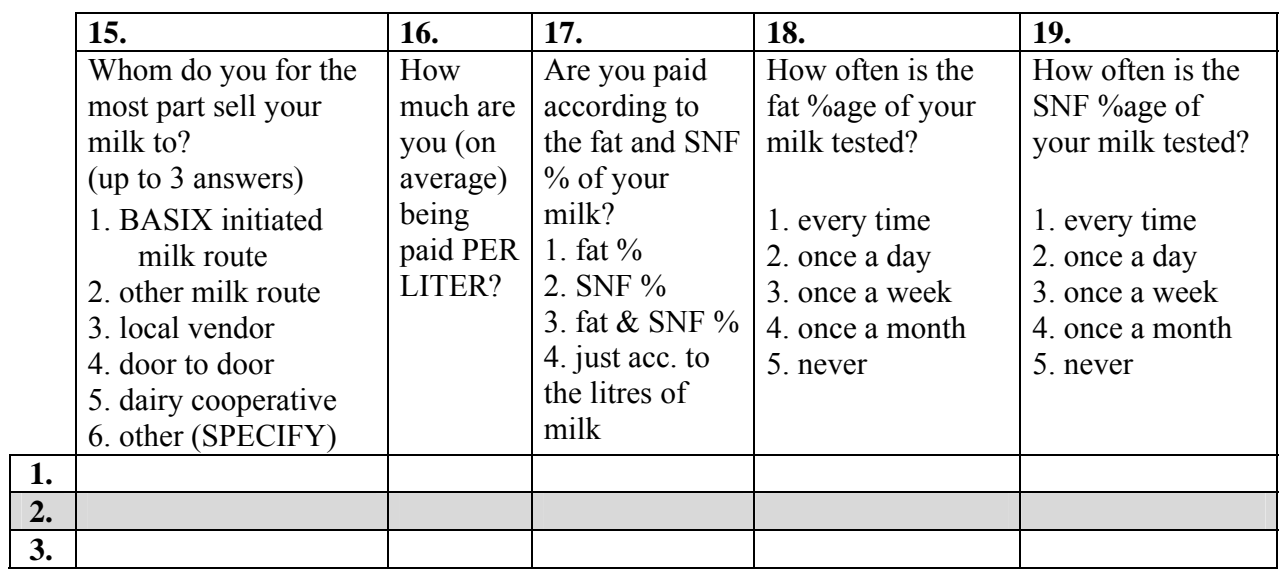

For ALL Animals:

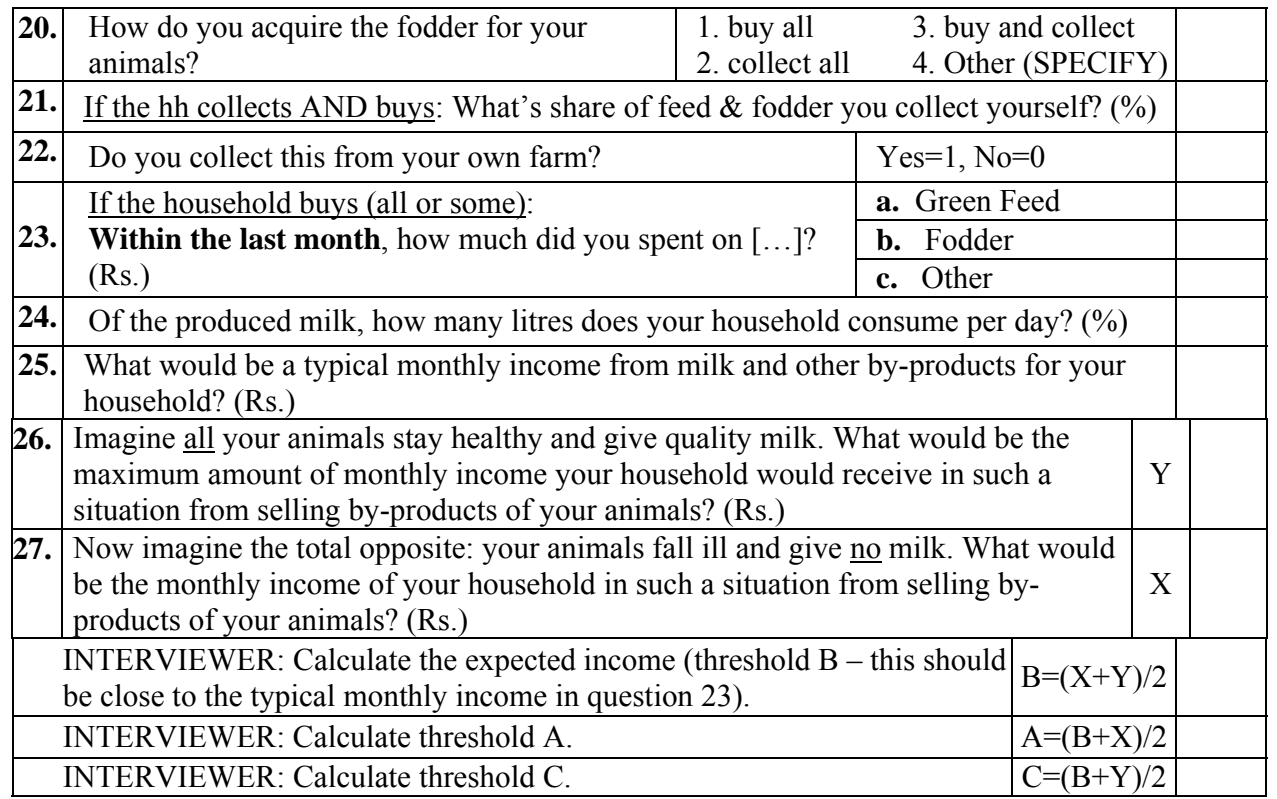

INTERVIEWER: Use again the ruler to ask question 28-30. In case the household only receives income from dairy activities, use first the rainfall question to explain the idea of probabilities.

So, what do you think how likely it is that it will rain tomorrow?

So, what do you think how likely it is that it will rain in the coming week?

So, what do you think how likely it is that it will rain in the coming month?

We will now use the same rules as with the rain-question. 
28. How likely do you think it is that your typical monthly income from selling products of the animals in the coming month will be higher than (A) Rupees?

29. How likely do you think it is that your typical monthly income from selling roducts of the animals in the coming month will be higher than (B) Rupees?

30. How likely do you think it is that your typical monthly income from selling products of the animals in the coming month will be higher than (C) Rupees?

HEALTH of the animal:

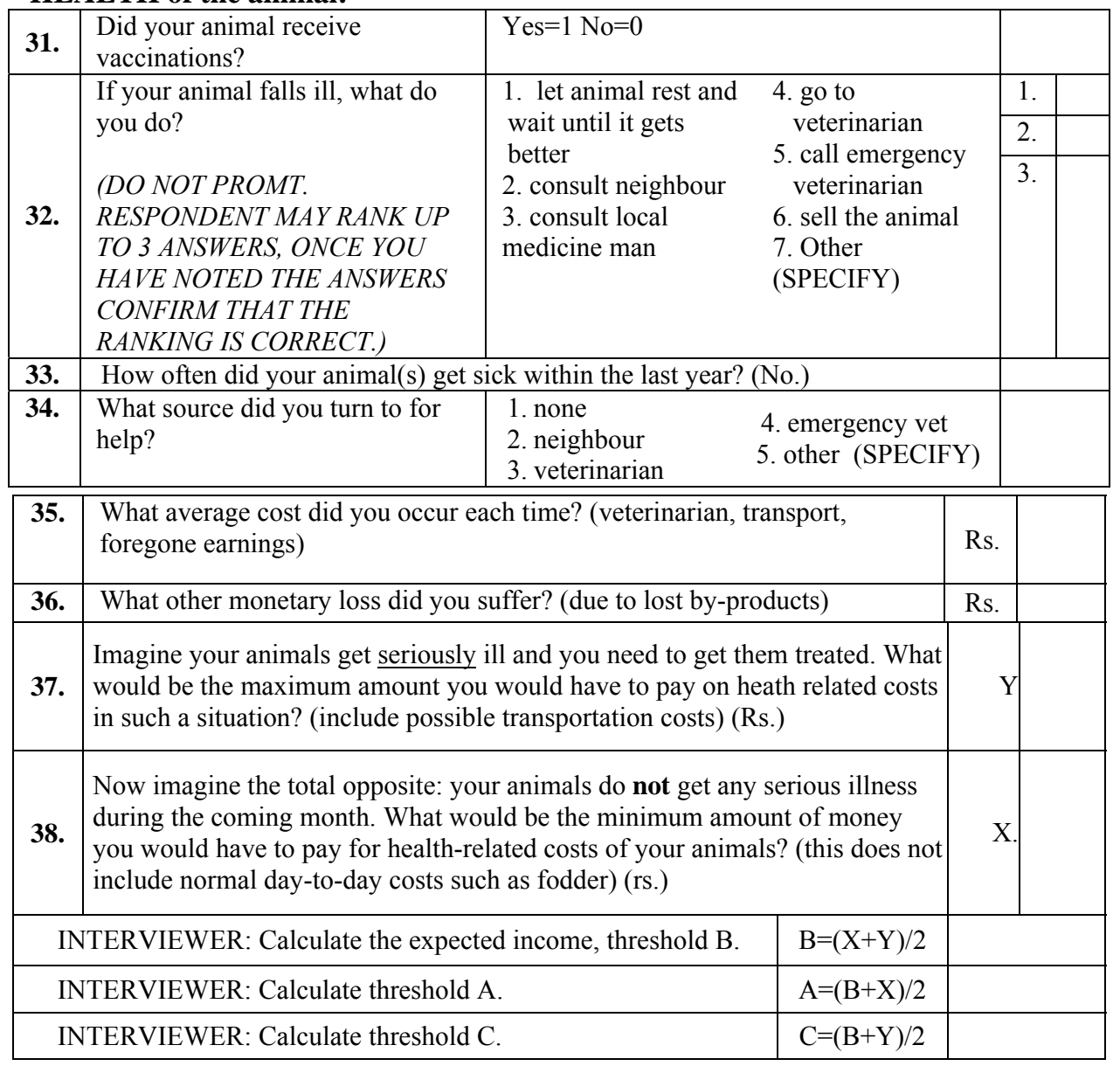


As before, we will now use the same rules as with the rain-question

\begin{tabular}{|c|c|c|}
\hline 39. & $\begin{array}{l}\text { How likely do you think it is that you will have to spend more than } \\
\text { (A) Rupees on health services for your animals in the coming } \\
\text { month? }\end{array}$ & \\
\hline 40. & $\begin{array}{l}\text { How likely do you think it is that you will have to spend more than } \\
\text { (B) Rupees on health services for your animals in the coming } \\
\text { month? }\end{array}$ & \\
\hline 41. & $\begin{array}{l}\text { How likely do you think it is that you will have to spend more than } \\
\text { (C) Rupees on health services for your animals in the coming } \\
\text { month? }\end{array}$ & \\
\hline \multicolumn{2}{|c|}{ How likely is it that... } & $\%$ \\
\hline 42. & ...you will sell at least one animal in the coming YEAR? & \\
\hline 43. & ...you will buy at least one animal in the coming YEAR? & \\
\hline 44. & ...you will breed at least one animal in the coming YEAR? & \\
\hline 45. & ... none of your animal(s) dies within the coming YEAR? & \\
\hline 46. & ...none of your animal(s) gets sick within the coming MONTH? & \\
\hline
\end{tabular}

\section{RISKS}

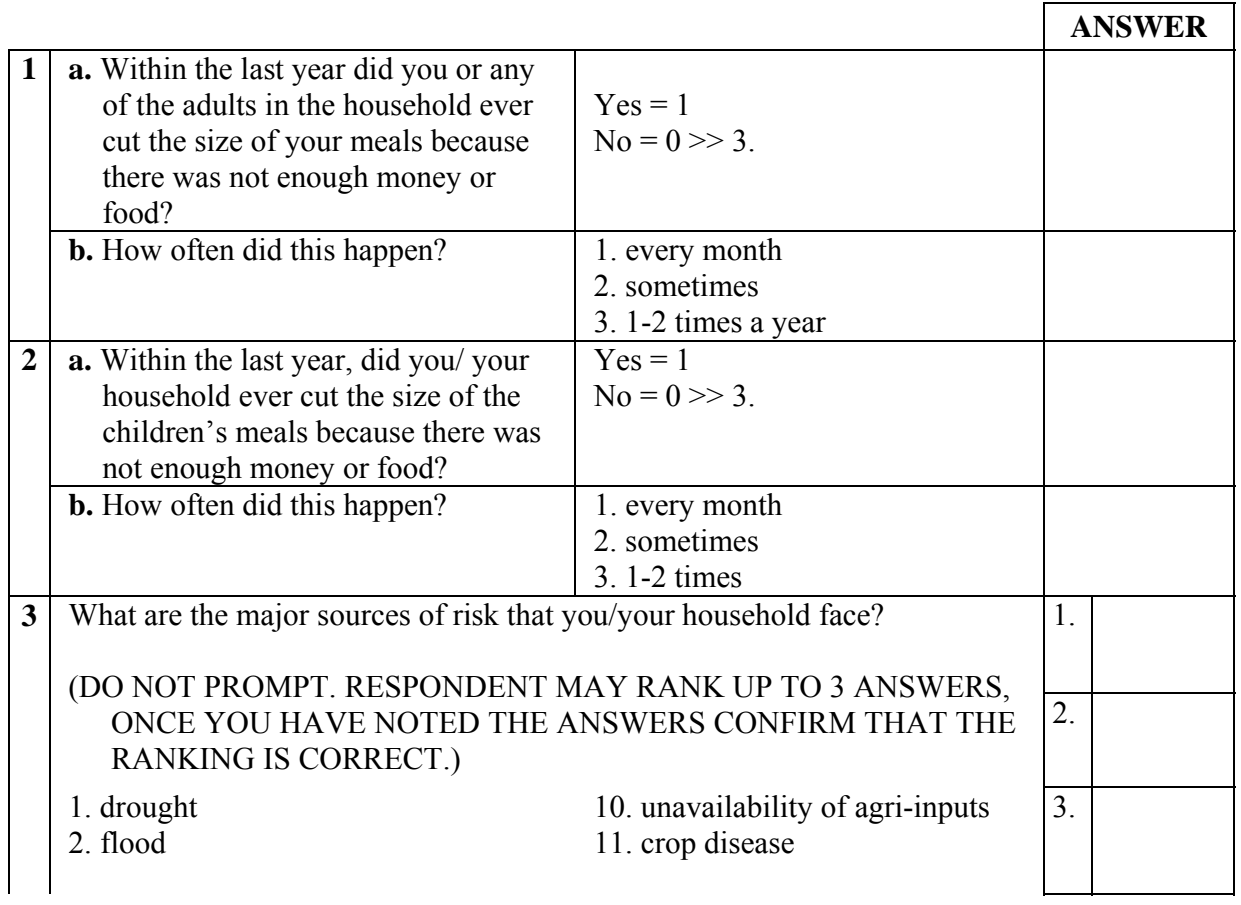




\begin{tabular}{|c|c|c|c|c|}
\hline & $\begin{array}{l}\text { 3. fires } \\
\text { 4. illness of household member } \\
\text { 5. sudden death of household member } \\
\text { 6. loss of livestock / disease } \\
\text { 7. dramatic change in crop prices } \\
\text { 8. price changes of inputs } \\
\text { 9. price changes of production }\end{array}$ & $\begin{array}{l}\text { 12. Quality of seeds (spurious } \\
\text { seeds) } \\
\text { 13. erratic electricity supply } \\
\text { 14. crop failure } \\
\text { 15. loss of land } \\
\text { 16. job loss } \\
\text { 17. unsuccessful investment } \\
\text { 18. other (SPECIFY) }\end{array}$ & & \\
\hline 4 & \multicolumn{2}{|c|}{ Which of these did you actually experience within the last year? } & 1. & \\
\hline & \multirow{5}{*}{$\begin{array}{l}\text { 1. drought } \\
\text { 2. flood } \\
\text { 3. fires } \\
\text { 4. illness of household member } \\
\text { 5. sudden death of household member } \\
\text { 6. loss of livestock / disease } \\
\text { 7. dramatic change in crop prices } \\
\text { 8. price changes of inputs }\end{array}$} & \multirow{5}{*}{$\begin{array}{l}\text { 9. price changes of production } \\
\text { 10. crop disease } \\
\text { 11. erratic electricity supply } \\
\text { 12. crop failure } \\
\text { 13. loss of land } \\
\text { 14. job loss } \\
\text { 15. unsuccessful investment (s.a. } \\
\text { well digging) } \\
\text { 16. other (SPECIFY) }\end{array}$} & 2. & \\
\hline & & & 3. & \\
\hline & & & 4. & \\
\hline & & & 5. & \\
\hline & & & & \\
\hline
\end{tabular}

\section{CREDIT, SAVINGS \& INSURANCE}

\section{CREDIT}

\begin{tabular}{|c|c|c|c|c|c|c|c|c|}
\hline 1. & \multicolumn{5}{|c|}{ Has your household any debt? } & \multicolumn{2}{|c|}{ Yes $=1 \mathrm{No}=0>>5$} & \\
\hline \multirow{12}{*}{$\begin{array}{l}1 . \\
2 .\end{array}$} & & $\begin{array}{l}\text { What are the sources of } \\
\text { credit at present? }\end{array}$ & $\begin{array}{l}\mathrm{Yes}=1 \\
\mathrm{No}=0\end{array}$ & $\begin{array}{l}(\mathrm{A}) \\
\text { Year } \\
\text { taken }\end{array}$ & $\begin{array}{c}\text { (B) } \\
\text { Amount } \\
\text { taken }\end{array}$ & $\begin{array}{c}\mathrm{C}) \\
\text { Amount } \\
\text { outstanding }\end{array}$ & $\begin{array}{c}\text { (D) } \\
\text { Interest } \\
\text { Rate }\end{array}$ & $\begin{array}{c}(\mathrm{E}) \\
\text { Loan } \\
\text { Period } \\
\end{array}$ \\
\hline & 1 & Public sector Banks & & & & & & \\
\hline & 2 & PACS & & & & & & \\
\hline & 3 & $\begin{array}{l}\text { Private Banks/Finance } \\
\text { Companies }\end{array}$ & & & & & & \\
\hline & 4 & BASIX & & & & & & \\
\hline & 5 & Other MFIs & & & & & & \\
\hline & 6 & $\begin{array}{l}\text { Commission } \\
\text { Agents/Traders/Dealers }\end{array}$ & & & & & & \\
\hline & 7 & Chit Funds & & & & & & \\
\hline & 8 & SHGs & & & & & & \\
\hline & 9 & Money lenders & & & & & & \\
\hline & 10 & Relatives/Friends & & & & & & \\
\hline & 11 & Any other (Specify) & & & & & & \\
\hline 3. & & $\begin{array}{l}\text { the amount of your debt } \\
\text { age as compared to one } \\
\text { ago? }\end{array}$ & $\begin{array}{l}\text { 1. incre } \\
\text { 2. sam }\end{array}$ & & & $\begin{array}{l}\text { 3. decrease } \\
\text { 4. don't know }\end{array}$ & & \\
\hline 4. & & $\begin{array}{l}v \text { is your household's } \\
\text { acity to pay the debt as } \\
\text { pared to one year ago? }\end{array}$ & $\begin{array}{l}\text { 1. easi } \\
\text { 2. sam } \\
\text { difficu }\end{array}$ & $\begin{array}{l}\text { to take } \\
\text { amount } \\
\text { y/ease }\end{array}$ & are of & $\begin{array}{l}\text { 3. more diffict } \\
\text { care of } \\
\text { 4. don't know }\end{array}$ & to take & \\
\hline
\end{tabular}




\section{SAVINGS}

\begin{tabular}{|c|l|l|l|l|l|l|l|}
\hline 5. & Has your household any savings? & $\begin{array}{l}\text { Yes=1 No=0 }>9 . \\
\text { (Ahat are the sources of } \\
\text { savings at present? }\end{array}$ & $\begin{array}{l}\text { Yes=1 } \\
\text { No=0 }\end{array}$ & $\begin{array}{l}\text { (A) What is } \\
\text { the money } \\
\text { value of } \\
\text { this saving } \\
\text { now? (Rs.) } \\
\text { receive } \\
\text { interest? If so, } \\
\text { how much? } \\
\text { Yes=1 } \\
\text { No=0 Interest }\end{array}$ & $\begin{array}{l}\text { (C) Do you make } \\
\text { regular } \\
\text { contributions? } \\
\text { 1. Yes, weekly } \\
\text { 2. Yes, monthly } \\
\text { 3. Yes, other } \\
\text { 4. No }\end{array}$ \\
\hline $\mathbf{1}$ & Deposits with any bank & & & & & \\
\hline $\mathbf{2}$ & $\begin{array}{l}\text { Deposit with any private } \\
\text { financial institution }\end{array}$ & & & & & \\
\hline $\mathbf{3}$ & Deposits with post office & & & & & \\
\hline $\mathbf{4}$ & Deposit with any chit fund & & & & & & \\
\hline $\mathbf{5}$ & Cash at home & & & & & \\
\hline $\mathbf{6}$ & SHG or other group & & & & & & \\
\hline $\mathbf{7}$ & Other (SPECIFY) & & & & & \\
\hline
\end{tabular}

7. Did the amount of your savings change as compared to one year

1. increase

2. same ago?

8. What are the most important reasons that you save? save (more)?

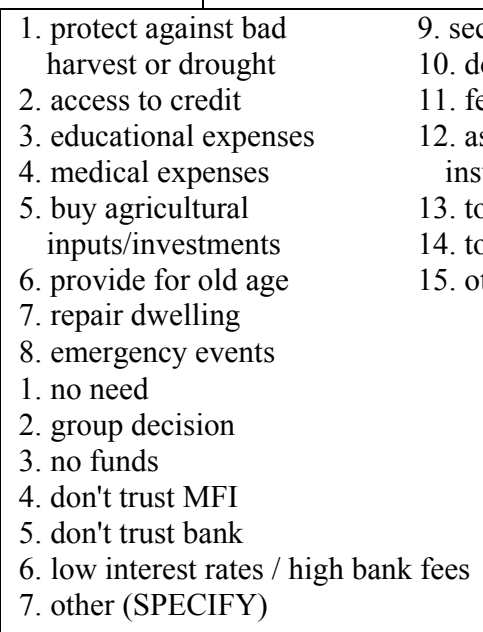
harvest or drought

2. access to credit

3. educational expenses

4. medical expenses

5. buy agricultural inputs/investments

6. provide for old age

7. repair dwelling

8. emergency events

1. no need

2. group decision

3. no funds

4. don't trust MFI

5. don't trust bank

6. low interest rates / high bank fees

7. other (SPECIFY)

\section{3. decrease}

4. don't know

9. secure consumption

10. dowry

11. festival expenses

12. as form of other insurance

13. to leave bequest

14. to pay for debt

15. other (SPECIFY)

\begin{tabular}{|l|l|}
\hline \multicolumn{2}{|c|}{} \\
\hline $1^{\text {st }}$ & \\
\hline $2^{\text {nd }}$ & \\
\hline 3 rd & \\
\hline $1^{\text {st }}$ & \\
\hline $2^{\text {nd }}$ & \\
& \\
\hline 3 rd & \\
\hline
\end{tabular}

\section{INSURANCE}

\begin{tabular}{|c|c|c|c|}
\hline 10. & \multicolumn{2}{|c|}{ Has your household any insurance? } & Yes $=1 \gg 12 . \mathrm{No}=0 \gg 11$. \\
\hline 11. & If no, why not? & $\begin{array}{l}\text { 1. no need } \\
\text { 2. too expensive } \\
\text { 3. don't know good } \\
\text { insurance } \\
\text { 4. never pays out }\end{array}$ & $\begin{array}{l}\text { 5. don't know what insurance } \\
\text { is } \\
\text { 6. other (SPECIFY) } \\
\text { >> NEXT SECTION }\end{array}$ \\
\hline
\end{tabular}




\begin{tabular}{|c|c|l|c|c|}
\hline 12. & \multicolumn{2}{|l|}{$\begin{array}{l}\text { Does your household have any of the } \\
\text { following kinds of insurance? }\end{array}$} & $\begin{array}{c}\text { (A) } \\
\text { Yes }=1 \text { No }=0\end{array}$ & Source \\
\hline & $\mathbf{1}$ & Crop insurance & & \\
\hline $\mathbf{2}$ & weather or rainfall insurance & & \\
\hline $\mathbf{3}$ & life insurance & & \\
\hline $\mathbf{4}$ & health insurance & & \\
\hline $\mathbf{5}$ & fire insurance & & \\
\hline $\mathbf{6}$ & vehicle insurance & & \\
\hline $\mathbf{7}$ & livestock / insurance & & \\
\hline $\mathbf{8}$ & Old age & & \\
\hline $\mathbf{9}$ & other (SPECIFY) & & \\
\hline
\end{tabular}

\section{NON-BASIX CUSTOMERS}

\begin{tabular}{|c|c|c|c|c|c|}
\hline & & & & & NSWER \\
\hline 1. & $\begin{array}{l}\text { Have you previously had a } \\
\text { or have applied for one? }\end{array}$ & loan with or BASIX & $\begin{array}{l}\text { Yes }=1 \\
\text { No }=0\end{array}$ & & \\
\hline 2. & $\begin{array}{l}\text { Why do you (currently) } \\
\text { not have a loan with } \\
\text { BASIX? }\end{array}$ & $\begin{array}{l}\text { 1. do not need credit } \\
\text { 2. better credit sourc } \\
\text { 3. I was rejected } \\
\text { 4. Not offered in my } \\
\text { 5. Other (SPECIFY) }\end{array}$ & $\begin{array}{l}\text { available } \\
\text { illage }\end{array}$ & & \\
\hline 3. & $\begin{array}{l}\text { Have you heard about any s } \\
\text { your cow / buffalo (veterina } \\
\text { camps...) in the village / lo }\end{array}$ & $\begin{array}{l}\text { ervices offered for } \\
\text { arian, health } \\
\text { cal area? }\end{array}$ & $\begin{array}{l}\text { Yes }=1 \\
\text { No }=0>>\text { NEXT } \\
\text { SECTION }\end{array}$ & & \\
\hline 4. & What services have you & 1. general veterinc & & $1^{\text {st }}$ & \\
\hline & heard of and who provides & 2. Ag/BDS DAIR & services from BASIX & $2^{\text {nd }}$ & \\
\hline & $\begin{array}{l}\text { them? } \\
\text { (SEVERAL ANSWERS }\end{array}$ & $\begin{array}{l}\text { 3. services from R } \\
\text { 4. other (SPECIFY }\end{array}$ & $\mathrm{T}$ & $3^{\text {rd }}$ & \\
\hline & POSSIBLE) & If 2 . IS not amon & nswers $>>$ END of IN & ERV & [EW! \\
\hline
\end{tabular}

Ask the following questions only if BASIX is active in the village. If not, the interview finishes here.

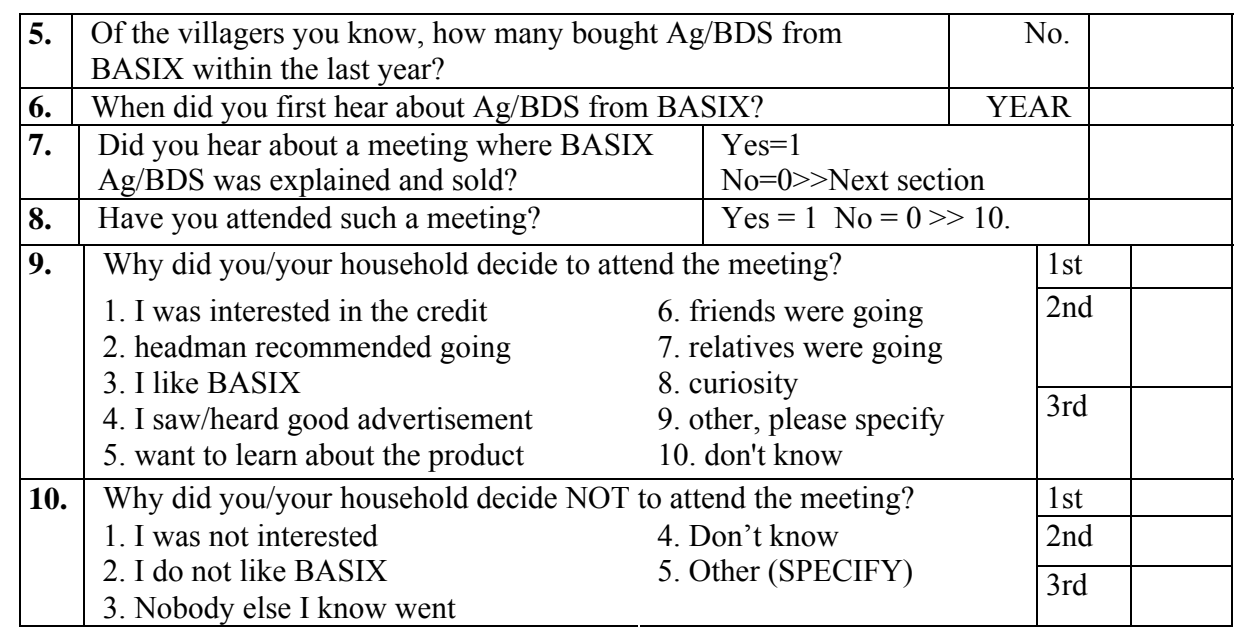




\section{BASIX - CUSTOMERS}

\section{A. GENERAL}

\begin{tabular}{|c|c|c|c|c|c|}
\hline & \multicolumn{2}{|c|}{ ANSWER } \\
\hline 1. & \multicolumn{3}{|c|}{ How many members does your group have? } & & \\
\hline \multirow[t]{6}{*}{2.} & \multirow{6}{*}{$\begin{array}{l}\text { For what purpose did } \\
\text { your group members } \\
\text { take a loan? }\end{array}$} & \multicolumn{2}{|l|}{ a. Agri-Allied Loan (=Dairy) } & No. & \\
\hline & & \multicolumn{2}{|l|}{ b. Crop Loan } & No. & \\
\hline & & \multicolumn{2}{|c|}{ c. Housing \& Infrastructure } & No. & \\
\hline & & \multicolumn{2}{|c|}{ d. Non-farm Micro or Small Enterprise } & & \\
\hline & & \multicolumn{2}{|c|}{ e. General Purpose Loan } & No. & \\
\hline & & \multicolumn{2}{|l|}{ f. Other (SPECIFY) } & No. & \\
\hline 3. & \multicolumn{3}{|c|}{ If for Agri-Allied, how many chose to take Dairy-Ag/BDS? } & No. & \\
\hline 4. & \multicolumn{3}{|c|}{ How many would have chosen not to take Dairy-Ag/BDS? } & No. & \\
\hline 5. & \multicolumn{2}{|c|}{ How long have you been a member of this group? } & \multicolumn{2}{|c|}{ No. of Years } & \\
\hline 6. & \multicolumn{2}{|c|}{ Did you belong to a different group before? } & Yes $=1$ & & \\
\hline 7. & \multicolumn{2}{|c|}{ Did your group ever experience repayment difficulties? } & Yes $=1$ & & \\
\hline 8. & \multicolumn{3}{|c|}{$\begin{array}{l}\text { How many group members had difficulties WITHIN THIS LOAN } \\
\text { PERIOD? }\end{array}$} & No. & \\
\hline 9. & \multicolumn{3}{|c|}{ How often did this happen WITHIN THIS LOAN PERIOD? } & No. & \\
\hline 10. & How was this solved? & \multicolumn{3}{|c|}{$\begin{array}{l}\text { 1. member was convinced to pay } \\
\text { 2. other members paid for her } \\
\text { 3.other (SPECIFY) }\end{array}$} & \\
\hline \multirow[t]{6}{*}{11.} & \multirow{6}{*}{$\begin{array}{l}\text { For what purpose did } \\
\text { those group members } \\
\text { take a loan? }\end{array}$} & \multicolumn{2}{|l|}{ a. Agri-Allied Loan (=Dairy) } & No. & \\
\hline & & \multicolumn{2}{|l|}{ b. Crop Loan } & No. & \\
\hline & & \multicolumn{2}{|l|}{ c. Housing \& Infrastructure } & No. & \\
\hline & & \multicolumn{2}{|c|}{ d. Non-farm Micro or Small Enterprise } & No. & \\
\hline & & \multicolumn{2}{|c|}{ e. General Purpose Loan } & No. & \\
\hline & & \multicolumn{2}{|l|}{ f. Other (SPECIFY) } & No. & \\
\hline
\end{tabular}

12. Will you take another loan with this group?

13. Will you try to join another group with BASIX?

14. Would you prefer borrowing individual liability?

\begin{tabular}{|l|l|}
\hline Yes $=1>14 . \mathrm{No}=0$ & \\
\hline Yes $=1 \mathrm{No}=0$ & \\
\hline Yes $=1 \mathrm{No}=0$ & \\
\hline
\end{tabular}

\section{B. AG/BDS - DAIRY}

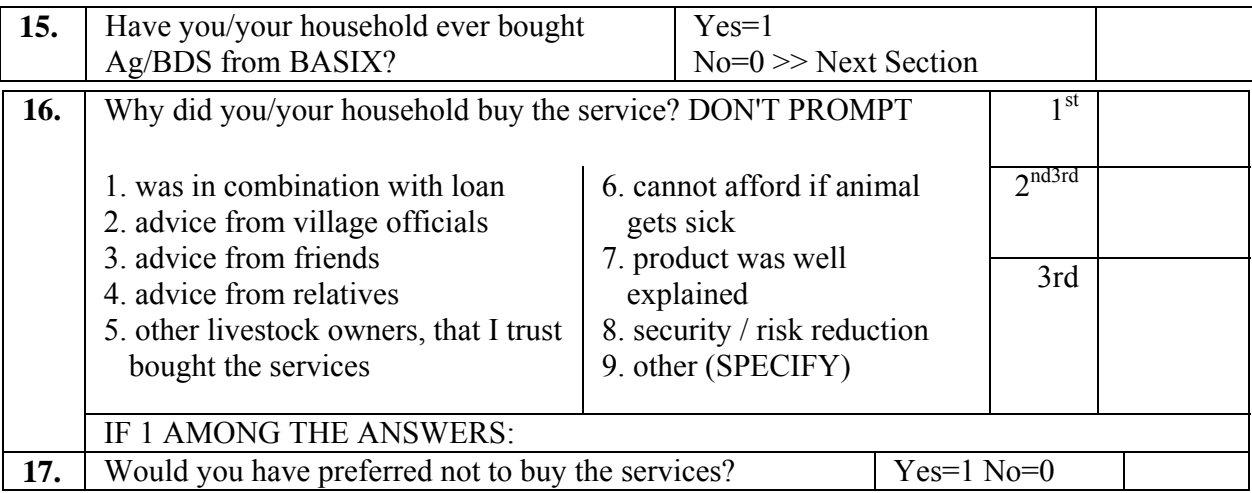




\begin{tabular}{|c|c|c|c|}
\hline 18. & Will you buy Ag/BDS again? & \multicolumn{2}{|c|}{$\begin{array}{l}\text { 1. yes in combination with loan } \\
\text { 2. yes without taking a loan } \\
\text { 3. no }\end{array}$} \\
\hline 19. & $\begin{array}{l}\text { Why will you not buy the service } \\
\text { again? }\end{array}$ & \multicolumn{2}{|c|}{$\begin{array}{l}\text { 1. I will not take another loan } \\
\text { 2. too expensive } \\
\text { 3. no need } \\
\text { 4. services not enough } \\
\text { 5. not satisfied with services } \\
\text { 6. don't understand the product } \\
\text { 7. better alternatives } \\
\text { 8. do not like the product } \\
\text { 9. other (SPECIFY) }\end{array}$} \\
\hline 20. & \multicolumn{2}{|c|}{$\begin{array}{l}\text { Did you receive training in how to } \mathrm{keep} / \mathrm{feed} / . . . \text { your } \\
\text { animal? }\end{array}$} & $\mathrm{Yes}=1 \mathrm{No}=0$ \\
\hline 21. & \multicolumn{2}{|c|}{ Do you know when to best inseminate your animal? } & $\mathrm{Yes}=1 \mathrm{No}=0$ \\
\hline 22. & \multicolumn{2}{|c|}{ Did you visit a health camp? } & $\mathrm{Yes}=1 \mathrm{No}=0$ \\
\hline 23. & \multicolumn{2}{|l|}{ When was the last camp you visited? } & YEAR \\
\hline 24. & \multicolumn{2}{|l|}{ Will you visit the next health camp? } & $\mathrm{Yes}=1 \mathrm{No}=0$ \\
\hline
\end{tabular}


B. LIVESTOCK INSURANCE

\begin{tabular}{|c|c|c|c|c|c|}
\hline 25. & \multicolumn{2}{|c|}{$\begin{array}{l}\text { Have you/your household ever bought livestock } \\
\text { insurance from BASIX? }\end{array}$} & \multicolumn{2}{|c|}{$\begin{array}{l}\text { Yes }=1 \\
\mathrm{No}=0>>\text { End } \\
\text { Interview }\end{array}$} & \\
\hline \multirow[t]{4}{*}{26.} & \multirow{2}{*}{\multicolumn{3}{|c|}{ Why did you/your household buy the service? DON'T PROMPT }} & $1^{\mathrm{st}}$ & \\
\hline & & & & $2^{\text {nd }}$ & \\
\hline & $\begin{array}{l}\text { 1. was in combination with loan } \\
\text { 2. advice from village officials } \\
\text { 3. advice from friends } \\
\text { 4. advice from relatives } \\
\text { 5. other livestock owners that I } \\
\text { trust bought it }\end{array}$ & $\begin{array}{l}\text { 6. cannot } \\
\text { dies } \\
\text { 7. product } \\
\text { explaine } \\
\text { 8. security } \\
\text { 9. other (S }\end{array}$ & $\begin{array}{l}\text { if animal } \\
\text { well } \\
\text { reduction } \\
\text { FY) }\end{array}$ & $3 \mathrm{rd}$ & \\
\hline & \multicolumn{5}{|l|}{ IF 1 AMONG THE ANSWERS: } \\
\hline 27. & $\begin{array}{l}\text { Would you have preferred not to buy } \\
\text { the services? }\end{array}$ & \multicolumn{3}{|c|}{$\mathrm{Yes}=1 \mathrm{No}=0$} & \\
\hline 28. & Did you ever have a claim to settle? & \multicolumn{3}{|c|}{$\begin{array}{l}\text { Yes }=1 \\
\mathrm{No}=0>>\text { END INTERVIEW }\end{array}$} & \\
\hline 29. & Amount received for claim & \multirow{2}{*}{\multicolumn{3}{|c|}{$\begin{array}{l}1=\text { irregular premium payment } \\
2=\text { improper documentation } \\
3=\text { missing/tampering tag } \\
4=\text { insurance pre-conditions } \\
5=\text { any other (SPECIFY) }\end{array}$}} & \\
\hline 30. & $\begin{array}{l}\text { Reasons for the claim not being } \\
\text { settled: }\end{array}$ & & & & \\
\hline 31. & $\begin{array}{l}\text { Will you buy livestock insurance } \\
\text { again? }\end{array}$ & \multicolumn{3}{|c|}{$\begin{array}{l}\text { 1. yes in combination with a loan } \\
\text { 2. yes without taking a loan } \\
\text { 3. no }\end{array}$} & \\
\hline 32. & $\begin{array}{l}\text { Why will you not buy the service } \\
\text { again? }\end{array}$ & \multicolumn{3}{|c|}{$\begin{array}{l}\text { 1. I will not take another loan } \\
\text { 2. too expensive } \\
\text { 3. no need } \\
\text { 4. services not enough } \\
\text { 5. not satisfied with services } \\
\text { 6. don't understand the product } \\
\text { 7. better alternatives } \\
\text { 8. do not like the product } \\
\text { 9. other (SPECIFY) }\end{array}$} & \\
\hline
\end{tabular}




\subsubsection{Village Questionnaire}

\begin{tabular}{|c|c|c|c|c|c|}
\hline \multirow{7}{*}{ 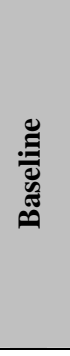 } & Village & \multirow{7}{*}{ 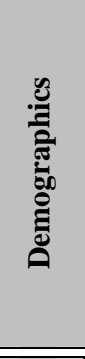 } & \multicolumn{3}{|c|}{ Total Population } \\
\hline & District & & \multicolumn{2}{|c|}{ Total No of Households } & \\
\hline & Block/Mandal/Taluk & & \multirow{5}{*}{ 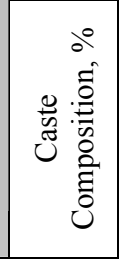 } & SC & \\
\hline & $\begin{array}{l}\text { BASIX Village: Distance from CSA } \\
\text { Location }\end{array}$ & & & ST & \\
\hline & Distance from main road & & & $\mathrm{OBC}$ & \\
\hline & & & & Minorities & \\
\hline & & & & Other Caste & \\
\hline \multirow{7}{*}{ 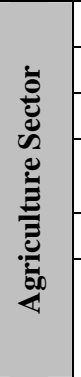 } & Total land under cultivation (Acres) & \multirow{7}{*}{ 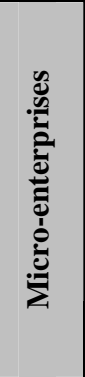 } & \multicolumn{3}{|c|}{ No of Grocery Shops } \\
\hline & Acrage under irrigation & & \multicolumn{3}{|c|}{\begin{tabular}{|l|} 
No of Tea Hotels \\
\end{tabular}} \\
\hline & Number of Tanks & & \multirow{2}{*}{\multicolumn{2}{|c|}{\begin{tabular}{|l} 
No of Tailoring Shops \\
No of Electric Repairs \& \\
Servicing \\
\end{tabular}}} & \\
\hline & Number of Pumpsets & & & & \\
\hline & Other Sources of Irrigation & & \multicolumn{3}{|c|}{ No of Cloth Shop } \\
\hline & Main Crops 1. Groundnut & & \multirow{2}{*}{\multicolumn{2}{|c|}{\begin{tabular}{|l|} 
No of Wine Shops \\
$\begin{array}{l}\text { No of Agri Processing } \\
\text { units }\end{array}$ \\
\end{tabular}}} & \\
\hline & $\begin{array}{l}\text { 2. Paddy } \\
\text { 3. Other (SPECIFY) }\end{array}$ & & & & \\
\hline \multirow{6}{*}{ 宽 } & No of families engaged in: & \multirow{6}{*}{ 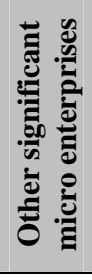 } & \multicolumn{3}{|c|}{ No of families engaged in: } \\
\hline & Dairy & & \multicolumn{3}{|c|}{\begin{tabular}{|l|l} 
Handloom Weavers \\
\end{tabular}} \\
\hline & Poultry & & \multicolumn{3}{|c|}{ Potters } \\
\hline & Fishery & & \multicolumn{3}{|c|}{ Bamboo Workers } \\
\hline & Piggery & & \multicolumn{3}{|c|}{\begin{tabular}{|l|} 
Other (SPECIFY) \\
\end{tabular}} \\
\hline & Goatery/Sheep rearing & & & & \\
\hline \multirow{9}{*}{ 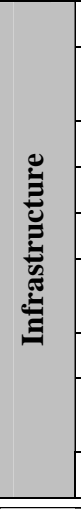 } & Comment on availability of: & \multirow{9}{*}{ 号 } & \multicolumn{3}{|c|}{ Comment on Presence of: } \\
\hline & Bus service $($ yes $=1$, no $=0)$ & & \multicolumn{3}{|c|}{$\begin{array}{l}\text { No of Banks servicing the } \\
\text { village }\end{array}$} \\
\hline & Auto Service $(\mathrm{yes}=1, \mathrm{no}=0$ ) & & \multicolumn{3}{|c|}{ No of SHGs } \\
\hline & Quality of Road & & \multicolumn{3}{|c|}{ No of Milk-cooperatives } \\
\hline & Distance to nearest Police Station & & \multicolumn{3}{|c|}{ No of Other Co-operatives } \\
\hline & $\begin{array}{l}\text { Distance to nearest Primary Health } \\
\text { Care Centre }\end{array}$ & & \multicolumn{3}{|c|}{$\begin{array}{l}\text { No of NGOs - offering } \\
\text { dairy services }\end{array}$} \\
\hline & Distance to nearly Primary School & & \\
\hline & $\begin{array}{l}\text { Distance to nearest Secondary } \\
\text { School }\end{array}$ & & \multicolumn{2}{|c|}{$\begin{array}{l}\text { Weekly } \\
\text { Bazar/market(yes }=1, \text { no }=0)\end{array}$} & \\
\hline & Canals $($ yes $=1$, no $=0$ ) & & & & \\
\hline \multirow{4}{*}{ 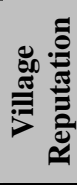 } & Comment on: & & & & \\
\hline & Law \& Order $(1=$ good/peaceful, $2=n$ & $=$ proble & ems) & & \\
\hline & Political Environment $(0=$ non, $1=\mathrm{gc}$ & ful, $2=1$ & normal, 3 & $3=$ problems $)$ & \\
\hline & Repayment Culture (1=very good, 2 & norma & $\mathrm{l}, 4=\mathrm{bad}$ & & \\
\hline
\end{tabular}


PrICES

\begin{tabular}{|c|c|c|c|}
\hline & Quantity & Product & Price \\
\hline 1 & $1 \mathrm{~kg}$ & Rice from market & \\
\hline 2 & $1 \mathrm{~kg}$ & Sugar from market & \\
\hline 3 & $1 \mathrm{~kg}$ & Wheat flower & \\
\hline 4 & $1 \mathrm{~kg}$ & Grains & \\
\hline 5 & $1 \mathrm{~kg}$ & Millets & \\
\hline 6 & 11 & Edible oils & \\
\hline 7 & $1 \mathrm{~kg}$ & Green chillis & \\
\hline 8 & $1 \mathrm{~kg}$ & Onions & \\
\hline 9 & $1 \mathrm{~kg}$ & Tomatoes & \\
\hline 10 & & \begin{tabular}{|l|} 
Other \\
\end{tabular} & \\
\hline 11 & 1 & \begin{tabular}{|l|} 
Banana \\
\end{tabular} & \\
\hline 12 & $1 \mathrm{~kg}$ & Papaya & \\
\hline 13 & 11 & Milk & \\
\hline 14 & $1 \mathrm{~kg}$ & Chicken & \\
\hline 15 & $1 \mathrm{~kg}$ & Mutton & \\
\hline 16 & $1 \mathrm{~kg}$ & \begin{tabular}{|l|} 
Fish \\
\end{tabular} & \\
\hline 17 & 1 & Egg & \\
\hline 18 & $100 \mathrm{~g}$ & Spices and condiments & \\
\hline 19 & 1 & tea & \\
\hline 20 & 1 & coffee & \\
\hline 21 & 1 & soft drink & \\
\hline 22 & $680 \mathrm{ml}$ & Beer (specific brand given) & \\
\hline \multirow[t]{3}{*}{23} & $180 \mathrm{ml}$ & Whiskey (quarter) (specific brand given) - cheap & \\
\hline & & - medium & \\
\hline & & - costly & \\
\hline \multirow[t]{3}{*}{24} & 1 pack & Cigarettes (specific brand given) & \\
\hline & & - medium & \\
\hline & & - costly & \\
\hline 25 & 1 pack & Bidis (specific brand given) & \\
\hline 26 & & Transport to Anantapur town & \\
\hline 27 & daily & Wage labour - men & \\
\hline 28 & daily & Wage labour - women & \\
\hline 29 & & Education fees & \\
\hline
\end{tabular}




\section{Samenvatting}

\section{Microfinanciering - en groot goed of een kleiner kwaad?}

India heeft gedurende de laatste decennia een sterke economische groei doorgemaakt die tot een gestage afname van armoede heeft geleid. Desalniettemin is het aantal armen nog steeds enorm: van de bijna 1 biljoen inwoners zijn er ongeveer 300 miljoen hoofdzakelijk bezig met van dag tot dag overleven, vinden van voedsel en lijdzaam toezien hoe hun kinderen sterven aan eenvoudig te voorkomen ziekten.Van deze mensen woont $75 \%$ in rurale gebieden.

De Indiase regering is zich bewust van de ernst van de stituatie en neemt dientengevolge maatregelen; een van de gekozen maatregelen is microfinanciering.

De ontwikkeling van microfinanciering begon ongeveer 40 jaar geleden, in de jaren 70 , toen experimentele programma's in Bangladesh, India en Brazilië en enkele andere landen kleine leningen begonnen te verstrekken aan de armen om te investeren in micro-ondernemeningen. Het meest bekende van deze programma's is zonder twijfel de Grameen (Dorps) Bank in Bangladesh, opgericht door Professor Muhammed Yunus, de Nobelrijswinnaar voor de Vrede van 2006. Yunus' initiatief wordt vaak geroemd als een van de eerste microfinanciering ondernemingen waarbij kleine leningen beschikbaar werden gemaakt voor arme lokale dorpelingen die geen toegang hadden tot het traditionele formele financiële circuit. Vanaf dat moment heeft de ontwikkeling van microfinanciering een vlucht genomen. Hoewel het zich in de eerste plaats geheel concentreerde op formele kredietverstrekking, omvat het begrip tegenwoordig een breed scala aan financiële diensten zoals spaartegoed, verzekeringen en geldtransacties. Door het creeeren van kapitaal en hiermee gepaard gaande verkleining van risico's en vergemakkelijking van consumptie, volgen de aanbieders van microfinanciering een sociale missie gericht op armoedebestrijding en het vergroten van ontwikkelingsmogelijkheden en kansen van armen.

Het concept bleek grote consequenties te hebben: Microfinanciering genereerde een breed enthousiasme bij zowel hulpdonoren, NGO's, deskundigen, politici en de academici. Het werd en wordt nog steeds geszien als een middel om armoede te verminderen, zelfs als het middel dat de potentie heeft om de Millenium Ontwikkelingsdoelstelling om de absolute armoede met de helft te verminderen in 2015, werkelijkheid te laten worden.

De realiteit is echter minder rooskleurig dan vaak wordt voorgespiegeld. Hoewel de legitimiteit van microfinanciering buiten kijf staat, blijft de belangrijkste ruggegraat 
van de Indiase microfinanciering, achter. Deze ruggegraat bestaat uit de extreem afgelegen en de extreem achter gebleven gebieden en uit de extreem arme mensen.

Het eerste deel van deze dissertatie houdt zich bezig met juist deze onderbelichte factoren van microfinanciering in India. Gelukkig worden deze factoren niet door iedereen over het hoofd gezien. Een boek uitgegeven door Dichter \& Harper (2007) brengt herhaaldelijk naar voren dat microfinanciering andere initiatieven kan 'overschaduwen' (p.258). Ondanks dat dergelijke opmerkingen gemaakt worden is er weinig kwantitatief bewijs om deze te bevestigen. Hoofdstuk twee van deze dissertatie levert bewijs voor deze claim door een kwantitatieve analyse te maken van de bepalende factoren van de verspreiding van het SHG model. Naast andere bevindingen wordt aangetoond dat het SHG model voornamelijk in gebieden actief is waar een bankwezen al aanwezig is, dus niet in gebieden s waar de formele financiële sector zich vooralsnog niet heeft willen vestigen.. Daarnaast wordt de aanwijzing gegeven dat de focus op SHGs een soort van 'trade-off' is met andere sociale plannen waardoor verschillende onbevoorrechte groepen niet bereikt worden.

In feite lijkt het alsof het SHG model buiten haar capaciteit groeit, een onderwerp dat ook wordt behandeld in het derde hoofdstuk. Dit hoofdstuk gaat dieper in op de consequenties van de groei en de microfinancieringshype die hieruit voortvloeit. De boodschap is duidelijk: er is zonder twijfel een behoefte aan meer transparantie en een groter bewustzijn.

Het grotere bewustzijn dat nodig is, is een publiek bewustzijn. Een publiek bewustzijn van zaken gekoppeld aan financiële indicatoren. Er is veel geschreven over de hoge kosten van microfinancieringsleningen en vooral deskundigen van het microfinancierings-institutionele model pleiten voor de noodzaak van hoge rentepercentages om de kosten te dekken. Hoofdstuk drie geeft een relaas van wat er kan gebeuren als er geen bewustzijn is; als de daadwerkelijke kosten niet bekend zijn bij de gemeenschap en er een overtuiging bestaat dat hoge rentepercentages het resultaat zijn van hebzucht en winstbejag en niet een noodzaak om de kosten te dekken. Instituten vinden manieren om de rentepercentages te verlagen, maar wat aan de ene kant wordt gespaard, moet aan de andere kant weer worden gecompenseerd -zij het door extra kosten voor de cliënt of de bijna perfecte herstelpercentages die vaak niet zonder dwang gepaard gaan. De crisis in Andhra Pradesh is slechts een van de voorbeelden van de ernstige gevolgen.

In tegenstelling tot wat gewoonlijk wordt aanbevolen, is de transparantie waartoe in deze dissertatie wordt opgeroepen gerelateerd aan de bescherming van consumenten. Vooral binnen de context van financiering onstaan er discussies rondom de asymetrische informatie omtrent wat instituten niet van cliënten weten. Het succes van microfinanciering is gedeeltelijk gebaseerd op oplossingen die voor dit probleem gevonden zijn, zoals het zogeheten 'joint-liability model' (een model waarin beide partijen een deel van de financiele risico's dragen). Er wordt echter veel minder 
gesproken over de asymetrieen die de andere kant opgaan -alle informatie die een instituut bezit en die zij haar clienten bewust of onbewust onthoudt; bovenaan deze lijst staan de werkelijke kosten van krediet..

Hoofdstuk drie beargumenteert dat het de donoren zijn die een belangrijke rol kunnen en zouden moeten spelen bij het streven naar meer rechten voor consumenten van microfinanciering, door duidelijke signalen te geven dat hulp wordt gegeven aan instituten die niet alleen goed presteren inzake financiële indicatoren, maar dat het sociale aspect op zijn minst net zo belangrijk is. Dit zou betekenen dat veel donoragentschappen hun focus op uitsluitend financiële indicatoren zullen moeten veranderen.

Deze dissertatie gaat een stap verder en beargumenteerd dat donoren -in iedergeval op de lange termijn- helemaal geen rol zouden moeten spelen in microfinanciering- met de nadruk op financiering!

Hoofdstuk vijf legt uit hoe in de laatste decennia een bredere aanpak van microfinanciering is ontwikkeld. Dit was voornamelijk een reactie op de constateringen dat de allerarmsten meer nodig hebben dan alleen krediet en dat microfinanciering - het hulpmiddel bij het uitbannen van armoede- juist dit deel van de populatie zou verwaarlozen als het zich niet aan hun behoeften zou aanpassen.

Veel microfinancieringsinstituten bieden nu diensten naast leningen aan die erop gericht zijn de efficiëntie en de productiviteit te verhogen. Natuurlijk laten deze diensten de kosten stijgen -kosten die al hoog zijn gegeven het karakter van de cliënten en hiermee de diensten die worden verleend. Doordat microfinancieringsinstituten een leegte vullen; doordat ze een taak vervullen die eigenlijk door iemand anders vervuld zou moeten worden, zou juist het geld van de donoren op een zinvolle manier geïnvesteerd moeten worden.

De reeks van extra diensten die tegenwoordig wordt aangeboden is groot. Hoofdstuk vijf en zes gaan dieper in op zo'n geïntegreerde aanpak. Als voorbeeld wordt gekeken naar een programma dat wordt aangeboden door BASIX, een instituut voor de verbetering van levensomstandigheden, dat leningen verstrekt met het doel een koe of een buffel te kopen en hiermee, door middel van melkproductie, een extra inkomstenbron te genereren. Aan de lening is een gezondheids -en levensverzekering gekoppeld, zowel voor de cliënt als diens echtgenoot. Een extra veehouderijverzekering wordt aangeboden, net als een niet-financieel dienstenpakket dat o.a training geeft over hoe je het beste een dier kunt voeden en houden, regelmatige controles door een dierenarts en ook een gezondheidskamp. Bovendien worden er contacten met de markt opgezet in gebieden waar dit nodig is en worden er melkvettests geïntroduceerd om eerlijke prijzen te garanderen.

Voordat er wordt begonnen met de evaluatie van het specifieke programma van BASIX, is het vierde hoofdstuk van deze dissertatie gewijd aan het analyseren van 
van melkveehouderij als een algemene, extra inkomstenbron. De resultaten laten zien dat huishoudens daadwerkelijk economisch profiteren van de verkoop van melkproducten: in het afgelopen jaar, op dit moment en naar verwachtingen ook in de toekomst, hebben en hadden zij een significant hogere algemene inkomensstroom dan van mensen die geen melkverkoop bij hun huishoudinkomsten hadden. Deze resultaten zijn bevestigd in een Lorenz curve-analyse die aantoont dat het meedoen aan melkveehouderij inderdaad de welvaart verbeterd.

Op dit moment is India zelfs de grootste producent van melk ter wereld met een jaarlijkse productie van 88,1 miljoen liter in 2003-2004 (Ali, 2007). Dealniettemin ligt de productiviteit lager dan het wereldgemiddelde wat aanleiding biedt voorverdere beleidsinterventies, ontwikkeling en innovatie binnen deze sector.

Een ander belangrijk resultaat dat in hoofdstuk vier naar boven komt is dat terwijl er een grotere variatie in inkomen wordt waargenomen bij die huishoudens die hun inkomen verkrijgen door de verkoop van melk, deze huishoudens minder onzekerheid kennen ten aanzien van hun toekomstige inkometen.

Deze laatste observatie is mogelijk ondanks het feit dat er alleen dwarsdoorsnede data beschikbaar is ter analyse. Data betreffende subjectieve verwachtingen van cliënten maakt een onderscheid mogelijk tussen variatie en onzekerheid, zoals is beschreven in hoofdstuk vier. Het werk van subjectieve verwachtingen is een relatief nieuw doch een groeiend gebied. Deze dissertatie heeft een toegevoegde waarde voor de bestaande literatuur door het verzamelen van nieuwe data in een ontwikkelingsland met een populatie die een bovengemiddelde onzekerheid het hoofd moet bieden en daarnaast doet (deze dissertatie) prognoses voor wat betreft de investerings-specifieke rendementen . Deze laatste prognoses betreffende de rendementen die een direkt verband hebben met interventies, worden uitgebreider behandeld in de evaluatiestudies die in hoofdstukken vijf en zes worden gepresenteerd.

Significante positieve invloed van programma's wordt gevonden op het inkomen van huishoudens, op bezittingen en consumptiecategorieën (voedsel,andere niet-duurzame goederen en duurzame goederen) van cliënten. Het positieve en significante effect op de consumptie geldt voor alle sub-groepen van betrokken cliënten (kijkende naar de extra (niet) financiële diensten). Dit resultaat bekrachtigt de uitspraak van Monique Cohen (2003) dat microfinanciering moet worden gezien als een "noodzakelijk doch niet voldoende voorwaarde voor ontwikkeling"; dat krediet voor (het inkomen van) de armen hen niet noodzakelijker wijze boven de armoedegrens tilt, maar dat een cruciale rol speelt in belangrijke zaken zoals het spreiden van consumptie, het terugdringen van risico's en onzekerheid en het vermogen het hoofd te bieden aan onverwachte tegenspoed.

Feitelijk dienen de Landbouw en Bedrijfsontwikkelingsdiensten als ook de veehouderijverzekering die BASIX aanbiedt, naast leningen, precies deze bovengenoemde doelen van o.a. de verhoging van productiviteit en risicovermindering. 
En inderdaad zijn de effecten op consumptie het grootst voor die consumenten die $\mathrm{ag} / \mathrm{BDS}$ hadden ten tijde van de enquete.

Een onverwacht resultaat is de constatering dat deelnemers aan het programma een negatief effect op hun inkomen hebben van melkverkoop als activiteit die bedoeld is om extra inkomen te genereren. Dit resultaat is significant voor deelnemers die bovenop de lening tevens voor een verzekering van hun veestapel kozen.

Een aantal verklaringen voor dit resultaat wordt besproken. Een van de verklaringen is dat het opzetten van contacten met andere markten soms onderdeel is van de maatregel en dat deelnemers meer van de geproduceerde melk consumeren dan verkopen. Een bijkomende verklaring zou kunnen zijn dat in de analyse informatie ontbreekt die wel te verzamelen is maar niet beschikbaar is. Ten eerste ontbreekt een nul-meting en ten tweede ontbreekt informatie op dorpsniveau. Vertekeningen die hieruit voortvloeien worden geminimaliseerd door de toegepaste technieken alsmede door gebruik van informatie op mandal-niveau. Desondanks blijft wellicht enige vertekening bestaan.

Hoofdstuk zes geeft het bewijs dat het niet meerekenen van informatie op dorpsniveau (zoals de beschikbare verbanden tussen markten) resulteert in een onderschatting van het effect. Hoewel de selectie van de te onderzoeken dorpen volgens een grondig proces tot stand is gekomen en als uitgangspunt had om de verschillen tussen programma en niet-programma dorpen te minimaliseren, zou het effciënter zijn om informatie op dorpsniveau hierin mee te nemen. Om deze reden werd dorpsinformatie verzameld gedurende het onderzoek, maar de kwalitiet van de data werd niet als goed genoeg bevonden om deel uit te maken van de analyse. Van een aantal dorpen werd twee keer data verzameld, maar de vergelijking toonde te grote verschillen om zeker van de informatie te zijn. Helaas lieten tijd- (en geld)beperkingen het opnieuw verwerven van de data niet toe.

Gedurende de analyse die voor deze dissertatie werd uitgevoerd werd er naar beste weten aandacht gegegeven aan het minimaliseren van afwijkingen en werd er rekening gehouden met beperkingen bij het interpreteren van de resultaten. Hierdoor kan met zekerheid worden gezegd dat de conclusies een duidelijk beeld geven van wat er daadwerkelijk in het veld gebeurt. 


\title{
Curriculum Vitae
}

\author{
Britta Augsburg
}

\section{EMPLOYMENT}

2008 - present The Institute for Fiscal Studies, London, UK. Research Economist

2005 - (2008) Graduate School of Governance, University Maastricht, Ph.D. in Social Protection Policy and Research Fellow

Relevant Field Work:

- Implementation of a survey of 1,041 households, half of which were clients of the microfinance institutions BASIX, India (11/07 - 03/08)

- Research Field Work with BASIX India, Hyderabad, India. Preparation for a survey to be conducted in fall 2007, included collection of secondary data as well as piloting of questionnaire. $(09 / 06-03 / 07)$

\section{EDUCATION}

$2001-2005$

$10 / 04-2 / 05$

University Maastricht - Doctorandus in Econometrics.

$1993-2000$

University Toulouse I, France - Study abroad.

Pestalozzigymnasium Idstein, Germany - Abitur.

\section{OTHER WORK \& PROJECT EXPERIENCE}

09/05-05/06 Assisting in Research for further implementation of the ongoing pension reform in the Russian Federation. A project of the EU.

08/04-09/04 Research on 'Migration from the Cook Islands' in collaboration with the Statistical Office of the Cook Islands, Avarua, Cook Islands.

08/03 - 09/03 Internship at the Bangladeshi Business Development Program for Private Section Promotion (BDS) of the German Technical Cooperation (GTZ).

\section{AWARDS}

Economic and Social Research Council - Funding for the implementation of a 2nd survey round. Universiteitsfonds Limburg (Limburg University Fund) - Funding for the Implementation of a household survey in India

"Best paper Award" at the International Convention on Micro Finance and Sustainable Enterprise Development, November 29-30, 2005, Cochin, India.

\section{SELECTED PUBLICATIONS}

- Augsburg, B. (2009), The impact of a Dairy intervention in rural India - Evidence from realized outcomes and expected returns to investment. Journal of Development Effectiveness. Forthcoming.

- Augsburg, B. \& Fouillet, C. (2008b), Profit Empowerment: How Donors push Microfinance away from its primary objective, Perspectives on Global Technology and Development, special issue: Microfinance and Society, forthcoming.

- Fouillet, C. \& B. Augsburg (2008a) "La microfinance, un objet de pouvoir de plus? Conflits et enjeux d'un outil de 'développement'", in L. Baixas, L. Dejouhanet and P.-Y. Trouillet (Ed.), Conflits et rapports sociaux en Asie du Sud, Aux Lieux d'Etre, Montreuil, France. Forthcoming 